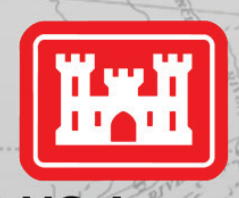

US Army Corps of Engineers ${ }_{\mathbb{Q}}$

\title{
Channel Geometry Trends of the Mississippi River, Old River Control Complex to St. Louis, Missouri
}

MRG\&P Report No. 11 • July 2017

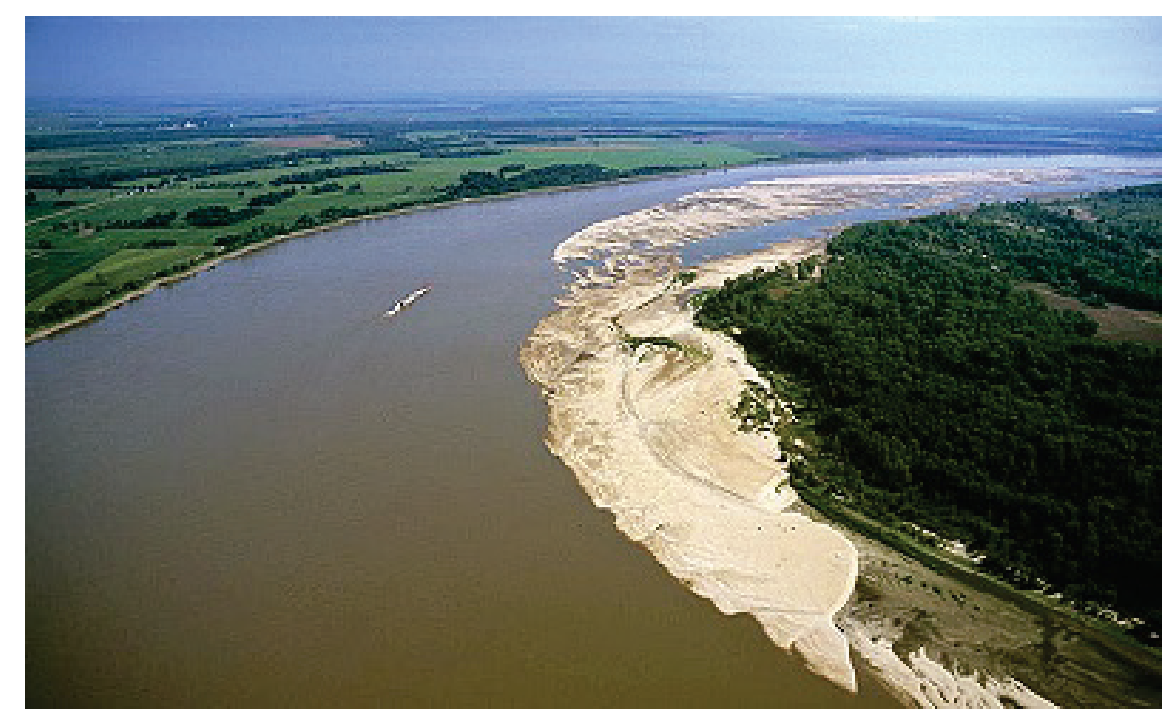

MRG\&P

Mississippi River Geomorphology \& Potamology Program 


\section{Channel Geometry Trends of the Mississippi River, Old River Control Complex to St. Louis, Missouri}

Charles D. Little, Jr.

Mendrop Resources Engineering, LLC

854 Wilson Drive, Suite A

Ridgeland, MS 39157

David S. Biedenharn

Coastal and Hydraulics Laboratory

U.S. Army Engineer Research Development Center

3909 Halls ferry Road

Vicksburg, MS 39180

Mead A. Allison

The Water Institute of the Gulf

One American Place

301 N. Main St., Suite 2000

Baton Rouge, LA 70825

Troy McCullough and Koby Wofford

Mendrop Resources Engineering, LLC

854 Wilson Drive, Suite A

Ridgeland, MS 39157

Final report

Approved for public release; distribution is unlimited.

Prepared for U.S. Army Corps of Engineers, Mississippi Valley Division Mississippi River Geomorphology \& Potamology (MRG\&P) Program 1400 Walnut Street

Vicksburg, MS 39180

Under Project 127672; "Geomorphic Assessment of the Mississippi River” 


\section{Abstract}

A geometric data analysis was conducted for the Mississippi River from the Old River Control Complex to St. Louis, MO, or approximately River Mile 325 Above Head of Passes to RM 180 Above Mouth of Ohio River. The purpose of the study was to document long-term trends in the dimension, pattern, and profile of the Mississippi River channel within the study reach. Hydrographic survey data from 1956 to 2013 were used to determine spatial and temporal variations in channel geometry and volume. Trends of geometric change in the channel were identified along defined geomorphic reaches of the river. Observed trends indicate the lower portion of the study reach from Old River to Vicksburg, MS, has experienced a general decrease in channel area and volume. Conversely, the reach from Helena, AR, to Hickman, KY, has undergone a general increase in area and volume. The reach of the middle Mississippi River above Cairo, IL, has seen a slight lowering of the channel.

The results of this study will be part of a detailed geomorphic assessment of the Mississippi River to be conducted as part of the on-going Mississippi River Geomorphology and Potamology Program sponsored by the U.S. Army Corps of Engineers, Mississippi Valley Division Science and Technology Office.

DISCLAIMER: The contents of this report are not to be used for advertising, publication, or promotional purposes. Citation of trade names does not constitute an official endorsement or approval of the use of such commercial products. All product names and trademarks cited are the property of their respective owners. The findings of this report are not to be construed as an official Department of the Army position unless so designated by other authorized documents. 


\section{Contents}

Abstract................................................................................................................................... ii

Figures and Tables............................................................................................................

Preface ................................................................................................................................................ vili

Unit Conversion Factors......................................................................................................

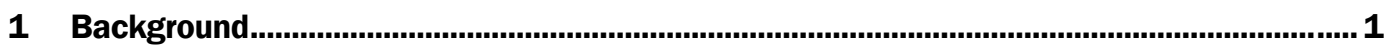

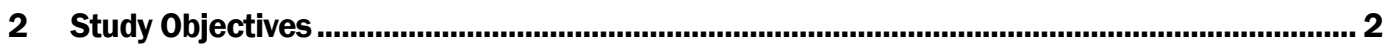

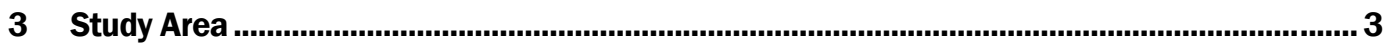

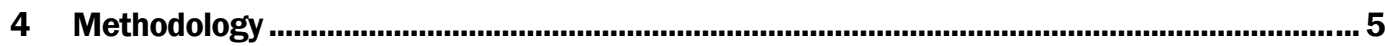

4.1 Methodology for Lower Mississippi River Reach (Old River Control Complex

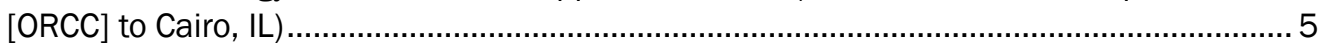

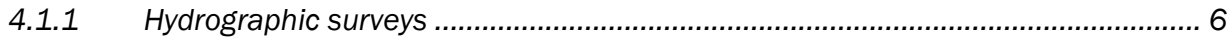

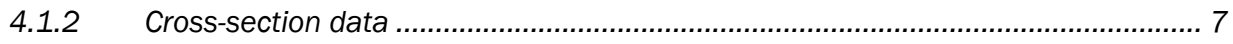

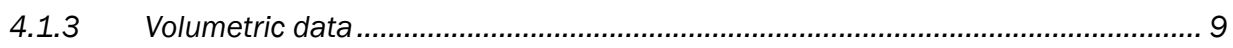

4.1.4 Statistical presentation with box plots................................................................. 9

4.1.5 Geomorphic reaches................................................................................... 10

4.2 Methodology for Middle Mississippi River Reach (Mouth of Ohio River to St.

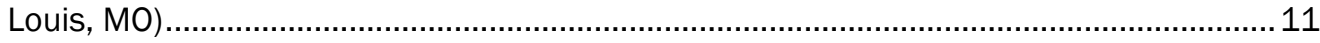

5 Results ..................................................................................................................................13

5.1 Channel geometry analyses-Lower Mississippi River (LMR) section.....................13

5.1.1 Cross-section data analysis results.................................................................. 13

5.1.2 Volumetric data analysis results .................................................................. 30

5.1.3 Channel invert profile analysis results................................................................. 38

5.2 Channel geometry analyses-Middle Mississippi River (MMR) section...................42

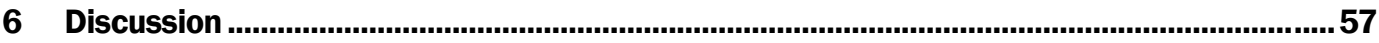

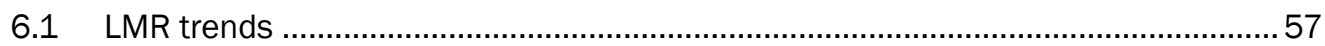

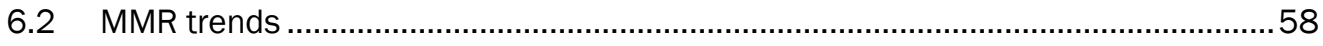

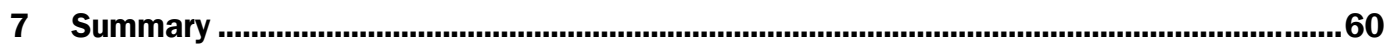

References.......................................................................................................................................61

Appendix A: Box Plots of Cross-sectional Area for Crossing Sections, RM 325 to RM

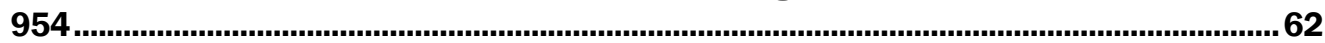

Appendix B: Box Plots of Channel Width for Crossing Sections, RM 325 to RM 954 ................68

Appendix C: Box Plots of Hydraulic Depth for Crossing Sections, RM 325 to RM $954 \ldots . . . . . . . . .74$ 
Appendix D: Box Plots of Channel Conveyance for Crossing Sections, RM 325 to RM 954 80

Appendix E: Box Plots of Cross-sectional Area for Pool Sections, RM 325 to RM 954. 86

Appendix F: Box Plots of Channel Width for Pool Sections, RM 325 to RM 954 ........................92

Appendix G: Box Plots of Hydraulic Depth for Pool Sections, RM 325 to RM 954......................98

Appendix H: Box Plots of Channel Conveyance for Pool Sections, RM 325 to RM 954 .......... 104

Report Documentation Page 


\section{Figures and Tables}

\section{Figures}

Figure 1. Study area portion within the Lower Mississippi River (LMR)........................................... 3

Figure 2. Study area portion within the Middle Mississippi River (MMR) ............................................ 4

Figure 3. Example of 1-mile channel polygons for volume computations.......................................... 9

Figure 4. Example box plot. ............................................................................................................ 10

Figure 5. Example cross-section comparison plot for the crossing at RM 426.5 ........................... 14

Figure 6. Cross-sectional area at LWRP for crossing sections RM 325-592 (Vicksburg

District reach). ........................................................................................................................ 14

Figure 7. Channel width at LWRP for crossing sections RM 325-592 (Vicksburg District

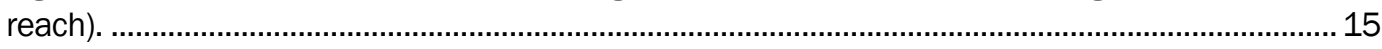

Figure 8. Hydraulic depth at LWRP for crossing sections RM 325-592 (Vicksburg District

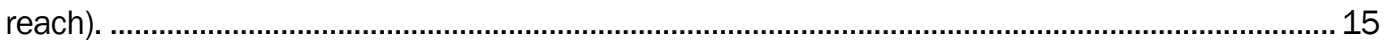

Figure 9. Channel conveyance at LWRP for crossing sections RM 325-592 (Vicksburg District reach). ..................................................................................................................... 16

Figure 10. Cross-sectional area at LWRP for pool sections RM 325-592 (Vicksburg

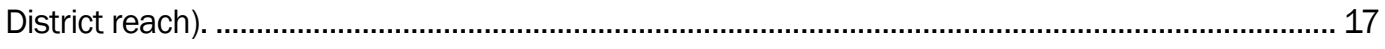

Figure 11. Channel width at LWRP for pool sections RM 325-592 (Vicksburg District

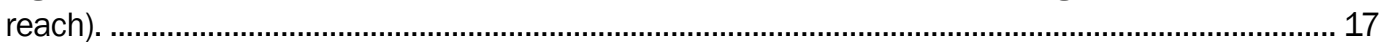

Figure 12. Hydraulic depth at LWRP for pool sections RM 325-592 (Vicksburg District

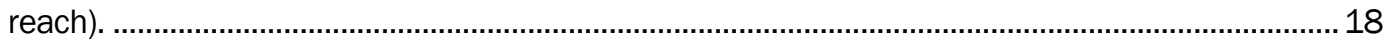

Figure 13. Channel conveyance at LWRP for pool sections RM 325-592 (Vicksburg District reach). ...................................................................................................................... 18

Figure 14. Cross-sectional area at LWRP for crossing sections RM 592-954 (Memphis

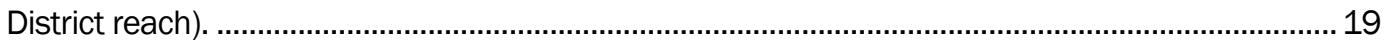

Figure 15. Channel width at LWRP for cross sections RM 592-954 (Memphis District

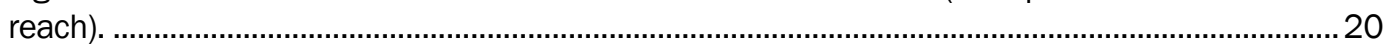

Figure 16. Hydraulic depth at LWRP for cross sections RM 592-954 (Memphis District

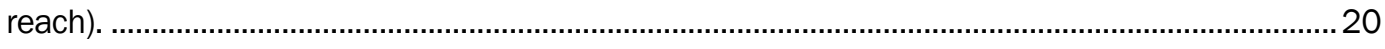

Figure 17. Channel conveyance at LWRP for crossing sections RM 592-954 (Memphis

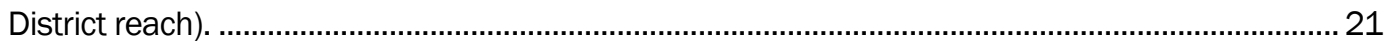

Figure 18. Cross-sectional area at LWRP for pool sections RM 592-954 (Memphis

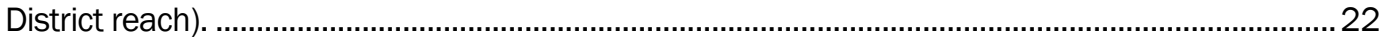

Figure 19. Channel width at LWRP for pool sections RM 592-954 (Memphis District

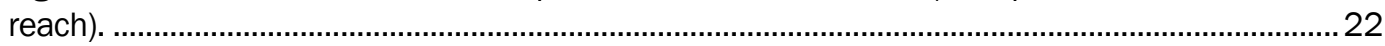

Figure 20. Hydraulic depth at LWRP for pool sections RM 592-964 (Memphis District

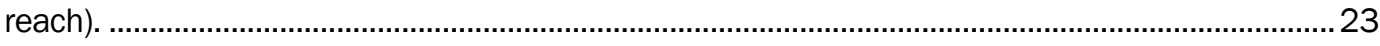

Figure 21. Channel conveyance at LWRP for pool sections RM 592-954 (Memphis District reach).

Figure 22. Example of box plot for cross-sectional area at LWRP for crossing sections, Reach 5. 
Figure 23. Trends of median channel volume at LWRP for Reach 1 (RM 954-907)....................... 31

Figure 24. Trends of median channel volume at LWRP for Reach 2 (RM 907-845)....................... 31

Figure 25. Trends of median channel volume at LWRP for Reach 3 (RM 845-773) ...................... 32

Figure 26. Trends of median channel volume at LWRP for Reach 4 (RM 773-702). ......................32

Figure 27. Trends of median channel volume at LWRP for Reach 5 (RM 702-650).......................33

Figure 28. Trends of median channel volume at LWRP for Reach 6 (RM 650-592). ......................33

Figure 29. Trends of median channel volume at LWRP for Reach 7 (RM 592-524)........................34

Figure 30. Trends of median channel volume at LWRP for Reach 8 (RM 524-437).......................35

Figure 31. Trends of median channel volume at LWRP for Reach 9 (RM 437-381).......................35

Figure 32. Trends of median channel volume at LWRP for Reach 10 (RM 381-325).....................36

Figure 33. Cumulative channel volume change for LMR RM 325-592........................................ 37

Figure 34. Cumulative channel volume change for LMR RM 592-954.......................................38

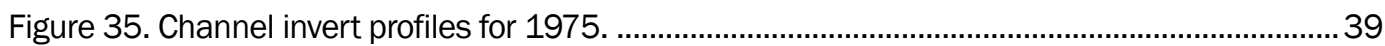

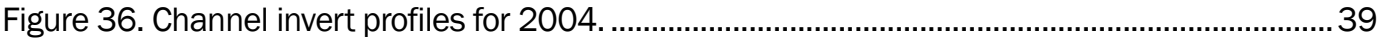

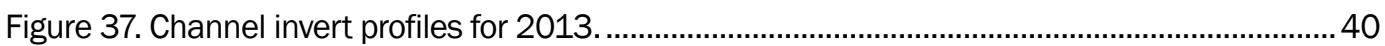

Figure 38. Channel invert profiles for 1975, 2004, and 2013.................................................... 41

Figure 39. Cross-sectional area (referenced to LWRP+10) between RM 0 and RM 180 on

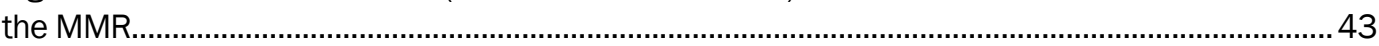

Figure 40. Hydraulic depth (referenced to LWRP+10) between RM 0 and RM 180 on the

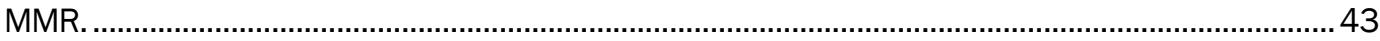

Figure 41. Channel conveyance (referenced to LWRP+10) between RM 0 and RM 180 on the MMR.

Figure 42. Channel volume (referenced to LWRP+10) between RM 0 and RM 180 on the MMR.

Figure 43. Five-mile average values of cross-sectional area (referenced to LWRP+10) between RM 0 and RM 180 on the MMR.

Figure 44. Five-mile average values of hydraulic depth (referenced to LWRP+10) between RM 0 and RM 180 on the MMR.

Figure 45. Five-mile average values of conveyance (referenced to LWRP+10) between RM 0 and RM 180 on the MMR.

Figure 46. Five-mile average values of channel volume (referenced to LWRP+10) between

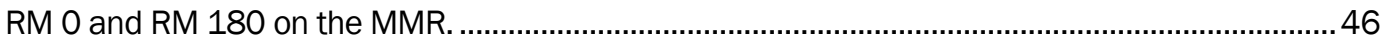

Figure 47. Box plot of cross-sectional area for RM 0-180................................................................ 47

Figure 48. Box plot of hydraulic depth for RM 0-180 ................................................................... 48

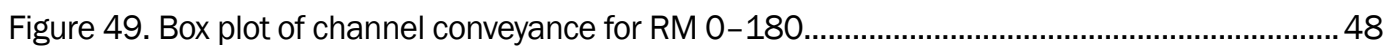

Figure 50. Box plot of channel volume for RM 0-180............................................................. 49

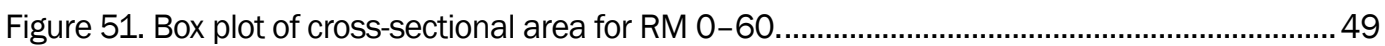

Figure 52. Box plot of cross-sectional area for RM 60-120...........................................................50

Figure 53. Box plot of cross-sectional area for RM 120-180.................................................... 50

Figure 54. Box plot of hydraulic depth for RM 0-60........................................................... 51

Figure 55. Box plot of hydraulic depth for RM 60-120 ............................................................. 51

Figure 56. Box plot of hydraulic depth for RM 120-180 ............................................................52 


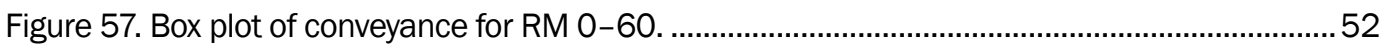

Figure 58. Box plot of conveyance for RM 60-120 ……..................................................... 53

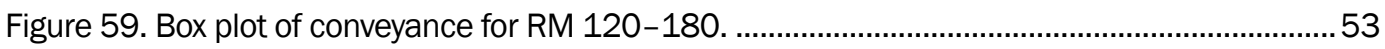

Figure 60. Box plot of channel volume for RM 0-60. ................................................................ 54

Figure 61. Box plot of channel volume for RM 60-120 ........................................................... 54

Figure 62. Box plot of channel volume for RM 120-180. ……….............................................55

\section{Tables}

Table 1. Hydrographic surveys used in LMR reach. .................................................................... 6

Table 2. Location of crossing sections for LMR reach. ................................................................... 7

Table 3. Location of pool sections for LMR reach......................................................................... 8

Table 4. Geomorphic reaches for lower Mississippi River section. ……......................................... 11

Table 5. General trends by geomorphic reach of median cross-sectional area at LWRP for

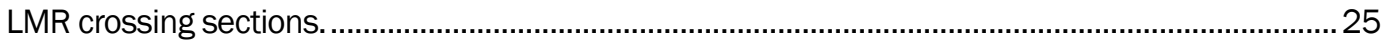

Table 6. General trends by geomorphic reach of median channel width at LWRP for LMR

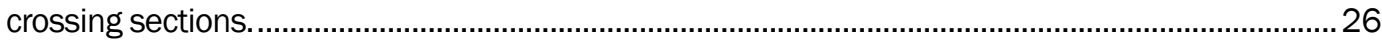

Table 7. General trends by geomorphic reach of median hydraulic depth at LWRP for LMR

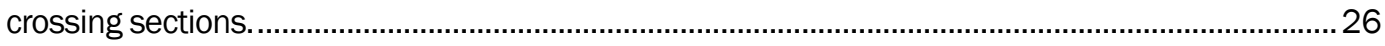

Table 8. General trends by geomorphic reach of median channel conveyance at LWRP for

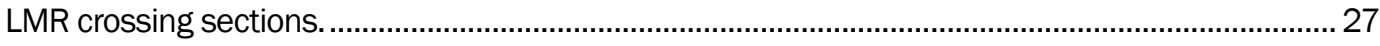

Table 9. General trends by geomorphic reach of median cross-sectional area at LWRP for LMR pool sections. ....................................................................................................................... 28

Table 10. General trends by geomorphic reach of median channel width at LWRP for LMR

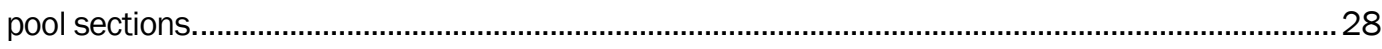

Table 11. General trends by geomorphic reach of median hydraulic depth at LWRP for LMR pool sections.

Table 12. General trends by geomorphic reach of median channel conveyance at LWRP

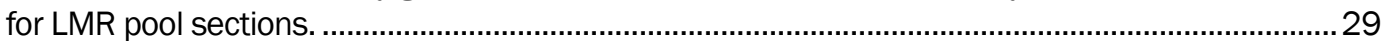

Table 13. Average channel invert slope (feet/mile) by geomorphic reach......................................42

Table 14. Reach average values for cross-sectional area, hydraulic depth, conveyance,

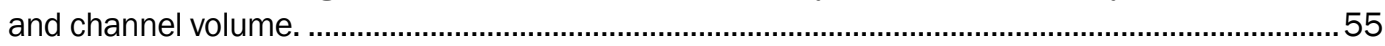

Table 15. Percent change in geometry parameters between survey years.......................................56 


\section{Preface}

The research documented in this report was conducted as part of the Mississippi River Geomorphology and Potamology (MRG\&P) Program, under Project 127672; "Geomorphic Assessment of the Mississippi River." The MRG\&P is sponsored by Headquarters, U.S. Army Corps of Engineers (USACE), and is managed by the USACE Mississippi Valley Division (MVD) in Vicksburg, MS. The MRG\&P Technical Director was Dr. Barbara Kleiss, and the Program Manager was Mr. Freddie Pinkard. The MVD Commander was MG Michael C. Wehr. The MVD Director of Programs was Mr. Jim Bodron.

The Mississippi River Commission (MRC) provided Mississippi River engineering direction and policy advice. The Commission members were MG Michael C. Wehr, USACE, President; the Honorable Sam E. Angel; the Honorable R. D. James; the Honorable Norma Jean Mattei, Ph.D.; RDML Gerd F. Glang, National Oceanic and Atmospheric Administration; BG Richard G. Kaiser, USACE-ORD; and BG David C. Hill, USACE-SWD.

The Deputy Director of the U.S. Army Engineer Research and Development Center (ERDC), Coastal and Hydraulics Laboratory, was Mr. Jeffery R. Eckstein, and the Director was Mr. José E. Sánchez.

COL Bryan S. Green was the Commander of ERDC, and the Director was Dr. David W. Pittman. 


\section{Unit Conversion Factors}

\begin{tabular}{|c|c|c|}
\hline Multiply & By & To Obtain \\
\hline acres & $4,046.873$ & square meters \\
\hline acre-feet & $1,233.5$ & cubic meters \\
\hline cubic feet & 0.02831685 & cubic meters \\
\hline cubic inches & 1.6387064 E-05 & cubic meters \\
\hline cubic yards & 0.7645549 & cubic meters \\
\hline feet & 0.3048 & meters \\
\hline gallons (U.S. liquid) & 3.785412 E-03 & cubic meters \\
\hline inches & 0.0254 & meters \\
\hline miles (U.S. statute) & $1,609.347$ & meters \\
\hline square feet & 0.09290304 & square meters \\
\hline square miles & $2.589998 E+06$ & square meters \\
\hline
\end{tabular}




\section{Background}

The development of the Mississippi River and its flood plain for navigation and flood control has taken place since the eighteenth century, with the most concerted efforts occurring as a result of the Flood Control Act of 1928 following the Great Flood of 1927. The Mississippi River and Tributaries Project that was spawned from the Flood Control Act of 1928 has produced a massive, comprehensive system for flood control and channel stabilization that includes levees, channel improvements, and floodways, as well as tributary reservoirs and other basin improvements. Additionally, the development of the river for dependable navigation has generated a substantial engineering effort in terms of river training structures, meander cutoffs, and dredging. The historical, present-day, and future morphology of the Mississippi River reflects an integration of all these features combined with natural factors such as floods and droughts, hurricanes, tectonic activity, geologic outcrops, climatic variability, and sea level rise. Understanding how these various factors affect the short- and long-term morphology of the river is a complex challenge for the river engineers and scientists responsible for managing this system for flood control, navigation, and habitat.

With the complex requirements in navigation, flood risk reduction, and environmental restoration, all with multiple stakeholders, future Mississippi River management will require the most advanced knowledge available. In recognition of this challenge, The Mississippi River Geomorphology and Potamology (MRG\&P) Program was developed. The MRG\&P is a joint effort of the U.S. Army Corps of Engineers (USACE), St. Louis, Memphis, Vicksburg, and New Orleans Districts, conducted with the oversight of the Mississippi Valley Division and technical contributions from the U.S. Army Engineer Research and Development Center. The study presented herein is one component of the MRG\&P. 


\section{Study Objectives}

The objectives of this study are to evaluate the Mississippi River channel geometry along the Vicksburg, Memphis, and St. Louis District reaches from approximately River Mile (RM) 325 Above Head of Passes (AHP) to RM 180 Above Mouth of Ohio River and to identify spatial or temporal trends for the time period 1970 to 2013. Specifically, this report summarizes the results of two separate analyses, one conducted for the Lower Mississippi River portion of the study reach within the USACE Vicksburg and Memphis District boundaries and a second conducted for the Middle Mississippi River portion of the study reach within the USACE St. Louis District boundary. Historical hydrographic survey data are utilized to determine geometric parameters such as cross-sectional area, width, hydraulic depth, and volume and variation of these parameters over time is assessed for the presence of discernable trends. The primary aim of this study is identification of these trends and not a comprehensive evaluation of the causative factors producing these changes. 


\section{Study Area}

The study area encompasses a significant portion of the lower and middle Mississippi River, extending from RM 325 AHP just upstream of the Old River Control Complex (ORCC) to River Mile 180 Above Mouth of the Ohio River at St. Louis, MO. The portion of the study area within the Lower Mississippi River (LMR) is shown in Figure 1. This reach covers approximately 630 river miles downstream of the confluence of the Ohio River that are contained within the boundaries of the USACE Vicksburg and Memphis Districts. Major tributaries within this reach include the Arkansas River, the White River, and the Ohio River at the upstream terminus of the reach.

Figure 1. Study area portion within the Lower Mississippi River (LMR).

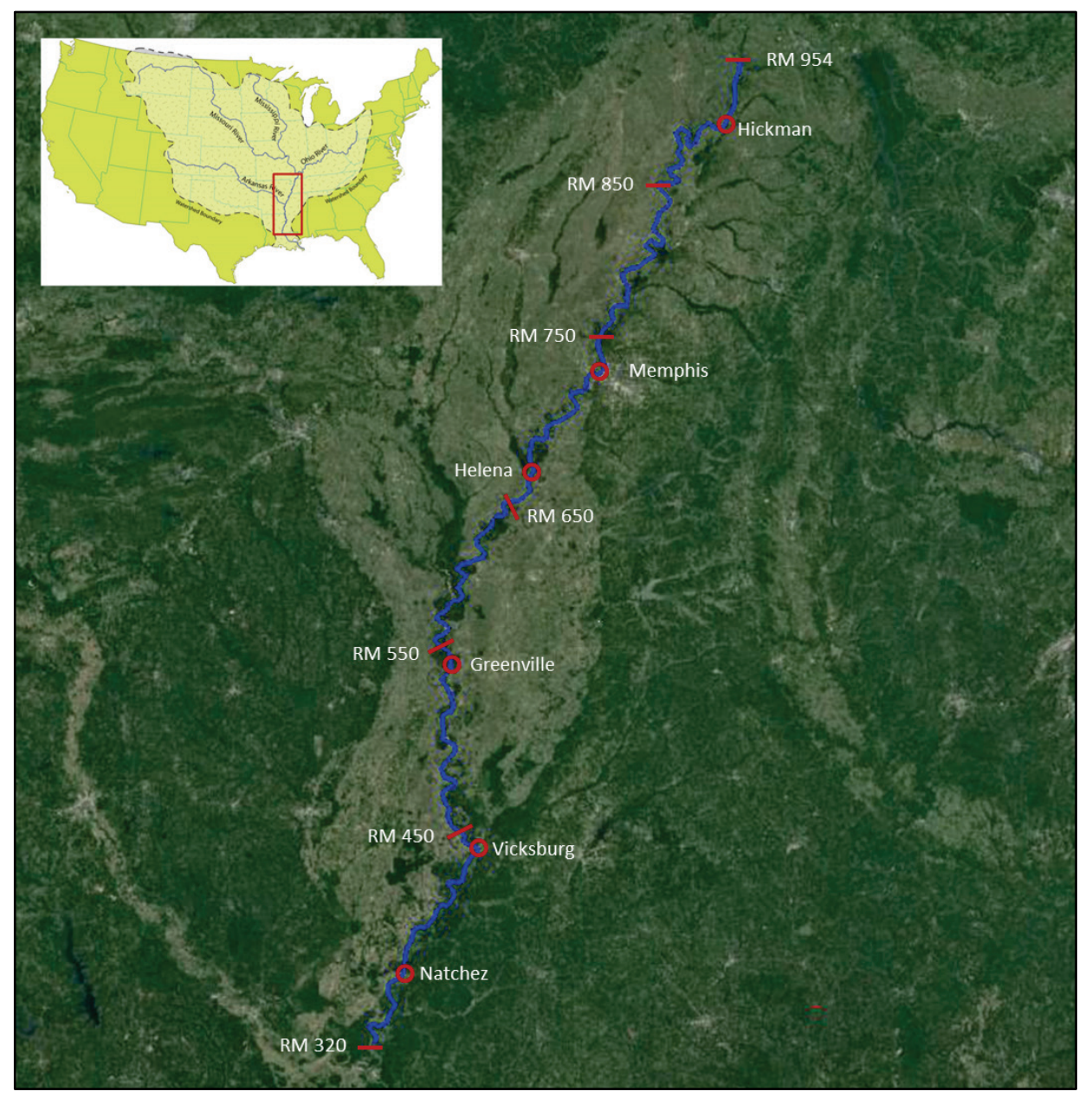


The portion of the study area within the Middle Mississippi River (MMR) is shown in Figure 2. This reach covers approximately 180 river miles upstream of the confluence of the Ohio River to the confluence of the Missouri River contained within the boundary of the USACE St. Louis District. Major tributaries within this reach include the Kaskaskia River, Meramec River, and the Missouri River at the upstream terminus of the reach.

Figure 2. Study area portion within the Middle Mississippi River (MMR).

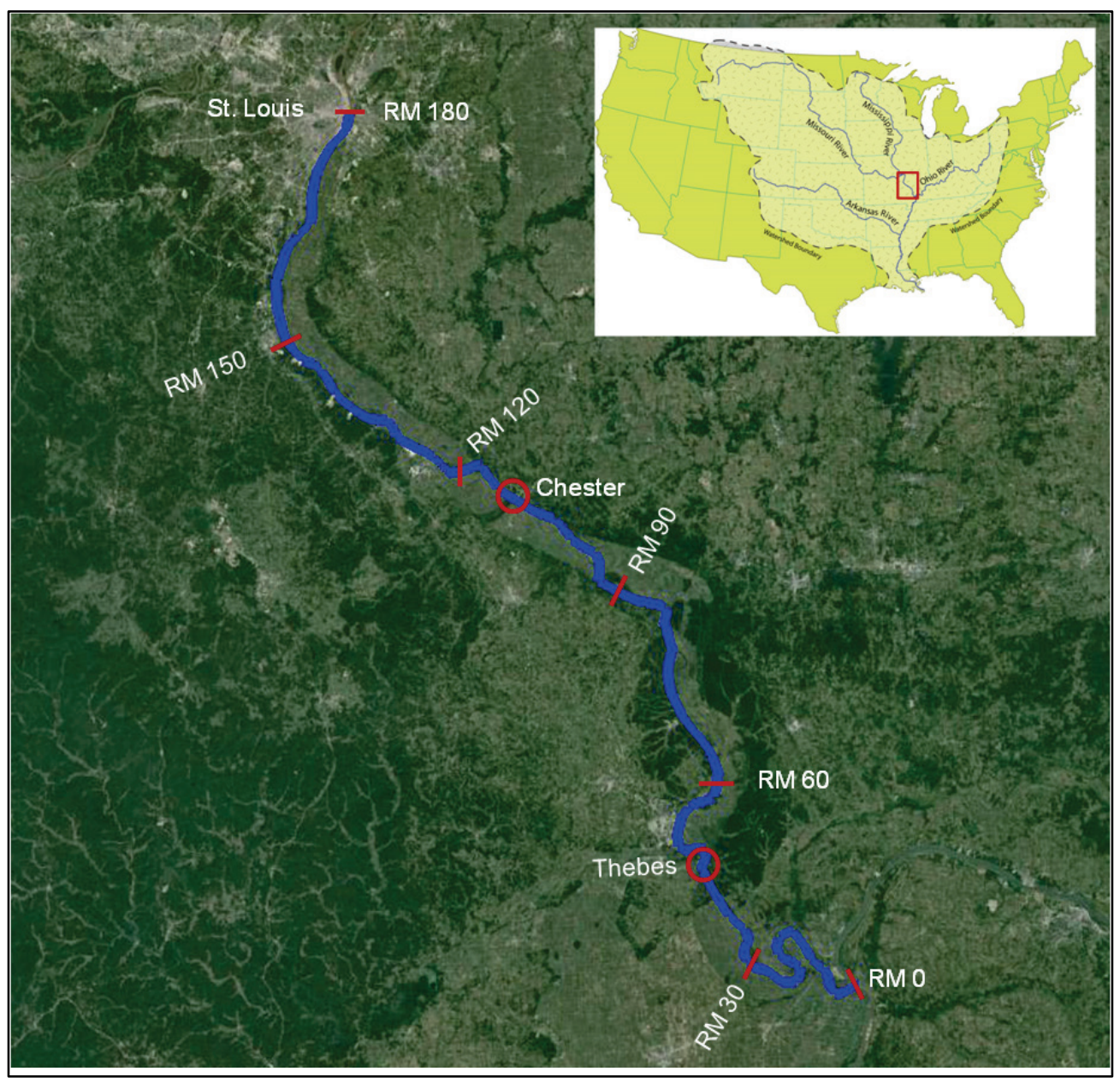




\section{Methodology}

\subsection{Methodology for Lower Mississippi River Reach (Old River Control Complex [ORCC] to Cairo, IL)}

Historical hydrographic survey data of the lower LMR were collected from the USACE Vicksburg and Memphis Districts and entered into a GIS database. A triangulated irregular network (TIN) surface was developed in the GIS for each hydrographic survey and was the basis for determination of the channel geometry for each survey time period. Cross sections were created in shape files at selected river crossings and pool locations, and the bathymetric data for each survey surface were extracted at these locations. The bathymetric data were then imported into spreadsheets, and the channel cross-sectional area, width, hydraulic depth, and channel conveyance were computed for each section. The minimum elevation was determined for each section, and thalweg profiles were constructed. Additionally, shape files were used to create polygons to capture the river channel in 1-mile segments. Channel volumes were computed for these 1-mile segments and used in the volumetric analysis. All cross-section and polygon volumes were referenced to the 2007 Low Water Reference Plane (LWRP) provided by the Vicksburg and Memphis Districts.

The cross-section and volume data are grouped along defined geomorphic reaches for analysis. The data are statistically presented using box plots to illustrate the central tendencies and spread of the data. In addition, the incremental volume data are presented in cumulative curves that allow identification of river segments characterized by net erosion or deposition. The slopes of the channel thalweg profiles for both crossing and pool sections were evaluated for potential trends.

Due to the pervasiveness of river stabilization revetments in the study reach for the study time period 1970 to 2013, changes in channel pattern have been minimal and if present, limited to local adjustments. Therefore, no effort to document planform trends of the river channel was attempted as part of this study.

Further details and explanations of the study methodology are presented in the following sections. 


\subsubsection{Hydrographic surveys}

Hydrographic surveys provide a series of bathymetric data that can be used to determine geometric changes of the river channel over time. The hydrographic surveys collected for the LMR reach were decadal comprehensive surveys and annual channel condition surveys from the Vicksburg and Memphis Districts. The hydrographic data were provided in either XYZ format or shape files. The data are oriented along transects on approximately $1,000 \mathrm{ft}$ spacing, with the exception of short reaches where limited multibeam data are available. A listing of the hydrographic surveys used in the study along with pertinent information of each survey is provided in Table 1.

Table 1. Hydrographic surveys used in LMR reach.

\begin{tabular}{|c|c|c|c|}
\hline Description & Year & Extent & Remarks \\
\hline MVK comprehensive hydrographic survey & $1975-1976$ & RM 324-595 & Data gaps at RM 360-362, 437-445 \\
\hline MVK comprehensive hydrographic survey & 1988-1989 & RM 320-595 & $\begin{array}{l}\text { Limited spatial coverage due to low } \\
\text { water }\end{array}$ \\
\hline MVK comprehensive hydrographic survey & $1995-1996$ & RM 320-596 & -ב--- \\
\hline MVK annual hydrographic survey & 2000 & RM 320-617 & $\begin{array}{l}\text { Data gaps at RM 435-441, 479-523, } \\
530-537,594-600\end{array}$ \\
\hline MVK annual hydrographic survey & 2002 & RM 320-617 & --ב--- \\
\hline MVK annual hydrographic survey & 2004 & RM 320-593 & 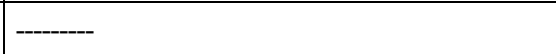 \\
\hline MVK comprehensive hydrographic survey & $2005-2006$ & RM 320-595 & -ב--- \\
\hline MVK annual hydrographic survey & 2008 & RM 320-617 & $\begin{array}{l}\text { Data gaps at RM 435-441, 529-537, } \\
594-600\end{array}$ \\
\hline MVK annual hydrographic survey & 2010 & RM 320-617 & $\begin{array}{l}\text { Data gaps at RM 435-441, 529-537, } \\
594-600\end{array}$ \\
\hline MVK annual hydrographic survey & $\begin{array}{l}2011 \text { (post- } \\
\text { flood) }\end{array}$ & RM 320-617 & $\begin{array}{l}\text { Data gaps at RM 435-441, 468-472, } \\
529-537,594-600\end{array}$ \\
\hline MVK annual hydrographic survey & 2013 & RM 320-617 & $\begin{array}{l}\text { Includes multi-beam data in some } \\
\text { locations }\end{array}$ \\
\hline MVM comprehensive hydrographic survey & $1975-1976$ & RM 595-954 & MVN \\
\hline MVM comprehensive hydrographic survey & 1996-1996 & RM 595-954 & $\begin{array}{l}\text { Data gaps at RM 624-629, 659- } \\
663,707-711,755-845,868-874, \\
925-954\end{array}$ \\
\hline MVM comprehensive hydrographic survey & 2003-2004 & RM 595-954 & -ב--- \\
\hline MVM annual hydrographic survey & 2008 & RM 595-954 & Data gap at RM 744-755 \\
\hline MVM annual hydrographic survey & 2013 & RM 595-954 & -ב---' \\
\hline
\end{tabular}




\subsubsection{Cross-section data}

Cross sections were created in shape files at selected river crossing and pool locations, and the bathymetric data for each survey surface were extracted at these locations. In general, the crossing and pool section locations were selected based on the most recent (2013) hydrographic survey. Station points were constructed at $25 \mathrm{ft}$ intervals along each section line, and the bathymetric data from each survey were extracted at these points. The extracted bathymetric data were imported into spreadsheets for geometric computations and generation of comparative plots. The location of the crossing and pool sections are shown in Tables 2 and 3 , respectively.

Table 2. Location of crossing sections for LMR reach.

\begin{tabular}{|c|c|c|c|c|}
\hline \multicolumn{5}{|c|}{ Crossing Section Locations (RM [AHP]) } \\
\hline \multicolumn{2}{|c|}{ Vicksburg District Reach } & \multicolumn{3}{|c|}{ Memphis District Reach } \\
\hline 325.5 & 449.5 & 597.0 & 701.0 & 832.0 \\
\hline 331.8 & 458.0 & 601.0 & 704.0 & 846.0 \\
\hline 339.6 & 463.0 & 604.0 & 711.0 & 853.0 \\
\hline 343.6 & 472.0 & 610.0 & 718.0 & 860.0 \\
\hline 348.5 & 479.5 & 617.0 & 726.0 & 866.0 \\
\hline 359.0 & 493.5 & 621.0 & 731.0 & 874.0 \\
\hline 364.5 & 500.9 & 623.0 & 742.0 & 878.0 \\
\hline 366.7 & 506.6 & 626.0 & 751.0 & 882.0 \\
\hline 369.3 & 409.5 & 631.0 & 753.0 & 896.0 \\
\hline 375.3 & 514.8 & 635.0 & 756.0 & 906.0 \\
\hline 380.0 & 523.2 & 641.0 & 761.0 & 911.0 \\
\hline 386.0 & 529.5 & 645.0 & 768.0 & 917.0 \\
\hline 394.8 & 535.8 & 649.0 & 772.0 & 923.0 \\
\hline 400.7 & 541.6 & 652.0 & 778.0 & 929.0 \\
\hline 410.7 & 548.63 & 658.0 & 781.0 & 938.0 \\
\hline 417.6 & 555.5 & 664.0 & 792.0 & 944.0 \\
\hline 421.6 & 565.9 & 669.0 & 796.0 & 949.0 \\
\hline 424.4 & 571.8 & 674.0 & 800.0 & \\
\hline 426.5 & 575.6 & 677.0 & 805.0 & \\
\hline 432.5 & 580.6 & 682.0 & 814.0 & \\
\hline 440.7 & 586.2 & 689.0 & 822.0 & \\
\hline 444.6 & 591.7 & 695.0 & 828.0 & \\
\hline
\end{tabular}


Table 3. Location of pool sections for LMR reach.

\begin{tabular}{|c|c|c|c|c|}
\hline \multicolumn{5}{|c|}{ Crossing Section Locations (RM [AHP]) } \\
\hline \multicolumn{2}{|c|}{ Vicksburg District Reach } & \multicolumn{3}{|c|}{ Memphis District Reach } \\
\hline 322.0 & 503.2 & 600.0 & 724.0 & 841.0 \\
\hline 329.6 & 513.8 & 607.0 & 730.0 & 850.0 \\
\hline 343.0 & 554.0 & 612.0 & 739.0 & 857.0 \\
\hline 356.1 & 561.0 & 620.0 & 747.0 & 864.0 \\
\hline 363.5 & 569.0 & 634.0 & 755.0 & 872.0 \\
\hline 384.1 & 574.8 & 639.0 & 759.0 & 877.0 \\
\hline 398.1 & 588.2 & 644.0 & 766.0 & 880.0 \\
\hline 413.0 & & 647.0 & 770.0 & 890.0 \\
\hline 419.7 & & 655.0 & 777.0 & 900.0 \\
\hline 429.3 & & 660.0 & 780.0 & 910.0 \\
\hline 436.0 & & 666.0 & 787.0 & 915.0 \\
\hline 444.0 & & 674.0 & 794.0 & 921.0 \\
\hline 455.9 & & 679.0 & 798.0 & 925.0 \\
\hline 460.0 & & 686.0 & 803.0 & 928.0 \\
\hline 469.0 & & 692.0 & 811.0 & 934.0 \\
\hline 474.0 & & 700.0 & 817.0 & 937.0 \\
\hline 480.9 & & 703.0 & 825.0 & 940.0 \\
\hline 490.5 & & 709.0 & 830.0 & 947.0 \\
\hline 497.6 & & 717.0 & 836.0 & 952.0 \\
\hline
\end{tabular}

The extracted bathymetric data for each crossing and pool section were used to compute cross-sectional area, channel width, hydraulic depth, and channel conveyance referenced to the 2007 LWRP elevation. The LWRP elevation was determined for each section location, and the computations were made for the portion of the cross section lying underneath the LWRP plane. Hydraulic depth was computed by dividing the cross-sectional area by the channel width. Channel conveyance was calculated by multiplying the cross-sectional area by the hydraulic depth to the two-third power $\left(\mathrm{AD}^{2 / 3}\right)$. The cross-section data were grouped according to defined geomorphic reaches for statistical presentation using box plots. In addition, the minimum channel elevation for each crossing and pool section was determined and plotted versus channel distance to create longitudinal profiles for each hydrographic survey 


\subsubsection{Volumetric data}

Polygon shape files were created in GIS that encompassed 1-mile segments of the channel throughout the lower Mississippi River portion of the study area. The average LWRP elevation was determined for each polygon segment, and the elevations were assigned as a lid elevation to each polygon. GIS tools were used to compute the volume of each polygon beneath the lid elevation for each hydrographic survey. The volumetric data were grouped along defined geomorphic reaches for statistical presentation using box plots. Volumetric change between surveys was determined and represents the net channel erosion or deposition for each 1-mile segment. The volumetric changes for each individual polygon were then cumulatively summed along the study reach to spatially identify trends of net erosion or deposition. An example of the volume polygons is shown in Figure 3.

Figure 3. Example of 1-mile channel polygons for volume computations.

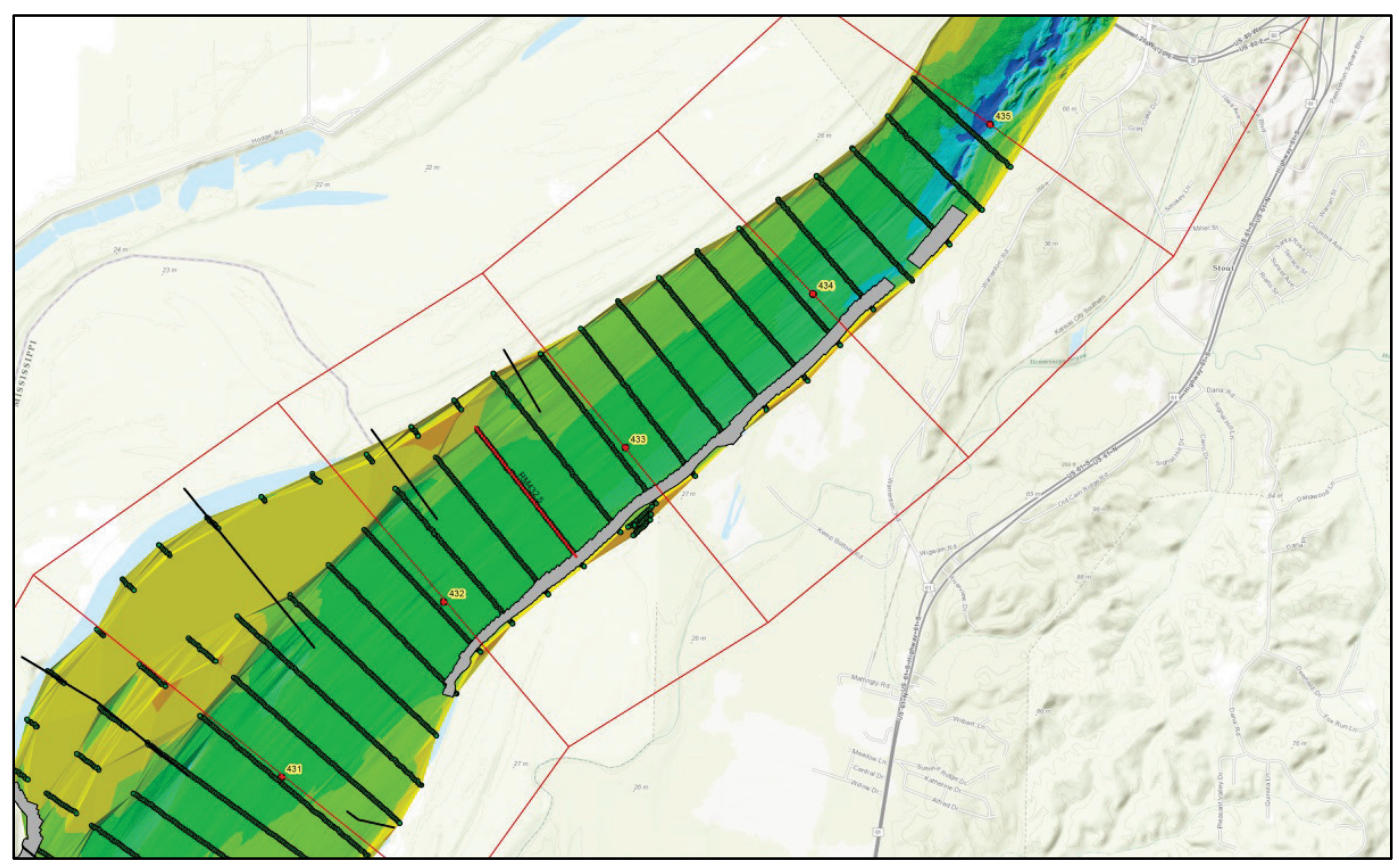

\subsubsection{Statistical presentation with box plots}

Box plots were used to statistically assess the LMR reach cross-sectional and volumetric data to identify trends. The box plot is attributed to John W. Tukey (1977) who developed a convenient method for depicting groups of numerical data. An example plot for volume data grouped by reach is shown in Figure 4. The bottom of the box, referred to as the lower hinge, represents the 25th percentile of the data (Q1), and the top of the box, or 
the upper hinge, represents the 75th percentile (Q3). The band within the box area represents the 5oth percentile, or median value (Q2). The 25th percentile means that $25 \%$ of the data is equal to or less than the value of the bottom hinge. The median and 75th percentiles follow similar definitions. Thus, the value range enclosed by the box area represents the central $50 \%$ of the dataset. The whiskers of the box plot are related to the height of the box (Q3 minus Q1), which is referred to as the interquartile range (IQR). For this investigation, the extent of the whiskers represents the minimum data point within $1.5 \times$ IQR of the lower quartile and the maximum data point within $1.5 \times$ IQR of the upper quartile (Tukey 1977). Data outside the whisker limits are referred to as outliers and are depicted as individual points in Figure 4.

Figure 4. Example box plot.

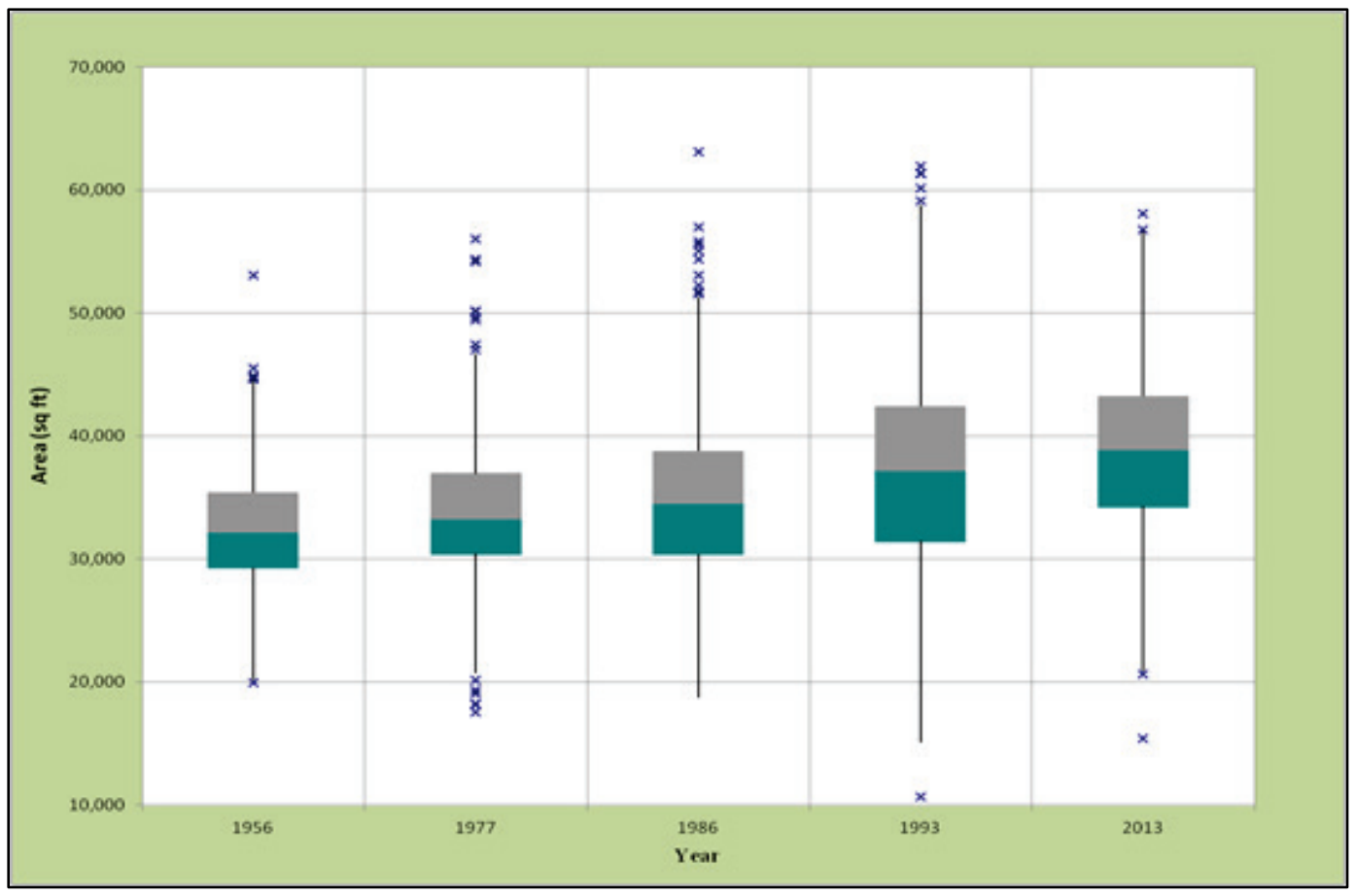

\subsubsection{Geomorphic reaches}

The cross-section and volume data were grouped along defined geomorphic reaches for analysis. The reach limits were initially selected to represent approximately 50 to 60 river miles and were adjusted to account for the location of tributary confluences or gage stations. The geomorphic reaches for the LMR section are listed in Table 4. 
Table 4. Geomorphic reaches for lower Mississippi River section.

\begin{tabular}{|l|l|l|}
\hline \multicolumn{1}{|c|}{ Reach } & \multicolumn{1}{c|}{ Limits (RM [AHP]) } & \multicolumn{1}{c|}{ Description } \\
\hline Reach 1 & RM 954-907 & Mouth of Ohio River to Island 9 \\
\hline Reach 2 & RM 907-845 & Island 9 to Caruthersville \\
\hline Reach 3 & RM 845-773 & Caruthersville to Hatchie River \\
\hline Reach 4 & RM 773-702 & Hatchie River to Island 53 \\
\hline Reach 5 & RM 702-650 & Island 53 to Friars Point \\
\hline Reach 6 & RM 650-581 & Friars Point to Arkansas River \\
\hline Reach 7 & RM 581-524 & Arkansas River to below Greenville \\
\hline Reach 8 & RM 524-437 & Below Greenville to Vicksburg \\
\hline Reach 9 & RM 437-381 & Vicksburg to Waterproof \\
\hline Reach 10 & RM 381-325 & Waterproof to above ORCC \\
\hline
\end{tabular}

\subsection{Methodology for Middle Mississippi River Reach (Mouth of Ohio River to St. Louis, MO)}

The channel geometry data used in the middle Mississippi River portion of the study was provided by the USACE St. Louis District, Applied River Engineering Center. Hydrographic surveys for the MMR for the years 1956, 1977, 1986, 1993, 2001, and 2013 were entered into GIS, and TIN surfaces were created for each survey. Shape files of cross sections at an even $1,320 \mathrm{ft}$ spacing were created in GIS. A total of 720 cross sections were created along the MMR from its confluence with the Ohio River (RM o) to St. Louis, MO (RM 180). The cross-section data for each section were plotted, and a fixed width was established that encompassed the portion of the section with coverage from all surveys. The cross-sectional area within this fixed width was then calculated referenced to the LWRP+10 elevations (feet, NGVD) for the sections. Hydraulic depth was calculated by dividing the cross-sectional area by the fixed width. Channel conveyance was then calculated by multiplying the cross-sectional area by the hydraulic depth to the two-third power ( $\left.\mathrm{AD}^{2 / 3}\right)$. Channel volume for each quarter-mile segment was calculated as the product of the average area of two adjacent cross sections and the distance between the cross sections.

As noted above, the original database had 720 cross sections. However, after examination of the database, it was concluded that some of these sections were problematic and needed to be removed. Each cross-section plot was examined to ensure that the cross-sectional data were truly representative of the main channel area. Cross sections where a significant portion of the river channel in some years may have shifted beyond the 
limits of the fixed width were removed, along with sections where the survey data clearly contained erroneous values. This reduced the number of cross sections from 720 to 550 . Note that the 2001 survey had a large number of problematic sections and was not included in the analysis.

Similar to the methodology of the LMR portion of the study, the crosssection data for the MMR portion of the study were grouped along 60-milelong geomorphic reaches: RM o-60, 60-120 and 120-180. The data for each reach were statistically presented using box plots to identify trends. 


\section{Results}

The results of the channel geometry analyses are provided in two sections:

(1) Lower Mississippi River (RM 320 to 954 AHP) and (2) Middle

Mississippi River (RM o to 180 Above Mouth of Ohio River). The results are presented in two graphical formats: a series of data points shown on $x-y$ graphs by river mile and box plots that portray the central tendencies and range of values present in the data. Both formats are valuable in illustrating the scatter range and general trends of the data.

\subsection{Channel geometry analyses-Lower Mississippi River (LMR) section}

\subsubsection{Cross-section data analysis results}

All crossing- and pool-section data were imported from GIS into spreadsheets and plotted for comparison. An example plot for the crossing section at RM 426.5 is shown in Figure 5. The spreadsheets were used for the computations of channel area, width, hydraulic depth, and channel conveyance for all crossing and pool sections.

The cross-sectional area, channel width, hydraulic depth, and channel conveyance referenced to LWRP for the crossings sections from RM 325 to 592 (Vicksburg District reach) are shown in Figures 6 through 9, respectively. A five-point moving average trend line is shown for each survey. Figure 6 indicates a general decreasing trend in cross-sectional area over time from RM 325 to approximately RM 425 near Vicksburg. The spatial variation in the magnitude of cross-sectional area is somewhat cyclical, but no reach-wide trend is observed. Channel width is shown to be fairly consistent in time from Figure 7. Little spatial variation is observed, with the exception of a slight increase in width at approximate RM 525 below Greenville followed by a sharp decrease in width up to approximate RM 575 upstream of Arkansas City. Hydraulic-depth temporal and spatial variation, as shown in Figure 8, are very similar to the variation of the cross-sectional area. The sharp increase in hydraulic depth from RM 525 to RM 575, along with the channel width reduction observed at the same location, suggests a river channel that is narrower and deeper in the general Greenville to Arkansas City reach. Channel conveyance in Figure 9 follows similar trends to the area and hydraulic depth, which is expected since conveyance is a product of cross-sectional area and hydraulic depth. 
Figure 5. Example cross-section comparison plot for the crossing at RM 426.5.

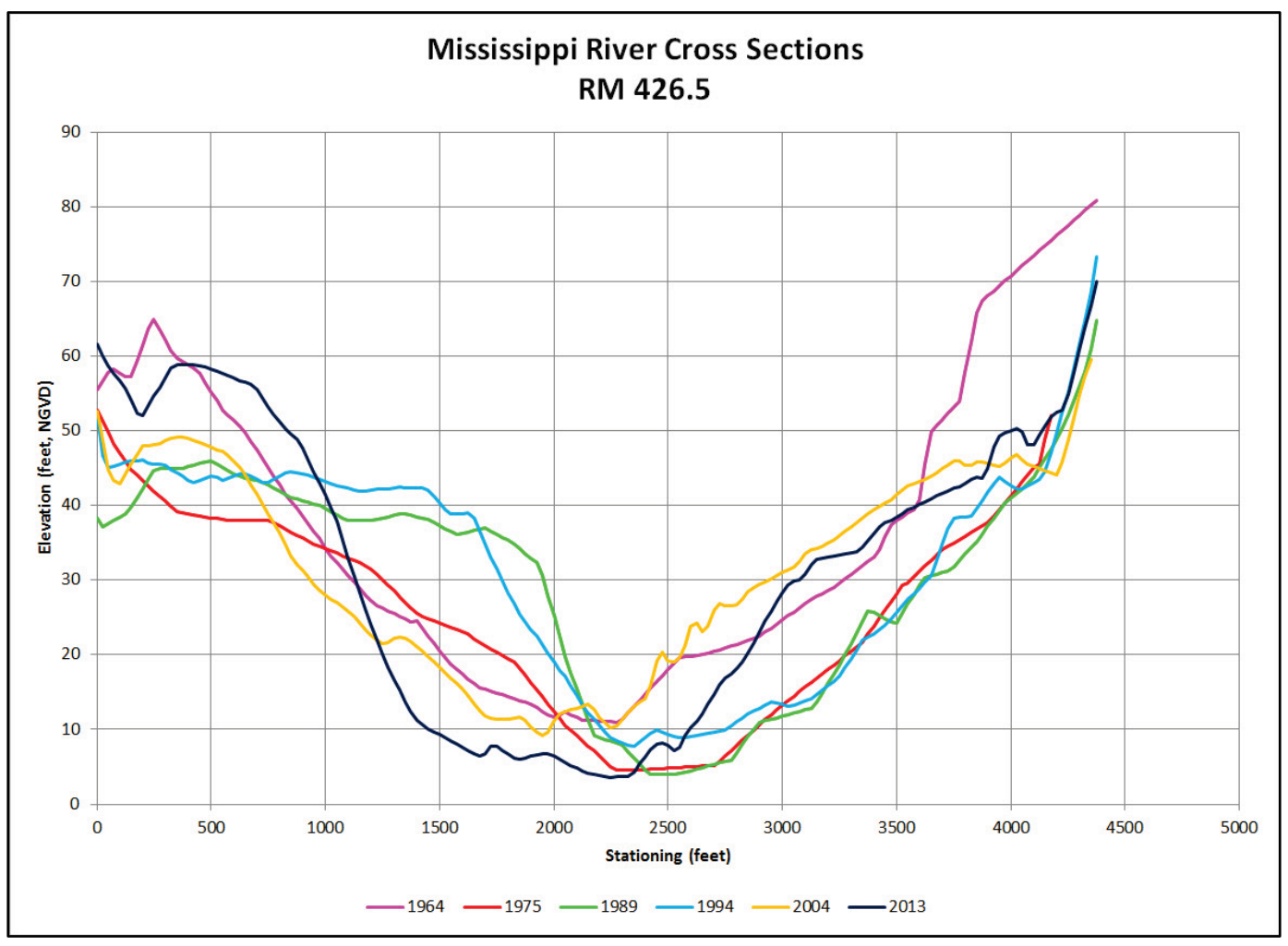

Figure 6. Cross-sectional area at LWRP for crossing sections RM 325-592 (Vicksburg District reach).

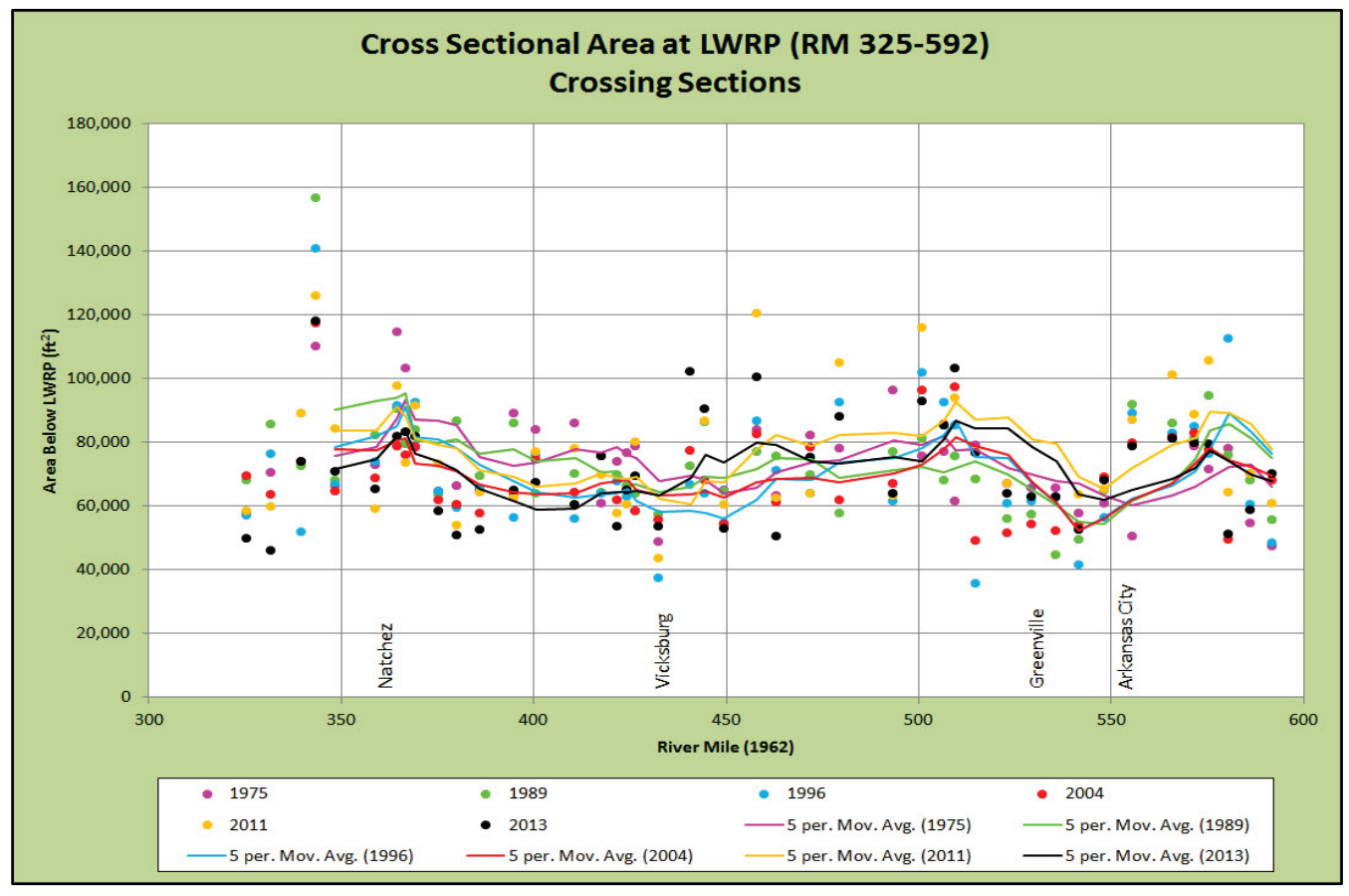


Figure 7. Channel width at LWRP for crossing sections RM 325-592 (Vicksburg District reach).

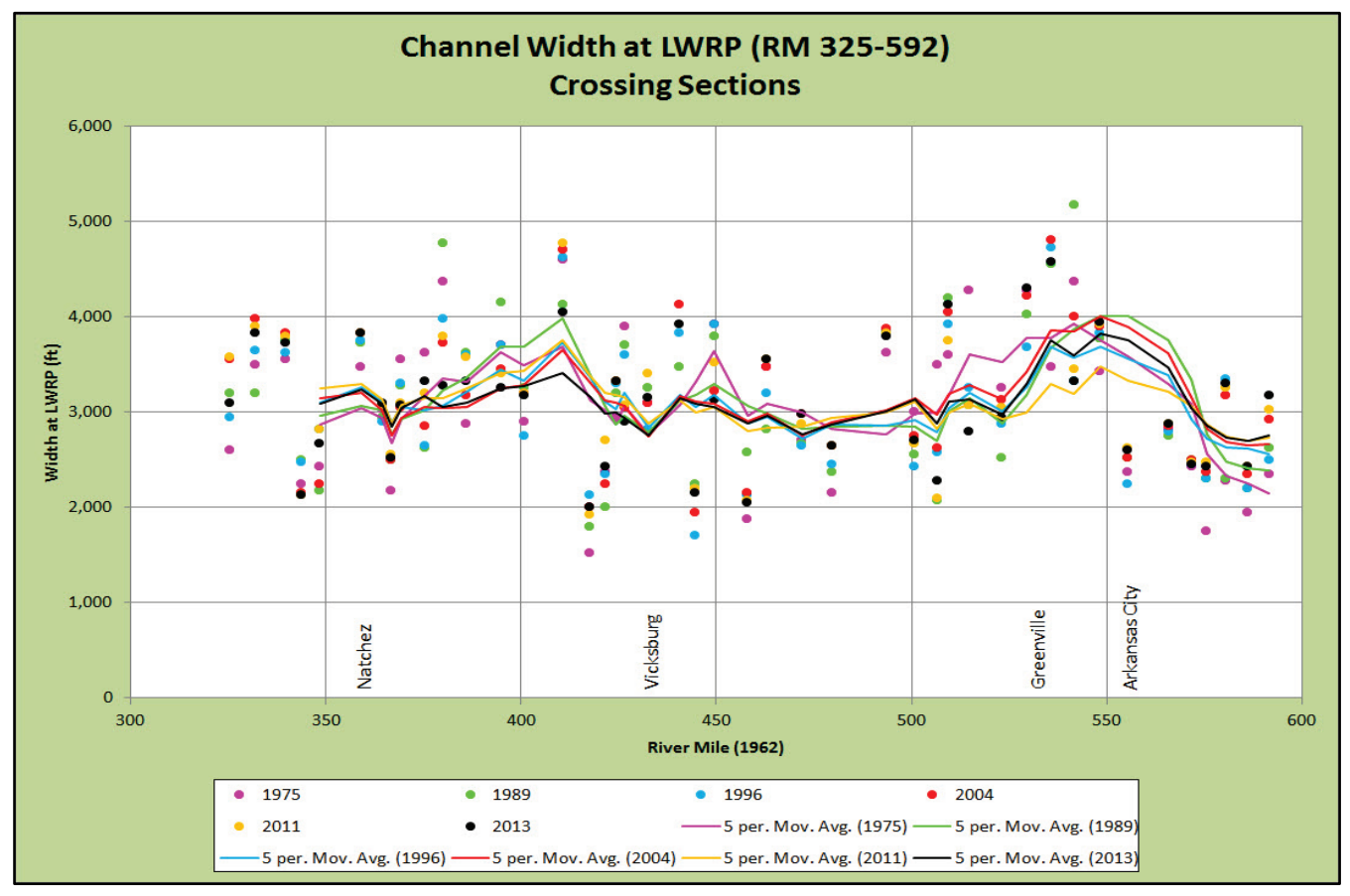

Figure 8. Hydraulic depth at LWRP for crossing sections RM 325-592 (Vicksburg District reach).

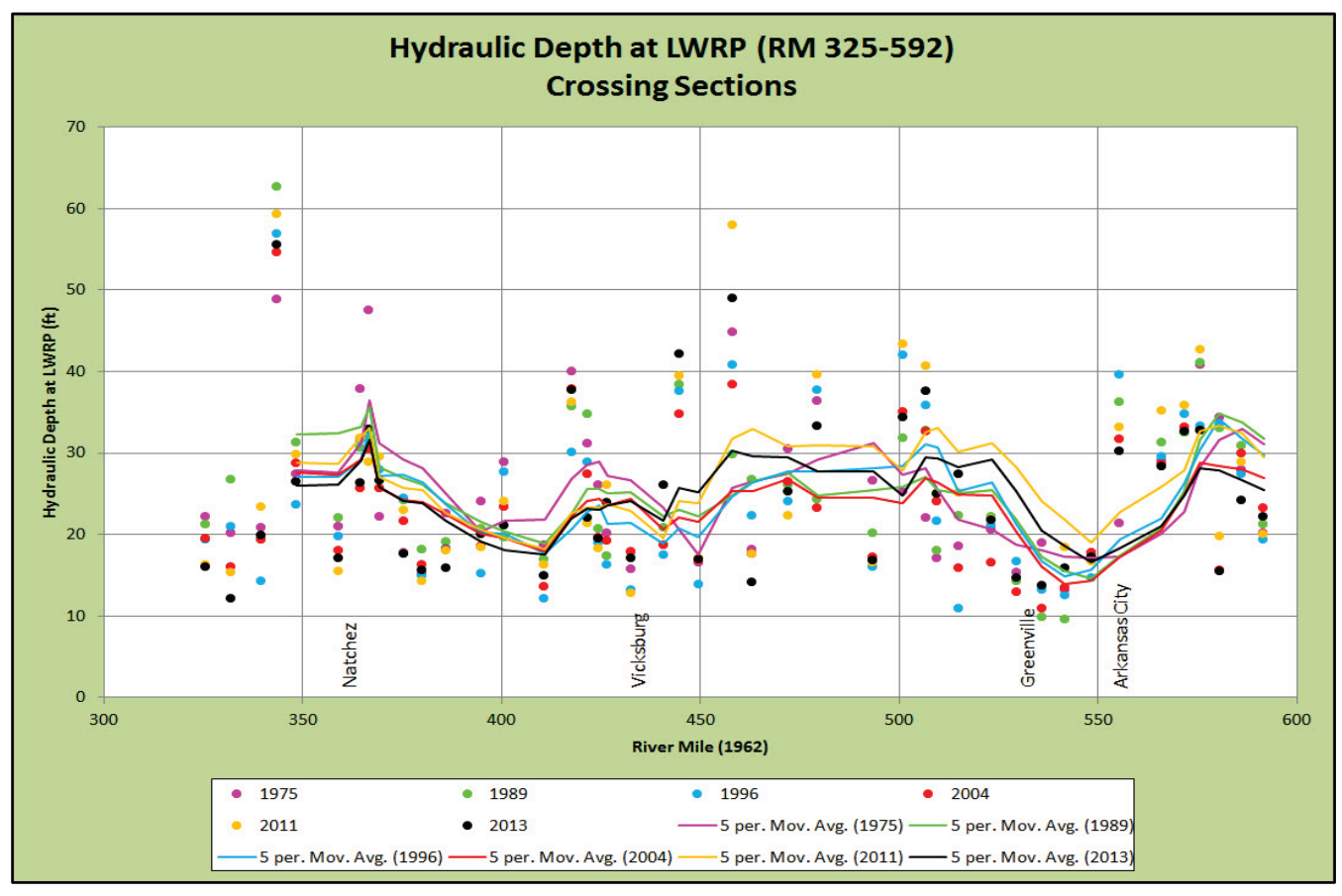


Figure 9. Channel conveyance at LWRP for crossing sections RM 325-592 (Vicksburg District reach).

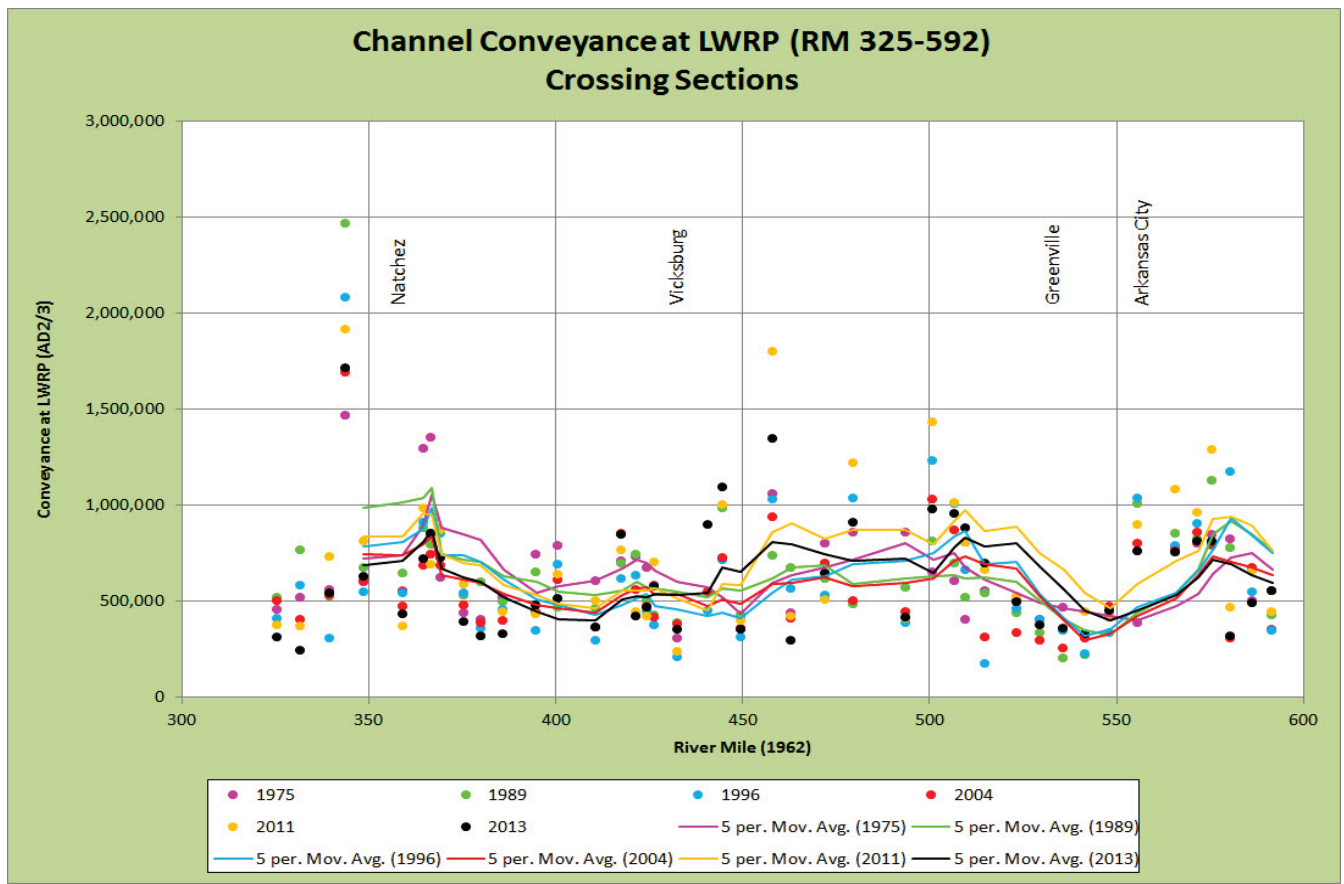

The cross-sectional area, channel width, hydraulic depth, and channel conveyance referenced to LWRP for the pool sections from RM 325 to 592 (Vicksburg District reach) are shown in Figures 10 through 13, respectively. A five-point moving average trend line is shown for each survey. The crosssectional area shown in Figure 10 indicates little temporal variation except from approximately RM 440 to 500 . Also noted is a slight decreasing trend in area from RM 325 to 592. Figure 11 indicates a general temporal decrease in cross-sectional area for the entire reach, with the greatest magnitudes occurring at approximately RM 490. Hydraulic depth and channel conveyance, shown in Figures 12 and 13, respectively, exhibit the same general decreasing trend from downstream to upstream as was observed in the cross-sectional area. 
Figure 10. Cross-sectional area at LWRP for pool sections RM 325-592 (Vicksburg District reach).

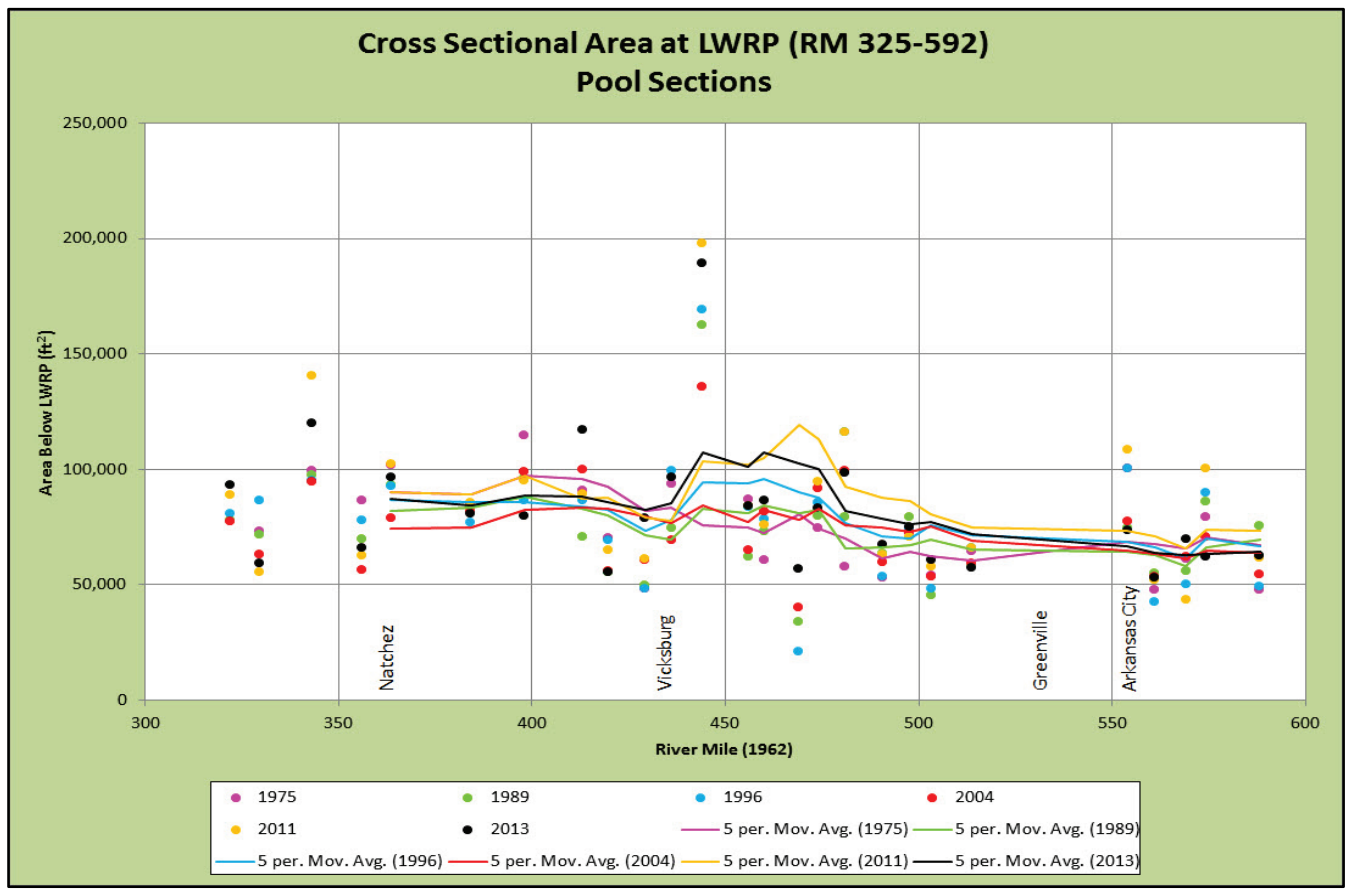

Figure 11. Channel width at LWRP for pool sections RM 325-592 (Vicksburg District reach).

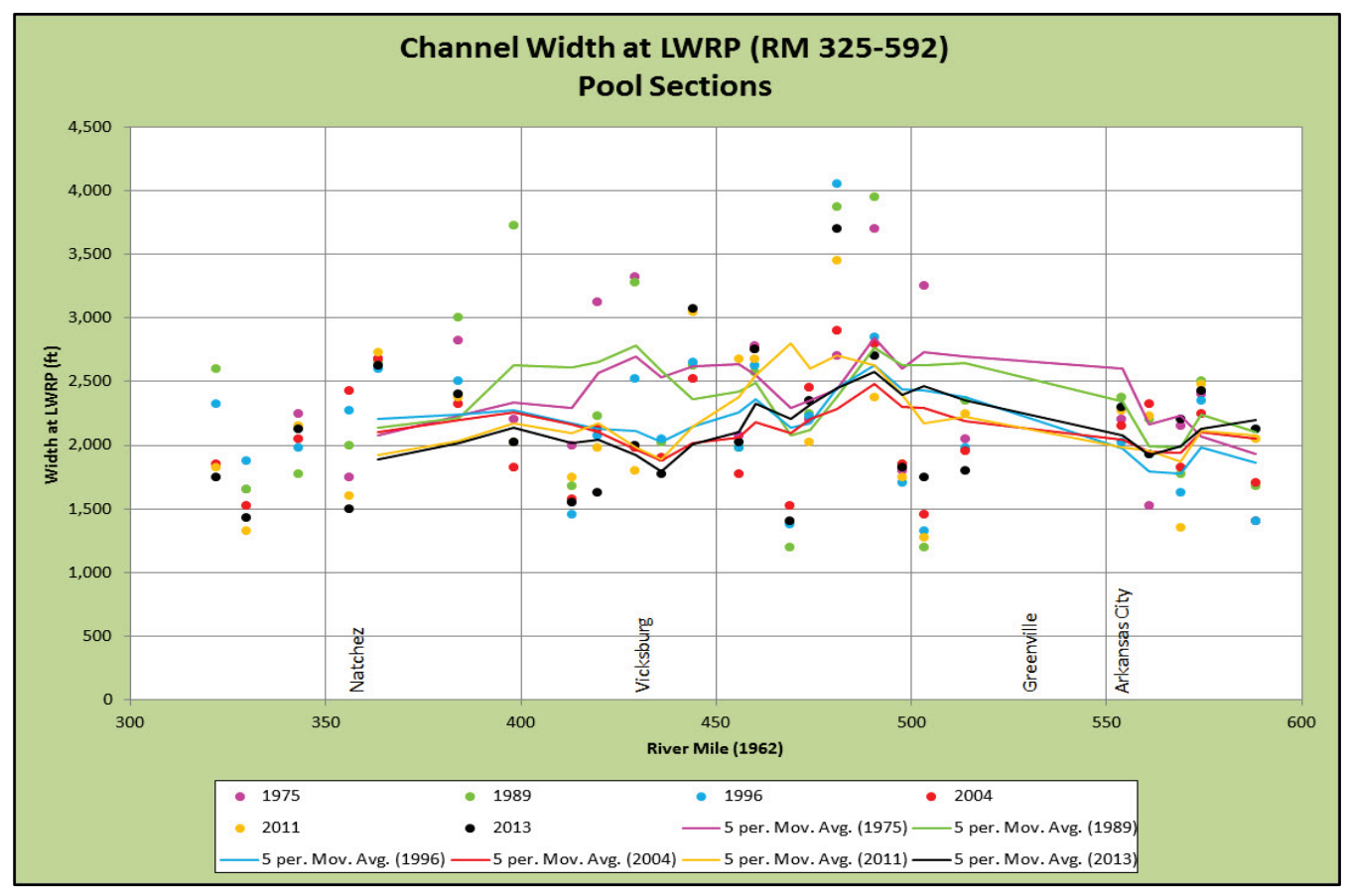


Figure 12. Hydraulic depth at LWRP for pool sections RM 325-592 (Vicksburg District reach).

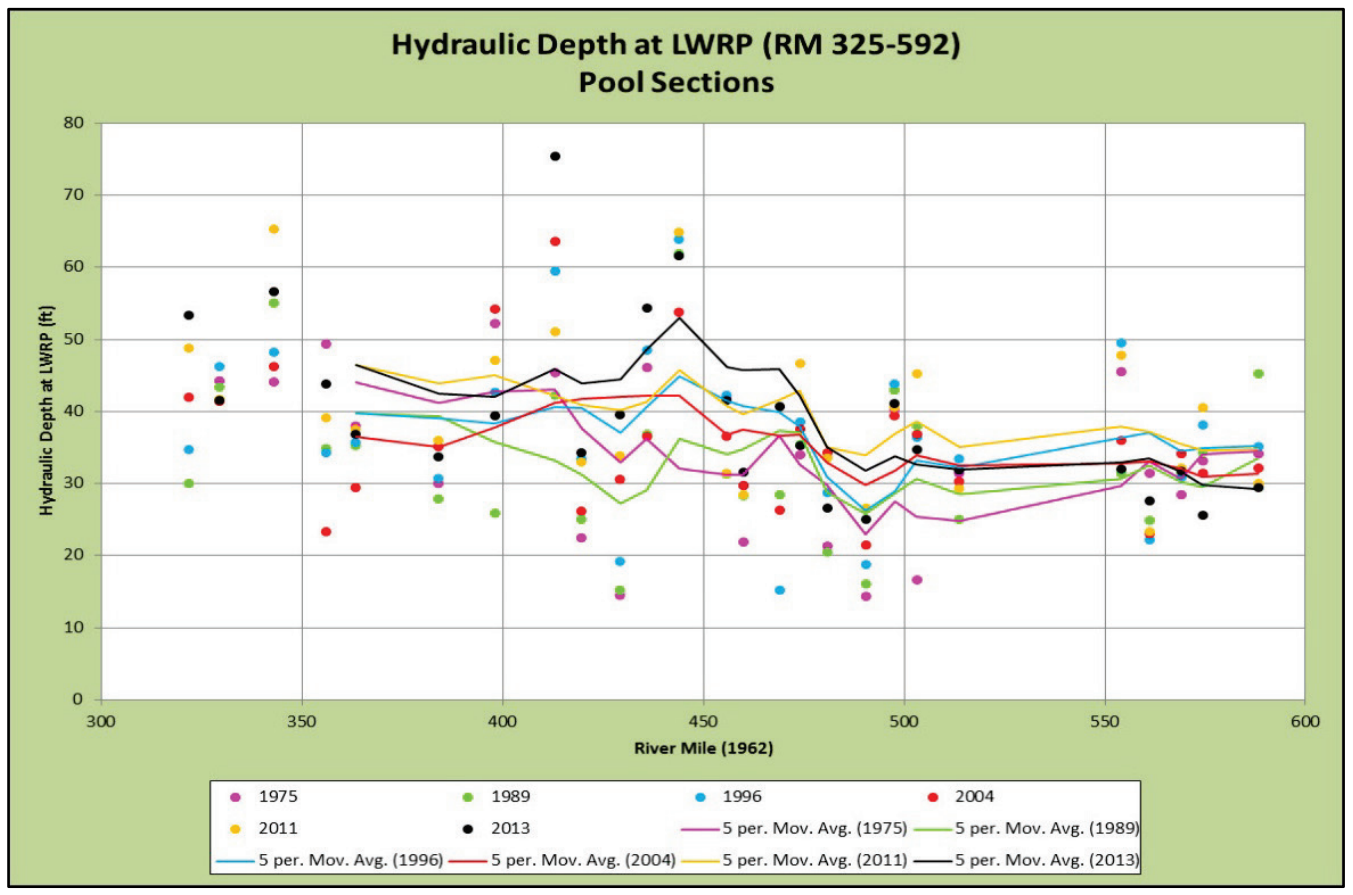

Figure 13. Channel conveyance at LWRP for pool sections RM 325-592 (Vicksburg District reach).

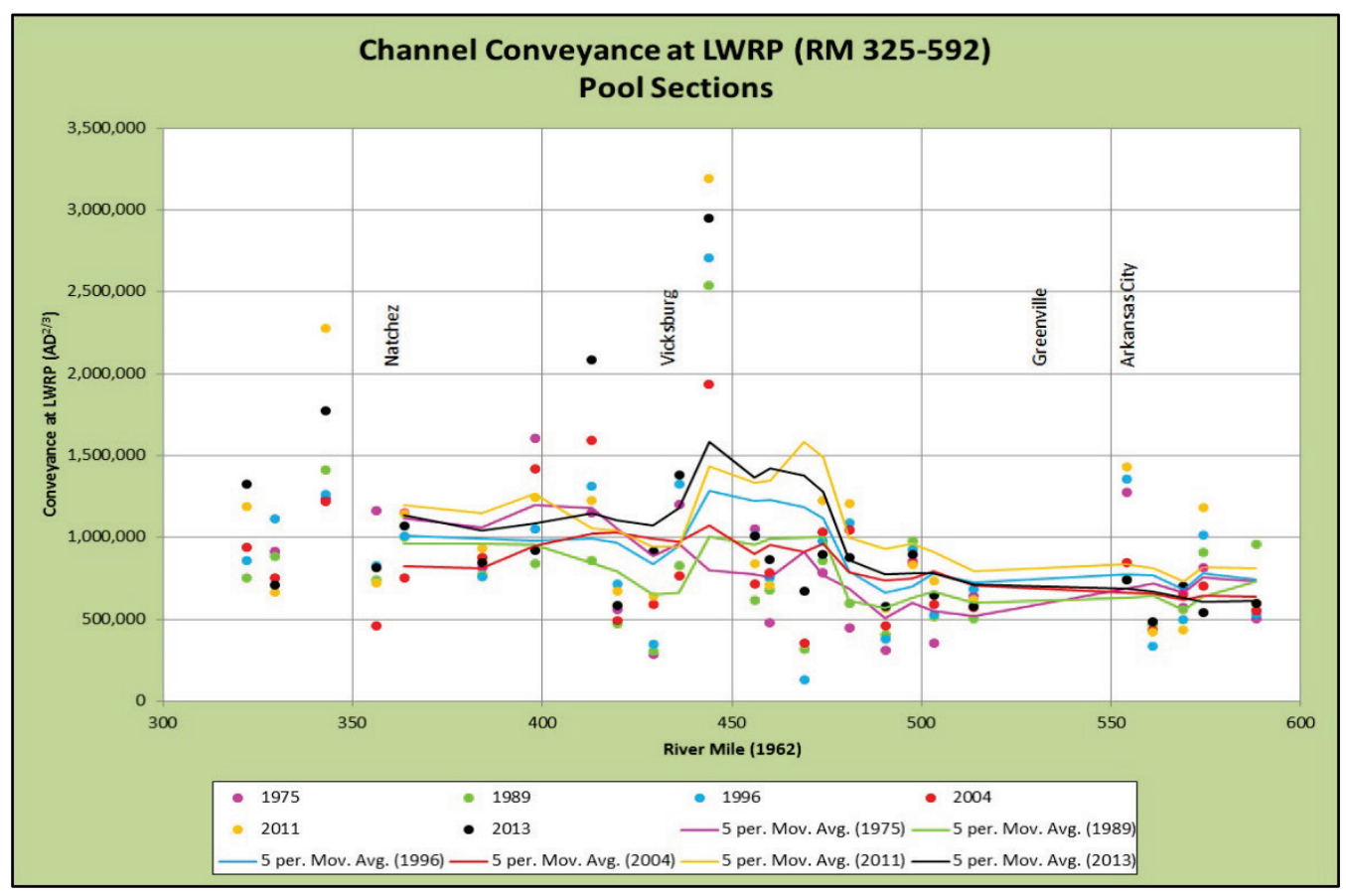


The cross-sectional area, channel width, hydraulic depth, and channel conveyance referenced to LWRP for the crossings sections from RM 592 to 954 (Memphis District reach) are shown in Figures 14 through 17, respectively. A ten-point moving average trend line is shown for each survey. In temporal terms, Figure 14 indicates a general increase in crosssectional area over the time of the surveys. No significant spatial trends are observed. Figure 15 suggests that the channel width has been fairly consistent over time, with a slight increasing trend from downstream to upstream. Hydraulic depth exhibits a slight increasing trend over time, as shown in Figure 16. As seen in Figure 17, there is considerable variation in channel conveyance throughout the reach; however, there is a general increasing trend over the survey time periods.

Figure 14. Cross-sectional area at LWRP for crossing sections RM 592-954 (Memphis District reach).

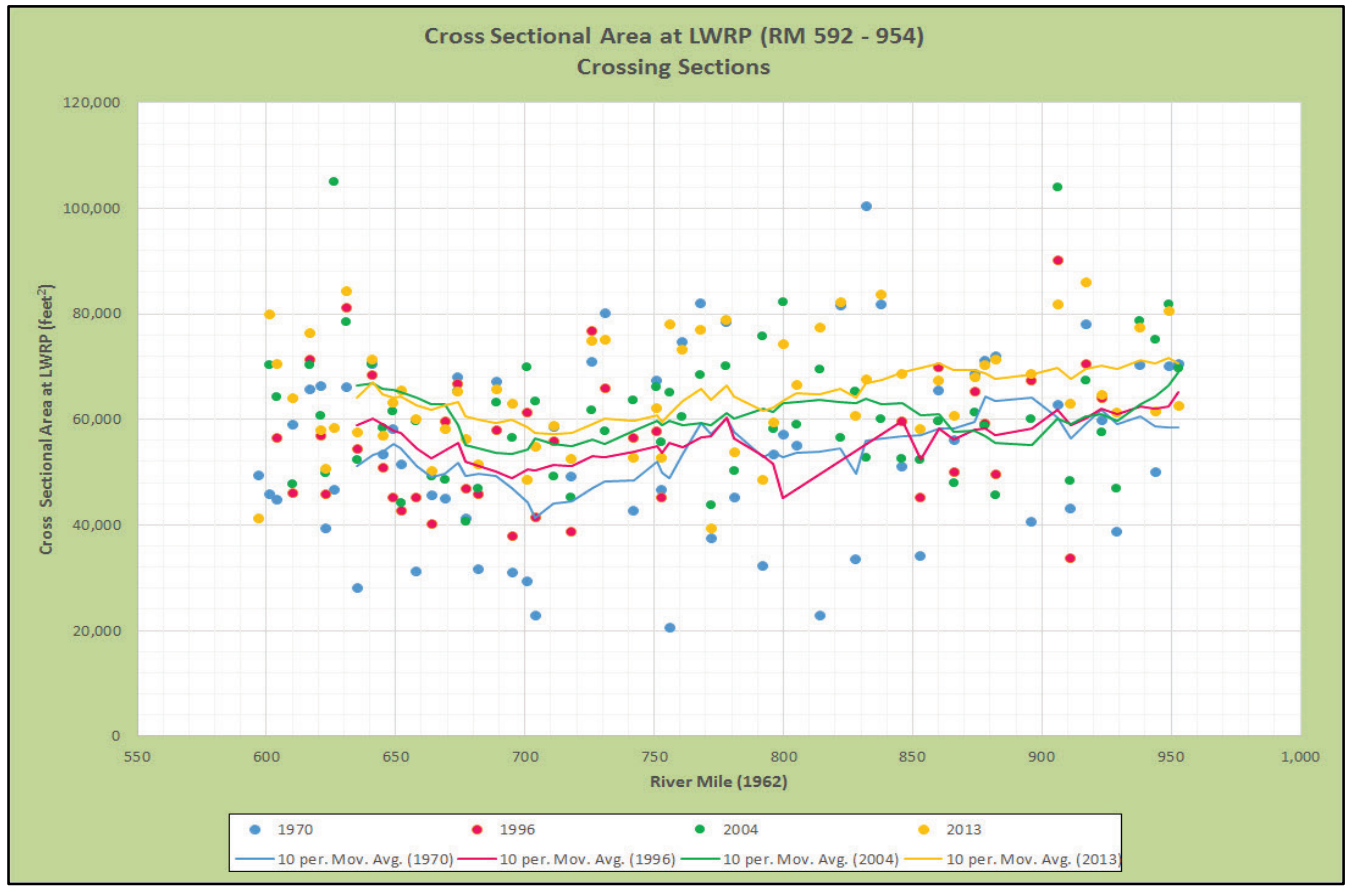


Figure 15. Channel width at LWRP for cross sections RM 592-954 (Memphis District reach).

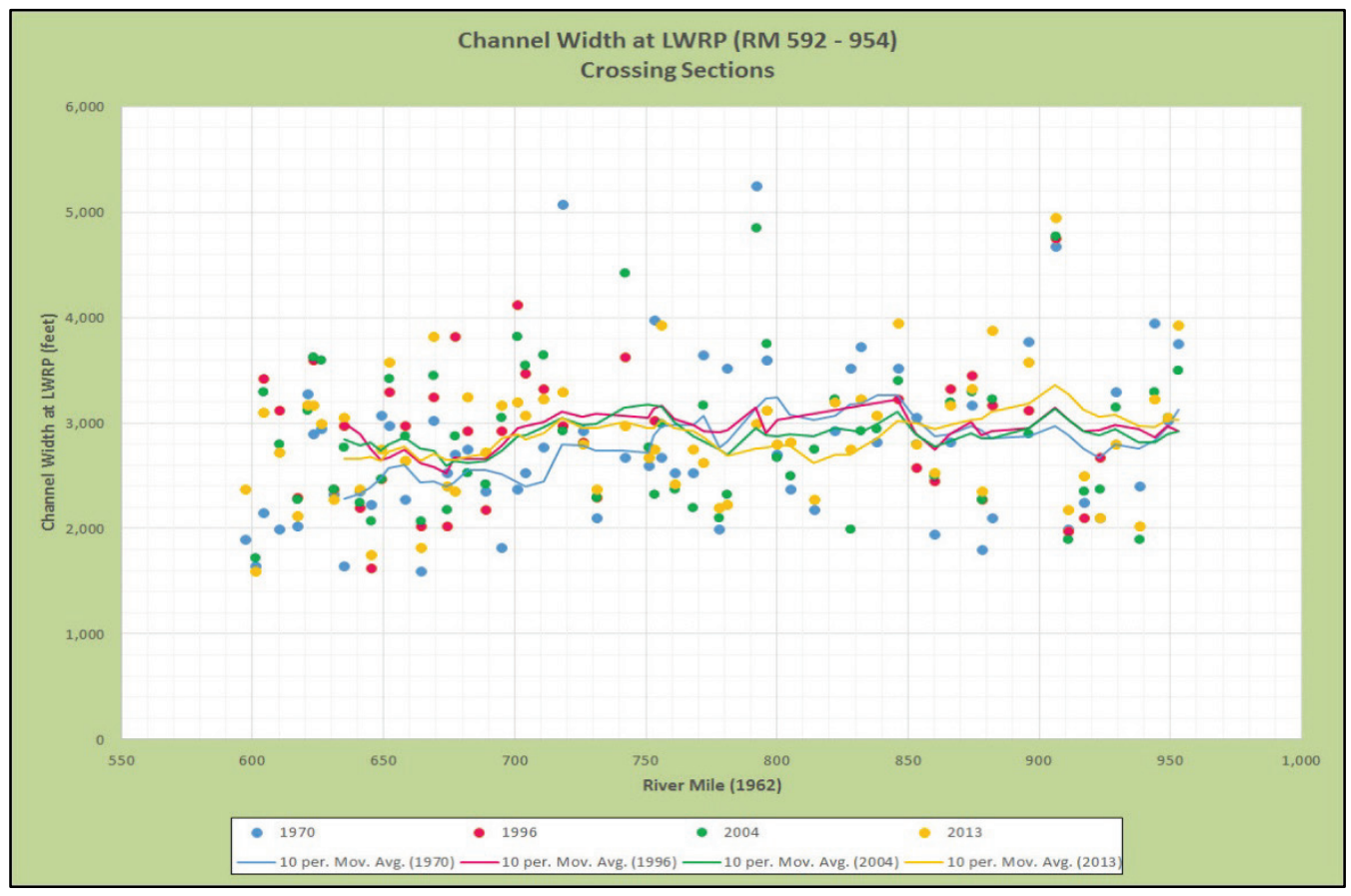

Figure 16. Hydraulic depth at LWRP for cross sections RM 592-954 (Memphis District reach).

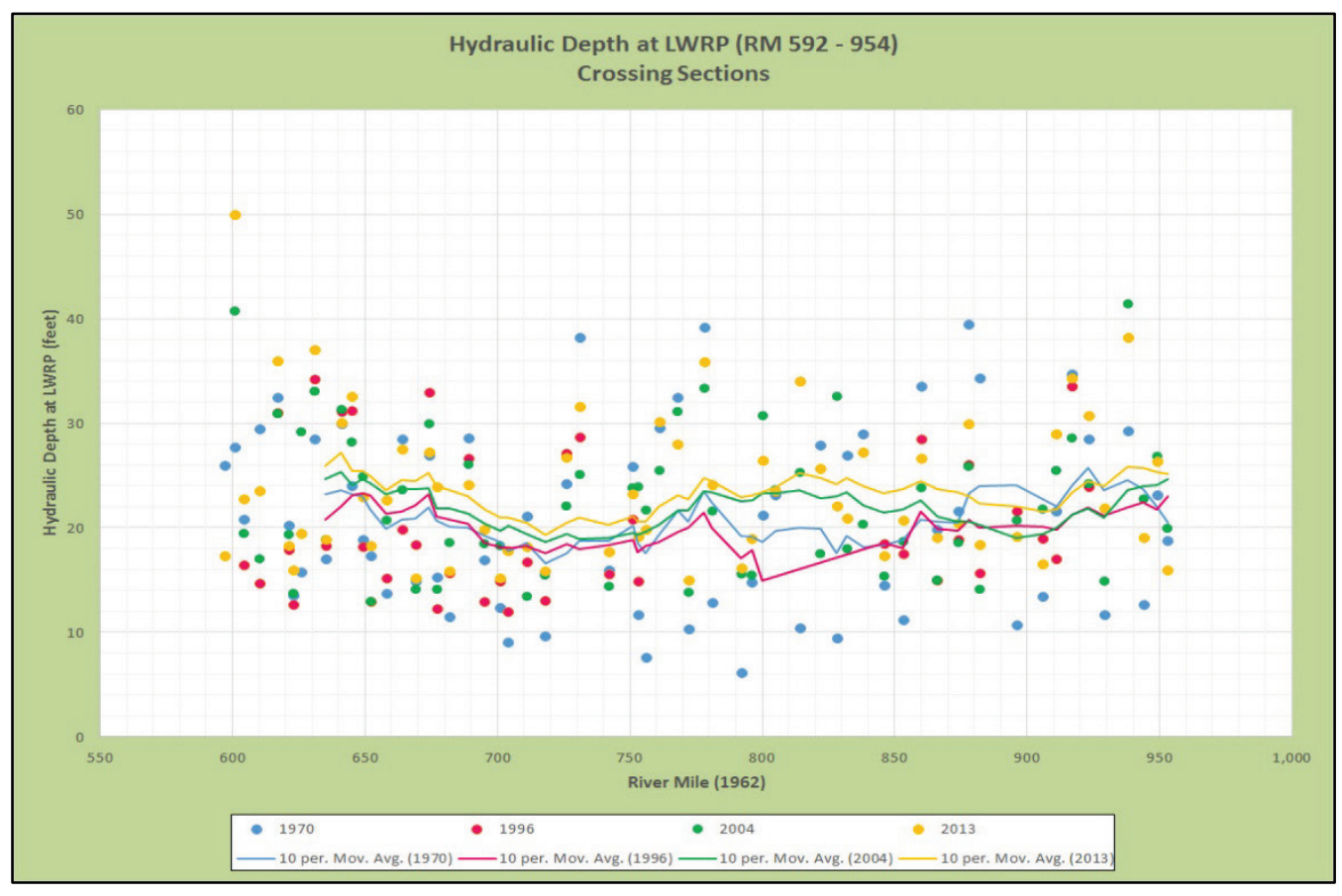


Figure 17. Channel conveyance at LWRP for crossing sections RM 592-954 (Memphis District reach).

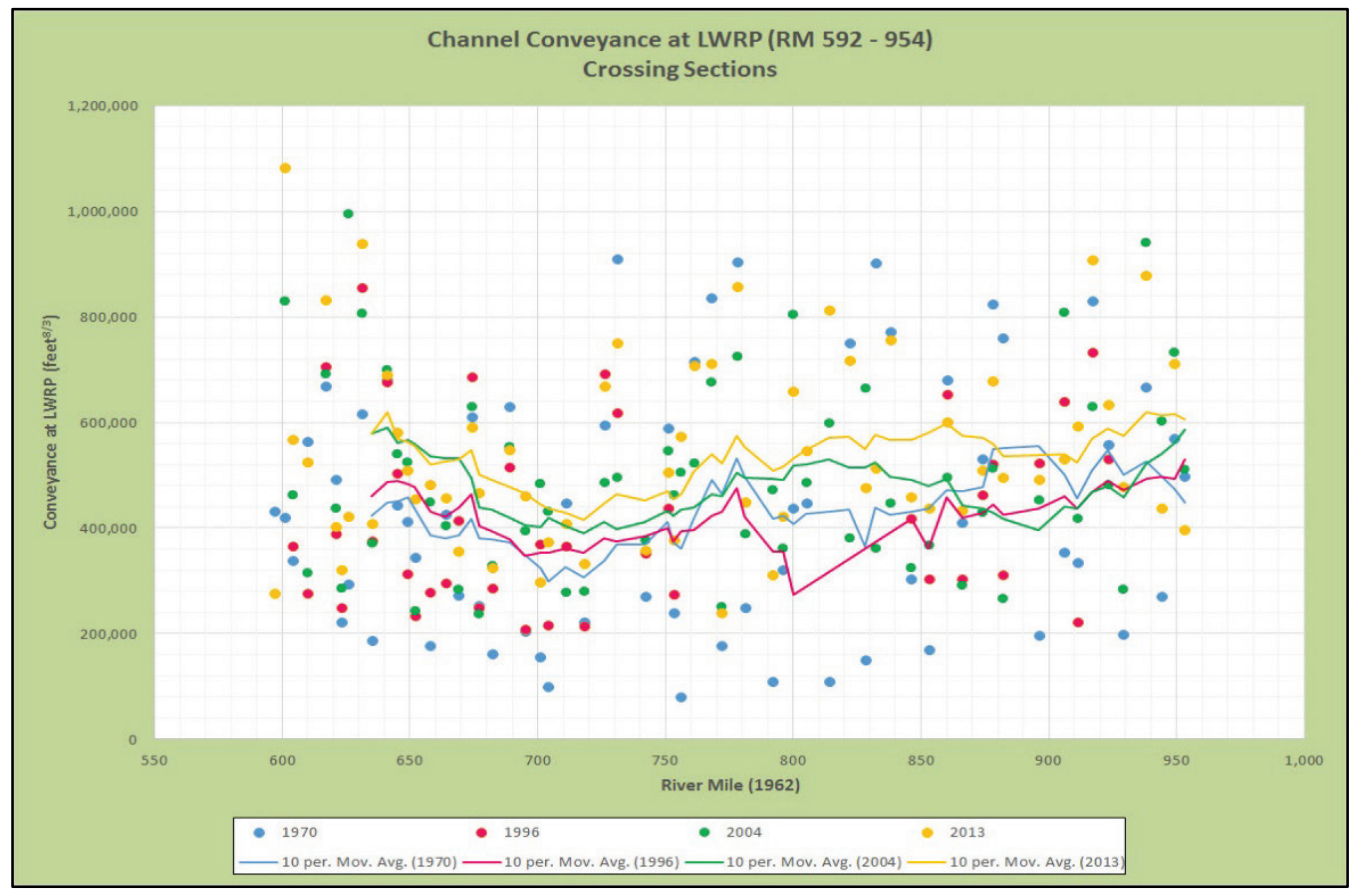

The cross-sectional area, channel width, hydraulic depth, and channel conveyance referenced to LWRP for the pool sections from RM 592 to 954 (Memphis District reach) are shown in Figures 18 through 21, respectively. A five-point moving average trend line is shown for each survey. In general, cross-sectional area has increased with time, as shown in Figure 18. Missing data from the 1996 survey from RM 775 to 850 make the moving average line artificially high in this reach. Figure 19 shows that the channel width follows a variable spatial trend, generally increasing from RM 600 to 775 , decreasing to RM 875, and then sharply increasing at RM 925. Figures 20 and 21 indicate the hydraulic depth and channel conveyance, respectively, exhibit similar but variable spatial trends. In general, both hydraulic depth and channel conveyance exhibit increasing trends over time. 
Figure 18. Cross-sectional area at LWRP for pool sections RM 592-954 (Memphis District reach).

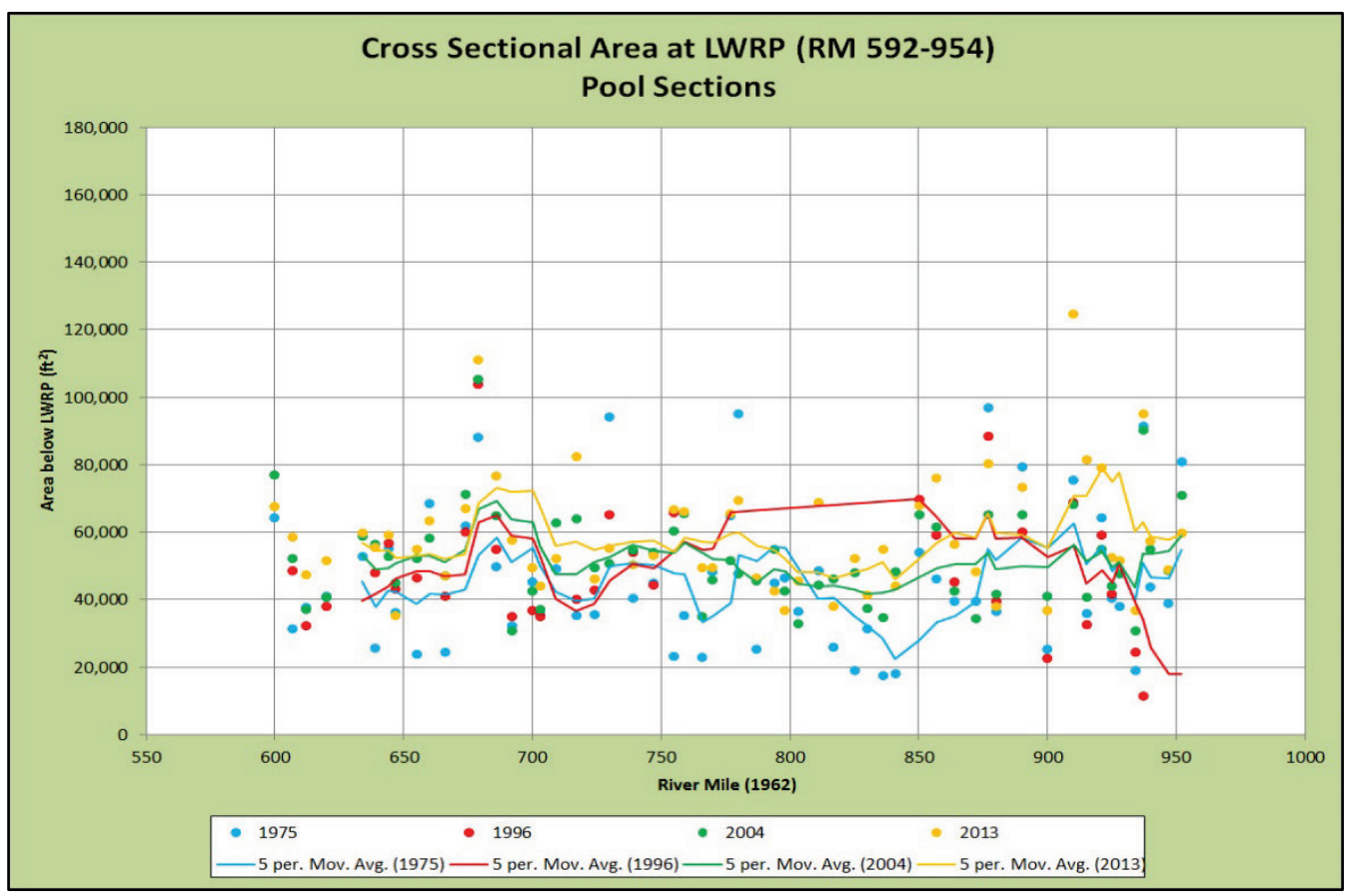

Figure 19. Channel width at LWRP for pool sections RM 592-954 (Memphis District reach).

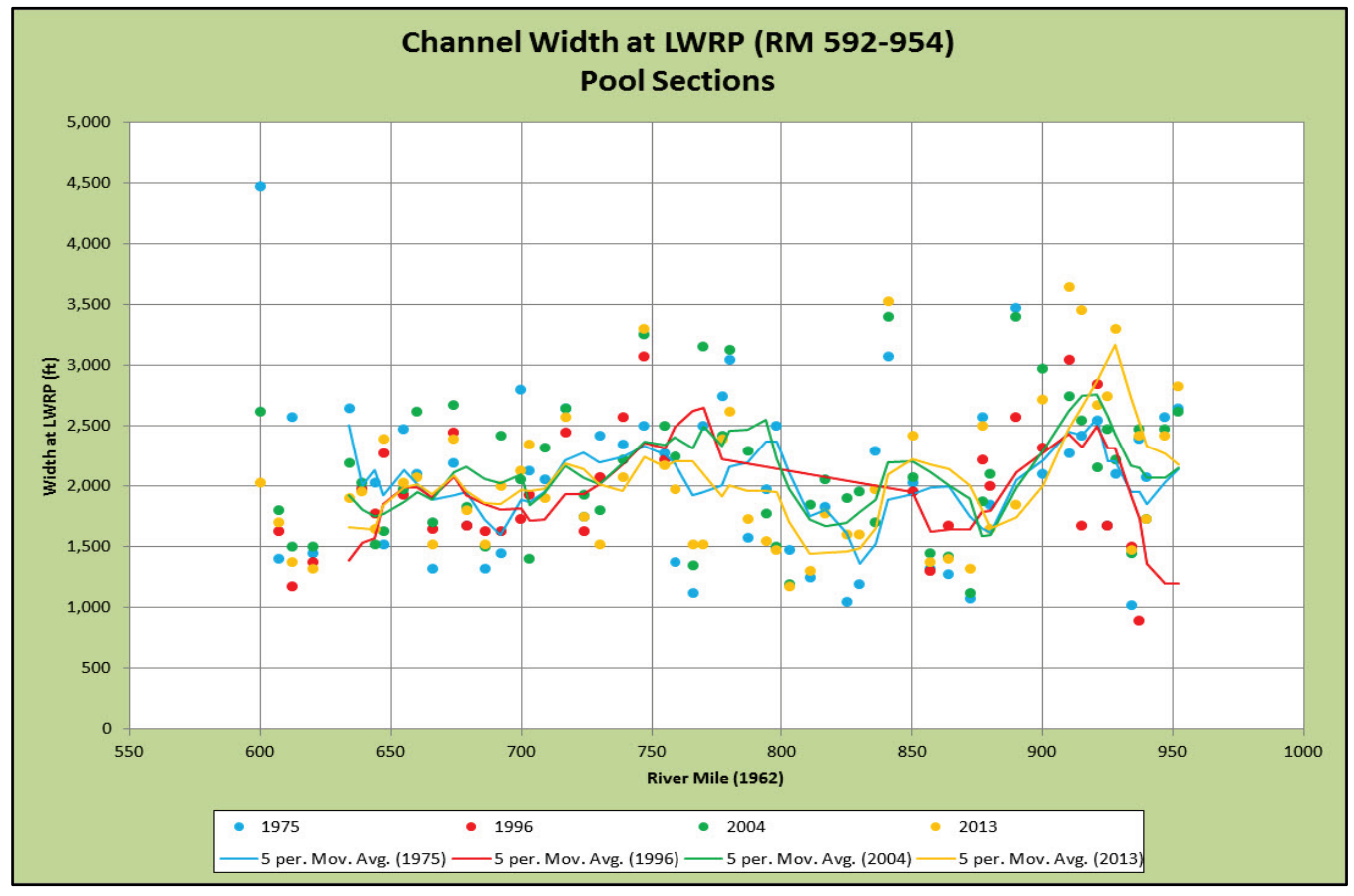


Figure 20. Hydraulic depth at LWRP for pool sections RM 592-964 (Memphis District reach).

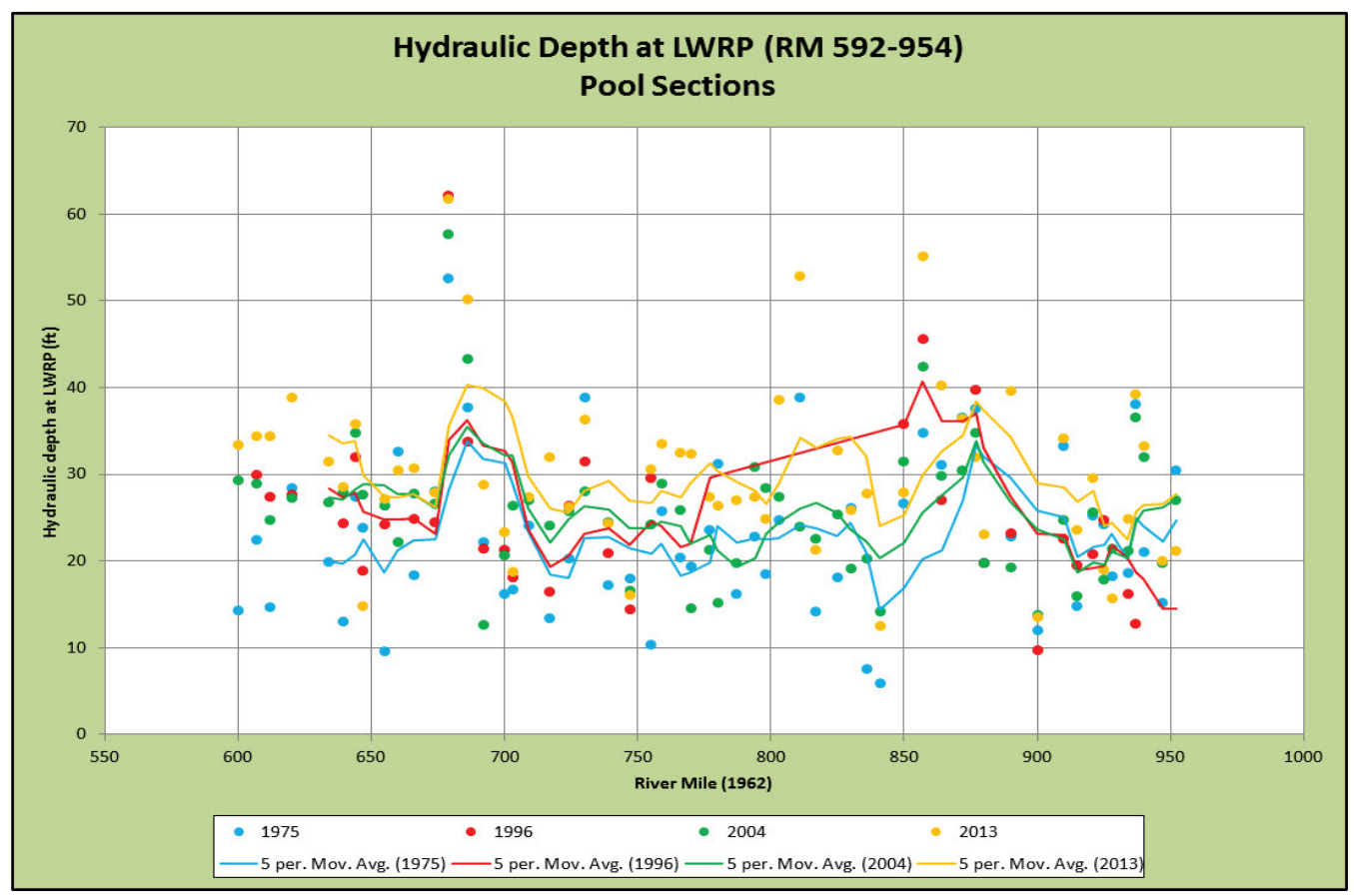

Figure 21. Channel conveyance at LWRP for pool sections RM 592-954 (Memphis District reach).

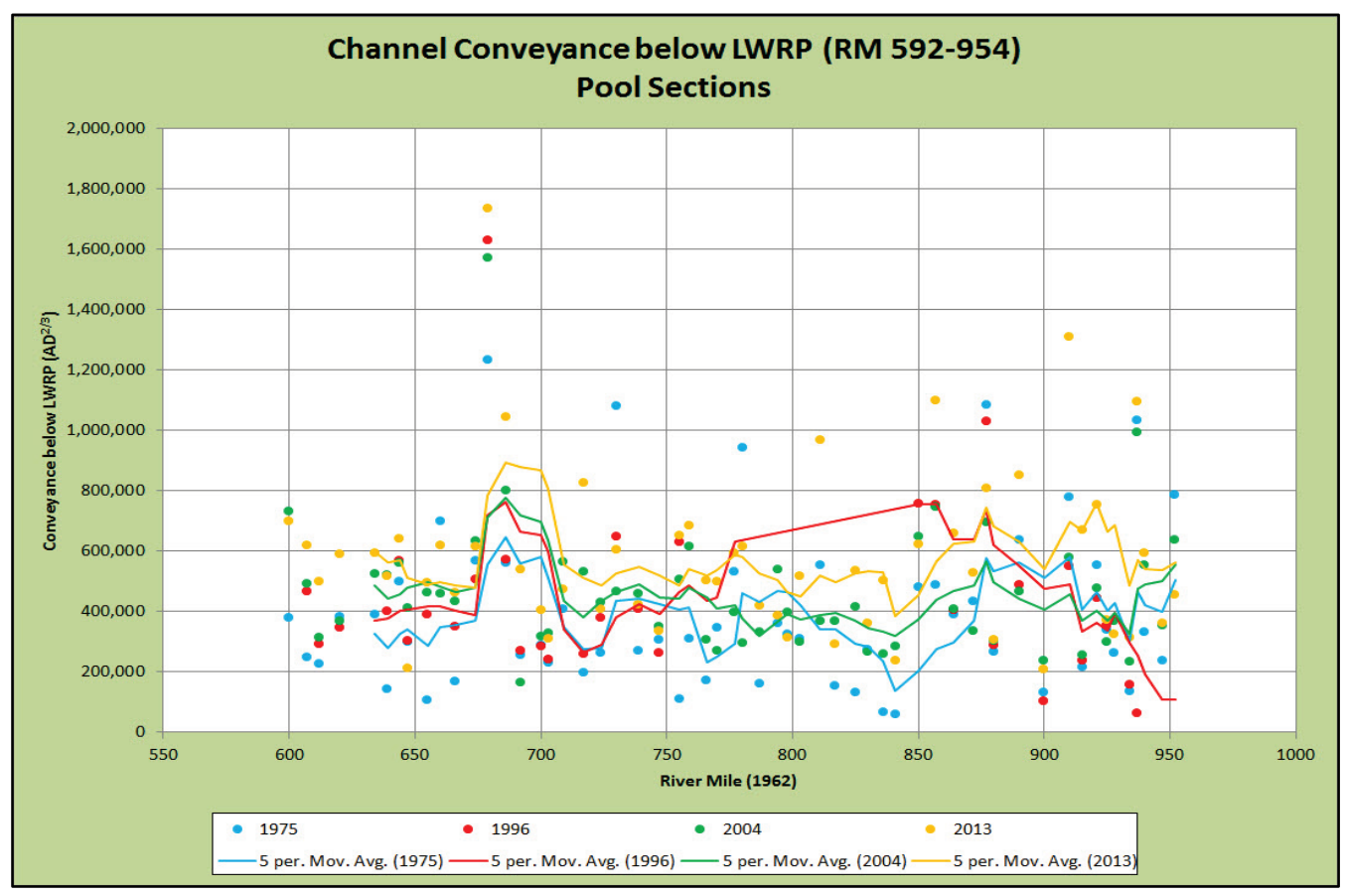


As evidenced from the preceding plots of computed cross-section geometry parameters, there is considerable variation in channel geometry in both time and space. This variability makes it difficult to readily identify spatial and temporal trends with certainty. In order to glean more understanding of the spatial and temporal trends in the channel geometry, the crosssection data are presented in box plots. Box plots provide additional statistical insight about the central tendencies and spread of the geometry data. The data for the Vicksburg and Memphis District reaches were combined into a total LMR dataset and organized in box plots for the defined geomorphic reaches described in Table 4. An example of a box plot of cross-sectional area at LWRP for the crossing sections in Reach 5 (RM 702-650) is shown in Figure 22. Because of the numerous plots for all of the reaches, the plots in their entirety are presented in Appendix A. These plots illustrate the temporal trends in the median value of cross-sectional area for each geomorphic reach, as well as the minimum/maximum limits and IQR of the data. Box plots were also constructed for the channel width, hydraulic depth and channel conveyance at LWRP for the crossing sections and are presented in Appendices B, C, and D, respectively. Similar box plots were constructed for the LMR pool sections and are shown in Appendices E, F, G, and $\mathrm{H}$.

Figure 22. Example of box plot for cross-sectional area at LWRP for crossing sections, Reach 5.

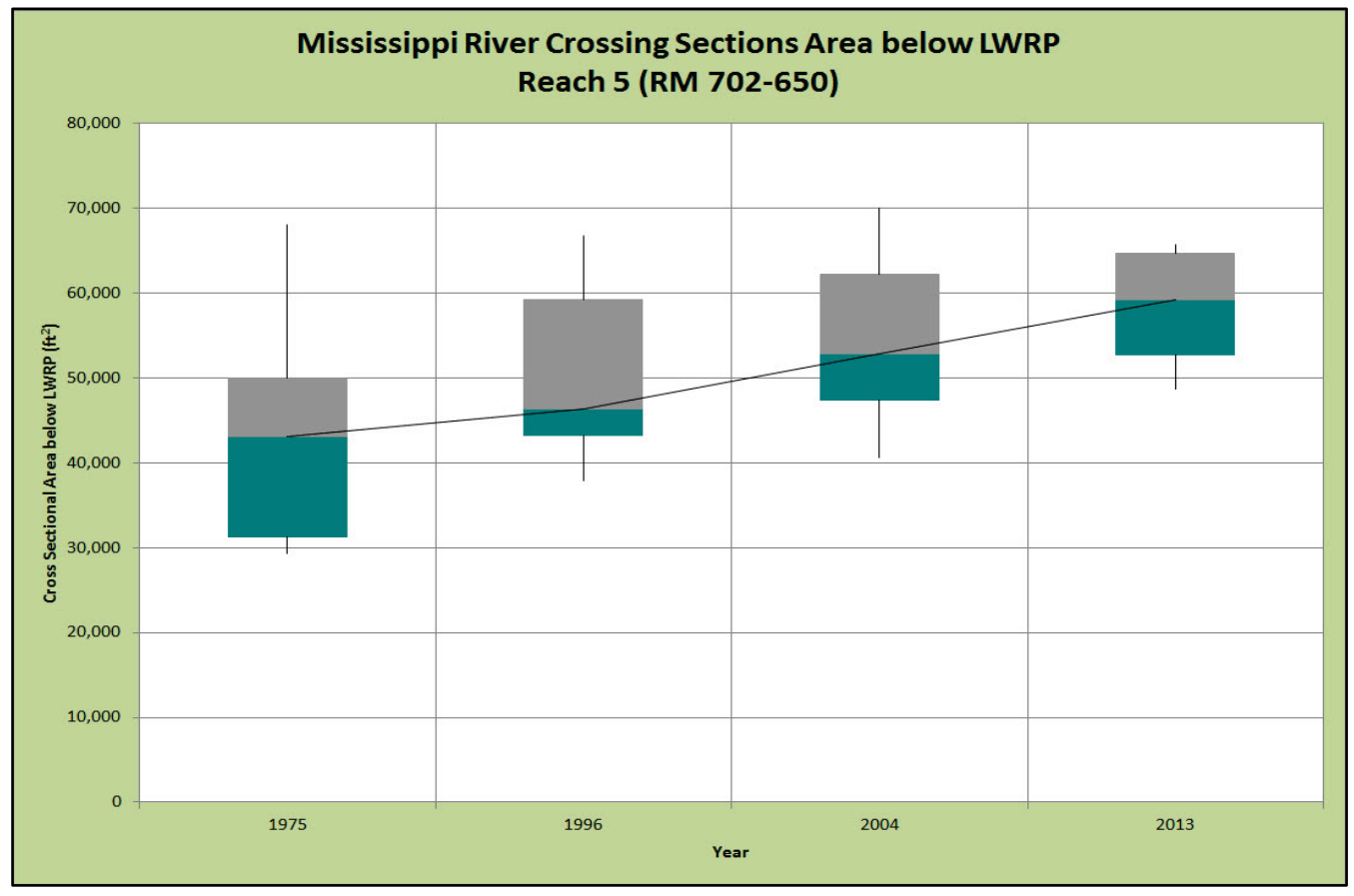


In order to present a comprehensive summary of the spatial and temporal trends observed in the box plots, the general change of the median value of each geometric parameter between successive surveys was tabularized. Table 5 shows the box plot results of cross-sectional area for the crossing sections of the LMR. The trends of the median values for each successive survey time period are presented in three generalized categories and color coded for visualization: (1) “I” for increasing values (color coded red), (2) "D" for decreasing values (color coded blue), and (3) "NC" for no significant change (color coded green). Reaches with increasing and decreasing cross-sectional area median values at LWRP can be considered as erosional and depositional reaches, respectively. The hydrographic survey periods are listed in the columns, but not all surveys are applicable to every reach. The color-coded bars extend between the successive surveys available for each reach.

Table 5. General trends by geomorphic reach of median cross-sectional area at LWRP for LMR crossing sections.

\begin{tabular}{|c|c|c|c|c|c|c|c|c|c|c|c|}
\hline \multirow[b]{2}{*}{ Reach } & \multicolumn{11}{|c|}{$\begin{array}{c}\text { General trend in median cross-sectional area at LWRP between successive surveys for LMR } \\
\text { crossing sections. }\end{array}$} \\
\hline & 1975 & 1989 & 1996 & 2000 & 2002 & 200 & 200 & 2008 & 2010 & 2011 & 2013 \\
\hline $\begin{array}{l}1 \text { (RM 954- } \\
907 \text { ) }\end{array}$ & \multicolumn{3}{|c|}{ NC } & \multicolumn{3}{|c|}{1} & \multicolumn{5}{|c|}{ D } \\
\hline $\begin{array}{l}2 \text { (RM 907- } \\
845)\end{array}$ & \multicolumn{3}{|c|}{ D } & \multicolumn{3}{|c|}{ NC } & \multicolumn{5}{|c|}{1} \\
\hline $\begin{array}{l}3 \text { (RM 845- } \\
773)\end{array}$ & \multicolumn{6}{|c|}{ I } & \multicolumn{5}{|c|}{1} \\
\hline $\begin{array}{l}4 \text { (RM 773- } \\
702)\end{array}$ & \multicolumn{3}{|c|}{ I } & \multicolumn{3}{|c|}{1} & \multicolumn{5}{|c|}{$\mathrm{NC}$} \\
\hline $\begin{array}{l}5 \text { (RM } 702- \\
650)\end{array}$ & \multicolumn{3}{|c|}{ I } & \multicolumn{3}{|c|}{1} & \multicolumn{5}{|c|}{1} \\
\hline $\begin{array}{l}6 \text { (RM 650- } \\
581)\end{array}$ & \multicolumn{3}{|c|}{ NC } & \multicolumn{3}{|c|}{1} & \multicolumn{5}{|c|}{ NC } \\
\hline $\begin{array}{l}7 \text { (RM 581- } \\
524)\end{array}$ & 1 & & D & $I$ & D & NC & NC & $I$ & D & NC & D \\
\hline $\begin{array}{l}8 \text { (RM 524- } \\
437)\end{array}$ & D & & D & D & 1 & D & 1 & NC & $I$ & 1 & 1 \\
\hline $\begin{array}{l}9 \text { (RM } 437- \\
381)\end{array}$ & D & & D & 1 & D & D & D & D & NC & 1 & NC \\
\hline $\begin{array}{l}10(\text { RM 381- } \\
325)\end{array}$ & 1 & & D & 1 & D & NC & D & D & D & 1 & $D$ \\
\hline
\end{tabular}


Although there are considerable noise and variability in the table data, it can be generalized that Reaches 9 and 10, corresponding to the area downstream of Vicksburg, are predominantly characterized by decreasing cross-sectional area, and Reaches 3, 4, and 5 are primarily areas of increasing cross-sectional area.

Table 6 illustrates the general trends in the median value of channel width by reach for the cross sections of the LMR. In general, the median channel width by reach exhibits either no significant change or oscillations between minor increases or decreases in width.

Table 6. General trends by geomorphic reach of median channel width at LWRP for LMR crossing sections.

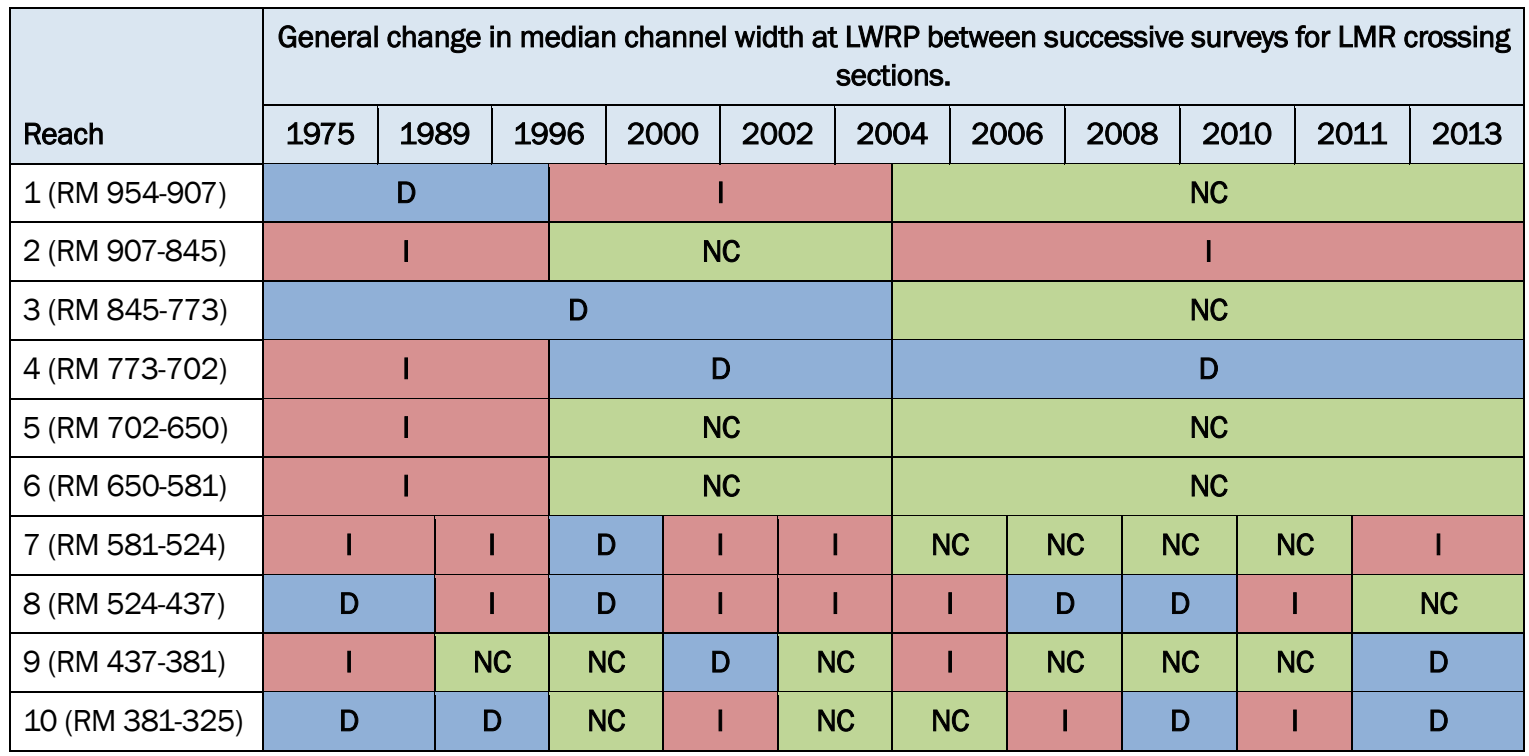

Table 7 shows the general trends in the median value of hydraulic depth by reach for the cross sections of the LMR. The data exhibit considerable variability and no apparent trends.

Table 7. General trends by geomorphic reach of median hydraulic depth at LWRP for LMR crossing sections.

\begin{tabular}{|c|c|c|c|c|c|c|c|c|c|c|c|}
\hline \multirow[b]{2}{*}{ Reach } & \multicolumn{11}{|c|}{$\begin{array}{l}\text { General trend in median hydraulic depth at LWRP between successive surveys for LMR crossing } \\
\text { sections. }\end{array}$} \\
\hline & 1975 & 1989 & 1996 & 2000 & 2002 & 2004 & 2006 & 2008 & 2010 & 2011 & 2013 \\
\hline 1 (RM 954-907) & \multicolumn{3}{|c|}{$\mathrm{I}$} & \multicolumn{2}{|c|}{ I } & & \multicolumn{5}{|c|}{ I } \\
\hline 2 (RM 907-845) & \multicolumn{3}{|c|}{ D } & \multicolumn{2}{|c|}{ NC } & & \multicolumn{5}{|c|}{ NC } \\
\hline 3 (RM 845-773) & \multicolumn{5}{|c|}{ NC } & & \multicolumn{5}{|c|}{ I } \\
\hline 4 (RM 773-702) & \multicolumn{2}{|r|}{ D } & \multicolumn{3}{|c|}{ I } & & \multicolumn{5}{|c|}{ D } \\
\hline
\end{tabular}




\begin{tabular}{|l|c|c|c|c|c|c|c|c|c|c|}
\hline 5 (RM 702-650) & \multicolumn{3}{|c|}{ D } & \multicolumn{3}{|c|}{ I } & \multicolumn{5}{c|}{ I } \\
\hline 6 (RM 650-581) & \multicolumn{3}{|c|}{ D } & \multicolumn{3}{|c|}{ I } & \multicolumn{5}{c|}{ D } \\
\hline 7 (RM 581-524) & I & D & NC & D & I & NC & I & NC & NC & D \\
\hline 8(RM 524-437) & I & D & NC & NC & I & NC & NC & I & I & I \\
\hline 9 (RM 437-381) & D & D & I & NC & NC & NC & D & I & NC & I \\
\hline 10 (RM 381-325) & I & D & D & NC & I & D & NC & NC & I & D \\
\hline
\end{tabular}

Table 8 shows the general trends in the median value of channel conveyance by reach for the cross sections of the LMR. In general, trends are very similar to those observed with the cross-sectional area.

Table 8. General trends by geomorphic reach of median channel conveyance at LWRP for LMR crossing sections.

\begin{tabular}{|c|c|c|c|c|c|c|c|c|c|c|c|c|c|c|c|}
\hline \multirow{3}{*}{$\frac{\text { Reach }}{1 \text { (RM 954-907) }}$} & \multicolumn{15}{|c|}{$\begin{array}{c}\text { General trend in median channel conveyance at LWRP between successive surveys for LMR } \\
\text { crossing sections. }\end{array}$} \\
\hline & 1975 & 1989 & \multicolumn{2}{|c|}{1996} & 2000 & \multicolumn{2}{|c|}{2002} & 2004 & & 006 & 2008 & & \multicolumn{2}{|r|}{2011} & 2013 \\
\hline & \multicolumn{3}{|c|}{ NC } & \multicolumn{5}{|c|}{ I } & \multicolumn{7}{|c|}{ I } \\
\hline 2 (RM 907-845) & \multicolumn{3}{|c|}{ I } & \multicolumn{5}{|c|}{ D } & \multicolumn{7}{|c|}{ I } \\
\hline 3 (RM 845-773) & \multicolumn{8}{|c|}{1} & \multicolumn{7}{|c|}{ I } \\
\hline 4 (RM 773-702) & \multicolumn{3}{|c|}{ NC } & \multicolumn{5}{|c|}{ I } & \multicolumn{7}{|c|}{ D } \\
\hline 5 (RM 702-650) & \multicolumn{3}{|c|}{1} & \multicolumn{5}{|c|}{ I } & \multicolumn{7}{|c|}{ I } \\
\hline 6 (RM 650-581) & \multicolumn{3}{|c|}{ D } & \multicolumn{5}{|c|}{ I } & \multicolumn{7}{|c|}{ NC } \\
\hline 7 (RM 581-524) & I & & כ & & & D & & 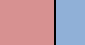 & D & & I & D & & C & D \\
\hline 8 (RM 524-437) & D & & IC & & 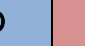 & I & & 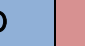 & I & & 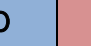 & I & & I & I \\
\hline 9 (RM 437-381) & D & & כ & & 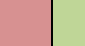 & $\mathrm{VC}$ & & 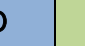 & NC & & 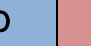 & $\mathrm{I}$ & & I & 1 \\
\hline 10 (RM 381-325) & I & & כ & & 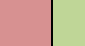 & NC & & 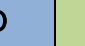 & NC & & ) & D & & I & D \\
\hline
\end{tabular}

Similar tables for the cross-section geometry data for the pool sections of the LMR are presented in Tables 9 through 12 . The variability of the data makes it difficult to identify definitive trends. Trends of median values for cross-sectional area at LWRP shown in Table 9 seem similar to those observed with the crossing sections. Channel width median values for the pool sections shown in Table 10 generally show no significant change or decreasing trends throughout the LMR reach. The hydraulic depth and channel conveyance at LWRP shown in Tables 11 and 12, respectively, exhibit similar trends as the cross sections, with increasing median values dominant in Reaches 1 through 6. 
Table 9. General trends by geomorphic reach of median cross-sectional area at LWRP for LMR pool sections.

\begin{tabular}{|c|c|c|c|c|c|c|c|c|c|c|c|}
\hline \multirow{3}{*}{$\frac{\text { Reach }}{1 \text { (RM 954-907) }}$} & \multicolumn{11}{|c|}{$\begin{array}{c}\text { General trend in median cross-sectional area at LWRP between successive surveys for LMR pool } \\
\text { sections. }\end{array}$} \\
\hline & 1975 & 1989 & 1996 & 2000 & 2002 & 2004 & 2006 & 2008 & 2010 & 2011 & 2013 \\
\hline & \multicolumn{3}{|c|}{ D } & \multicolumn{3}{|c|}{ I } & \multicolumn{5}{|c|}{ I } \\
\hline 2 (RM 907-845) & \multicolumn{3}{|c|}{ I } & \multicolumn{3}{|c|}{ D } & \multicolumn{5}{|c|}{ I } \\
\hline 3 (RM 845-773) & \multicolumn{6}{|c|}{1} & \multicolumn{5}{|c|}{ NC } \\
\hline 4 (RM 773-702) & \multicolumn{3}{|c|}{1} & \multicolumn{3}{|c|}{ I } & \multicolumn{5}{|c|}{ D } \\
\hline 5 (RM 702-650) & \multicolumn{3}{|c|}{ NC } & \multicolumn{3}{|c|}{ I } & \multicolumn{5}{|c|}{ I } \\
\hline 6 (RM 650-581) & \multicolumn{3}{|c|}{1} & \multicolumn{3}{|c|}{ I } & \multicolumn{5}{|c|}{ I } \\
\hline 7 (RM 581-524) & 1 & & & I & D & I & NC & D & 1 & D & NC \\
\hline 8 (RM 524-437) & 1 & & ) & כ la - a - a & I & VC & I & VC & I & NC & I \\
\hline 9 (RM 437-381) & D & & 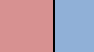 & כ & D & NC & NC & I & D & I & D \\
\hline 10 (RM 381-325) & D & & & כ & I & VC & 1 & I & D & 1 & I \\
\hline
\end{tabular}

Table 10. General trends by geomorphic reach of median channel width at LWRP for LMR pool sections.

\begin{tabular}{|c|c|c|c|c|c|c|c|c|c|c|c|c|c|}
\hline \multirow{3}{*}{$\frac{\text { Reach }}{1 \text { (RM 954-907) }}$} & \multicolumn{13}{|c|}{$\begin{array}{l}\text { General change in median channel width at LWRP between successive surveys for LMR pool } \\
\text { sections. }\end{array}$} \\
\hline & 1975 & 1989 & 1996 & 2000 & 2002 & 2004 & 2006 & & \multicolumn{2}{|r|}{2010} & \multicolumn{2}{|c|}{2011} & 2013 \\
\hline & \multicolumn{3}{|c|}{ D } & \multicolumn{3}{|c|}{ I } & \multicolumn{7}{|c|}{ I } \\
\hline 2 (RM 907-845) & \multicolumn{3}{|c|}{ NC } & \multicolumn{3}{|c|}{ NC } & \multicolumn{7}{|c|}{ D } \\
\hline 3 (RM 845-773) & \multicolumn{6}{|c|}{ NC } & \multicolumn{7}{|c|}{ D } \\
\hline 4 (RM 773-702) & \multicolumn{3}{|c|}{ NC } & \multicolumn{3}{|c|}{ NC } & \multicolumn{7}{|c|}{ D } \\
\hline 5 (RM 702-650) & \multicolumn{3}{|c|}{ D } & \multicolumn{3}{|c|}{ I } & \multicolumn{7}{|c|}{ NC } \\
\hline 6 (RM 650-581) & \multicolumn{3}{|c|}{ D } & \multicolumn{3}{|c|}{ NC } & \multicolumn{7}{|c|}{ NC } \\
\hline 7 (RM 581-524) & 1 & & & 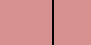 & I & 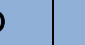 & D & I & [ & 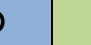 & NC & & NC \\
\hline 8 (RM 524-437) & D & & & 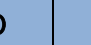 & $D$ & ta & VC & I & 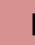 & tat & D & & D \\
\hline 9 (RM 437-381) & 1 & & & C & $D$ & 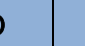 & D & I & [ & 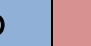 & I & & D \\
\hline 10 (RM 381-325) & $\mathrm{NC}$ & & & ) & I & 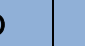 & D & NC & [ & ) & I & & D \\
\hline
\end{tabular}


Table 11. General trends by geomorphic reach of median hydraulic depth at LWRP for LMR pool sections.

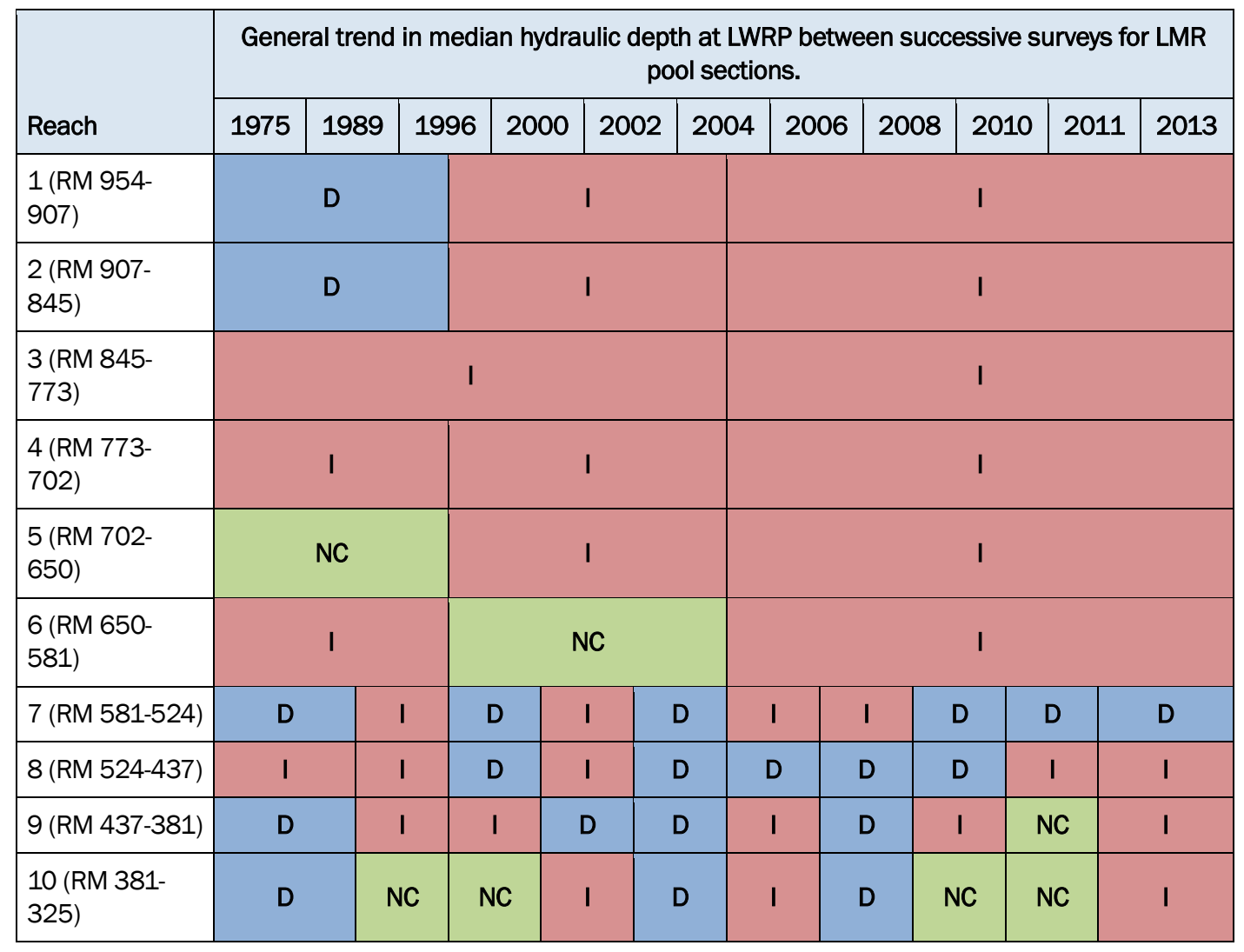

Table 12. General trends by geomorphic reach of median channel conveyance at LWRP for LMR pool sections.

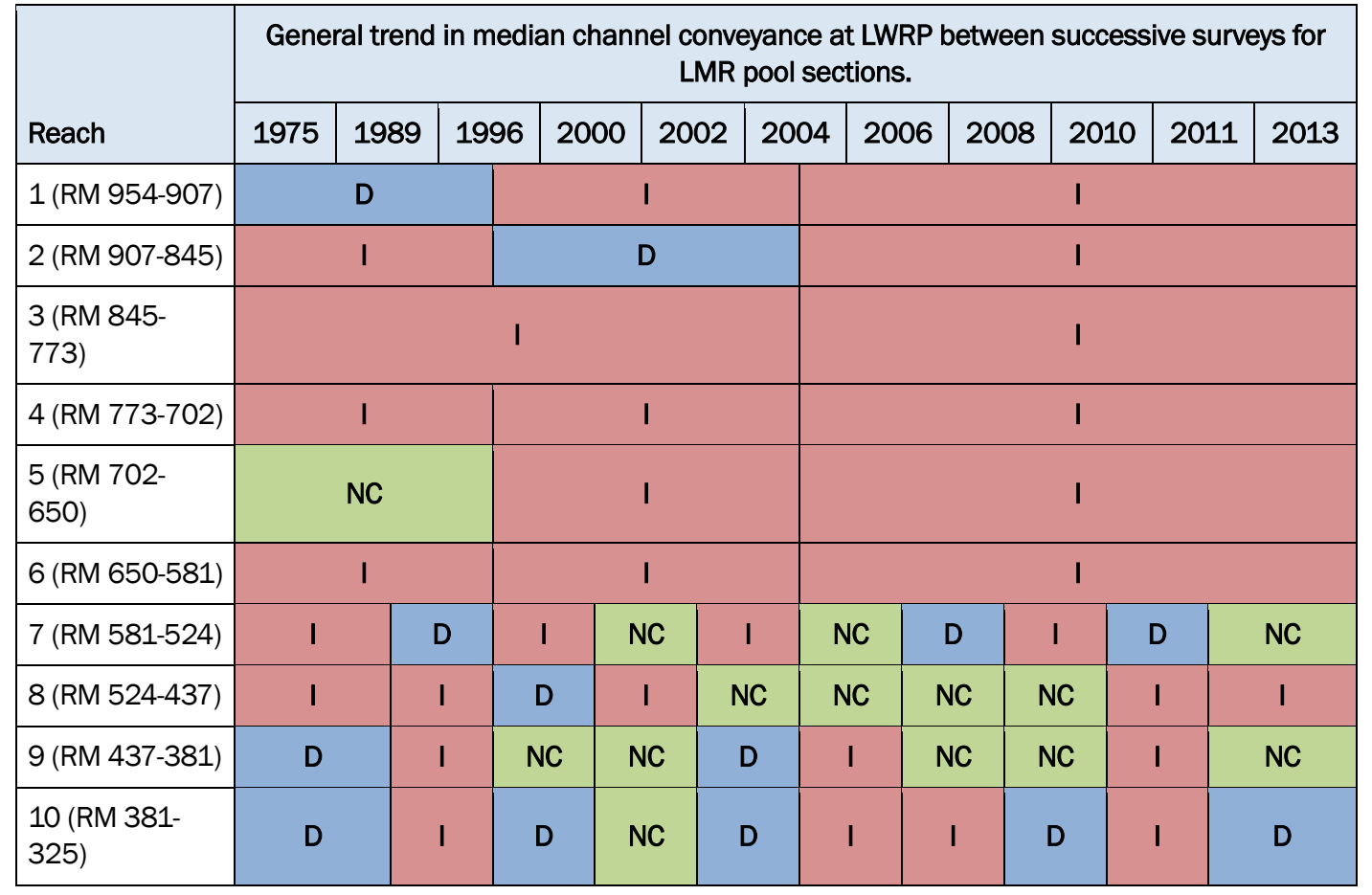




\subsubsection{Volumetric data analysis results}

Channel volumes referenced to LWRP were computed for 1-mile increments for the total LMR reach, grouped along the defined geomorphic reaches, and presented in box plots to illustrate the central tendencies of the median values. The observed trends in the median value of channel volume at LWRP illustrated in the box plots give insight into the net channel erosion and deposition for each reach. Decreasing median values of volume indicate net deposition during the period, and increasing values indicate net erosion. Figure 23 shows the channel volume box plot for Reach 1 . The plot indicates no significant change from 1975 to 2004, then an increase in volume from 2004 to 2013.

The channel volume for Reach 2 is shown in Figure 24. Cyclical periods of increasing and decreasing volume from survey to survey are evident, with perhaps a very slight overall increasing trend.

The channel volumes for Reaches 3 and 4 are shown in Figures 25 and 26. Both reaches exhibited a general period of increasing channel volume from 1975 to 2004, followed by no significant change from 2004 to 2013.

The channel volume at LWRP for Reaches 5 and 6 are shown in Figures 27 and 28 , respectively. Both of these reaches indicate an increase in channel volume median values from 1975 to 1996 , followed by no significant change from 1996 to 2013. 
Figure 23. Trends of median channel volume at LWRP for Reach 1 (RM 954-907).

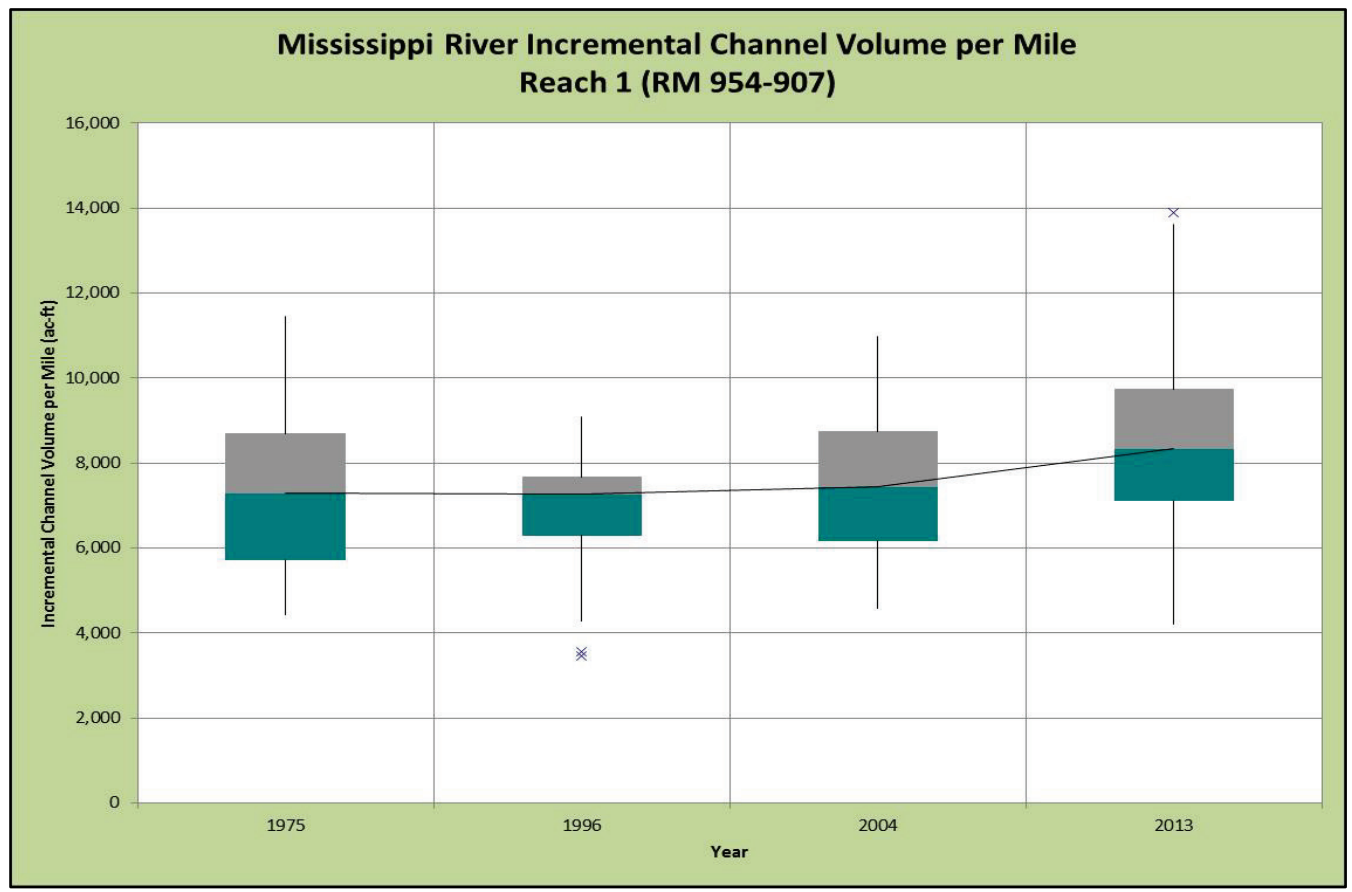

Figure 24. Trends of median channel volume at LWRP for Reach 2 (RM 907-845).

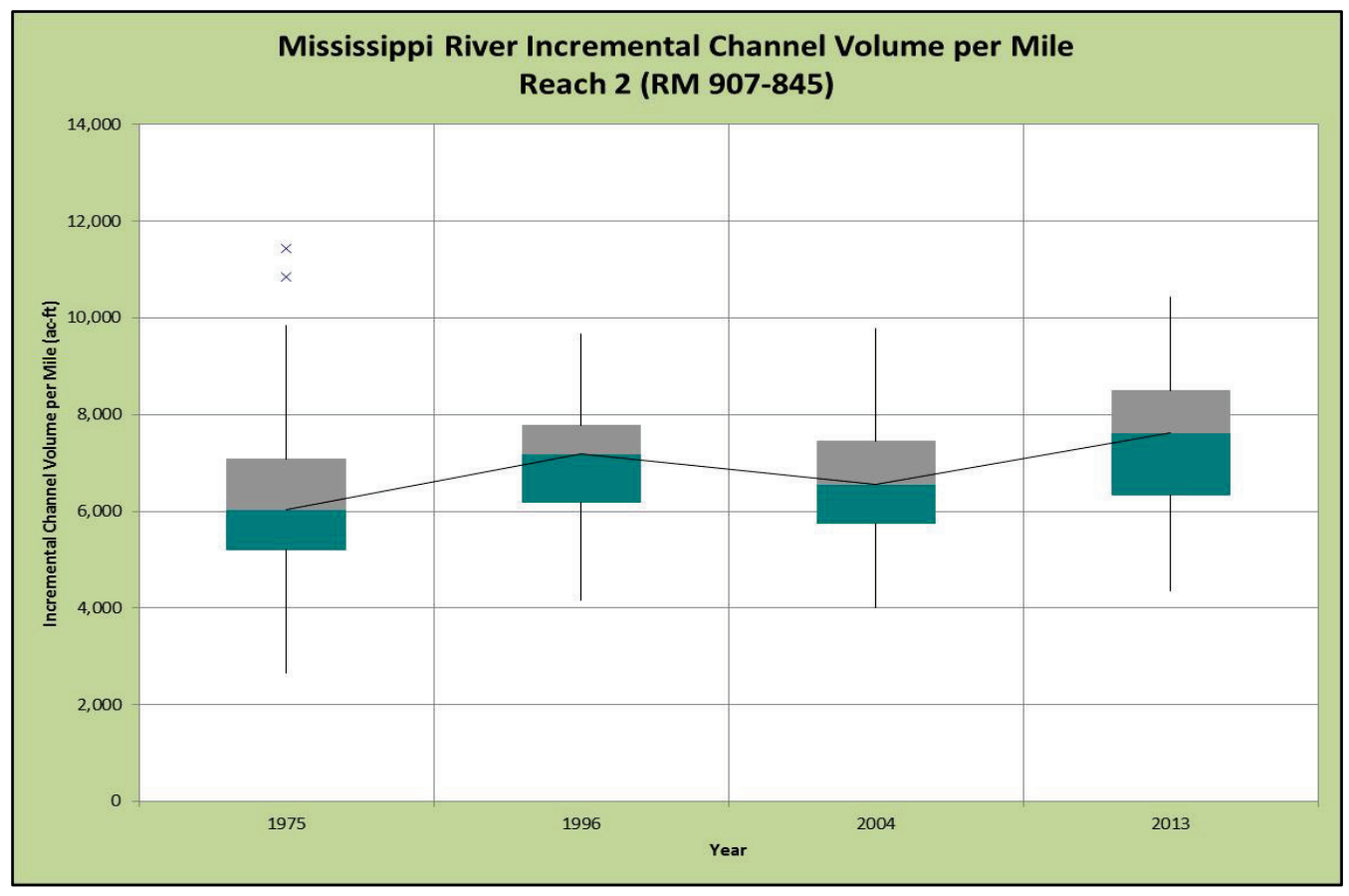


Figure 25. Trends of median channel volume at LWRP for Reach 3 (RM 845-773).

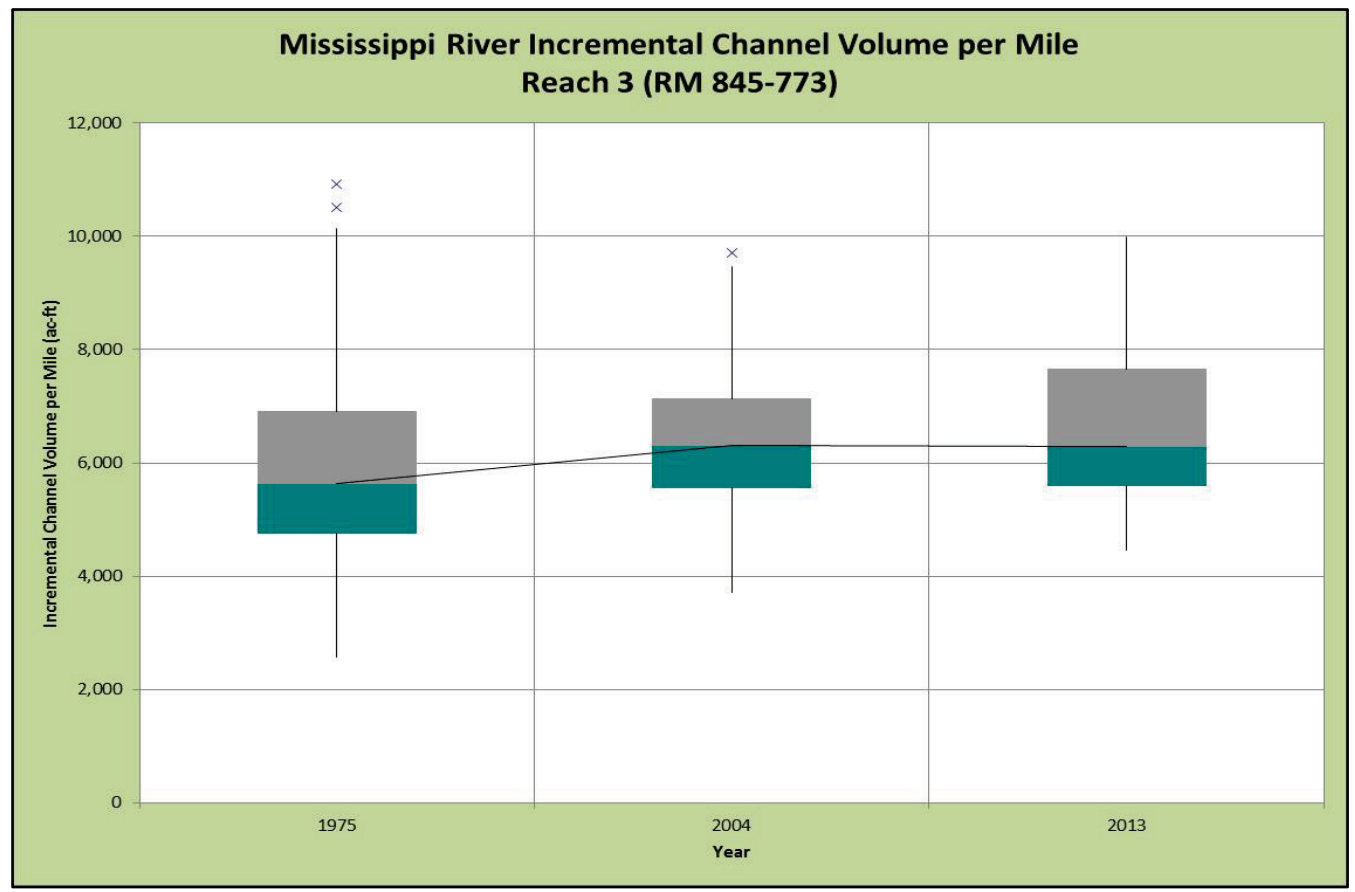

Figure 26. Trends of median channel volume at LWRP for Reach 4 (RM 773-702).

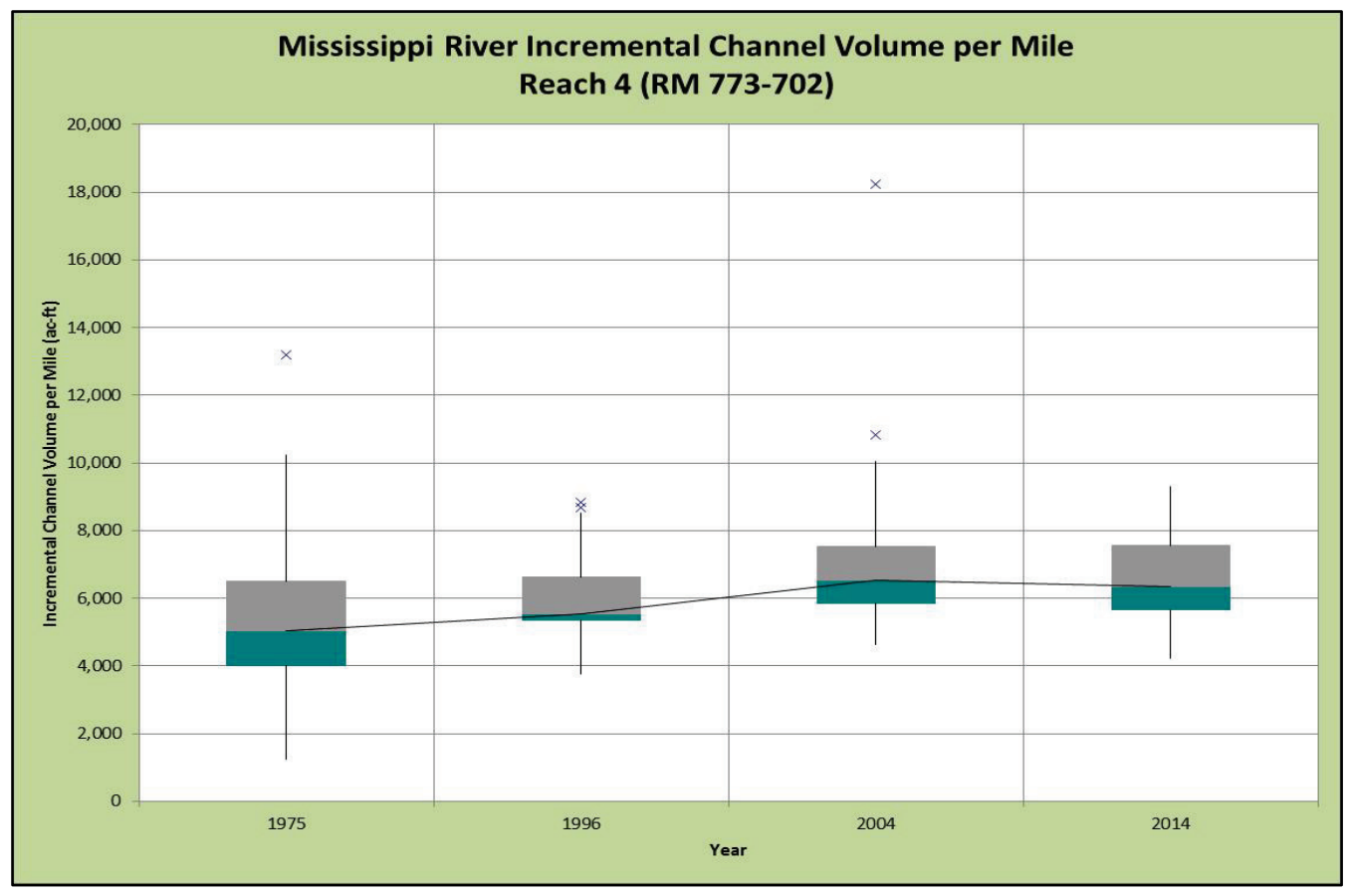


Figure 27. Trends of median channel volume at LWRP for Reach 5 (RM 702-650).

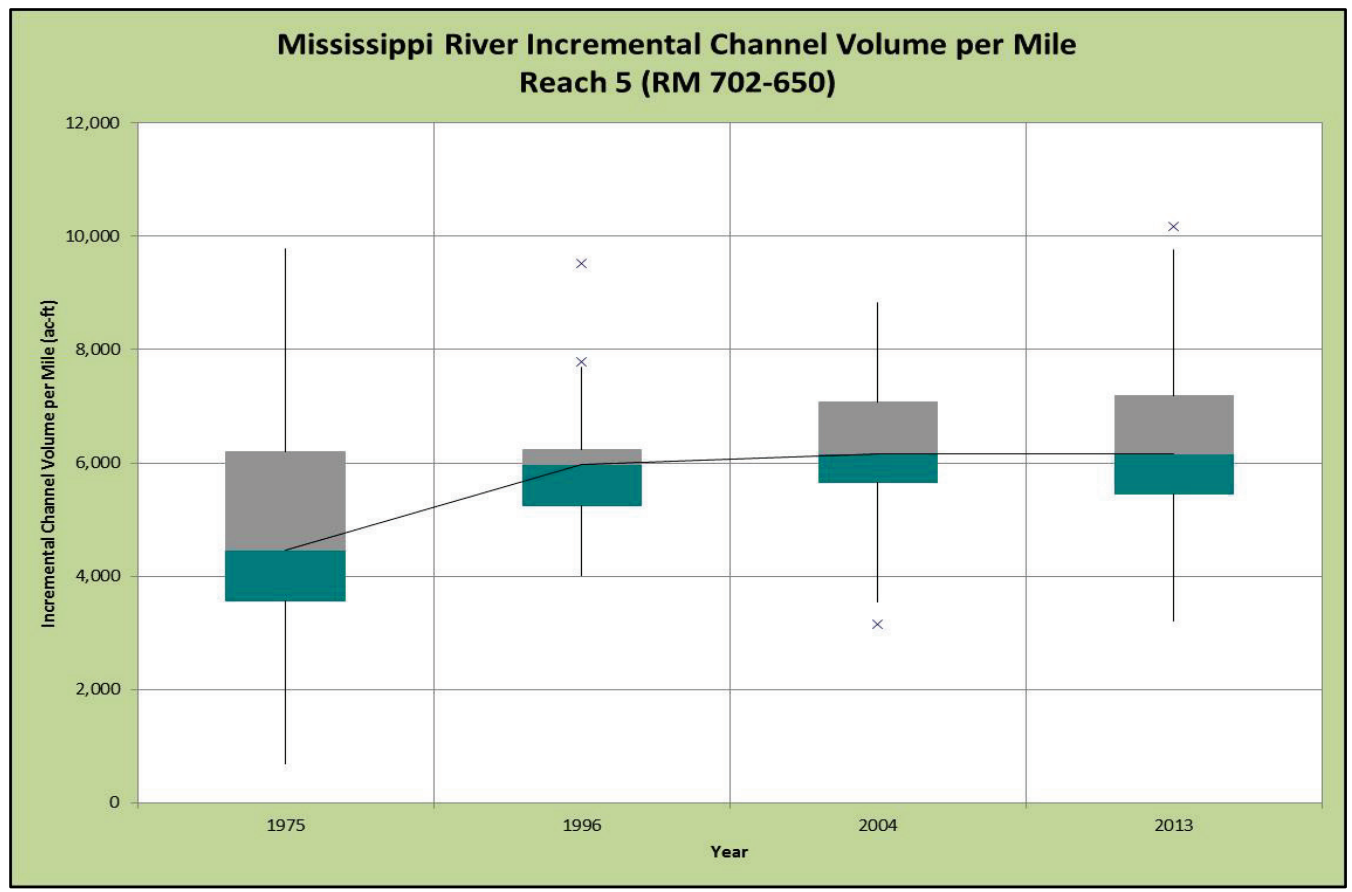

Figure 28. Trends of median channel volume at LWRP for Reach 6 (RM 650-592).

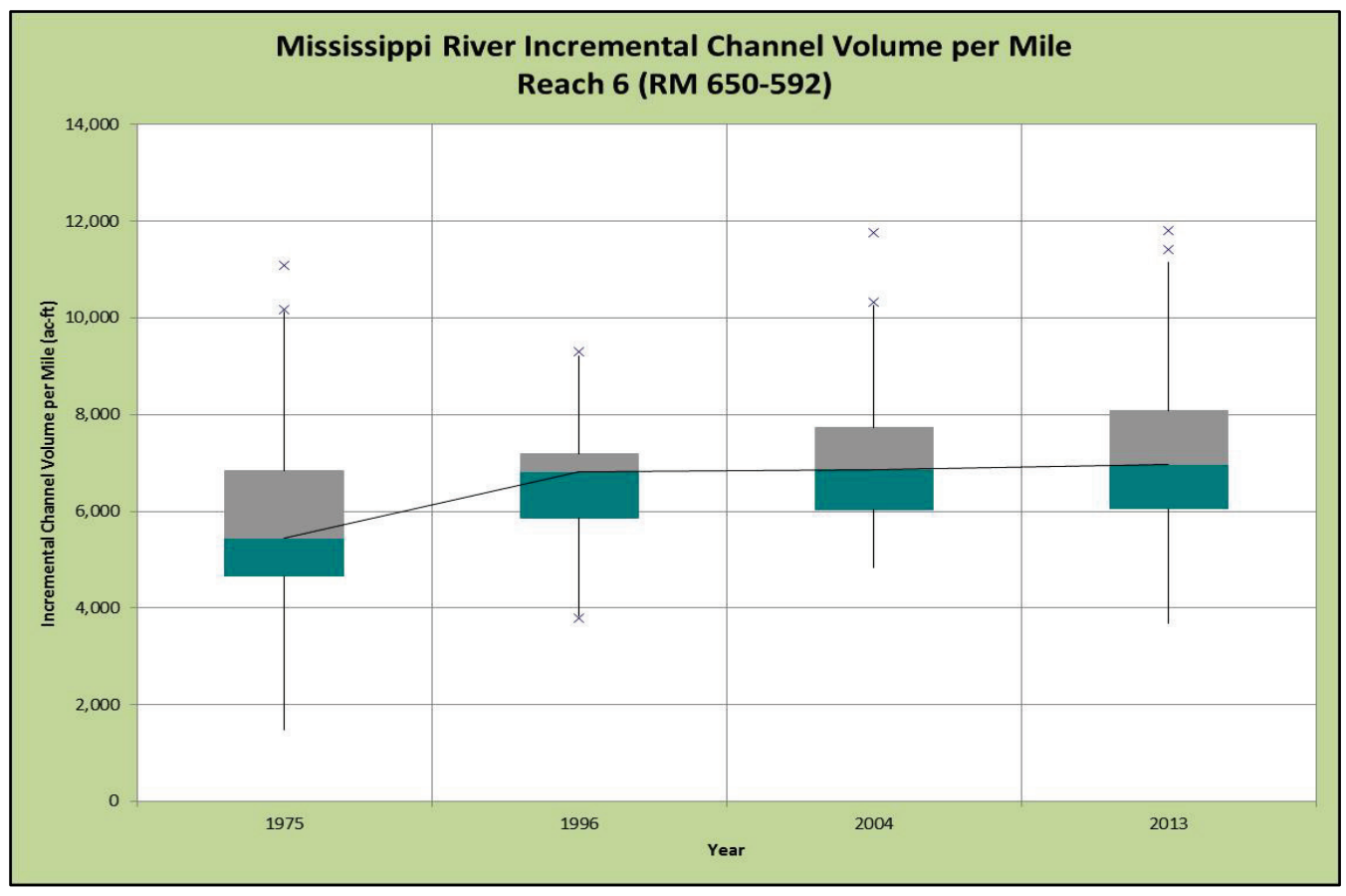

Reaches 7 and 8 represent the transition into the Vicksburg District jurisdiction of the LMR and likewise a transition into an area of stable channel volume over the study time period. Figures 29 and 30 show the trends in the median channel volume at LWRP for Reaches 7 and 8, 
respectively. Although there is slight variation between surveys, the overall trend in the median values of channel volume from 1975 to 2013 is very consistent with no significant change observed.

Reaches 9 and 10 represent the most downstream portion of the LMR study area. The trends in median channel volume at LWRP for these reaches shift to slightly decreasing for the 1975 to 2013 time period, as indicated in Figures 31 and 32. An interesting observation is made for Reach 10, where there is a noted increase in channel volume in 2011 after a period of steady decrease from 1975 to 2010. This sudden increase in channel volume may be a result of the 2011 flood. The change from 2011 to 2013 returns to a decreasing trend.

Figure 29. Trends of median channel volume at LWRP for Reach 7 (RM 592-524).

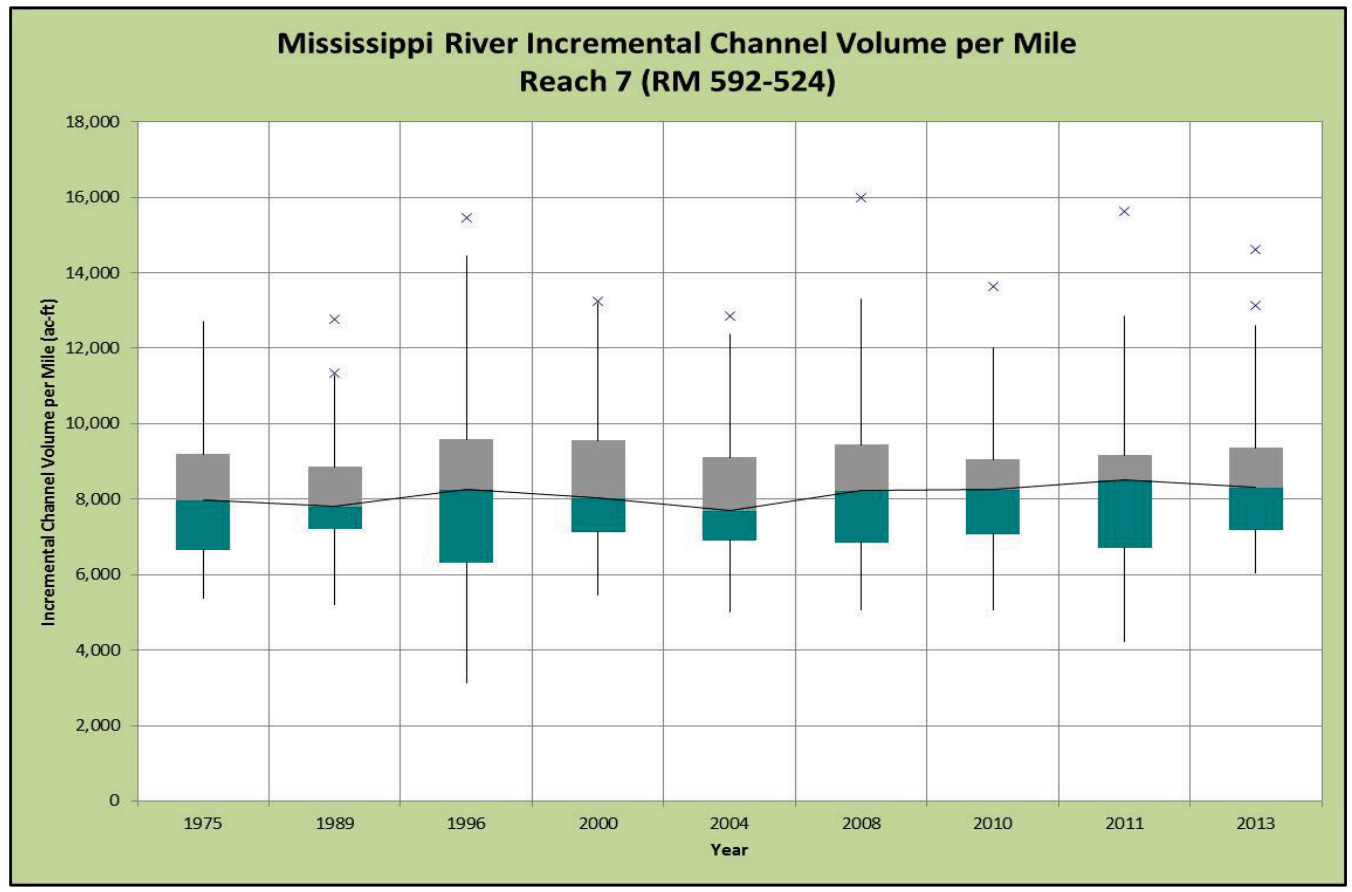


Figure 30. Trends of median channel volume at LWRP for Reach 8 (RM 524-437).

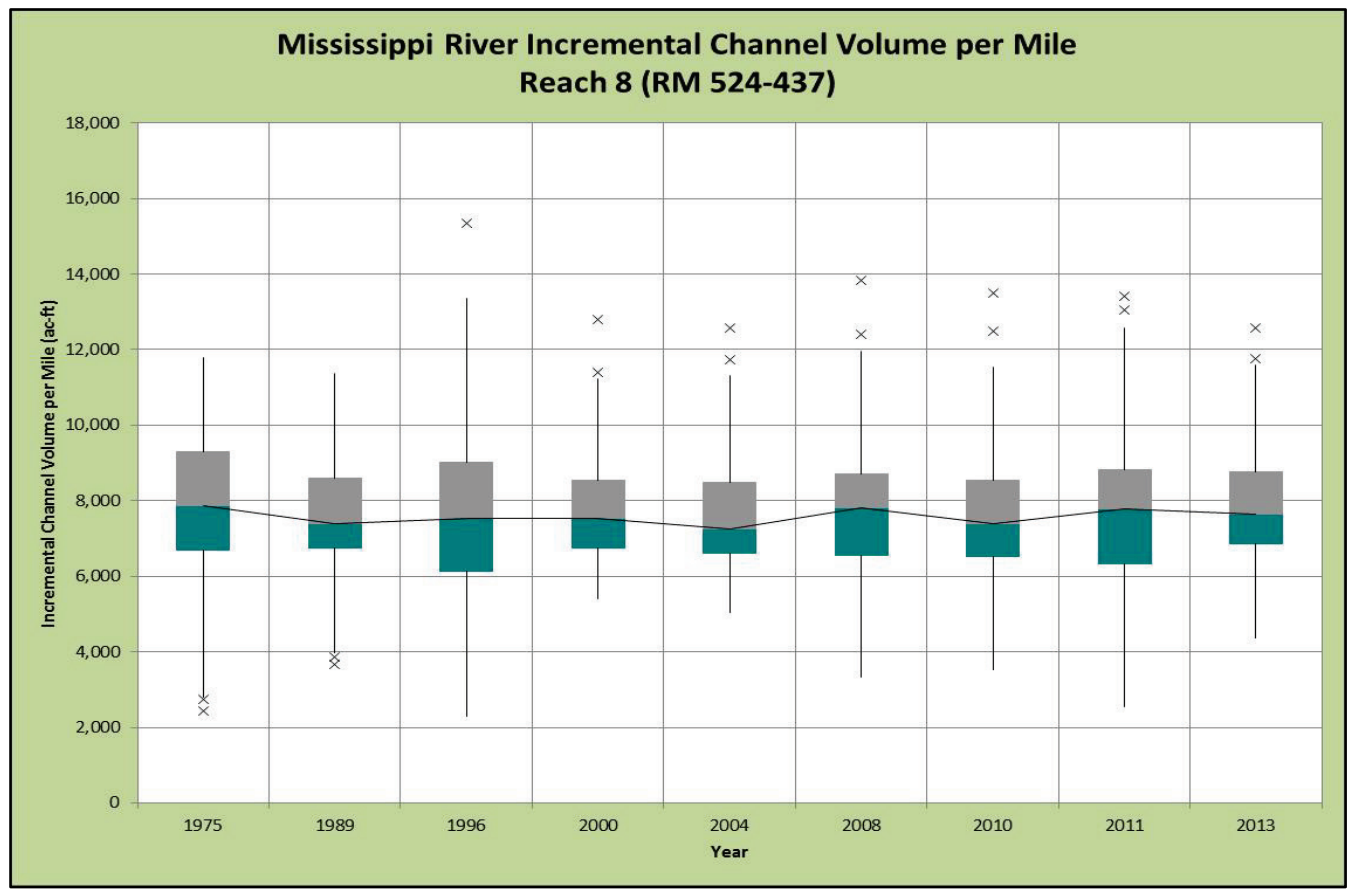

Figure 31. Trends of median channel volume at LWRP for Reach 9 (RM 437-381).

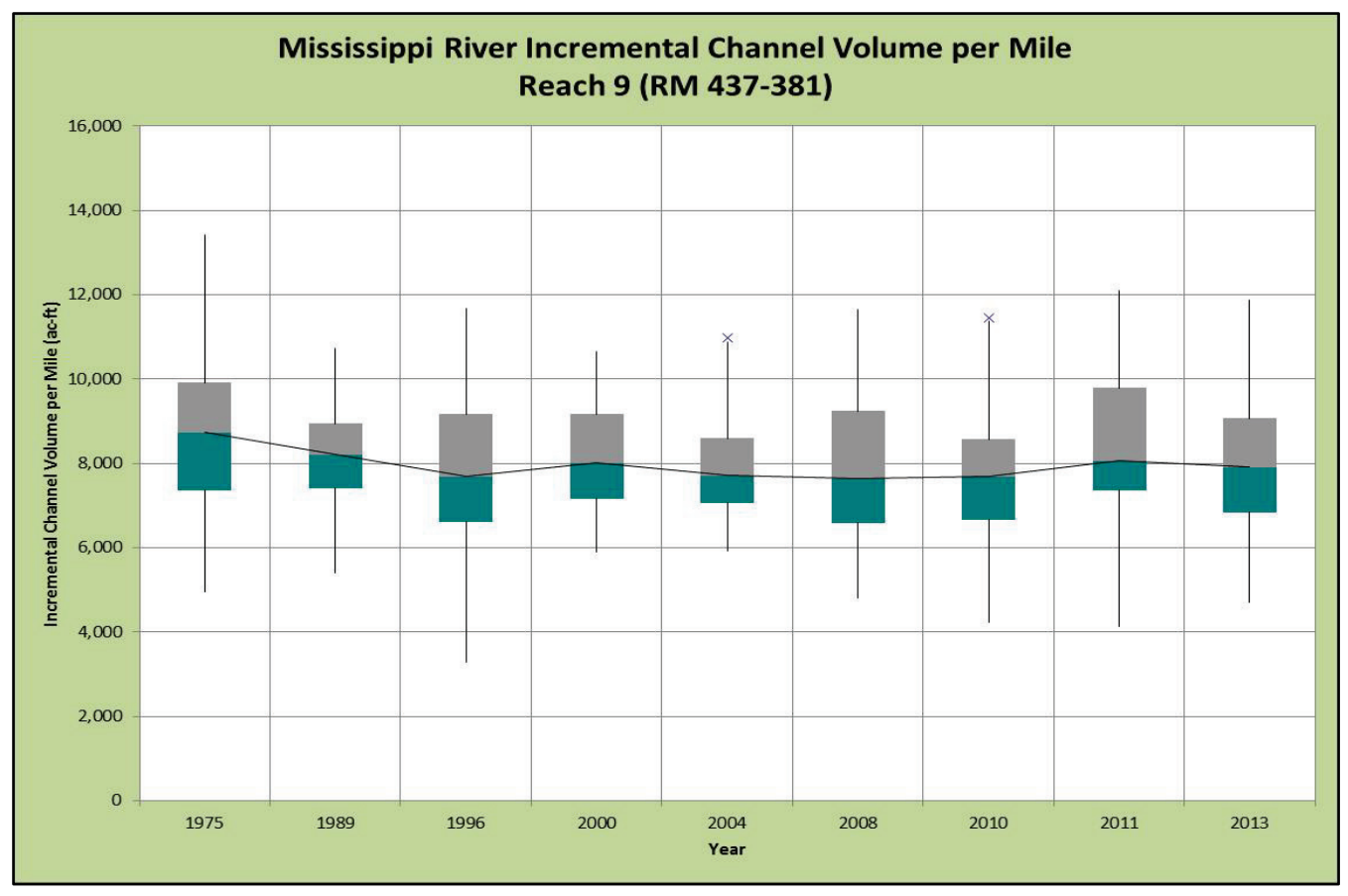


Figure 32. Trends of median channel volume at LWRP for Reach 10 (RM 381-325).

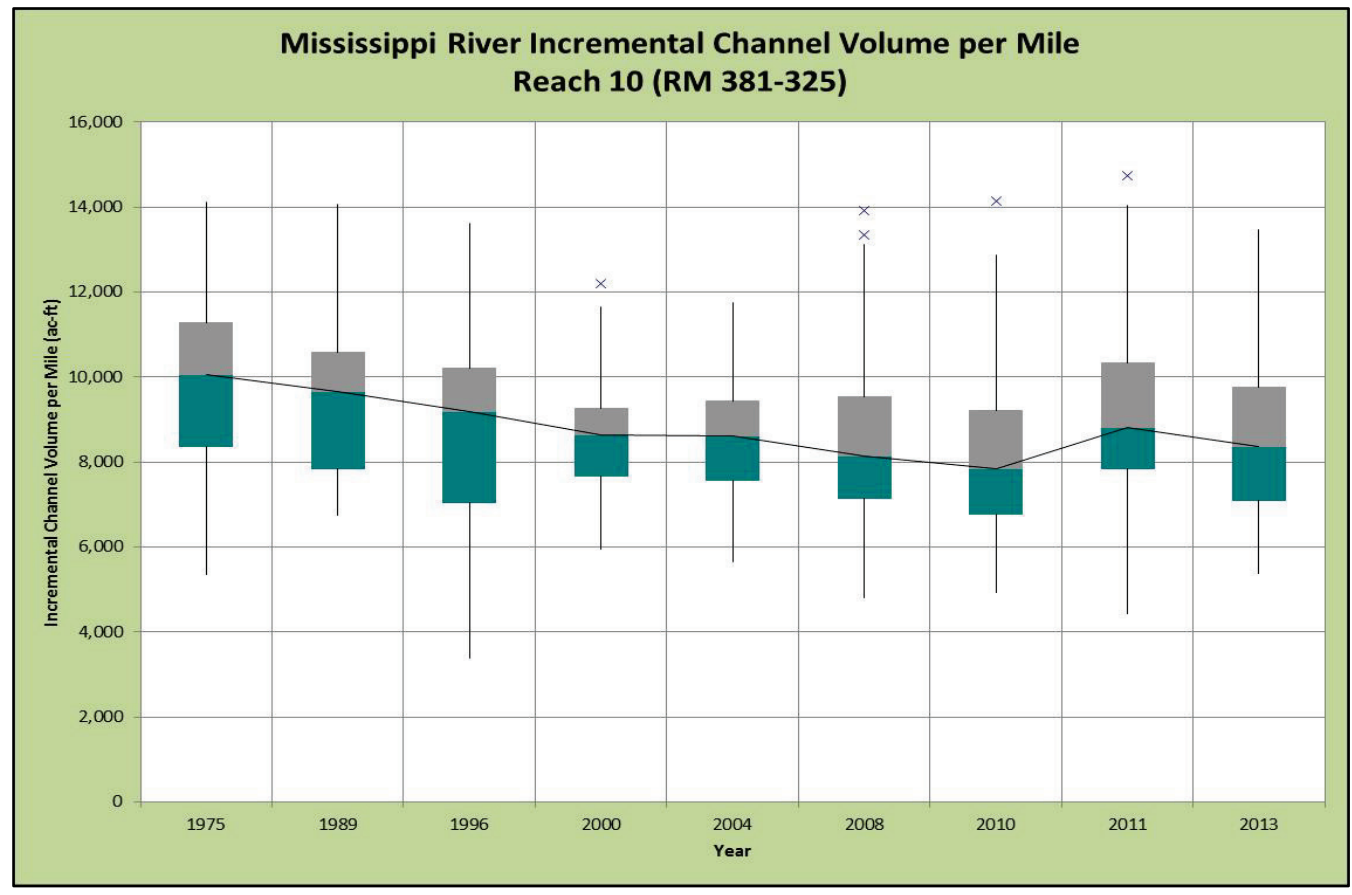

The incremental change in channel volume between successive hydrographic surveys was determined for each 1-mile segment of the LMR. The accumulated incremental volume change values were then plotted from downstream to upstream for both the Vicksburg and Memphis District reaches. Cumulative channel volume change was determined for each period between successive surveys as well as for the total study period 1975 to 2013. The cumulative volume change plots allow the spatial extent of the average volumetric change rates over time to be readily determined. The cumulative volume change for the Vicksburg District reach (RM 325-592) is shown in Figure 33. For the period 1975 to 2013, there has been a consistent rate of channel volume decrease from RM 325 to approximately RM 425 near Vicksburg, as evidenced by the near-constant slope of the cumulative volume curve for the time period. The negative slope of the cumulative volume change curve indicates that deposition (negative cumulative volume change) has occurred in this reach. From approximately RM 425 to 530, the cumulative channel volume change fluctuated but remained fairly constant in magnitude, indicating no significant net erosion or deposition during this time period. From approximately RM 530 to 570, a consistent average rate of channel volume increase is observed from 1975 to 2013, as indicated by the near-constant positive slope of the curve. This suggests that net erosion has occurred in this reach for the time period. From approximately RM 570 to 592, the observed rate of cumulative channel volume change was near 
zero, as evidenced by the near-horizontal slope of the curve. The rates of channel volume change and their spatial extents for the time periods between successive surveys can be evaluated by applying a similar analysis of the other cumulative curves shown in Figure 33.

Figure 33. Cumulative channel volume change for LMR RM 325-592.

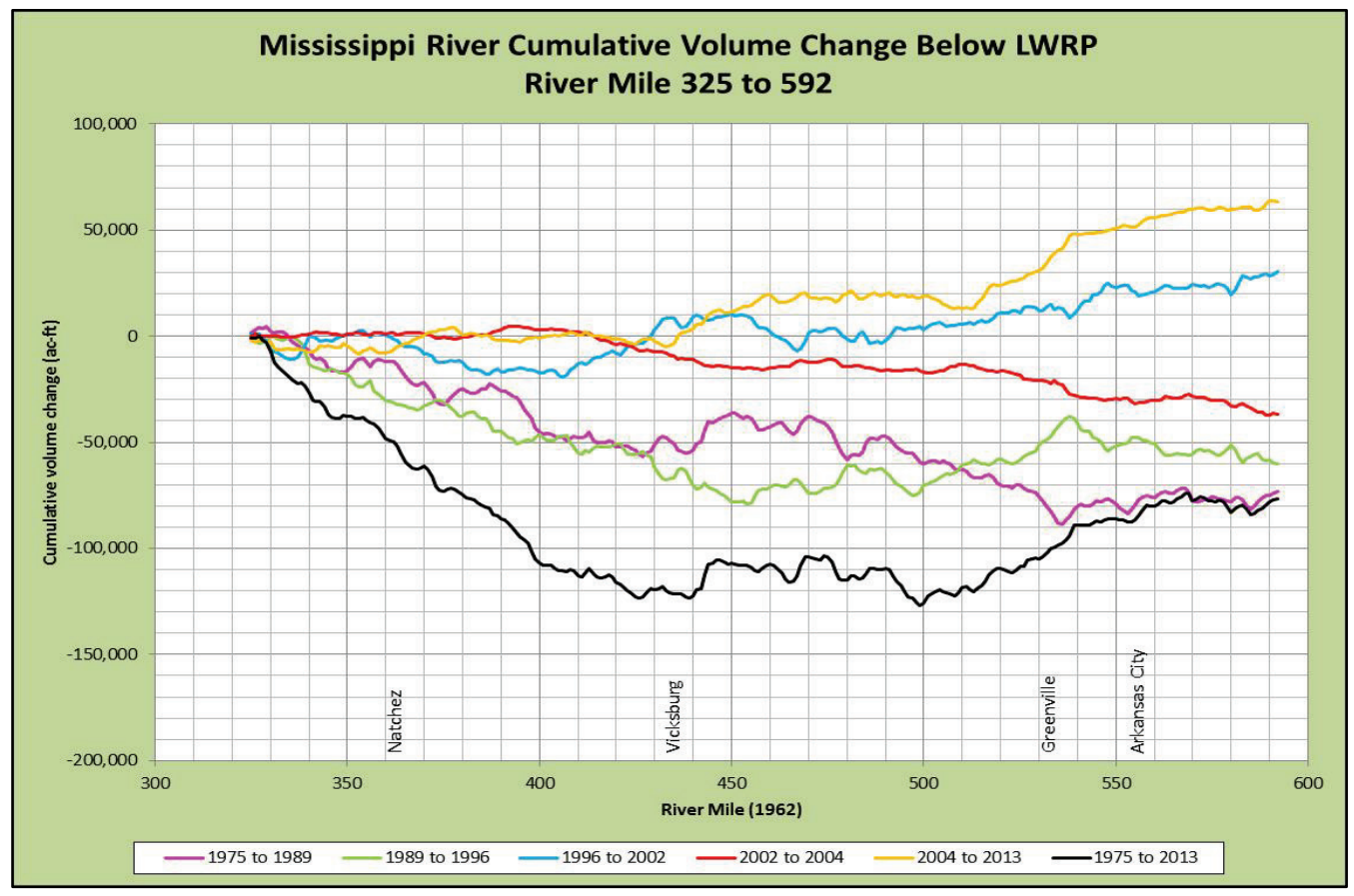

The cumulative channel volume at LWRP for the Memphis District reach (RM 592-954) is shown in Figure 34. The figure indicates increasing cumulative channel volume change has been prevalent during the period 1975 to 2013. The slope of the cumulative channel volume change curve for this entire time period can be approximated by a single, positive slope. This indicates that, on average, this reach has experienced consistent erosion throughout its entirety for the time period. The cumulative curve for the time period 1975 to 2004 closely duplicates the 1975 to 2013 curve for the reach downstream of Caruthersville (RM 592 to 840), suggesting that most of the cumulative change occurred from 1975 to 2004. This is verified by the near-horizontal cumulative curve for the 2004 to 2013 time period in this reach. The sharp discontinuities that occur in the 1975 to 2004 and 2004 to 2013 cumulative curves are a result of a large area of channel scour that was present in the 2004 hydrographic survey at approximately RM 740 and then subsequently filled by the time of the 2013 survey. Disregarding this area of discontinuity, the 2004 to 2013 
cumulative curve suggests that the most recent increases in channel volume, or erosion, have occurred from approximately RM 840 to 925 .

Figure 34. Cumulative channel volume change for LMR RM 592-954.

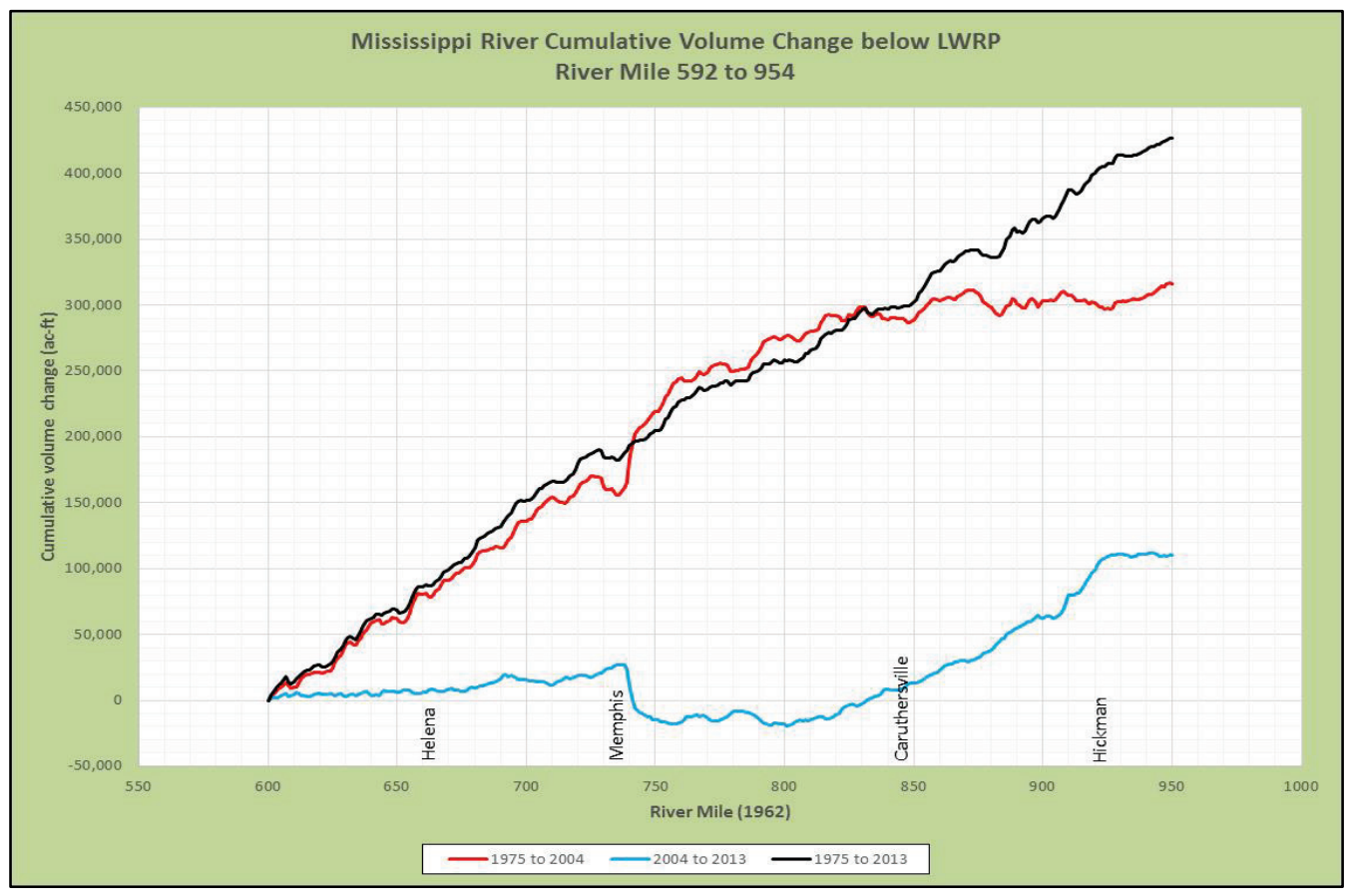

\subsubsection{Channel invert profile analysis results}

The channel invert elevations for all crossing and pool sections of the full LMR reach were determined and plotted versus river distance to create channel invert profiles. A smoothed channel invert profile was created through a linear regression of the invert data for the crossing and pool sections using the LOESS ${ }^{1}$ routine (Cleveland 1979; Cleveland and Devlin 1988). The invert data and smoothed profiles for both crossing and pool sections are shown in Figures 35, 36, and 37 for the 1975, 2004, and 2013 hydrographic surveys, respectively. In terms of the elevation differential between the crossings profile and pools profile, the magnitude of elevation differential is greater for the reach downstream of approximately RM 550 than the reach upstream of RM 550. It also appears that the magnitude of the elevation differential between the crossings profile and the pools profile increases from 1975 to 2004 to 2013.

\footnotetext{
1 LOESS is an acronym for "local regression" that employs a non-parametric strategy for fitting smooth curves to empirical data using a generalization of standard least squares methods.
} 
Figure 35. Channel invert profiles for 1975.

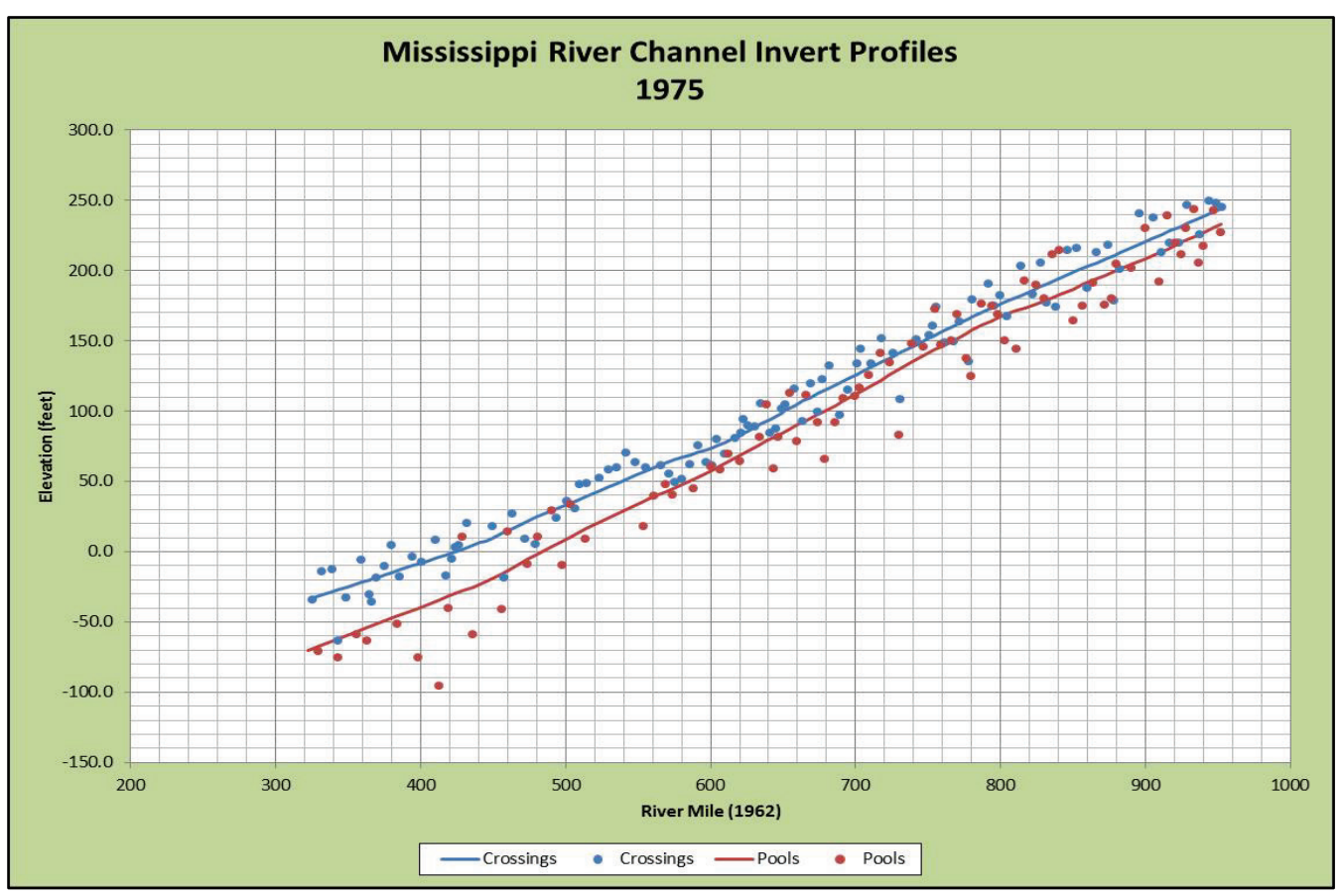

Figure 36. Channel invert profiles for 2004.

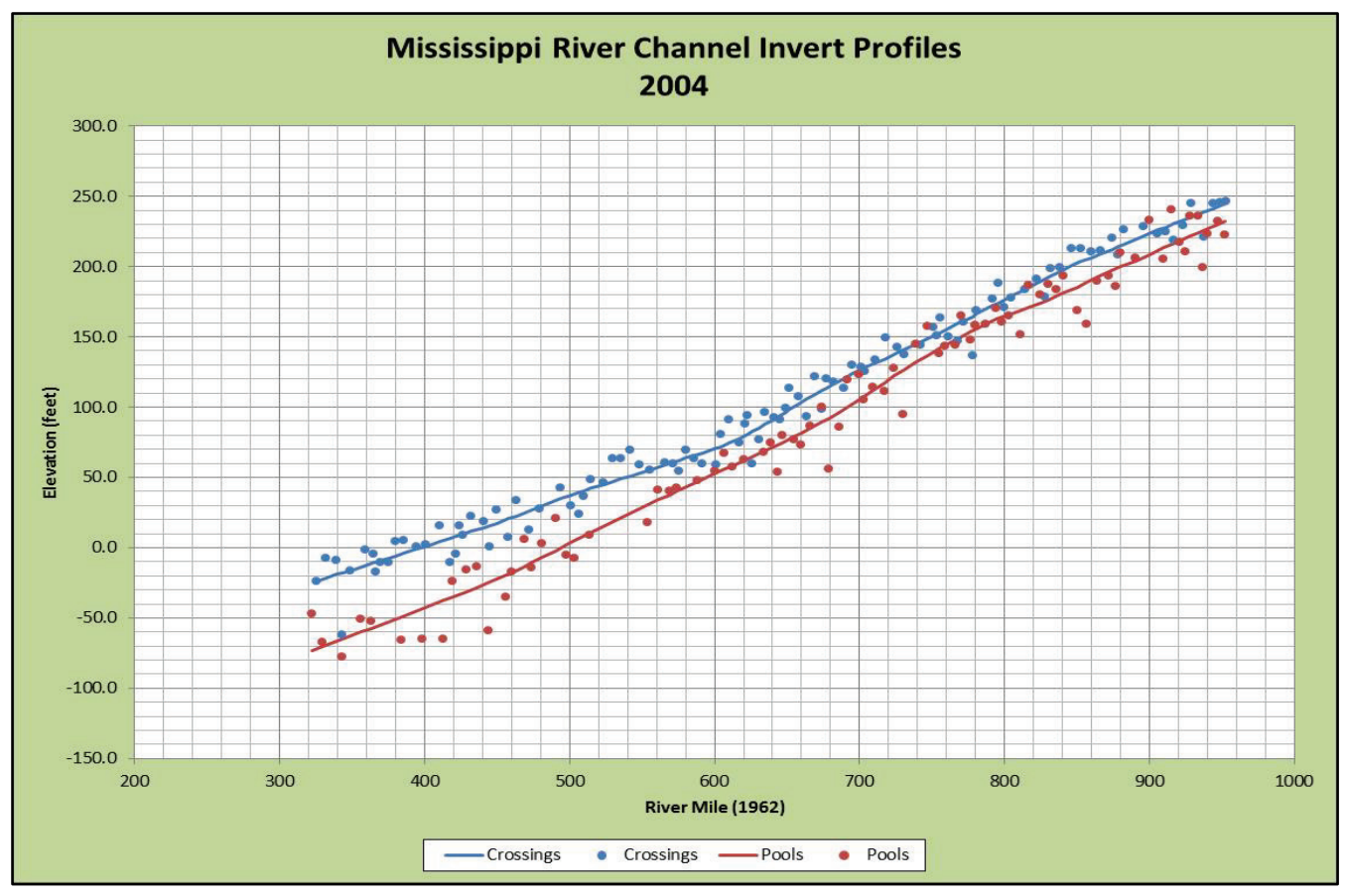


Figure 37. Channel invert profiles for 2013.

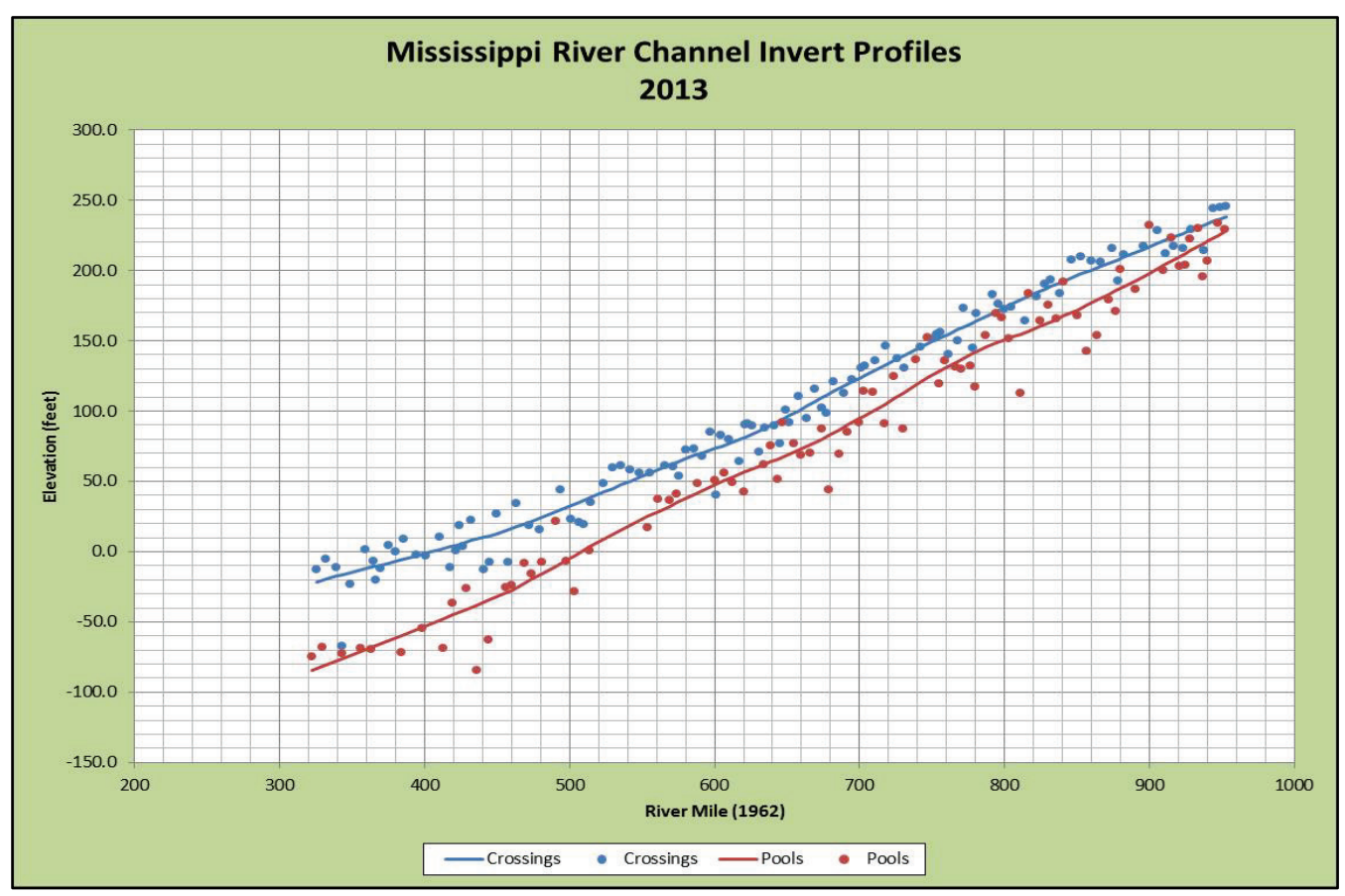


The channel invert profiles for all three survey periods were plotted to determine the variation with time and are shown in Figure 38 . The invert profiles for the crossing sections indicate a general depositional trend in the most downstream portion of the reach from RM 325 to RM 500 from 1975 to 2004. Upstream of RM 500, the invert profiles for the crossing sections are fairly consistent, although there is some variability. The most notable observation from the invert profiles of the pools sections is the apparent deepening of all pools throughout the LMR reach from 1975 to 2013 .

Figure 38. Channel invert profiles for 1975, 2004, and 2013.

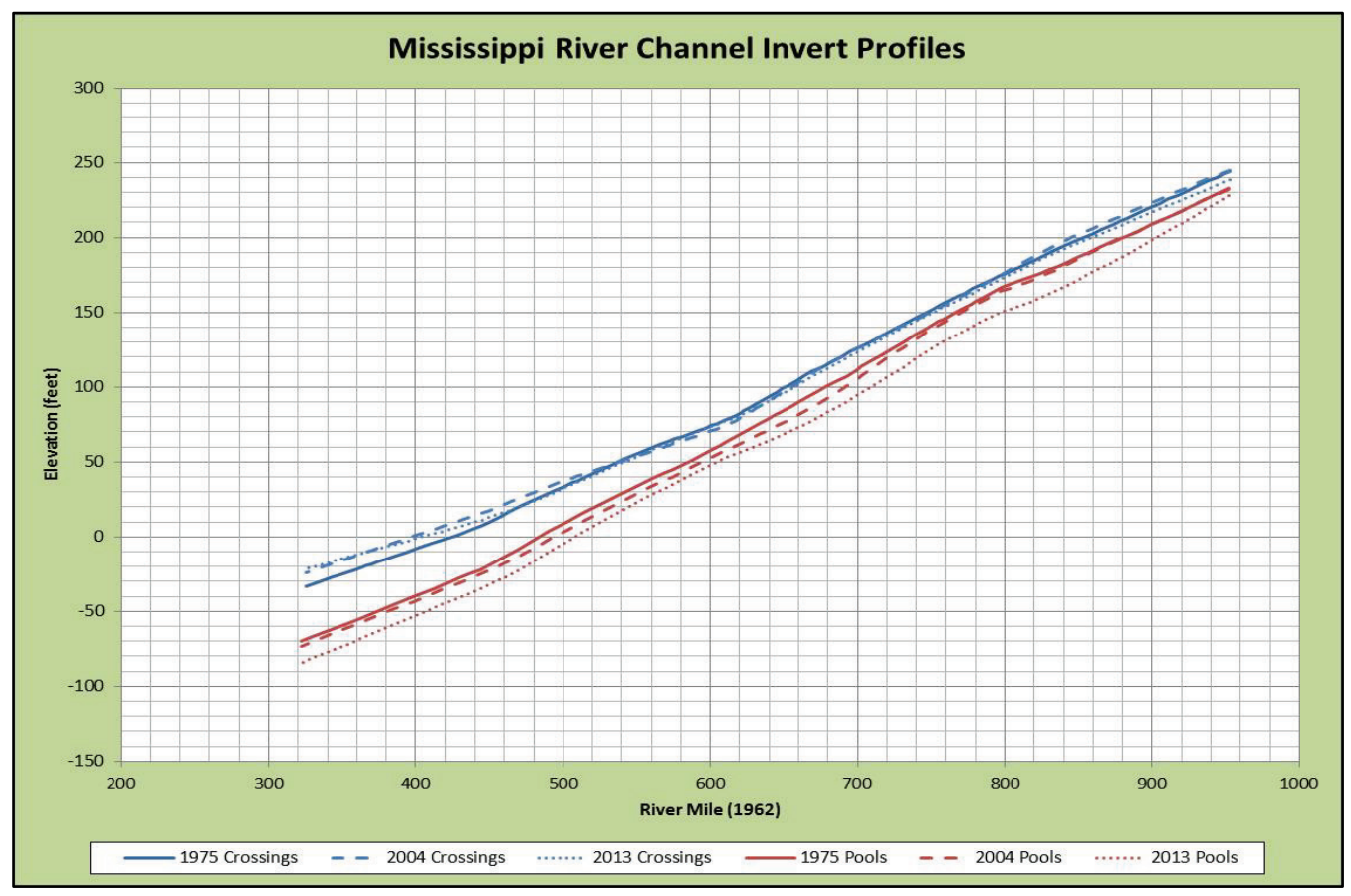

The average channel invert slopes for the crossings and pools smoothed profiles were determined for each geomorphic reach and are presented in Table 13. The slopes are computed in feet per mile of river channel. The table values are colored coded to indicate whether the slope for each reach is decreasing (shaded blue) or increasing (shaded red) with respect to the previous value. There are no clearly discernable spatial or temporal trends in the channel invert slopes. The slopes for the pools profiles do exhibit a greater percentage of increasing values than the crossings profiles. 
Table 13. Average channel invert slope (feet/mile) by geomorphic reach.

\begin{tabular}{|c|c|c|c|c|c|c|}
\hline \multirow{2}{*}{ Reach } & \multicolumn{3}{|c|}{$\begin{array}{c}\text { Slope of channel invert profile, } \\
\text { crossing sections (feet/mile) }\end{array}$} & \multicolumn{3}{c|}{$\begin{array}{c}\text { Slope of channel invert profile, pool } \\
\text { sections (feet/mile) }\end{array}$} \\
\cline { 2 - 7 } & 1975 & 2004 & 2013 & 1975 & 2004 & 2013 \\
\hline 1 (RM 954-907) & 0.44 & 0.40 & 0.40 & 0.47 & 0.45 & 0.57 \\
\hline 2 (RM 907-845) & 0.44 & 0.42 & 0.41 & 0.44 & 0.46 & 0.52 \\
\hline 3 (RM 845-773) & 0.46 & 0.53 & 0.47 & 0.44 & 0.44 & 0.44 \\
\hline 4 (RM 773-702) & 0.51 & 0.49 & 0.50 & 0.57 & 0.63 & 0.60 \\
\hline 5 (RM 702-650) & 0.53 & 0.58 & 0.55 & 0.55 & 0.58 & 0.52 \\
\hline 6 (RM 650-581) & 0.49 & 0.51 & 0.44 & 0.54 & 0.48 & 0.43 \\
\hline 7 (RM 581-524) & 0.40 & 0.33 & 0.41 & 0.47 & 0.49 & 0.52 \\
\hline 8 (RM 524-437) & 0.45 & 0.37 & 0.39 & 0.53 & 0.50 & 0.53 \\
\hline 9 (RM 437-381) & 0.34 & 0.33 & 0.27 & 0.40 & 0.40 & 0.42 \\
\hline 10 (RM 381- & 0.33 & 0.33 & 0.27 & 0.39 & 0.39 & 0.40 \\
\hline 325) & & & & &
\end{tabular}

\subsection{Channel geometry analyses-Middle Mississippi River (MMR) section}

Figure 39 shows the plot of cross-sectional area below the LWRP +10 reference elevation for all surveys for the entire MMR (RM o to RM 180). Similar plots of hydraulic depth, conveyance ( $\left.\mathrm{AD}^{2 / 3}\right)$, and channel volume are shown in Figures 40 through 42. The close spacing of the cross section results in a vast number of data points that make interpretation of trends difficult on these graphs. For this reason, the data were averaged over approximate 5-mile intervals, and the results are shown in Figures 43 through 46. The 5-mile average graphs allow for better examination of spatial and temporal trends. As shown in Figures 43 through 46, there has generally been an increase in cross-sectional area, hydraulic depth, conveyance, and volume throughout the time span of the surveys. 
Figure 39. Cross-sectional area (referenced to LWRP+10) between RM 0 and RM 180 on the MMR.

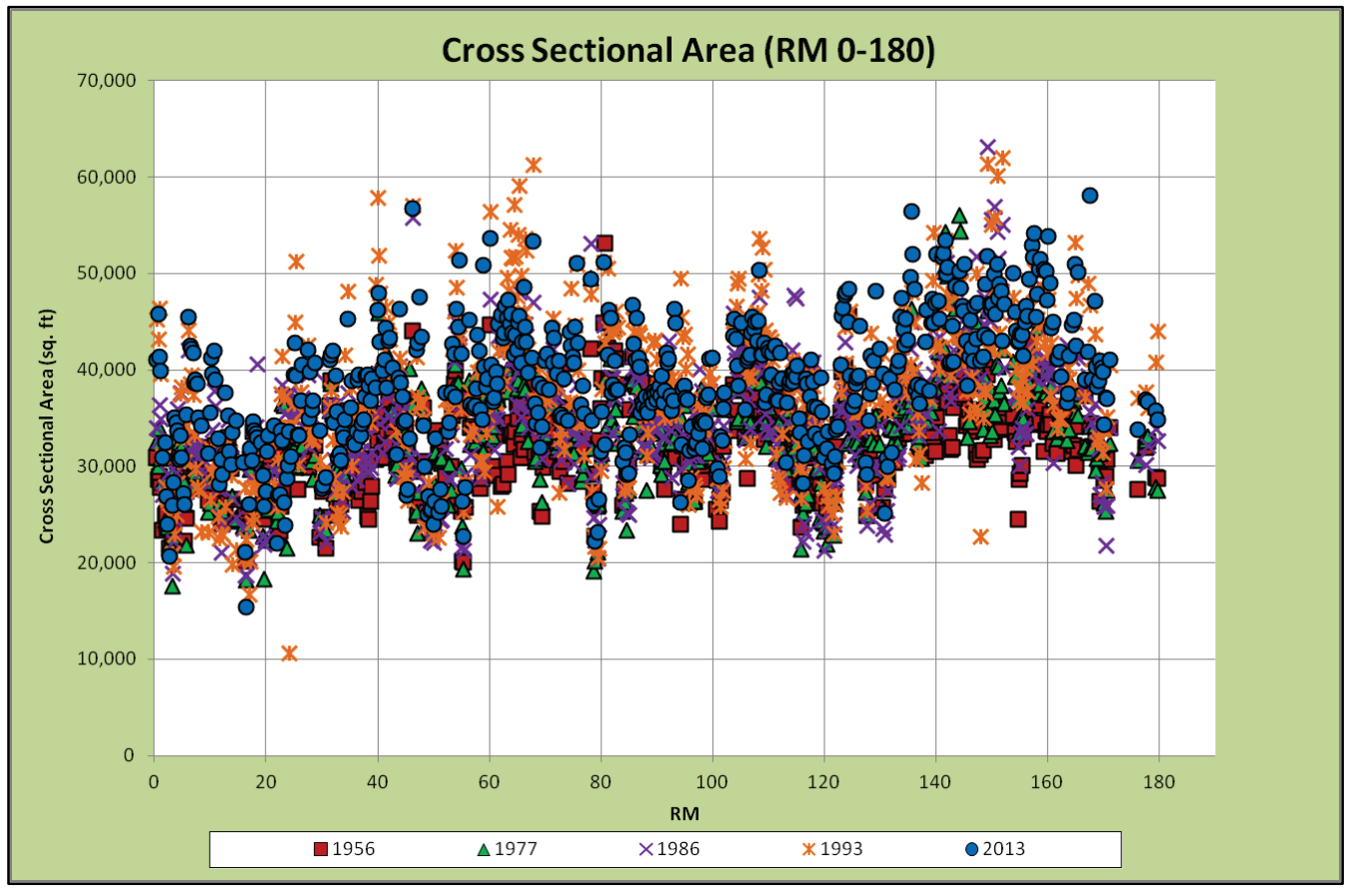

Figure 40. Hydraulic depth (referenced to LWRP+10) between RM 0 and RM 180 on the MMR.

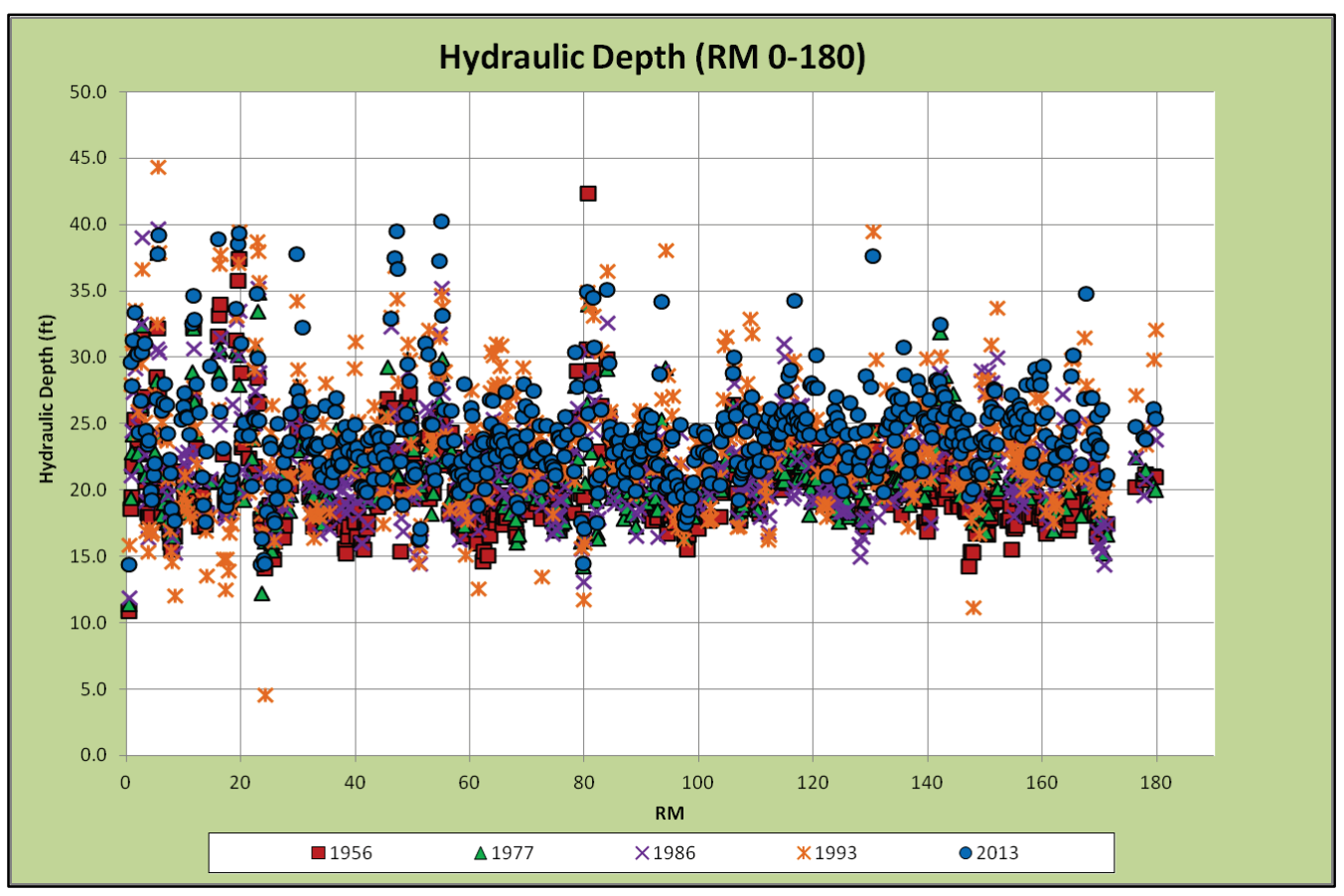


Figure 41. Channel conveyance (referenced to LWRP+10) between RM 0 and RM 180 on the MMR.

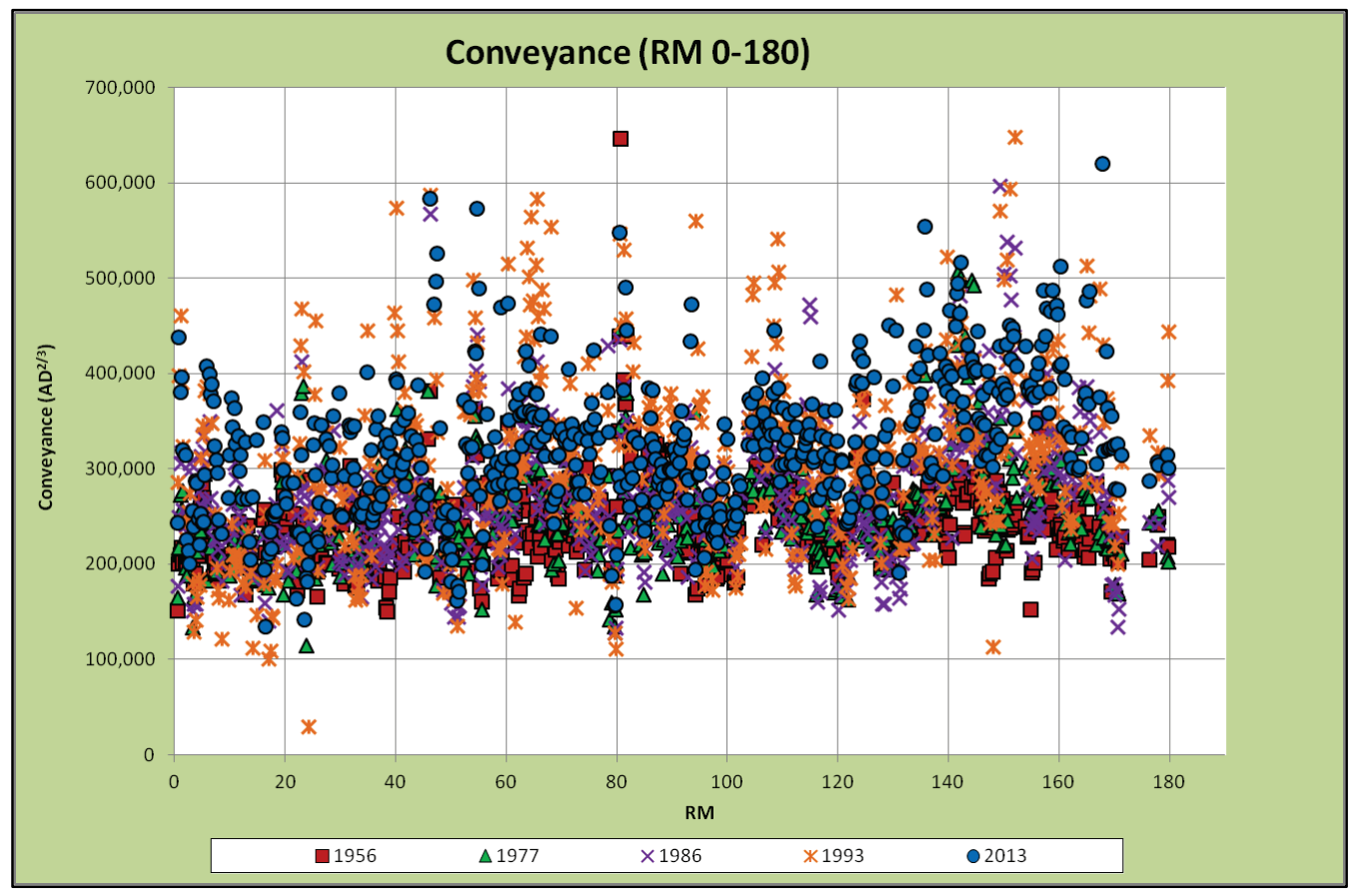

Figure 42. Channel volume (referenced to LWRP+10) between RM 0 and RM 180 on the MMR.

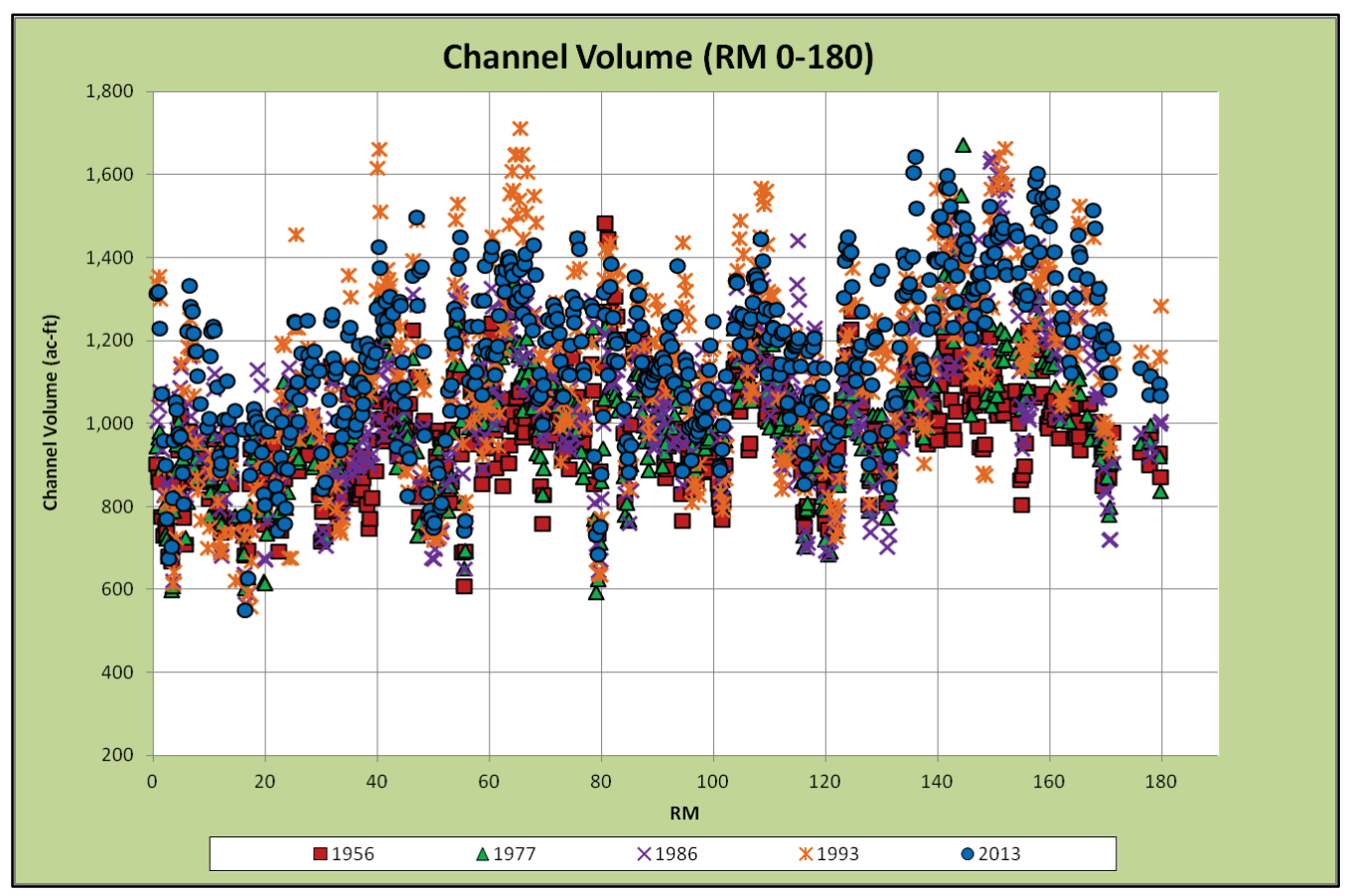


Figure 43. Five-mile average values of cross-sectional area (referenced to LWRP+10) between RM 0 and RM 180 on the MMR.

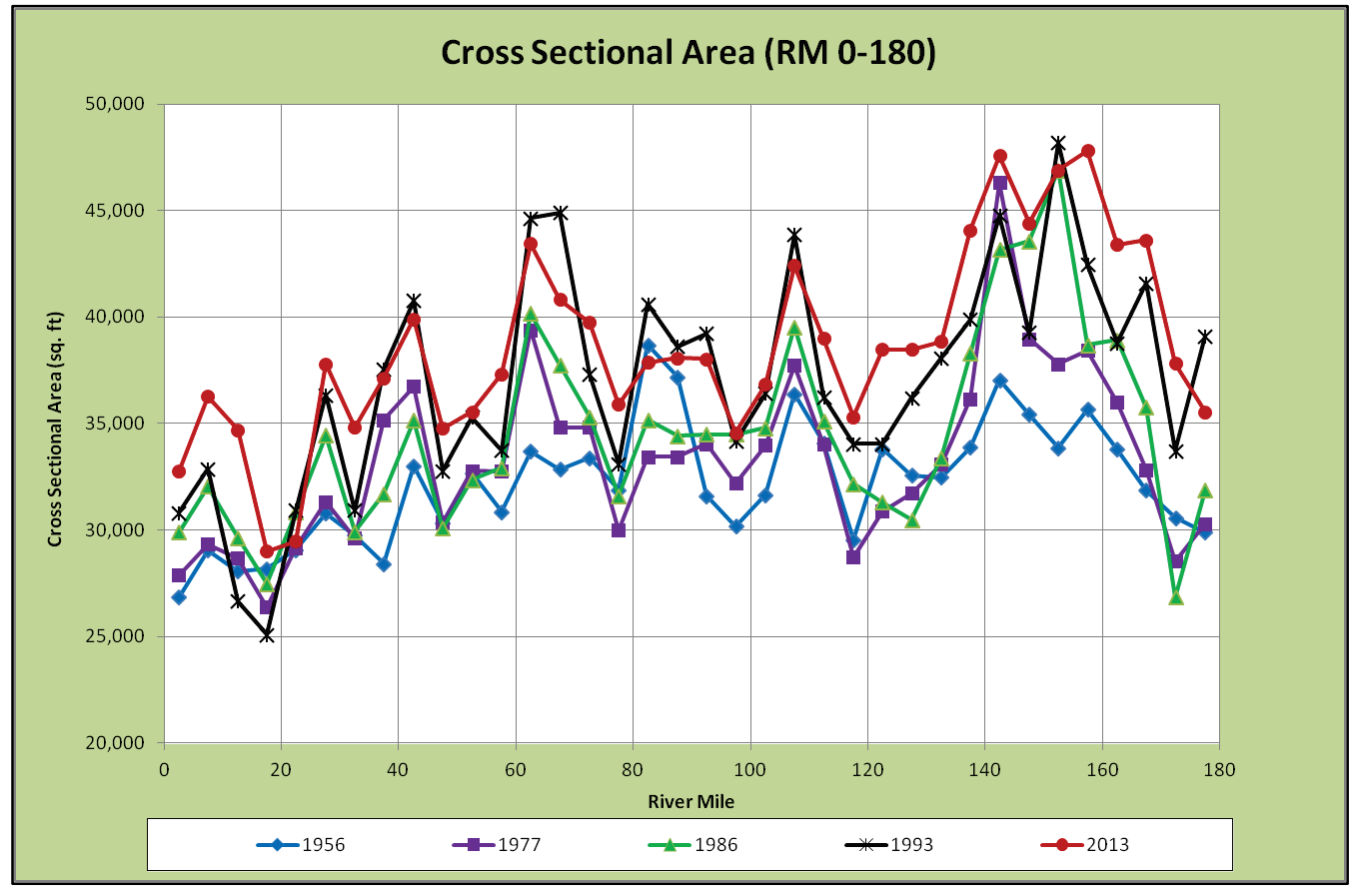

Figure 44. Five-mile average values of hydraulic depth (referenced to LWRP+10) between RM 0 and RM 180 on the MMR.

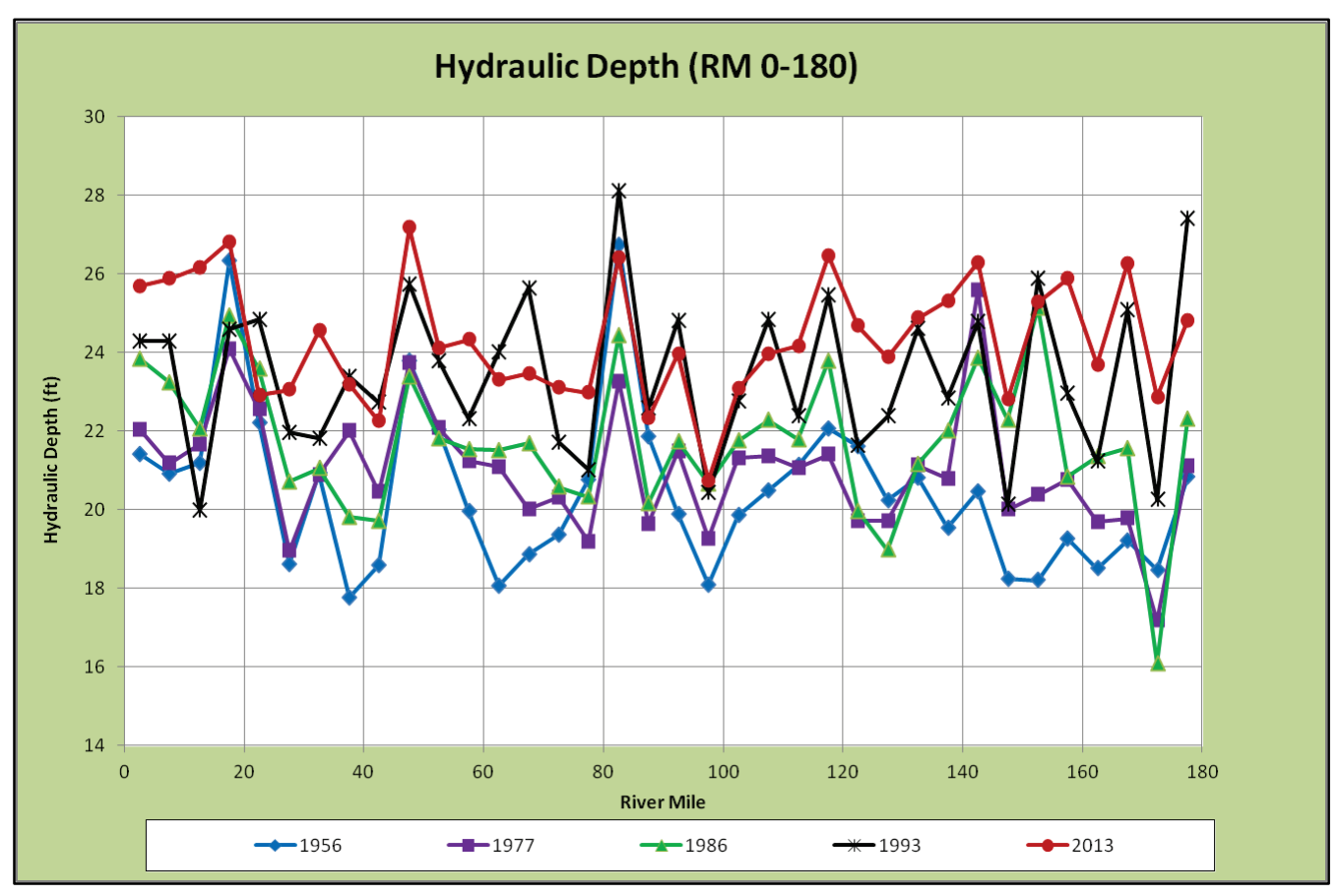


Figure 45. Five-mile average values of conveyance (referenced to LWRP+10) between RM 0 and RM 180 on the MMR.

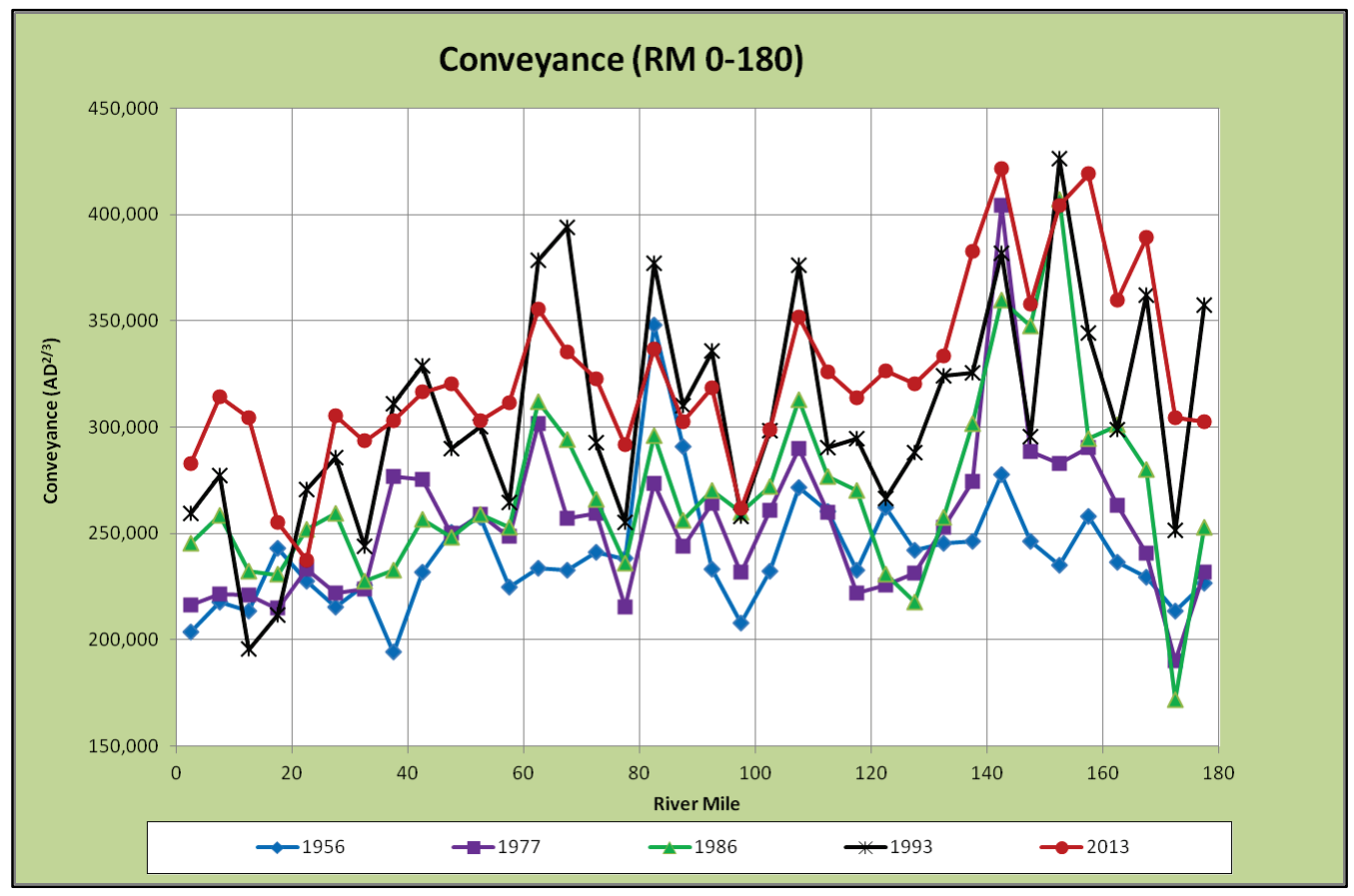

Figure 46. Five-mile average values of channel volume (referenced to LWRP+10) between RM 0 and RM 180 on the MMR.

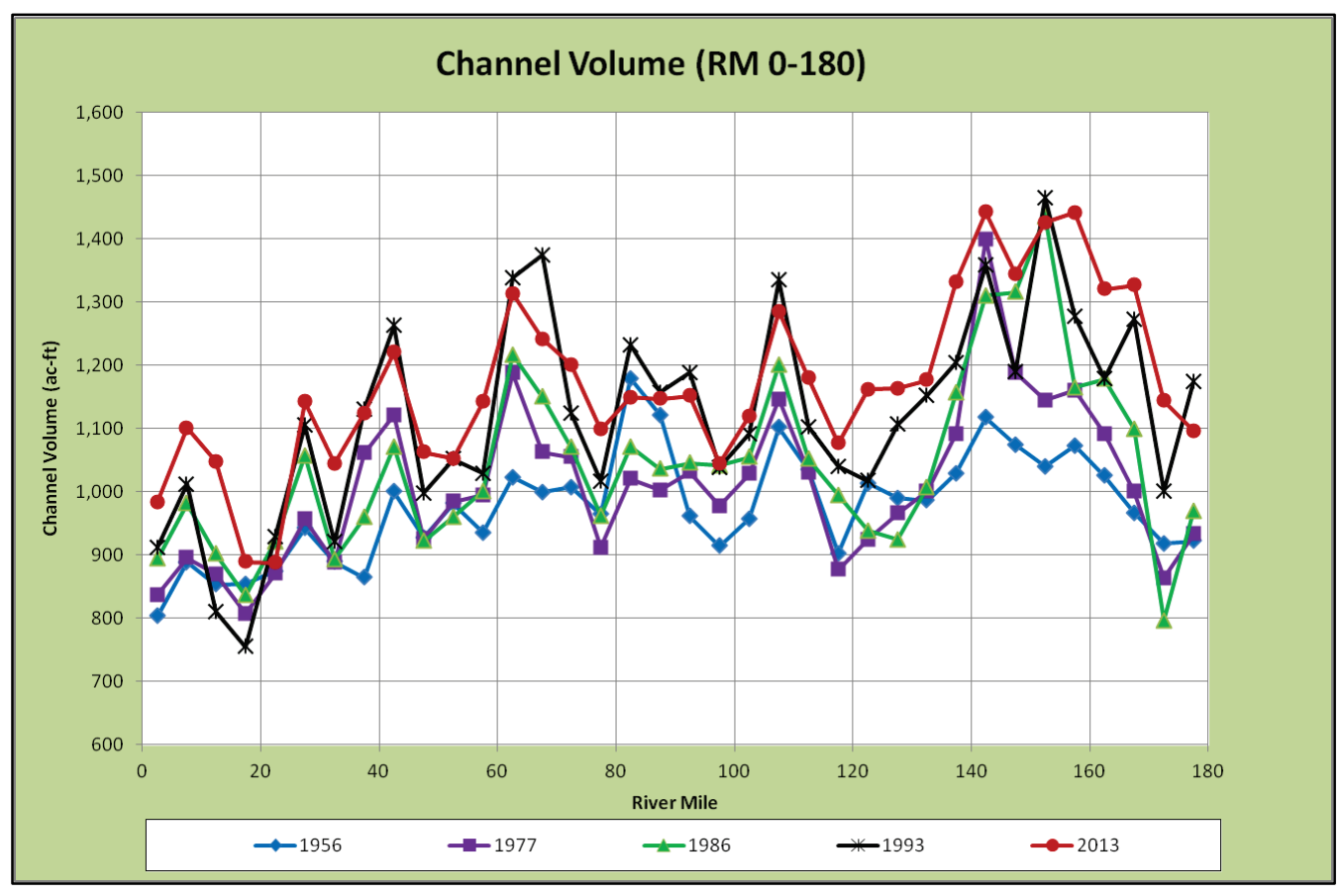


Box plots were developed to assist in visualizing the trends in the geometry data. The box plots were developed for the entire 180 miles of the MMR as well as for three 60-mile reaches: RM o to 60, RM 60 to 120 , and RM 120 to 180 . The river was divided into these three reaches to allow for detailed spatial and temporal assessment of trends. The box plots for crosssectional area, hydraulic depth, conveyance, and volume for the entire MMR (RM o to 180) are shown in Figures 47 through 50. The graphs of these four parameters for each of the three 60-mile reaches are shown in Figure 51 through 62 . Table 14 provides the reach average values for each parameter for the entire MMR (RM o-180) and for the three 60-mile reaches. The percent change between survey years for each of these parameters is shown in Table 15 .

Figure 47. Box plot of cross-sectional area for RM 0-180.

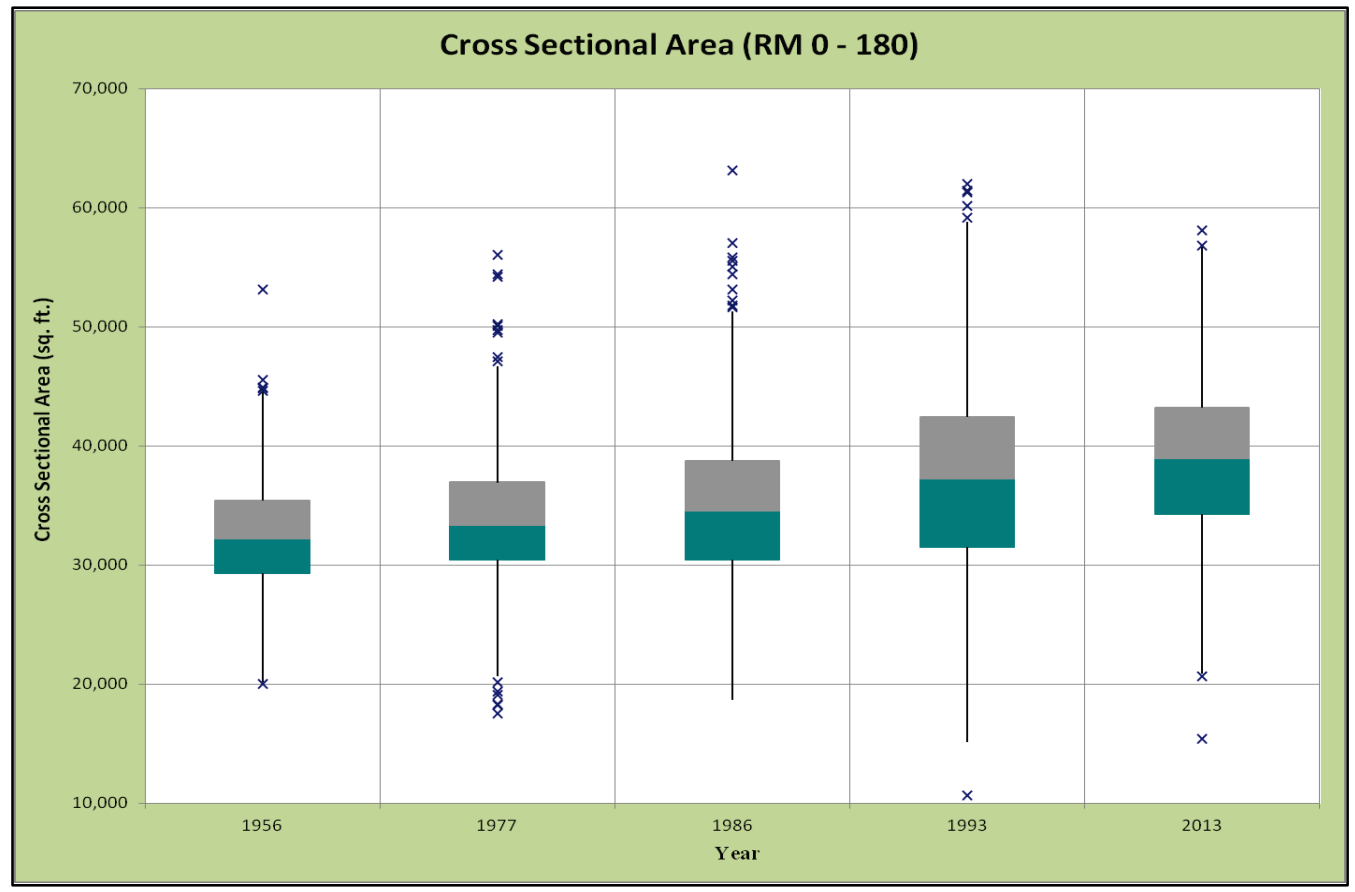


Figure 48. Box plot of hydraulic depth for RM 0-180.

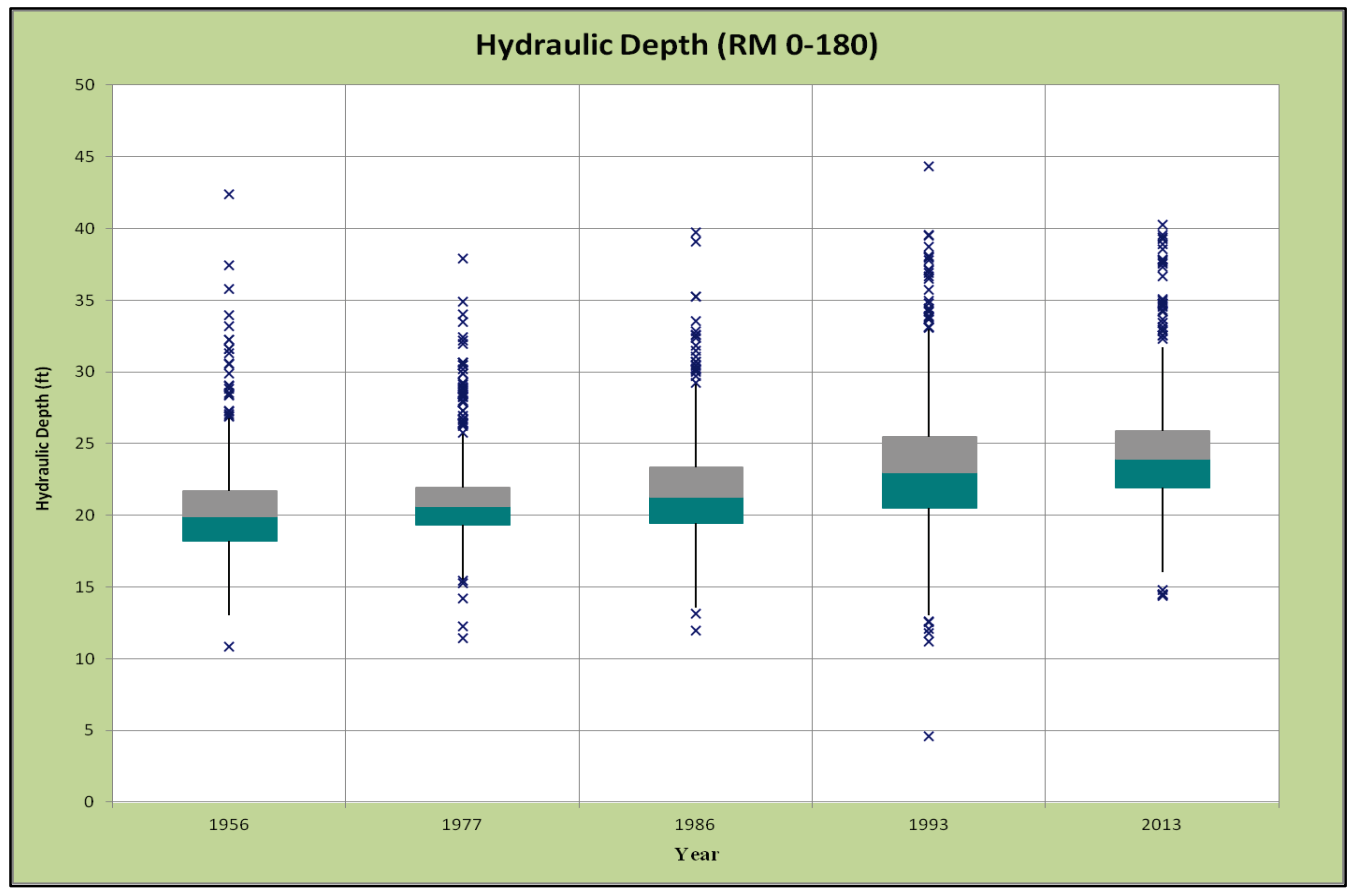

Figure 49. Box plot of channel conveyance for RM 0-180.

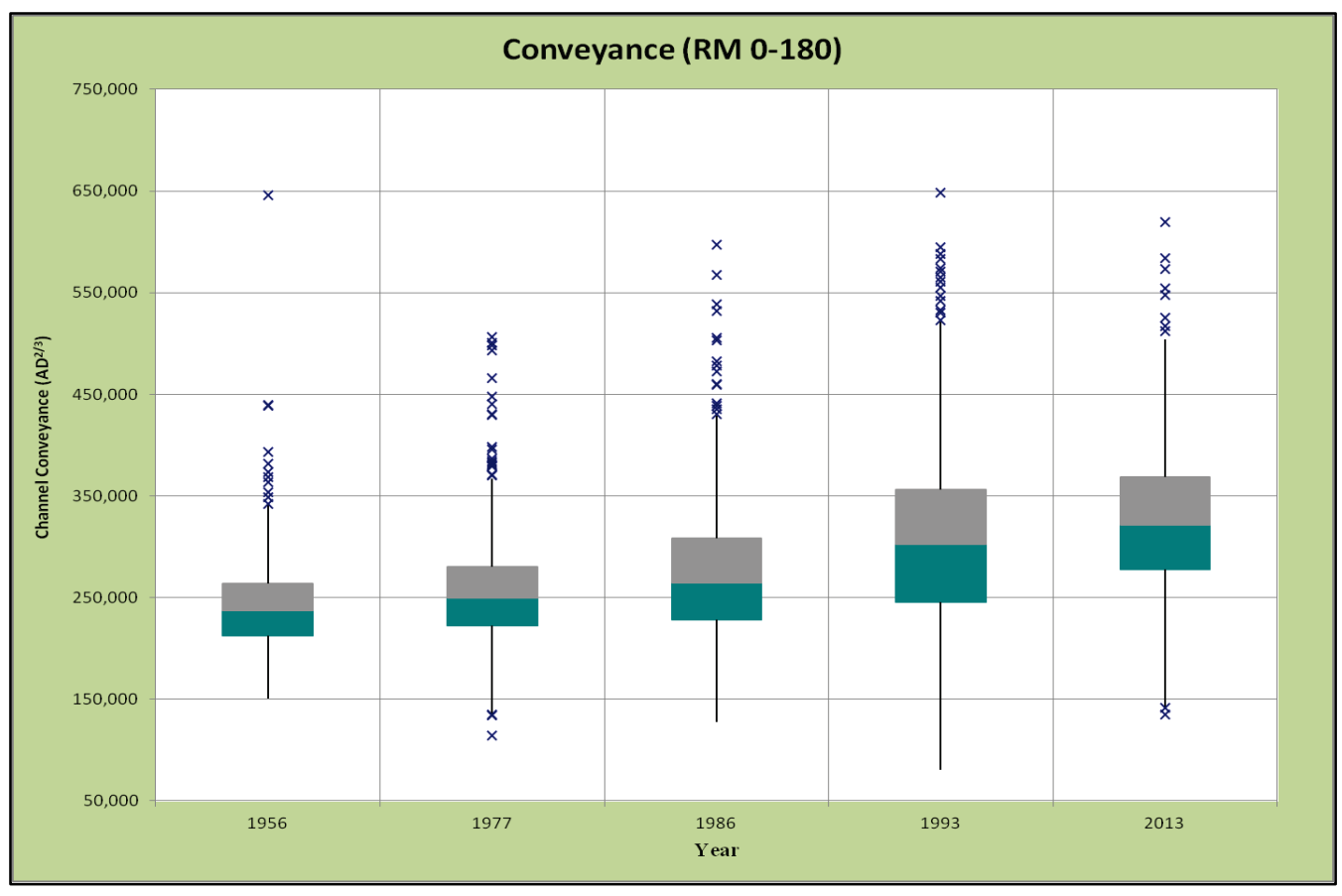


Figure 50. Box plot of channel volume for RM 0-180.

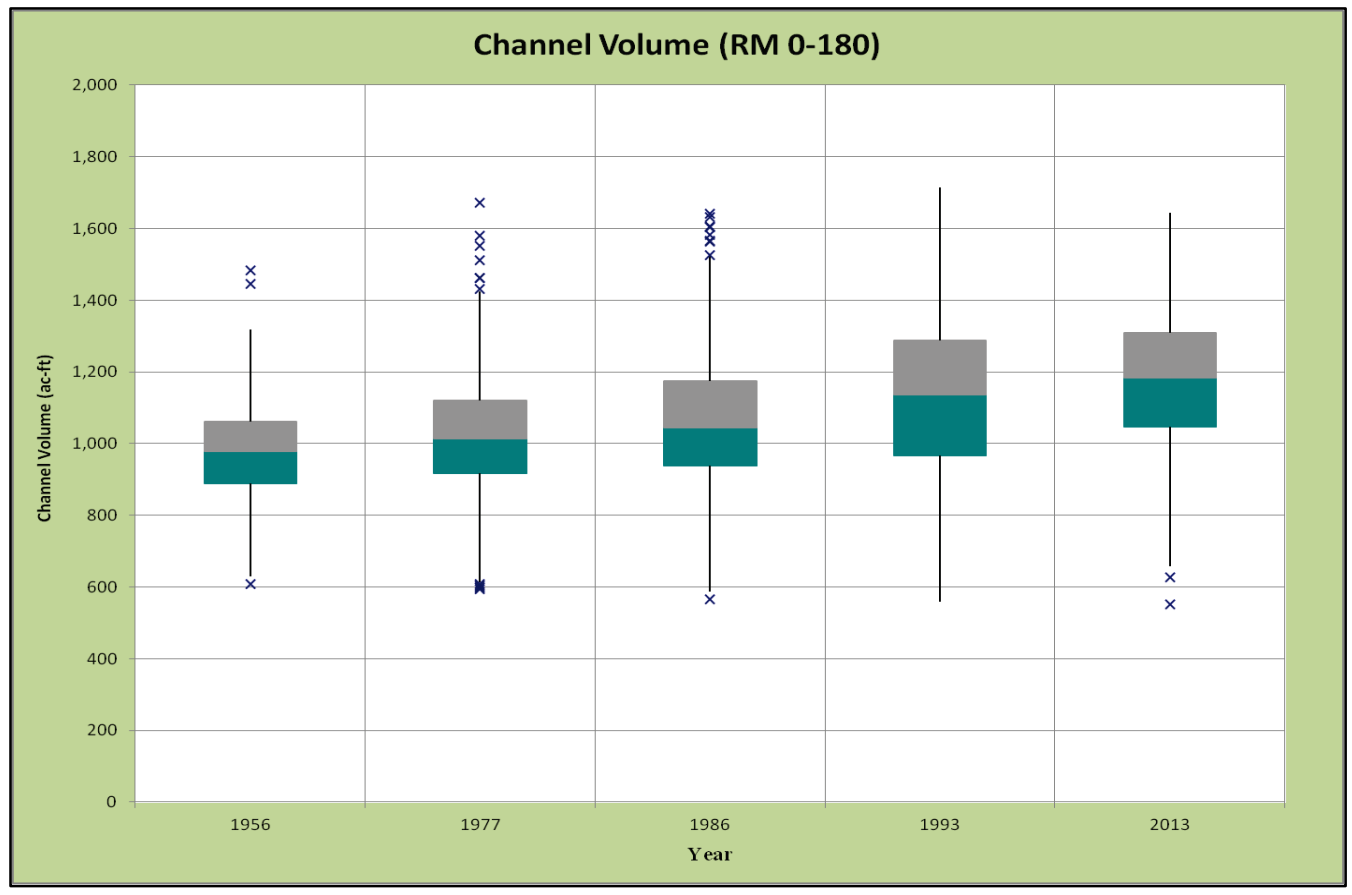

Figure 51. Box plot of cross-sectional area for RM 0-60.

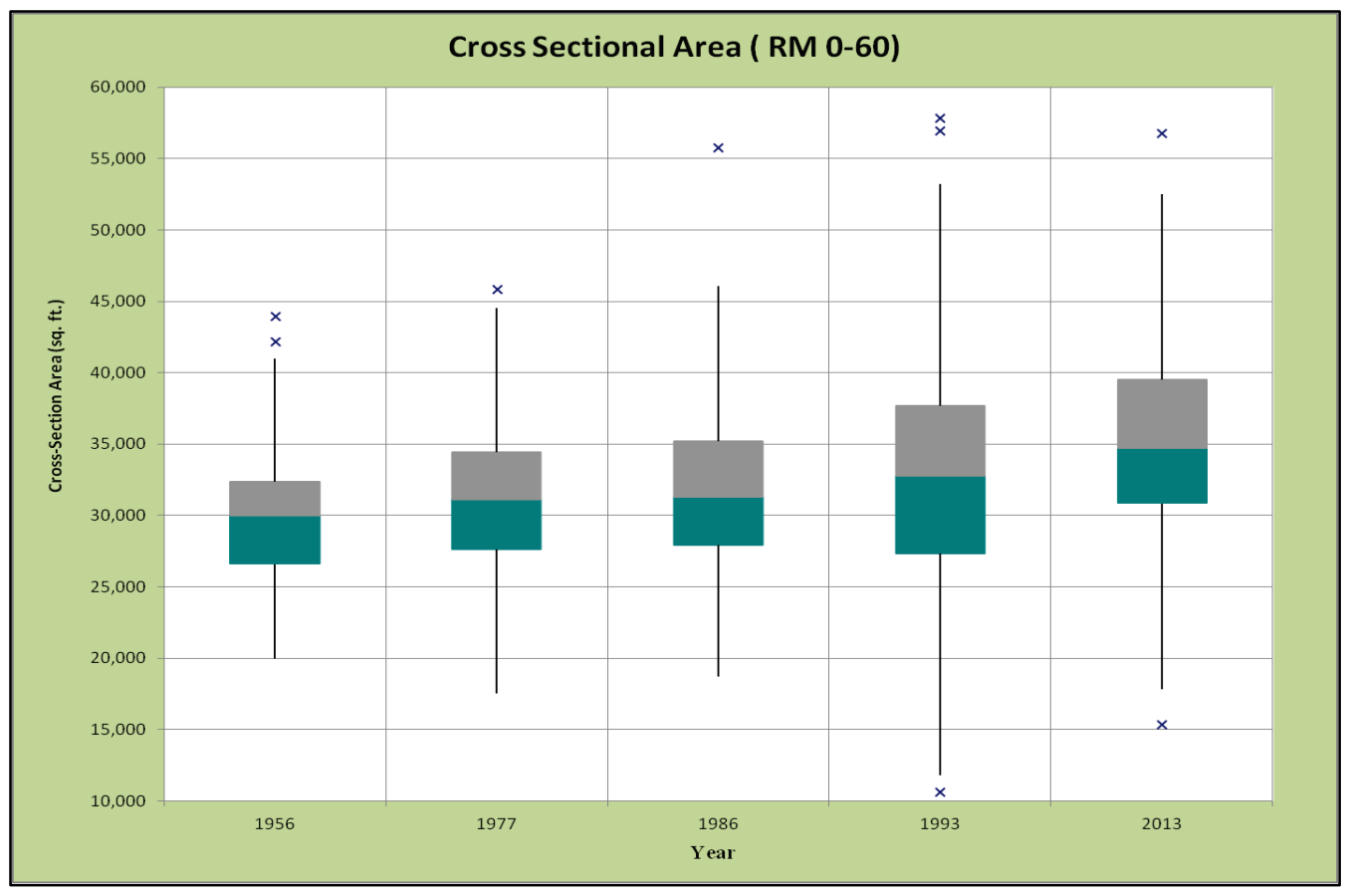


Figure 52. Box plot of cross-sectional area for RM 60-120.

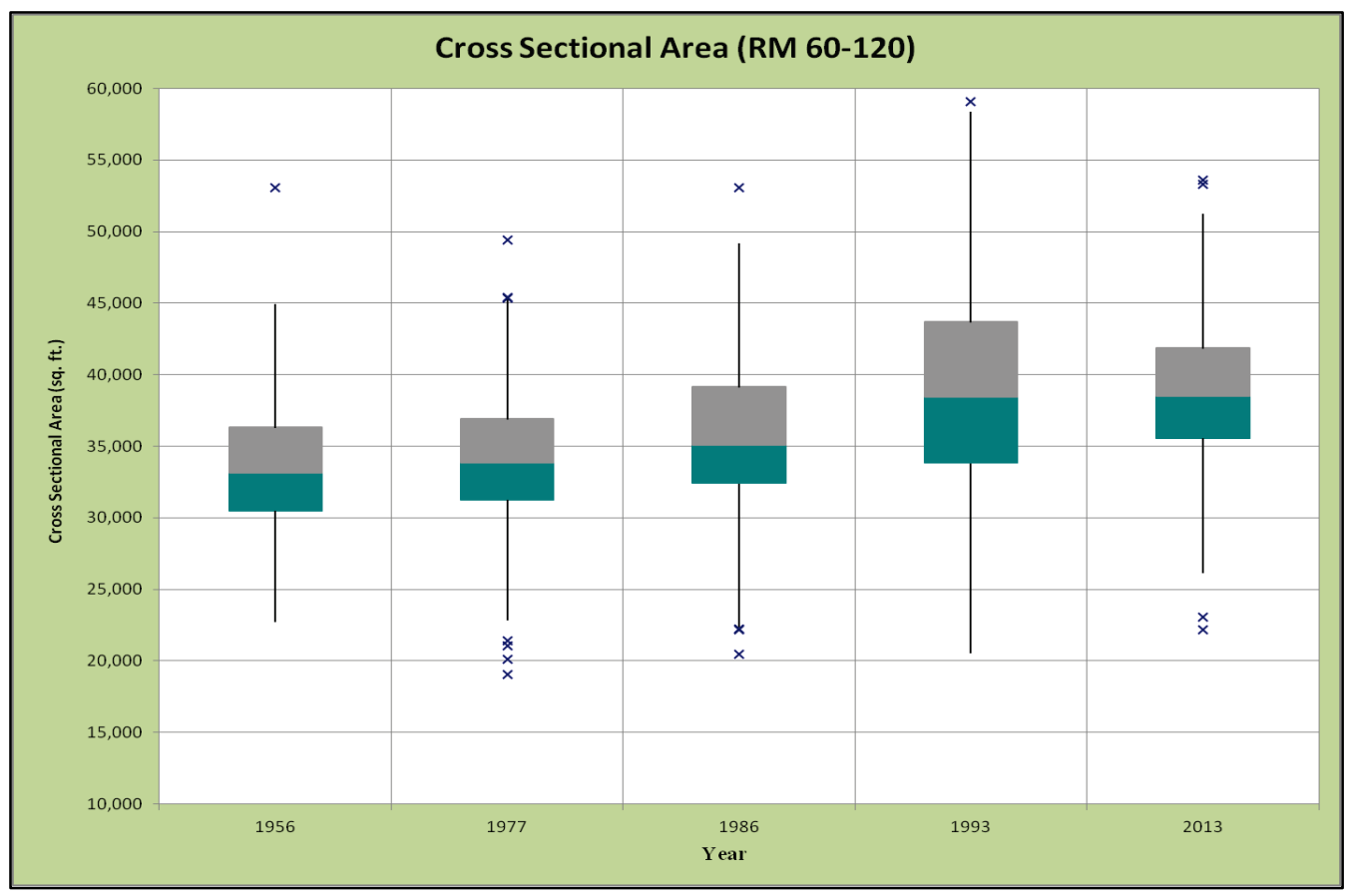

Figure 53. Box plot of cross-sectional area for RM 120-180.

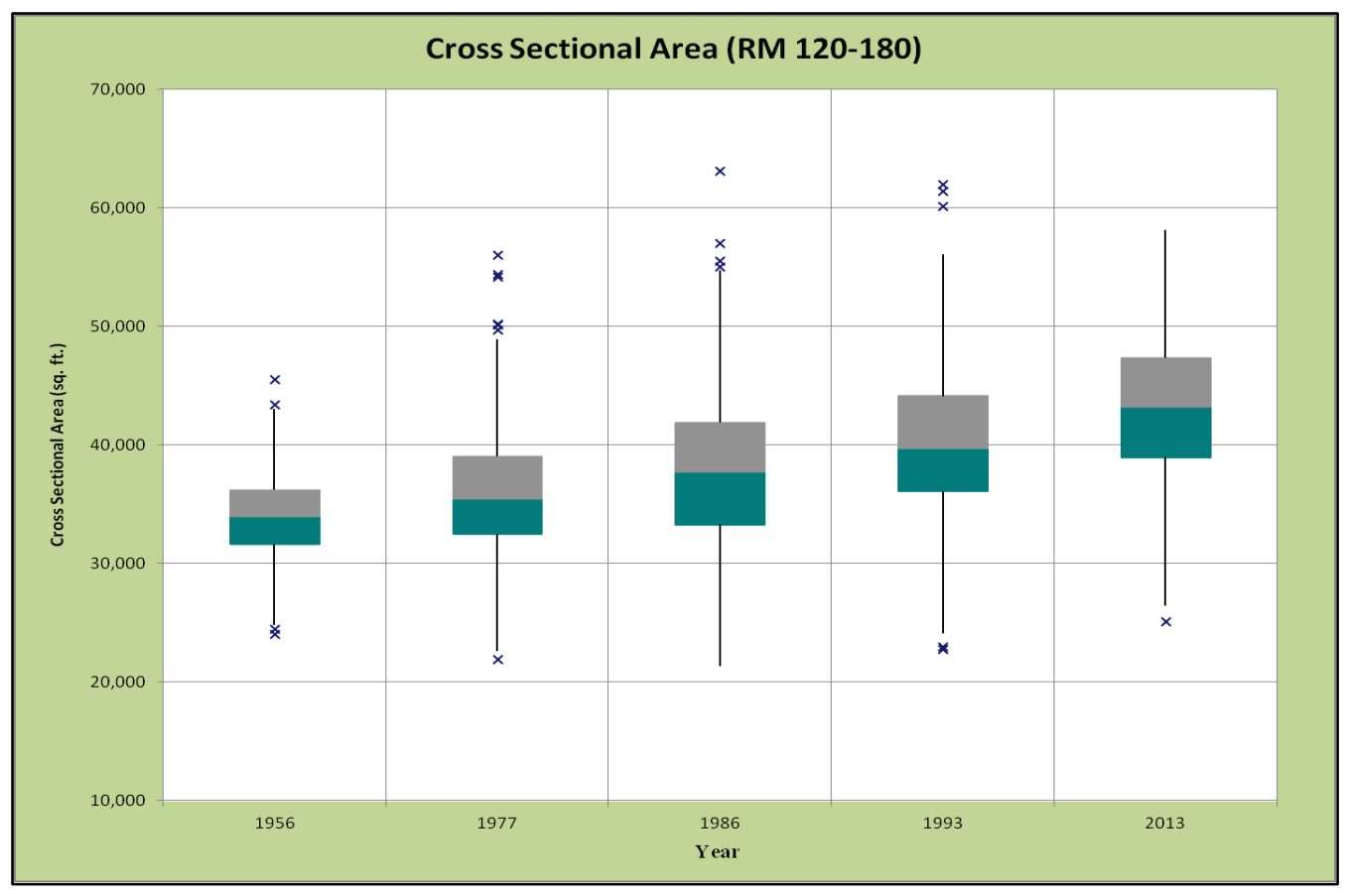


Figure 54. Box plot of hydraulic depth for RM 0-60.

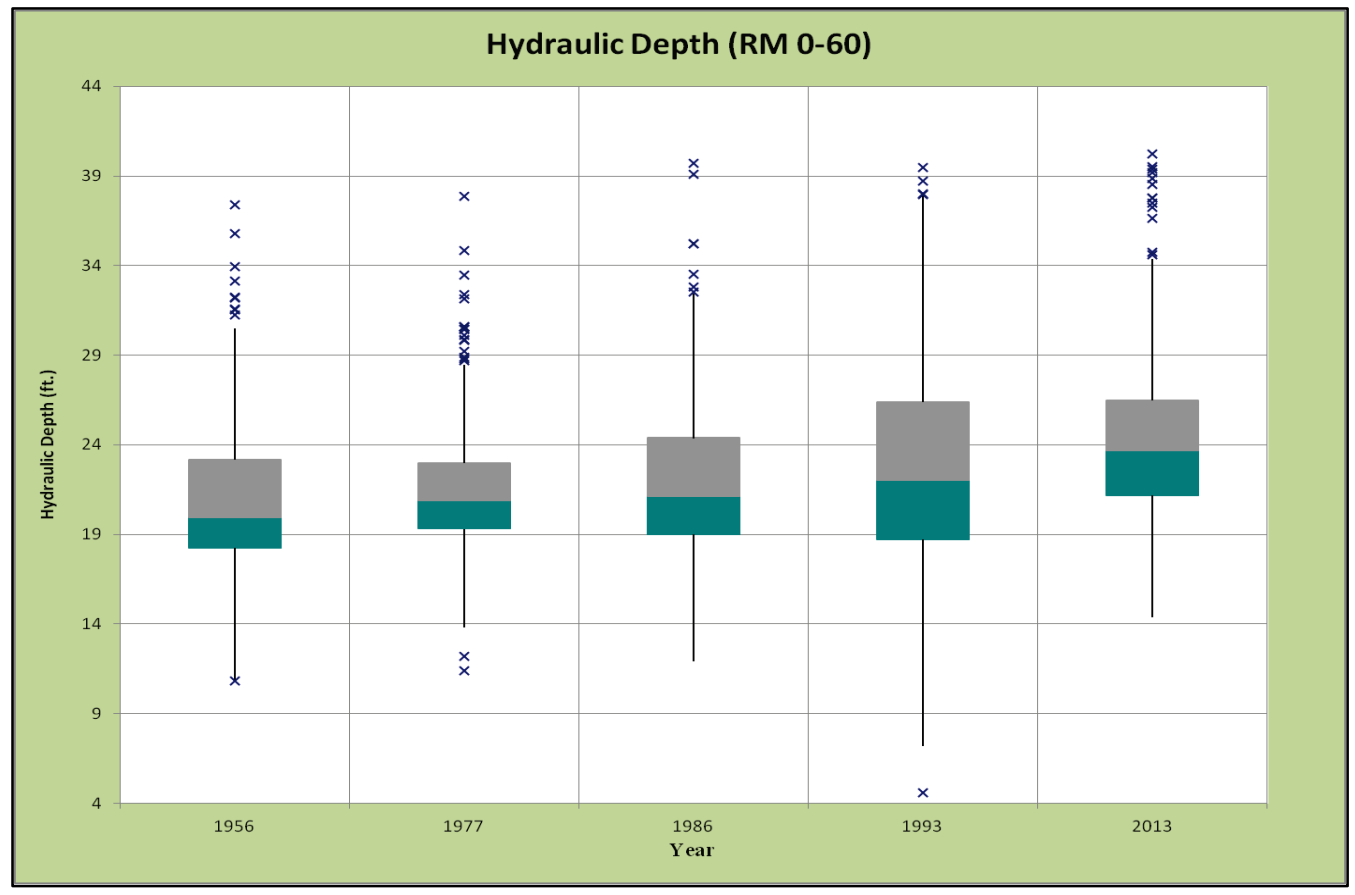

Figure 55. Box plot of hydraulic depth for RM 60-120.

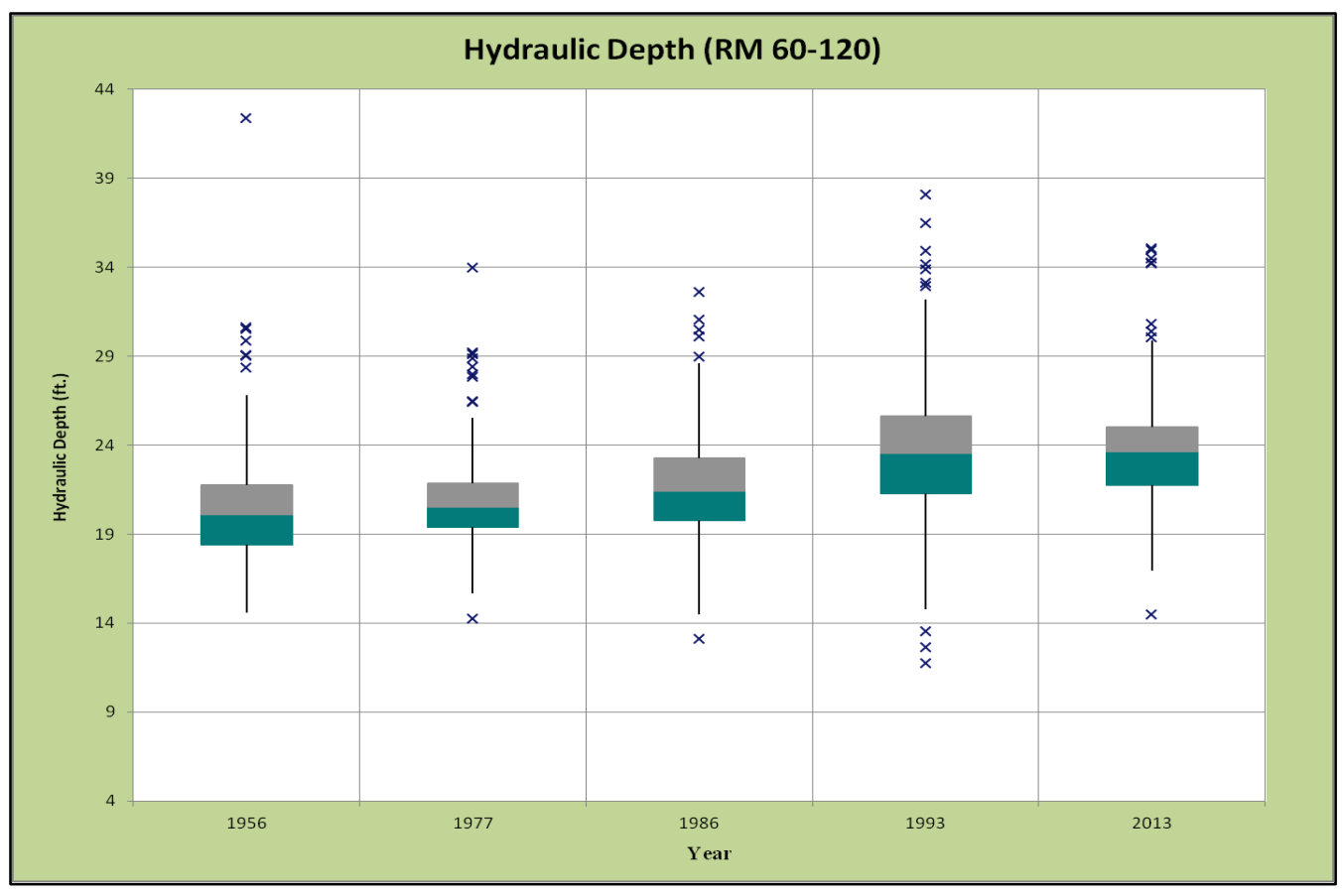


Figure 56. Box plot of hydraulic depth for RM 120-180.

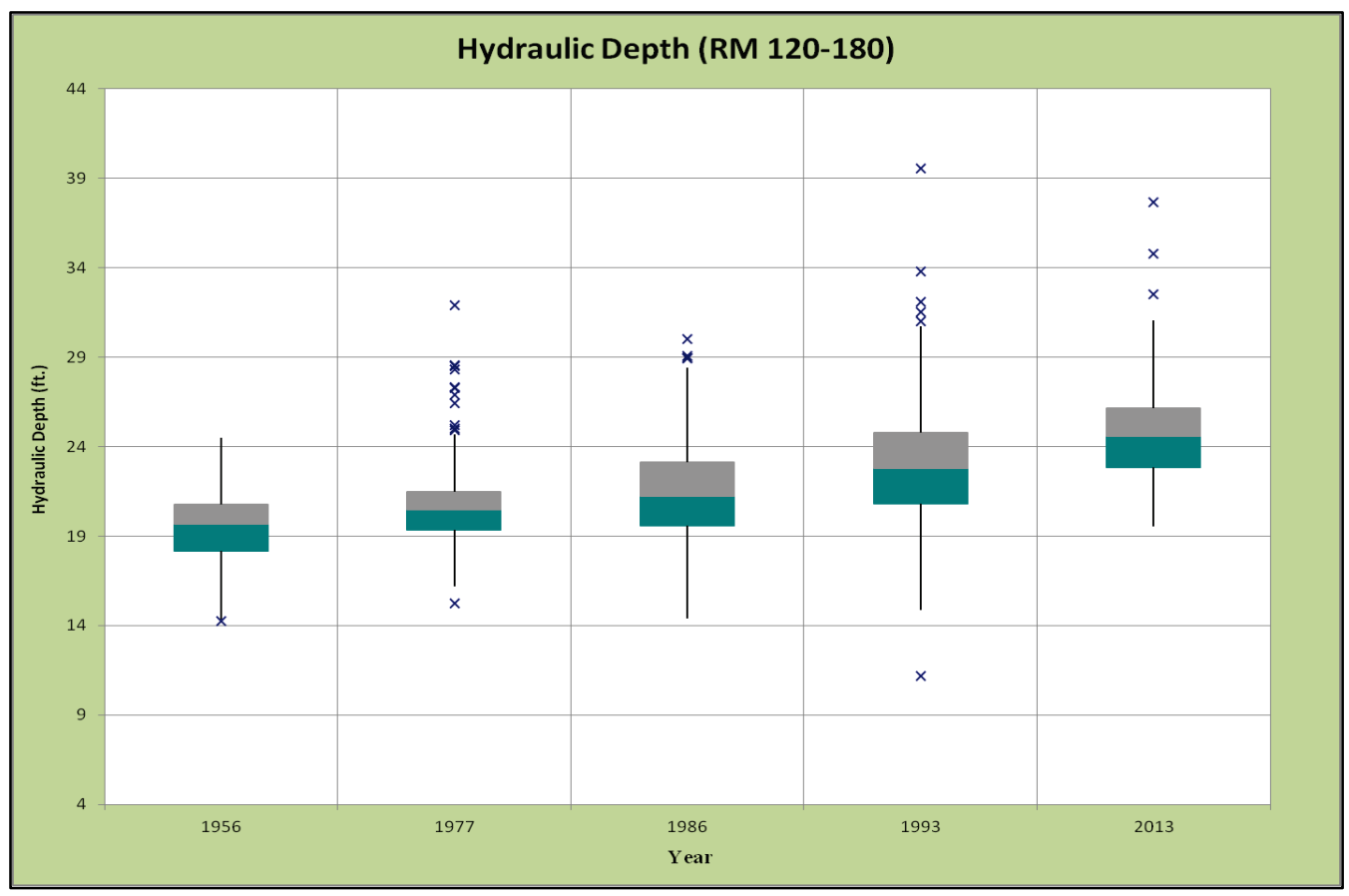

Figure 57. Box plot of conveyance for RM 0-60.

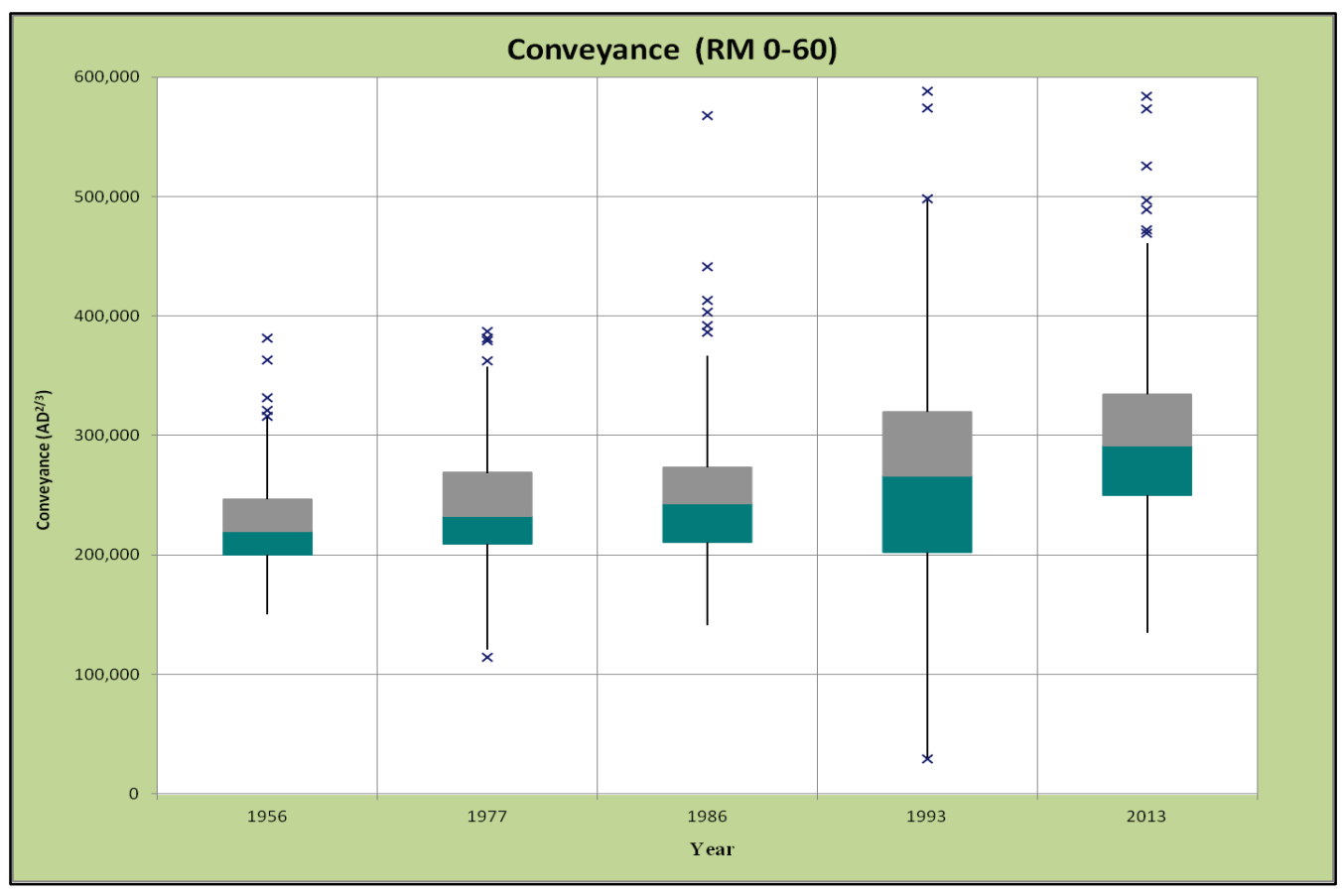


Figure 58. Box plot of conveyance for RM 60-120.

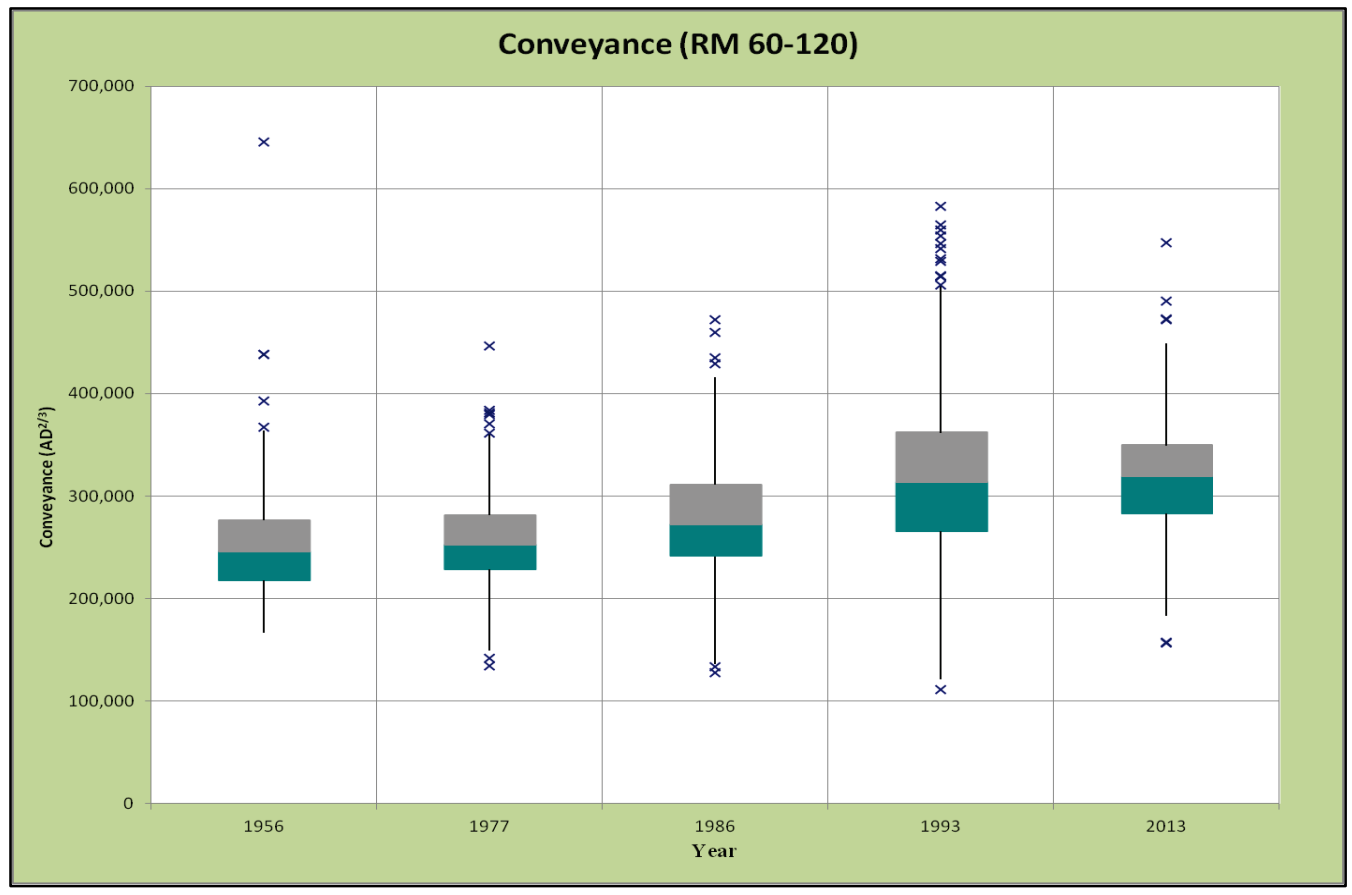

Figure 59. Box plot of conveyance for RM 120-180.

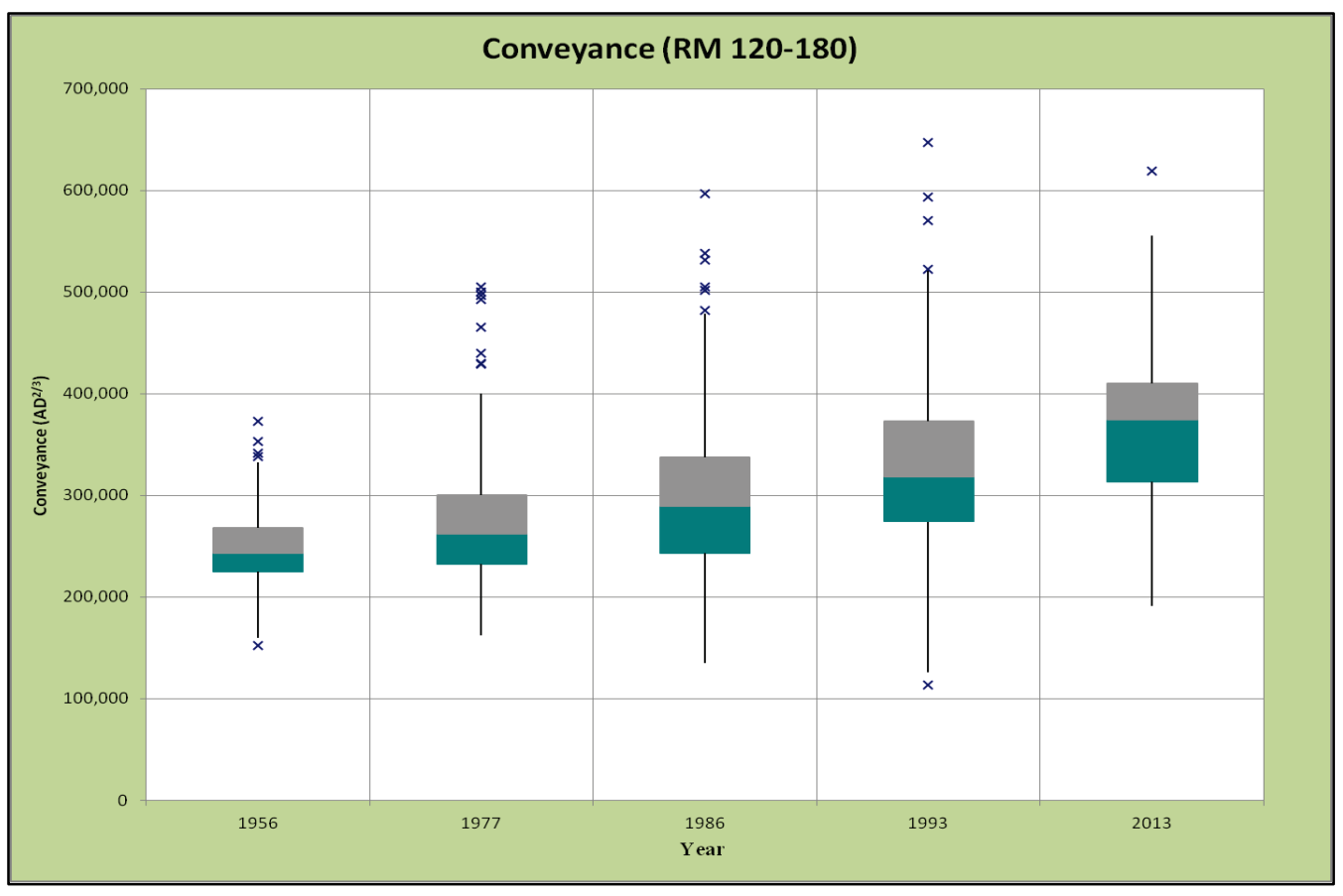


Figure 60. Box plot of channel volume for RM 0-60.

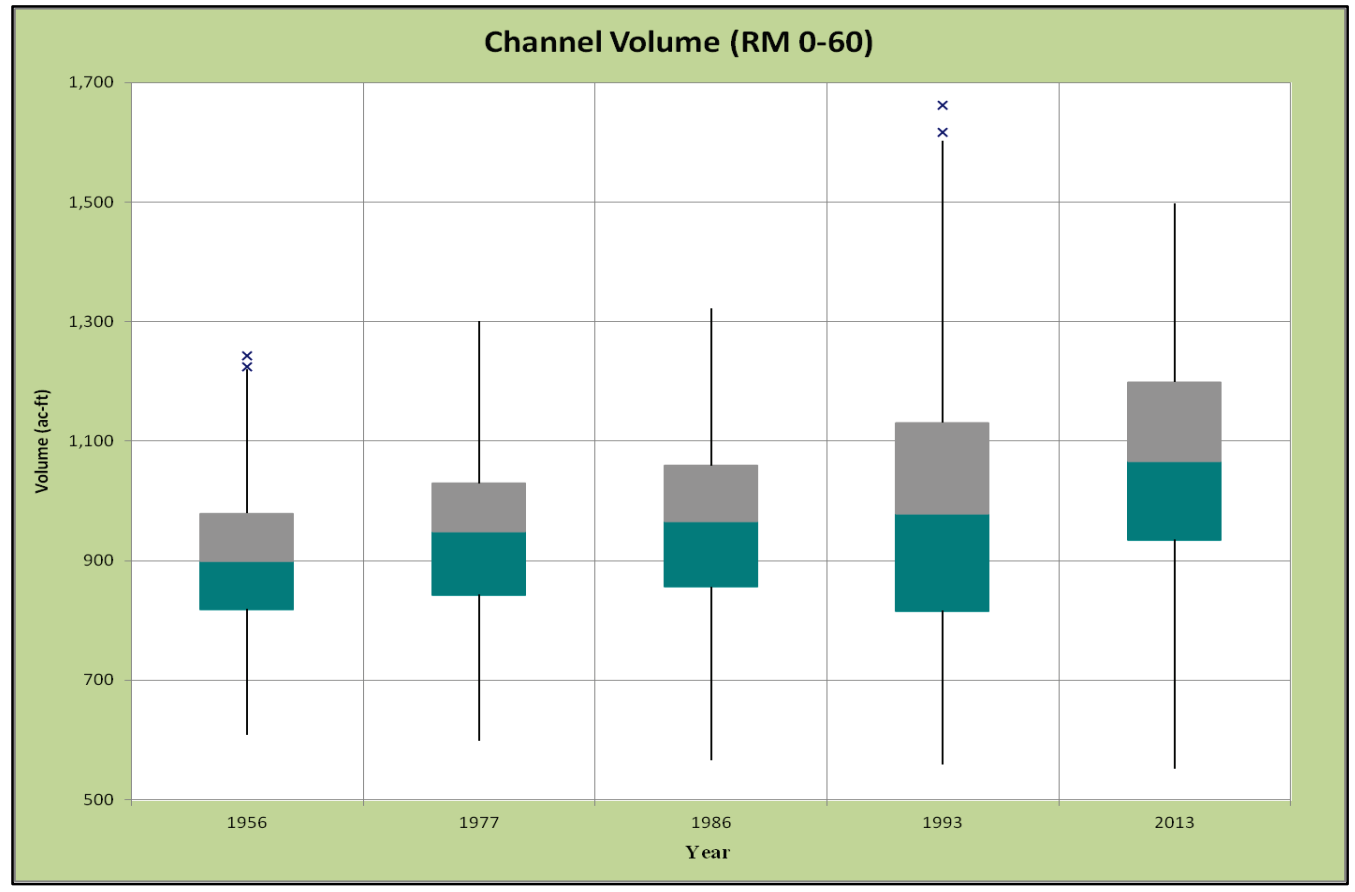

Figure 61. Box plot of channel volume for RM 60-120.

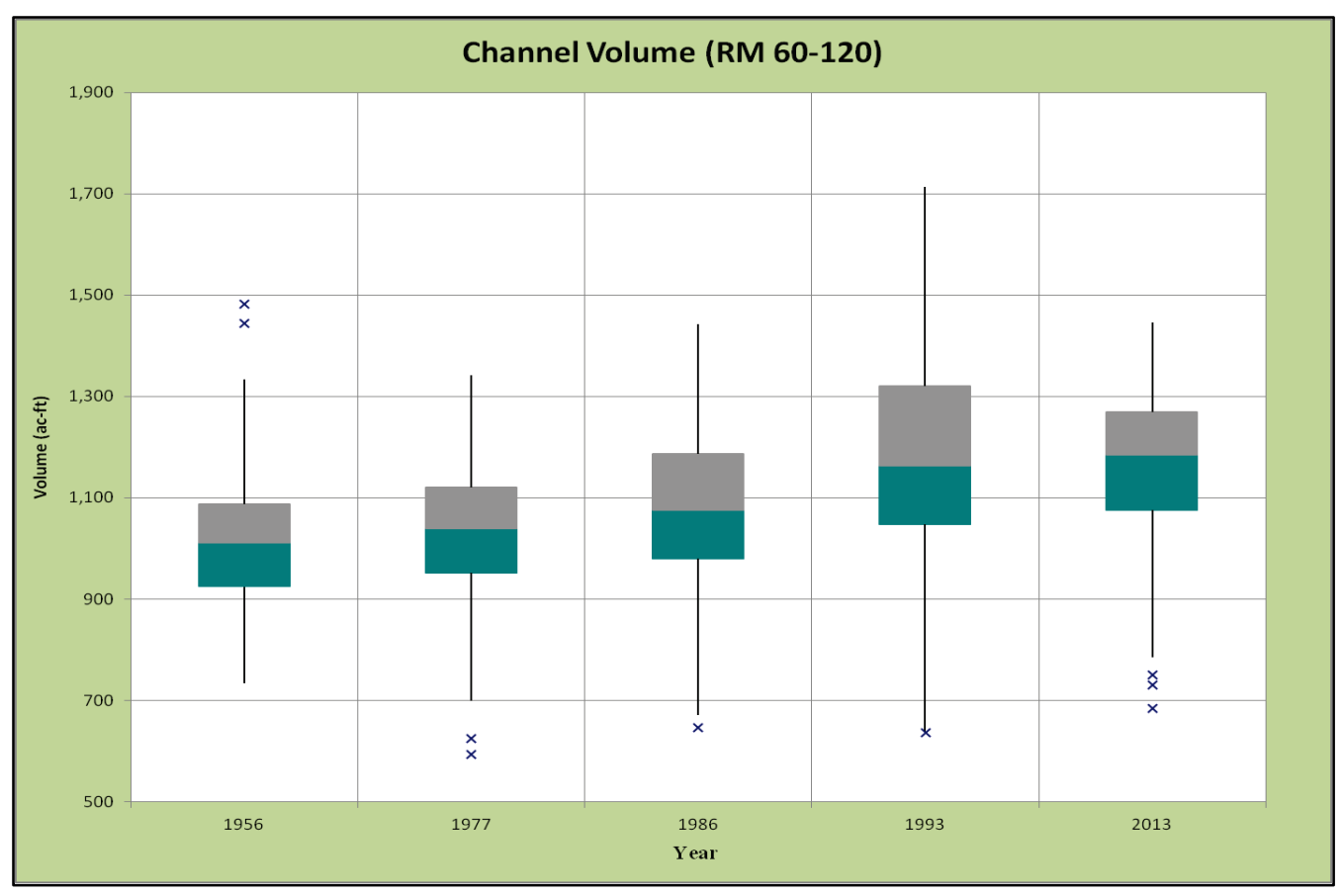


Figure 62. Box plot of channel volume for RM 120-180.

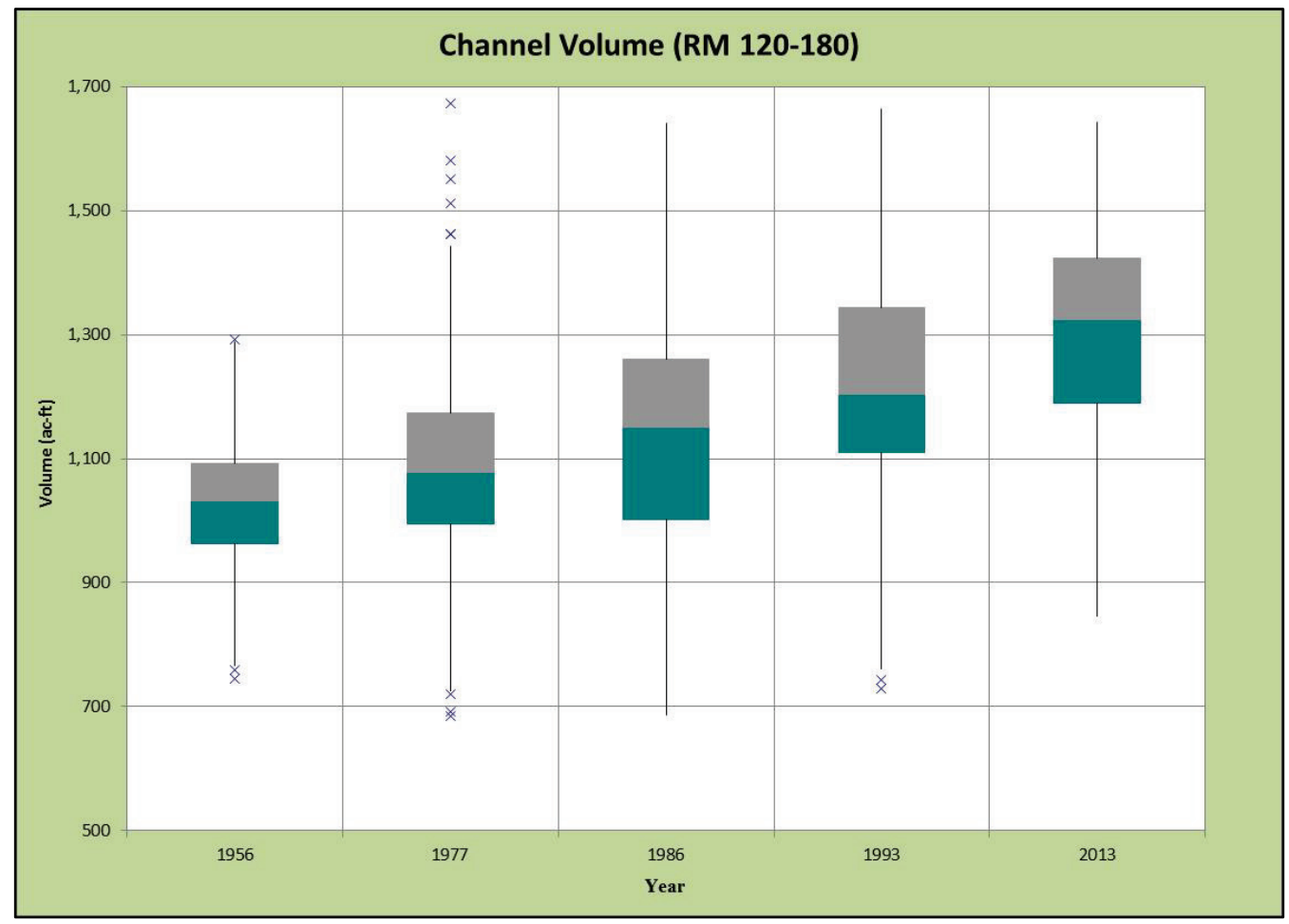

Table 14. Reach average values for cross-sectional area, hydraulic depth, conveyance, and channel volume.

\begin{tabular}{|c|c|c|c|c|c|c|}
\hline & River Reach & 1956 & 1977 & 1986 & 1993 & 2013 \\
\hline \multirow{4}{*}{$\begin{array}{l}\text { Cross-sectional Area } \\
\left(\mathrm{ft}^{2}\right)\end{array}$} & RM 0-180 & 32,341 & 33,564 & 34,762 & 37,201 & 38,724 \\
\hline & RM 0-60 & 29,782 & 31,014 & 31,426 & 32,998 & 35,076 \\
\hline & RM 60-120 & 33,416 & 33,936 & 35,531 & 38,736 & 38,577 \\
\hline & RM 120-180 & 33,911 & 35,986 & 37,584 & 40,062 & 43,020 \\
\hline \multirow{4}{*}{$\begin{array}{l}\text { Hydraulic Depth } \\
\text { (ft) }\end{array}$} & RM 0-180 & 20.4 & 21.1 & 21.8 & 23.4 & 24.3 \\
\hline & RM 0-60 & 21.0 & 21.7 & 22.1 & 23.3 & 24.6 \\
\hline & RM 60-120 & 20.5 & 20.8 & 21.8 & 23.7 & 23.7 \\
\hline & RM 120-180 & 19.6 & 20.7 & 21.6 & 23.1 & 24.8 \\
\hline \multirow{4}{*}{$\begin{array}{l}\text { Channel Conveyance } \\
\left(\mathrm{ft}^{5 / 3}\right)\end{array}$} & RM 0-180 & 241,110 & 256,038 & 272,260 & 307,344 & 325,719 \\
\hline & RM 0-60 & 224,800 & 239,716 & 246,139 & 271,245 & 296,247 \\
\hline & RM 60-120 & 251,279 & 256,819 & 277,865 & 323,112 & 318,490 \\
\hline & RM 120-180 & 247,046 & 273,493 & 294,856 & 328,740 & 367,826 \\
\hline \multirow{4}{*}{$\begin{array}{l}\text { Channel Volume } \\
\text { (acre-ft) }\end{array}$} & RM 0-180 & 980 & 1,017 & 1,053 & 1,127 & 1,174 \\
\hline & RM 0-60 & 902 & 939 & 951 & 999 & 1,062 \\
\hline & RM 60-120 & 1,013 & 1,029 & 1,078 & 1,174 & 1,169 \\
\hline & RM 120-180 & 1,027 & 1,090 & 1,138 & 1,213 & 1,304 \\
\hline
\end{tabular}


Table 15. Percent change in geometry parameters between survey years.

\begin{tabular}{|c|c|c|c|c|c|c|}
\hline & River Reach & $\begin{array}{l}1956 \\
\text { to } \\
1977\end{array}$ & $\begin{array}{l}1977 \\
\text { to } \\
1986\end{array}$ & $\begin{array}{l}1986 \\
\text { to } \\
1993\end{array}$ & $\begin{array}{l}1993 \\
\text { to } \\
2013\end{array}$ & $\begin{array}{l}1956 \\
\text { to } \\
2013\end{array}$ \\
\hline \multirow{4}{*}{$\begin{array}{l}\text { Cross-sectional } \\
\text { Area }\left(\mathrm{ft}^{2}\right)\end{array}$} & RM 0-180 & $3.8 \%$ & $3.6 \%$ & $7.0 \%$ & $4.1 \%$ & $19.7 \%$ \\
\hline & RM 0-60 & $4.1 \%$ & $1.3 \%$ & $5.0 \%$ & $6.3 \%$ & $17.8 \%$ \\
\hline & RM 60-120 & $1.6 \%$ & $4.7 \%$ & $9.0 \%$ & $-0.4 \%$ & $15.4 \%$ \\
\hline & RM 120-180 & $6.1 \%$ & $4.4 \%$ & $6.6 \%$ & $7.4 \%$ & $26.9 \%$ \\
\hline \multirow{4}{*}{$\begin{array}{l}\text { Hydraulic Depth } \\
\text { (ft) }\end{array}$} & RM 0-180 & $3.1 \%$ & $3.4 \%$ & $7.3 \%$ & $4.0 \%$ & $19.1 \%$ \\
\hline & RM 0-60 & $3.3 \%$ & $1.6 \%$ & $5.6 \%$ & $5.7 \%$ & $17.1 \%$ \\
\hline & RM 60-120 & $1.1 \%$ & $4.7 \%$ & $8.9 \%$ & $-0.1 \%$ & $15.2 \%$ \\
\hline & RM 120-180 & $5.6 \%$ & $4.0 \%$ & $7.3 \%$ & $7.3 \%$ & $26.5 \%$ \\
\hline \multirow{4}{*}{$\begin{array}{l}\text { Channel } \\
\text { Conveyance (ft5/3) }\end{array}$} & RM 0-180 & $6.2 \%$ & $6.3 \%$ & $12.9 \%$ & $6.0 \%$ & $35.1 \%$ \\
\hline & RM 0-60 & $6.6 \%$ & $2.7 \%$ & $10.2 \%$ & $9.2 \%$ & $31.8 \%$ \\
\hline & RM 60-120 & $2.2 \%$ & $8.2 \%$ & $16.3 \%$ & $-1.4 \%$ & $26.7 \%$ \\
\hline & RM 120-180 & $10.7 \%$ & $7.8 \%$ & $11.5 \%$ & $11.9 \%$ & $48.9 \%$ \\
\hline \multirow{4}{*}{$\begin{array}{l}\text { Channel Volume } \\
\text { (ac-ft) }\end{array}$} & RM 0-180 & $3.8 \%$ & $3.6 \%$ & $7.0 \%$ & $4.1 \%$ & $19.7 \%$ \\
\hline & RM 0-60 & $4.2 \%$ & $1.3 \%$ & $5.0 \%$ & $6.3 \%$ & $17.8 \%$ \\
\hline & RM 60-120 & $1.6 \%$ & $4.7 \%$ & $8.9 \%$ & $-0.4 \%$ & $15.4 \%$ \\
\hline & RM 120-180 & $6.1 \%$ & $4.4 \%$ & $6.6 \%$ & $7.5 \%$ & $26.9 \%$ \\
\hline
\end{tabular}

Positive values indicate an increase in area, depth, conveyance, or volume relative to the earlier survey year. Negative values (in red) indicate a decrease. 


\section{Discussion}

The discussion of the channel geometry trends are provided in two sections: (1) LMR (RM 320 to 954) and (2) MMR (RM o to 180).

\subsection{LMR trends}

The analysis results of the channel cross-section geometry data for the LMR indicate a decreasing trend for the period 1975 to 2013 in channel area, hydraulic depth, conveyance, and channel volume for the most downstream portion of the reach. In general, these decreasing trends occur from RM 325 to approximately RM 435 in the vicinity of Vicksburg. The patterns appear to be similar for both crossing and pool sections. Although no comprehensive assessment of causative factors is attempted in this report, these observed changes are most likely associated with a general depositional trend in this reach of the river. The increase in the channel crossings invert profiles for this reach shown in Figure 38 also indicates this depositional trend.

The reach of the LMR from RM 435 to approximately RM 530 is characterized by less observed change in channel area and volume parameters, which suggests the reach might be a transition zone from the depositional trends in downstream reaches to more stable conditions. The cumulative volume change plots indicate the upstream limit of this area may be closer to approximately RM 500. Although there is variability in the data, the volumetric data indicate generally stable channel conditions in this reach for the time period 1975 to 2013.

The reach of the LMR upstream of approximately RM 530 to RM 570 indicates little change in channel volume, suggesting generally stable channel conditions. The reach upstream of RM 570 to RM 954 exhibits trends of increasing channel area, hydraulic depth, and channel volume. The increasing trends suggest the reach can be generally characterized by channel erosion. However, these trends are observed over different time periods. As illustrated in Figure 34, the increases in channel volume from RM 600 to approximately RM 825 occur early in the study time period from 1975 to 2004. From 2004 to 2013, there is little change observed in channel volume for this reach. From RM 825 to RM 954 there is little to no 
change in channel volume observed between 1975 and 2004, but increases in volume occur from 2004 to 2013. These observations suggest the channel erosion process may be migrating in the upstream direction.

Figures 35 through 37 illustrate some interesting characteristics of the channel invert profiles for the LMR. Comparison of the invert profiles for the crossing sections and the pool sections indicates the elevation differential between crossing and pool profiles is greater downstream of RM 600 than upstream. Reasons for the greater pool depths for this reach are not clear, although the confluence of major tributaries, including the White River and the Arkansas River, between RM 600 and 580 and the associated increases in discharge may be a factor. Additionally, the 2013 profile of the pool section channel inverts displayed the most change of any profile during the study period. Profile elevation decreases in the range of 10 to $15 \mathrm{ft}$ were observed for almost the entire LMR reach.

In summary, the analysis of the channel geometry parameters for the LMR reach indicate the river channel in the lower portion of the reach from RM 325 to near Vicksburg has decreased in volume over the study time period. These trends may be interpreted as channel deposition in this reach. A transition reach of little to no change in channel geometry was observed from approximately RM 425 to RM 530, which may suggest a degree of channel stability in this reach. Upstream of RM 530 to RM 570, a general enlargement of the channel was observed. A generally stable reach of little volume change was observed from RM 570 to RM 592. Upstream of RM 592 to RM 954, a trend of general channel enlargement was observed. Most of the change occurred between 1975 and 2004 for the downstream portion of this reach while the majority of the change for the upstream portion of the reach occurred between 2004 and 2013. These trends suggest channel erosion to be prevalent in this reach for the study time period.

\subsection{MMR trends}

Examination of the results in Tables 14 and 15 and Figures 39 through 62 reveals that there has been a general increase in cross-sectional area, hydraulic depth, conveyance, and channel volume during the period or record from 1956 to 2013. As shown in Table 15, there has been a steady increase in all parameters and in all reaches through time. In fact, the only decreases occurred in one reach (RM 60-120) between 1993 and 2013, and the percent changes were very small (less than 1.5\%). Although the increases were persistent throughout the period of record, the 1986-to- 
1993 period appears to have experienced the greatest increases with values ranging from approximately $5 \%$ to $13 \%$. When the overall time period is considered (1956 to 2013), the percent increases in all parameters were typically in the range from approximately $15 \%$ to $30 \%$.

In summary, the analysis of the geometric parameters (area, hydraulic depth, conveyance, and channel volume) referenced to LWRP+10, indicate that the MMR channel between RM o and 180 has steadily been enlarging during the 1956 to 2013 time period. It was not the objective of this study to conduct detailed investigations of the numerous natural and anthropogenic factors responsible for these changes. However, the channel geometry analysis provides a critical tool that when combined with other river engineering and geomorphic assessment tools will aid in developing a better understanding of the complex fluvial processes that drive the morphology of the MMR. 


\section{Summary}

A geometric data analysis was conducted for the Mississippi River from ORCC to St. Louis, MO, or approximately RM 325 AHP to RM 180 Above Mouth of the Ohio River. The purpose of the study was to document longterm trends in the dimension, pattern, and profile of the LMR and MMR channel within the study reach. Hydrographic survey data from 1975 to 2013 were used to determine spatial and temporal variations in channel geometry and volume. Trends of geometric change (area, depth, width, conveyance, and channel volume) were identified along defined geomorphic reaches of the river.

Analysis of the volumetric changes in the river channel over time allowed trends of erosion, deposition, and relative channel stability to be identified in the study reach. While there are some local exceptions, the trends of the LMR and MMR reaches for the period 1975 to 2013 can be broadly classified as

- RM 325 AHP to RM 435 AHP: depositional trend

- RM 435 AHP to RM 530 AHP: relative stability trend

- RM 530 AHP to RM 570 AHP: erosional trend

- RM 570 AHP to RM 592 AHP: relative stability trend

- RM 592 AHP to RM 180 Above Mouth of Ohio River: erosional trend.

\section{Points of Contact}

David S. Biedenharn

Author, ERDC-CHL

David.S.Biedenharn@usace.army.mil

Ty V. Wamsley, Ph.D.

MRG\&P Technical Director, USACE MVD

Ty.V.Wamsley@usace.army.mil

Freddie Pinkard

MRG\&P Sr. Program Manager, USACE MVK

Freddie.Pinkard@usace.army.mil 


\section{References}

Cleveland, W. S. 1979. "Robust Locally Weighted Regression and Smoothing Scatterplots." Journal of the American Statistical Association 74: 829-836.

Cleveland, W. S., and S. J. Devlin. 1988. "Locally Weighted Regression: An Approach to Regression Analysis by Local Fitting." Journal of American Statistical Association 83(403): 596-610.

Tukey, John W. 1977. Exploratory Data Analysis. Reading, MA: Addison-Wesley. 


\section{Appendix A: Box Plots of Cross-sectional Area for Crossing Sections, RM 325 to RM 954}




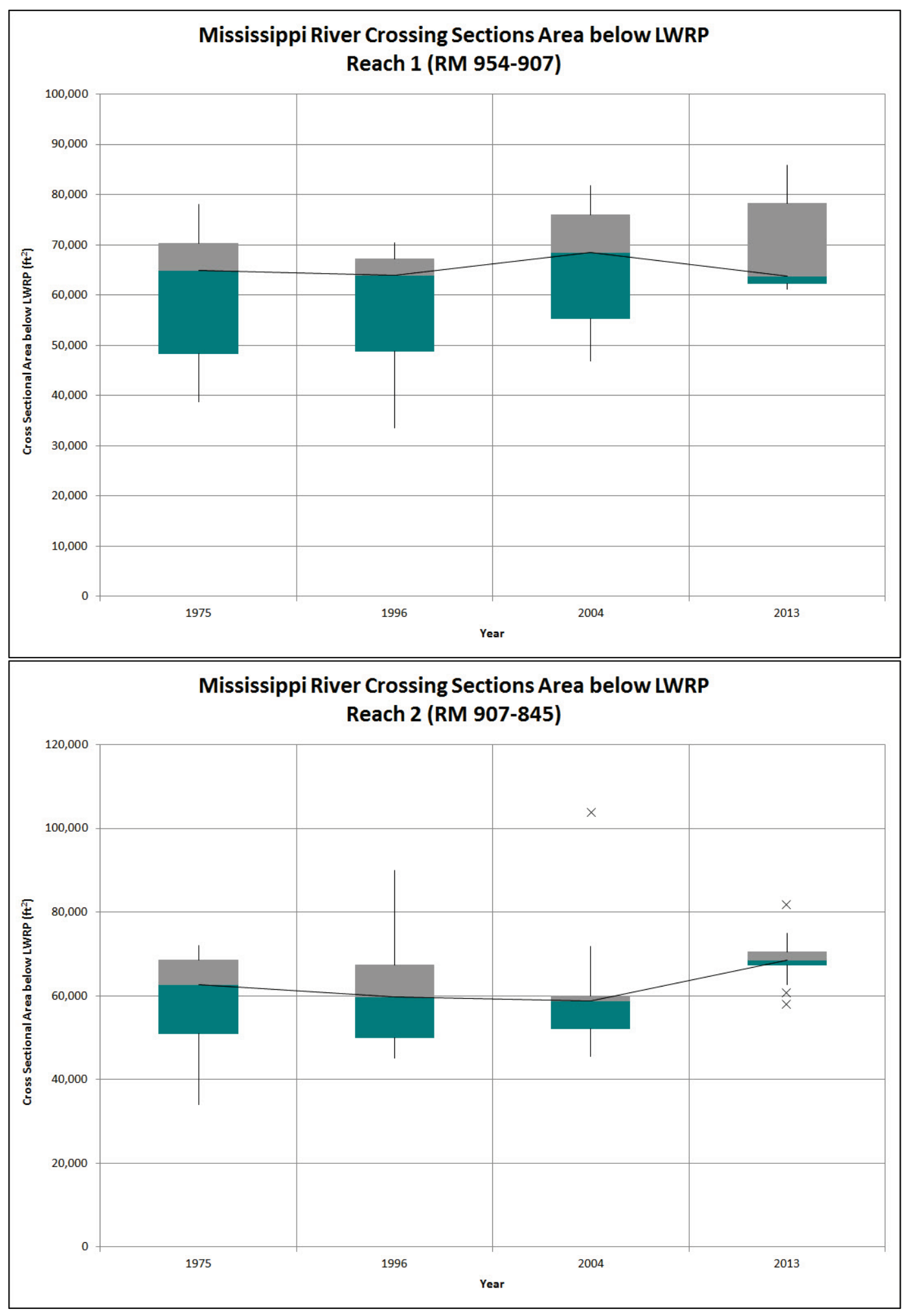




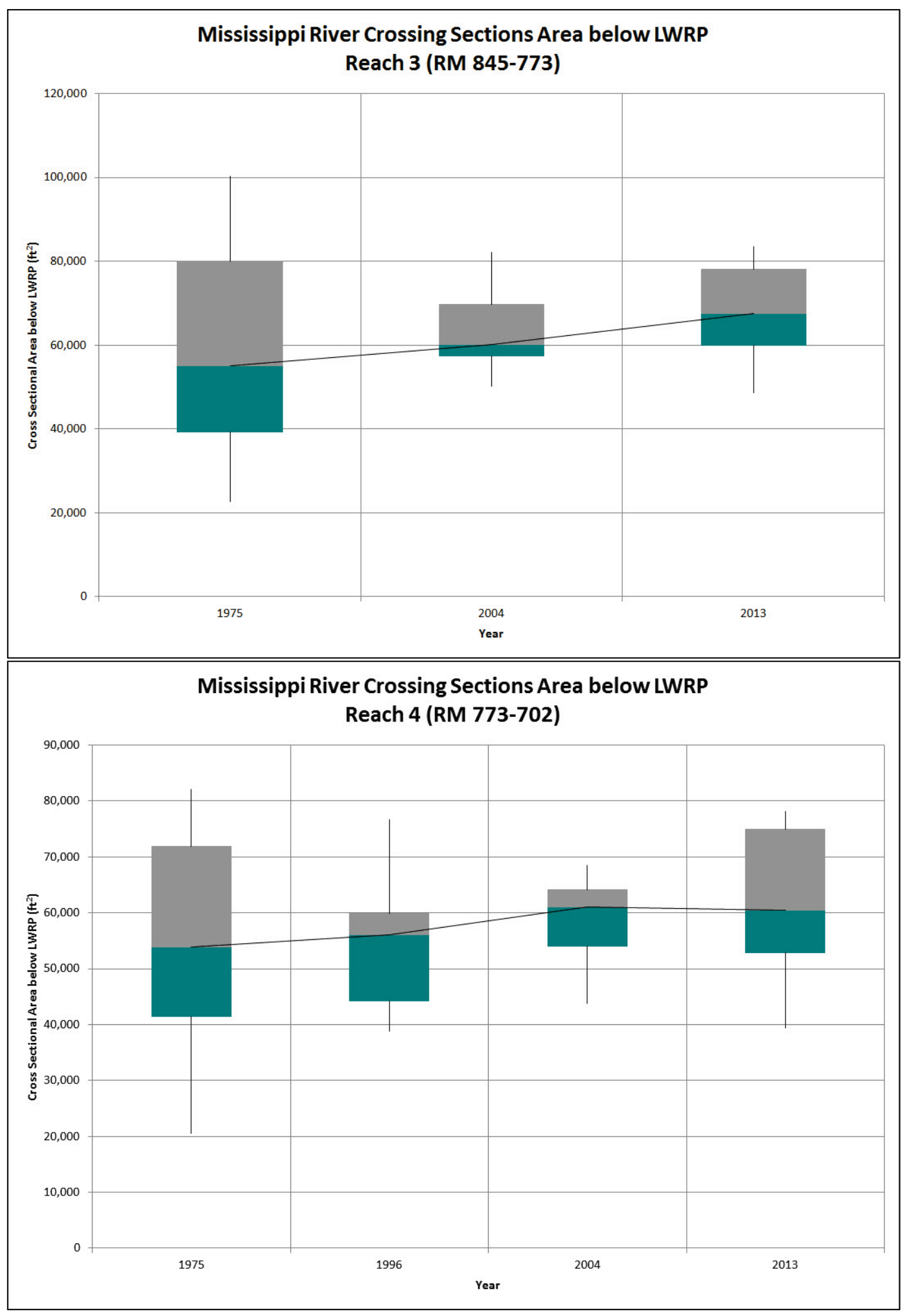




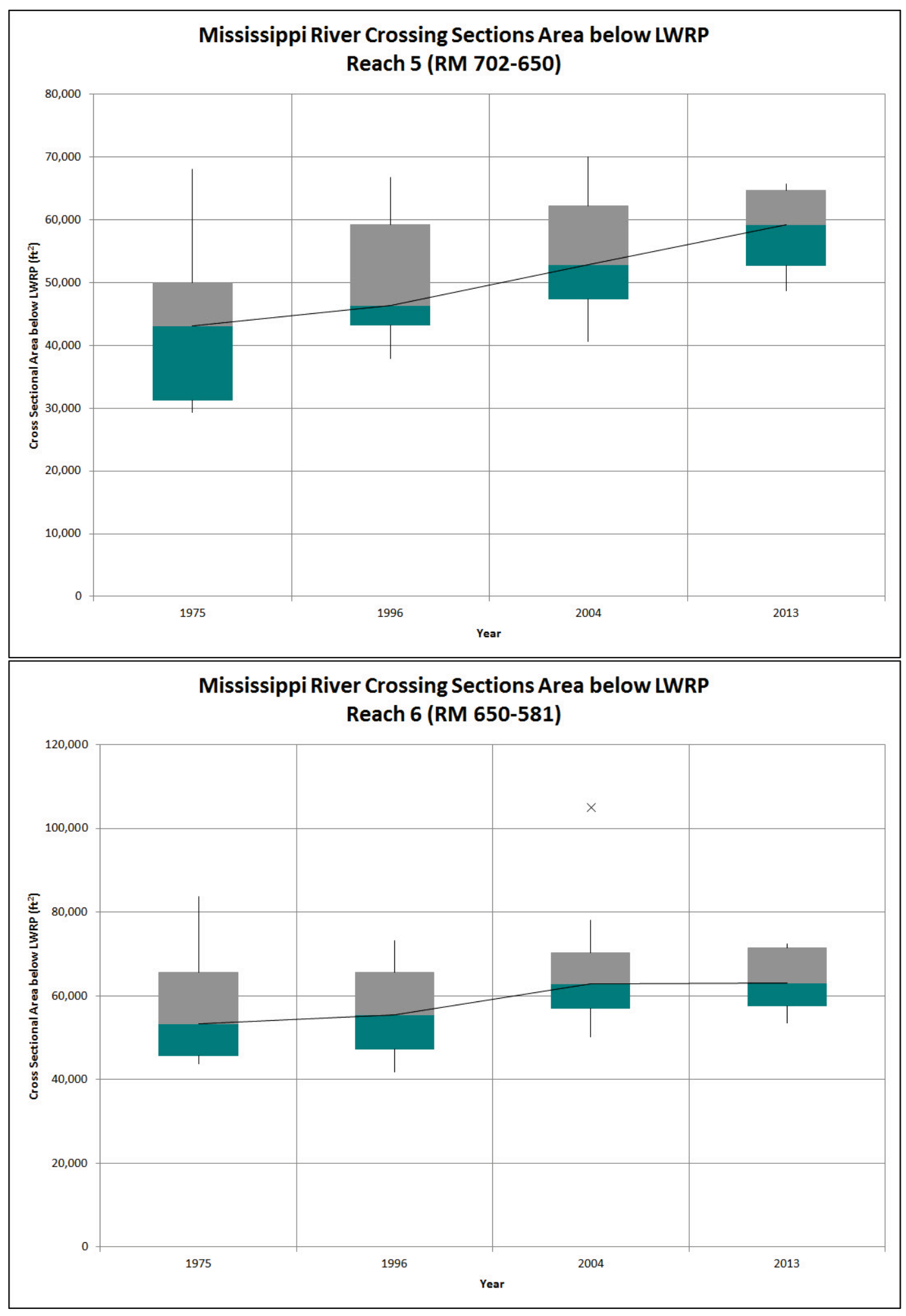




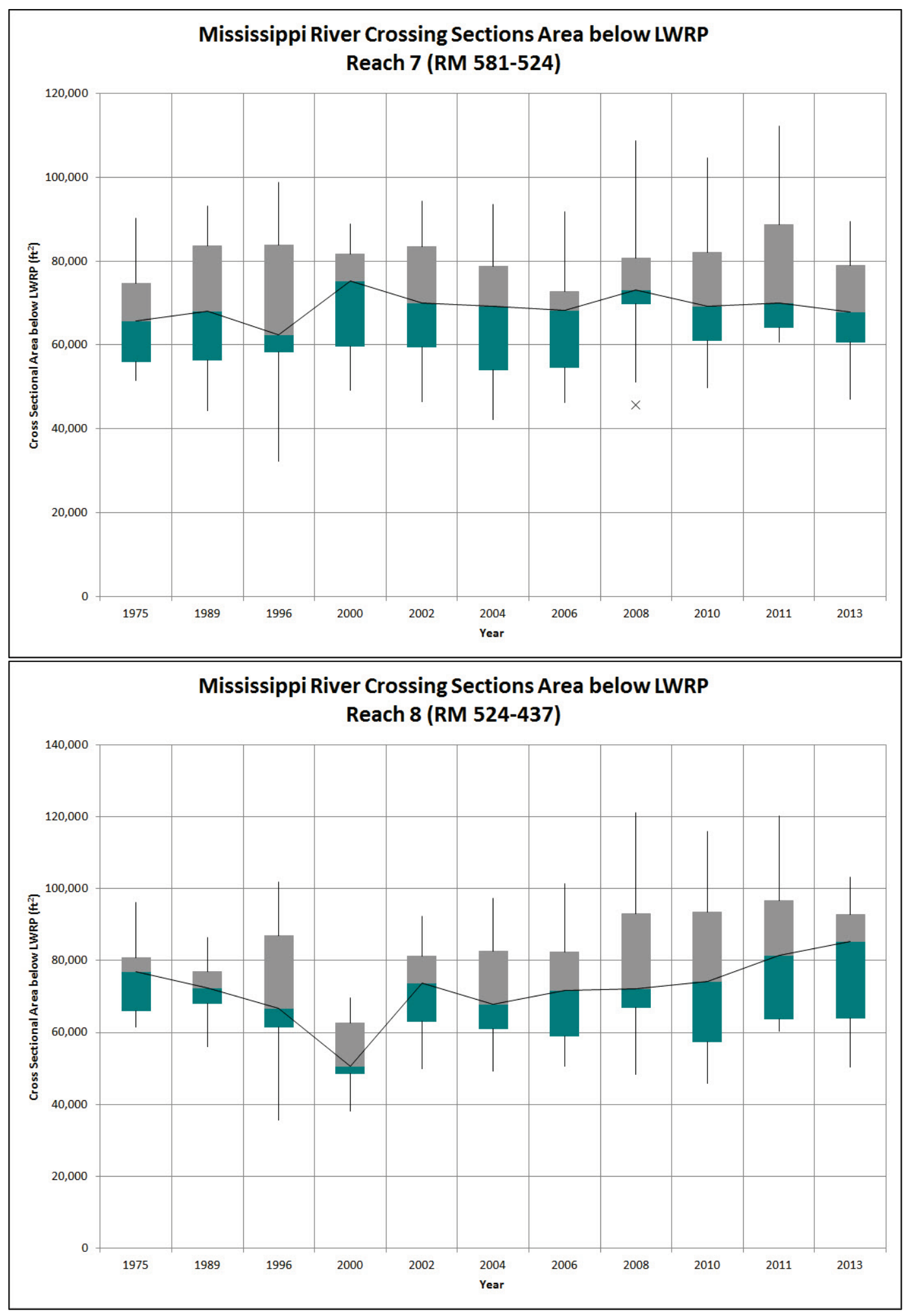




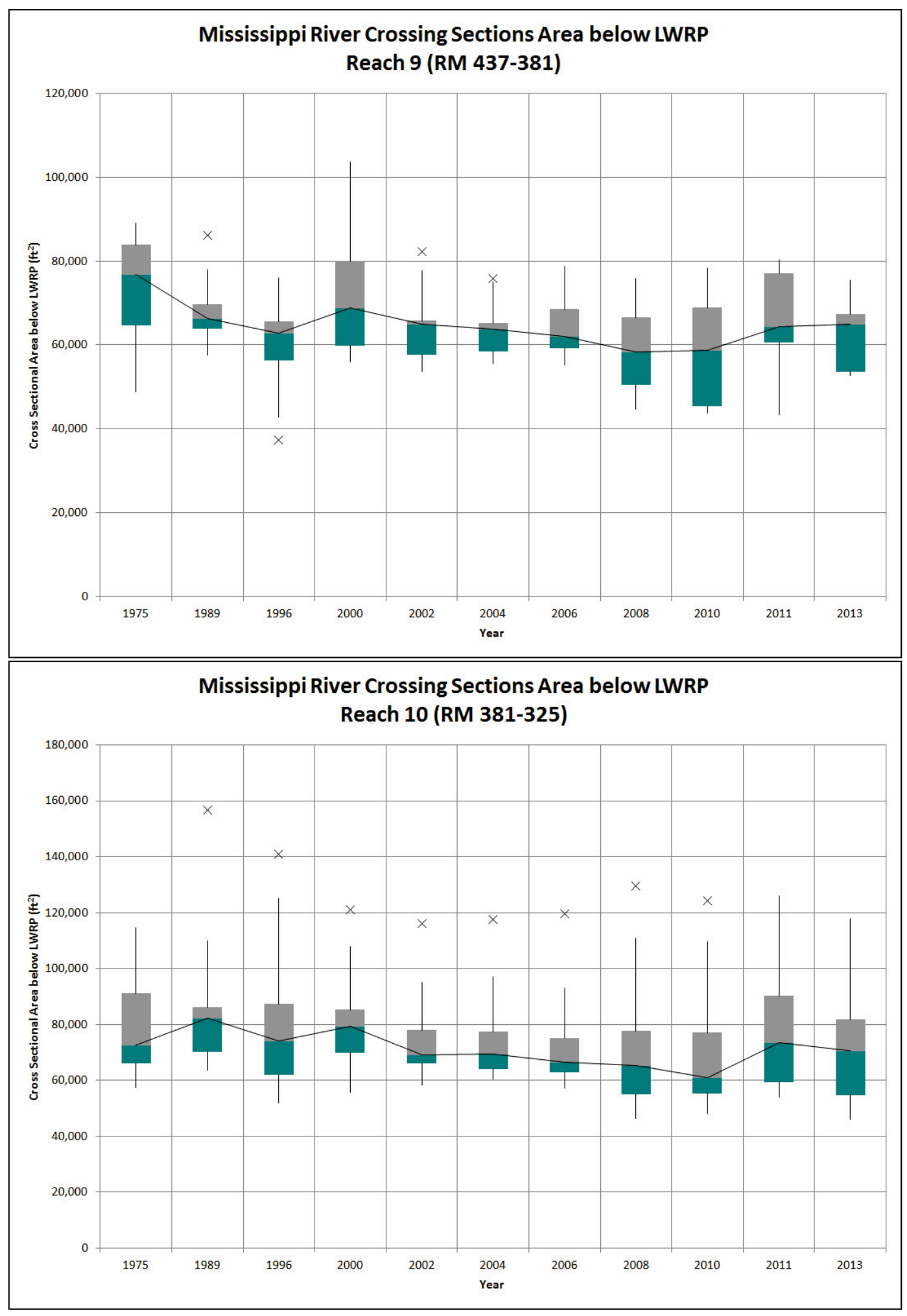




\section{Appendix B: Box Plots of Channel Width for Crossing Sections, RM 325 to RM 954}



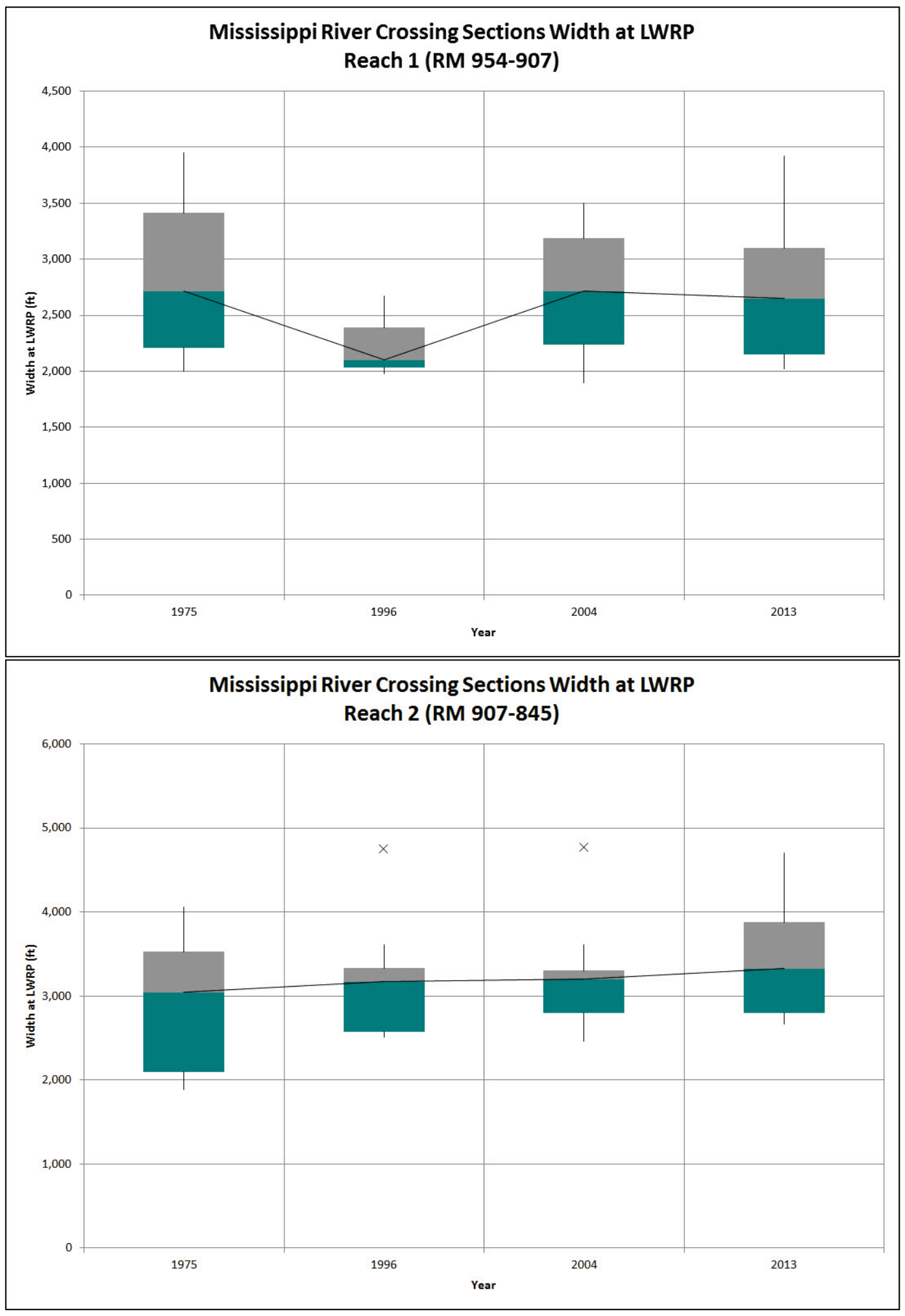


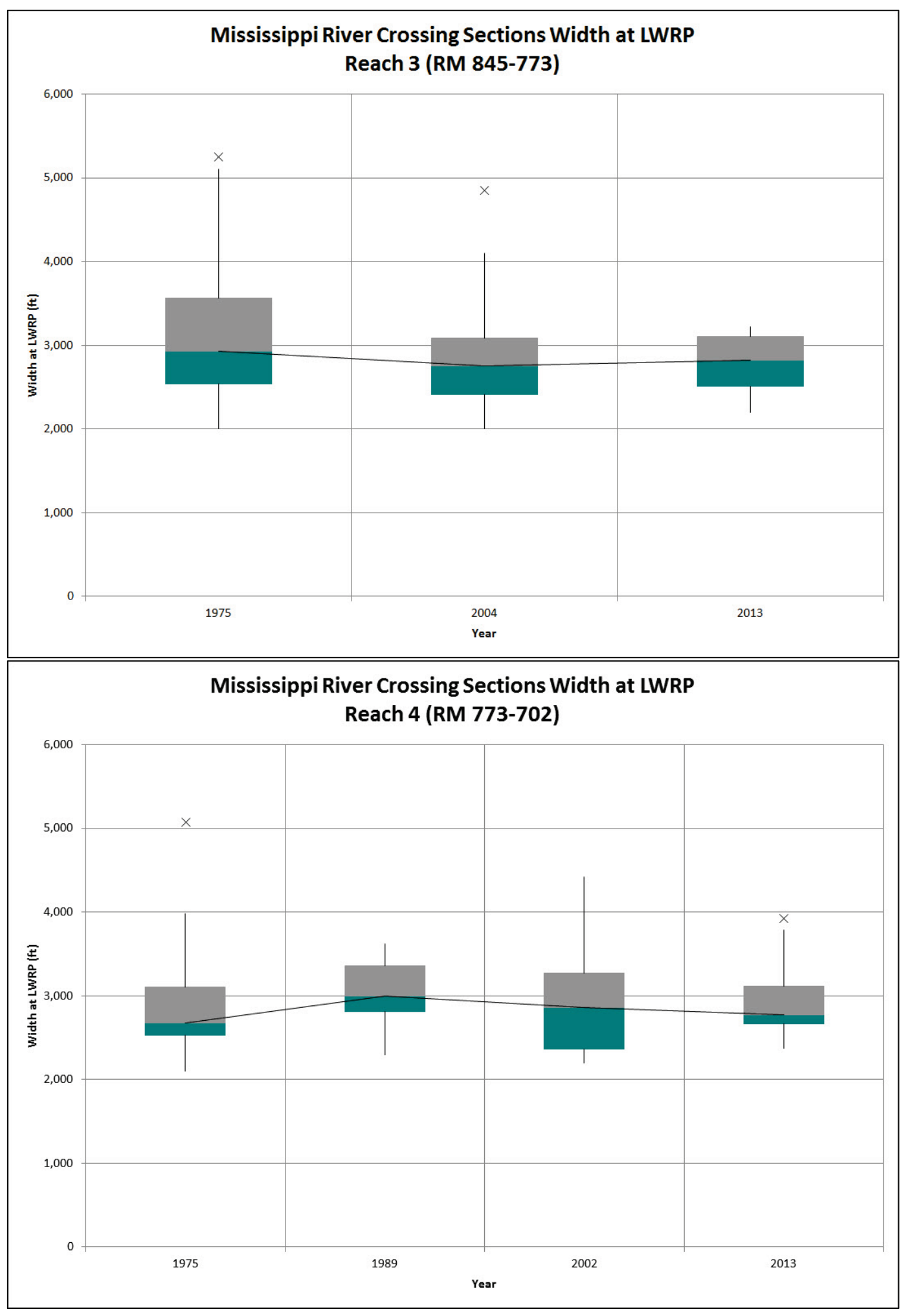




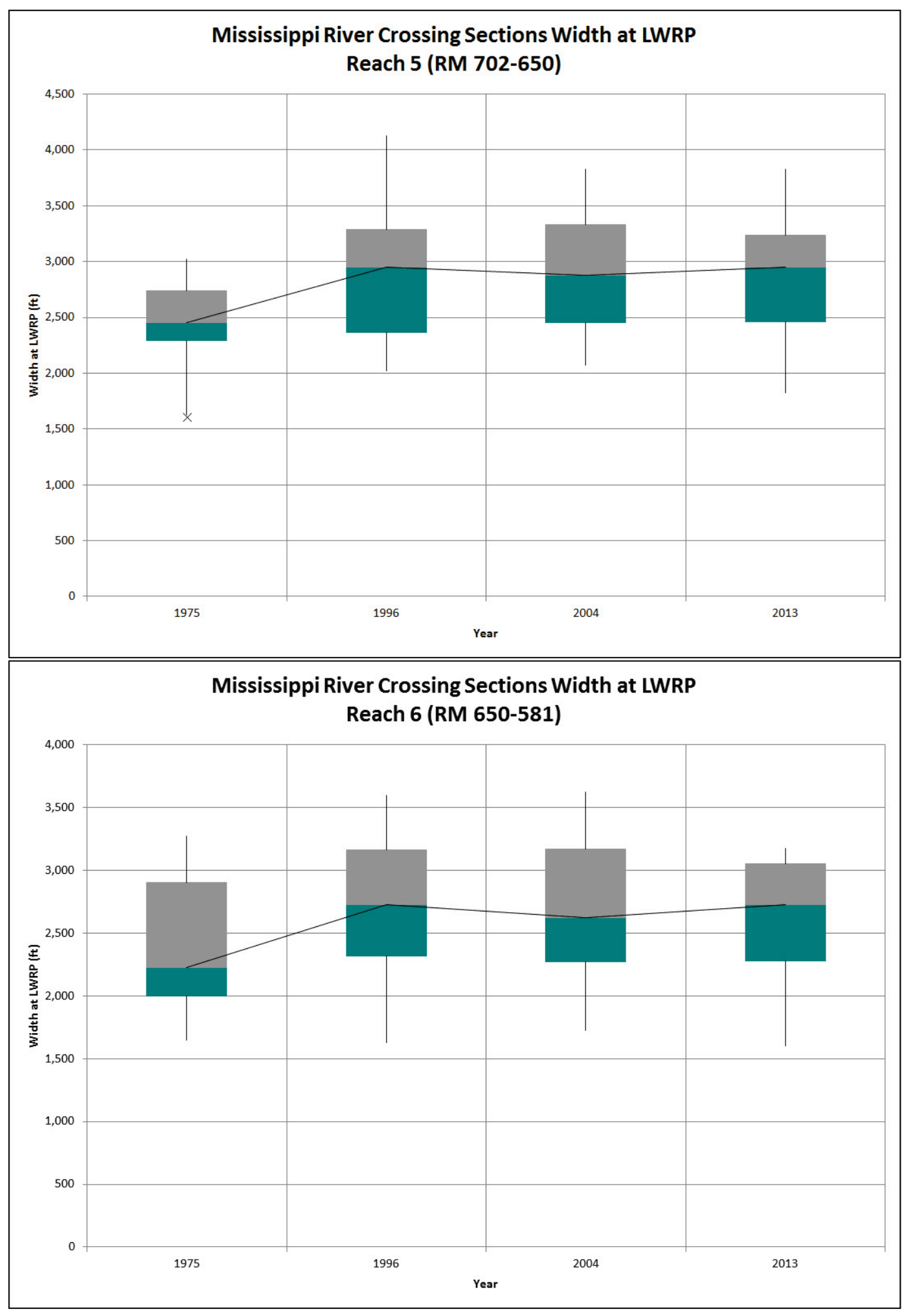




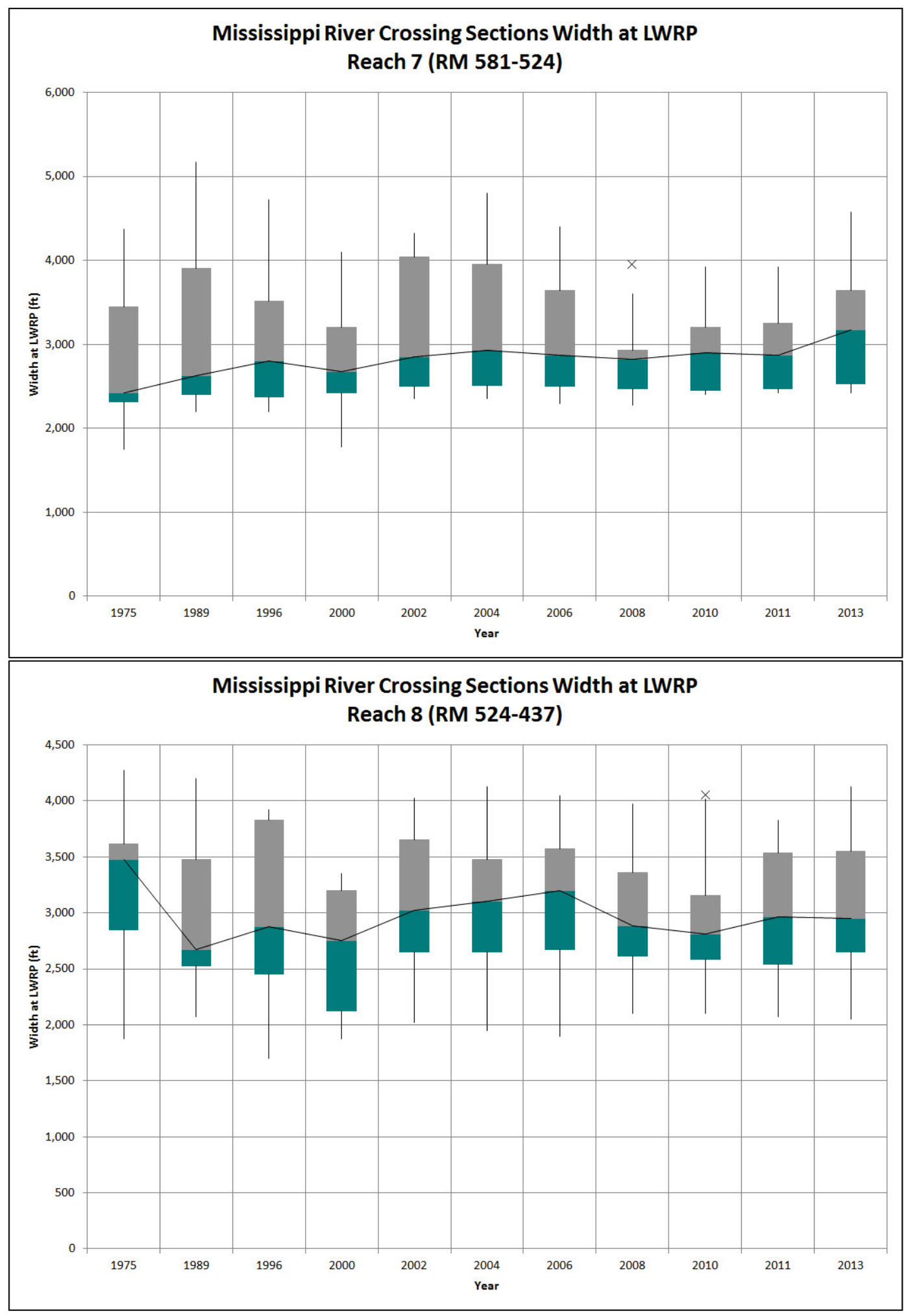




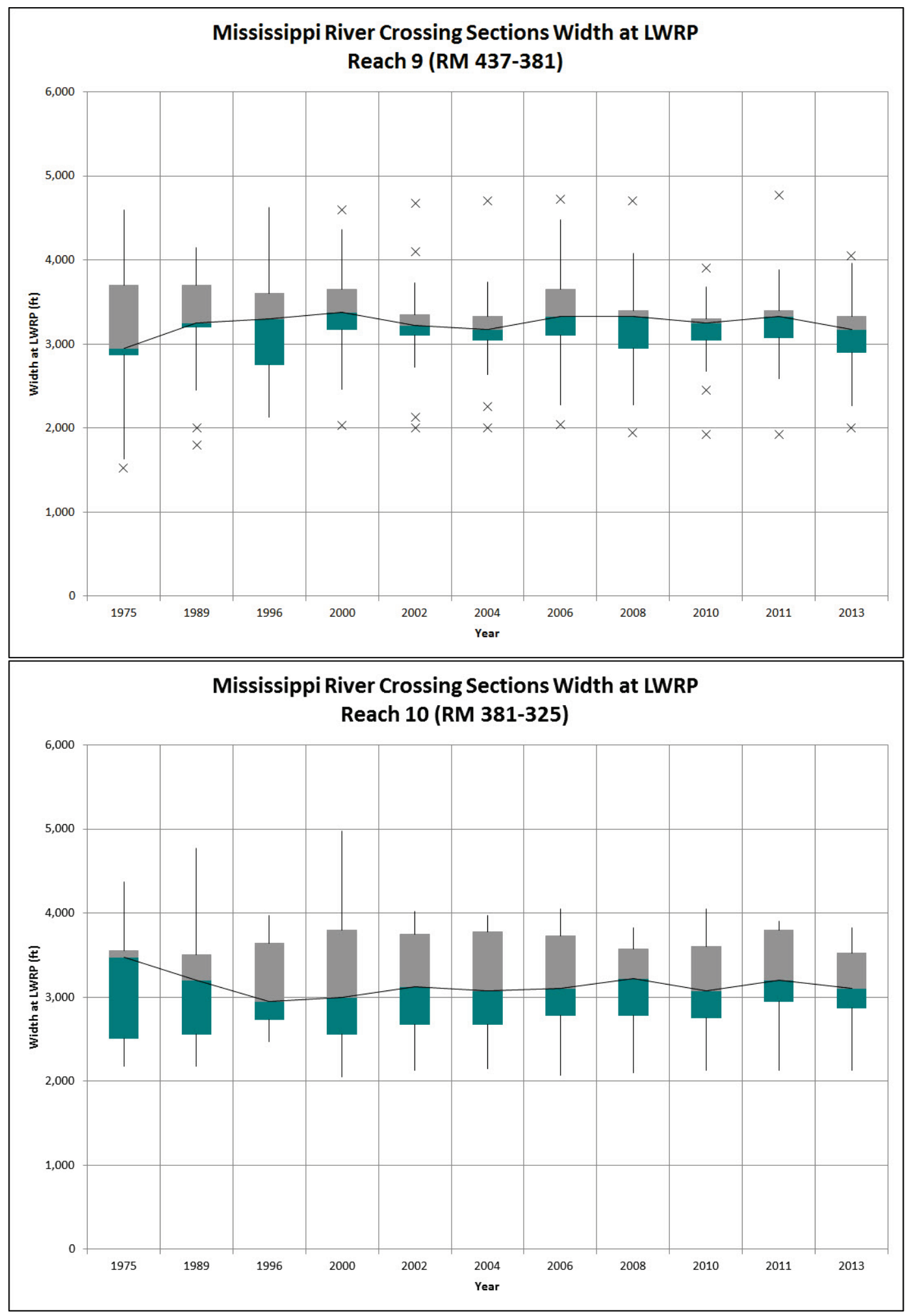




\section{Appendix C: Box Plots of Hydraulic Depth for Crossing Sections, RM 325 to RM 954}




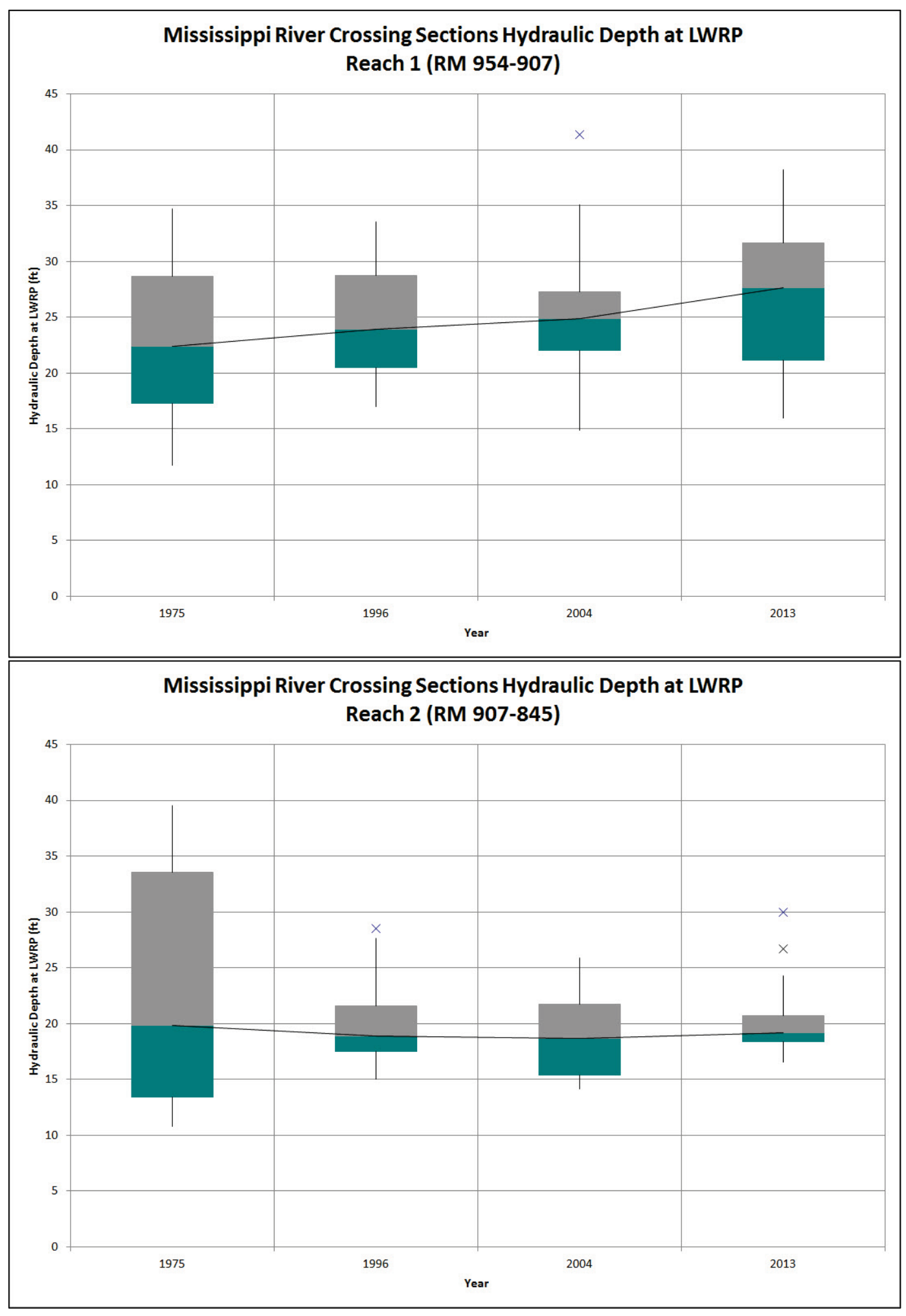




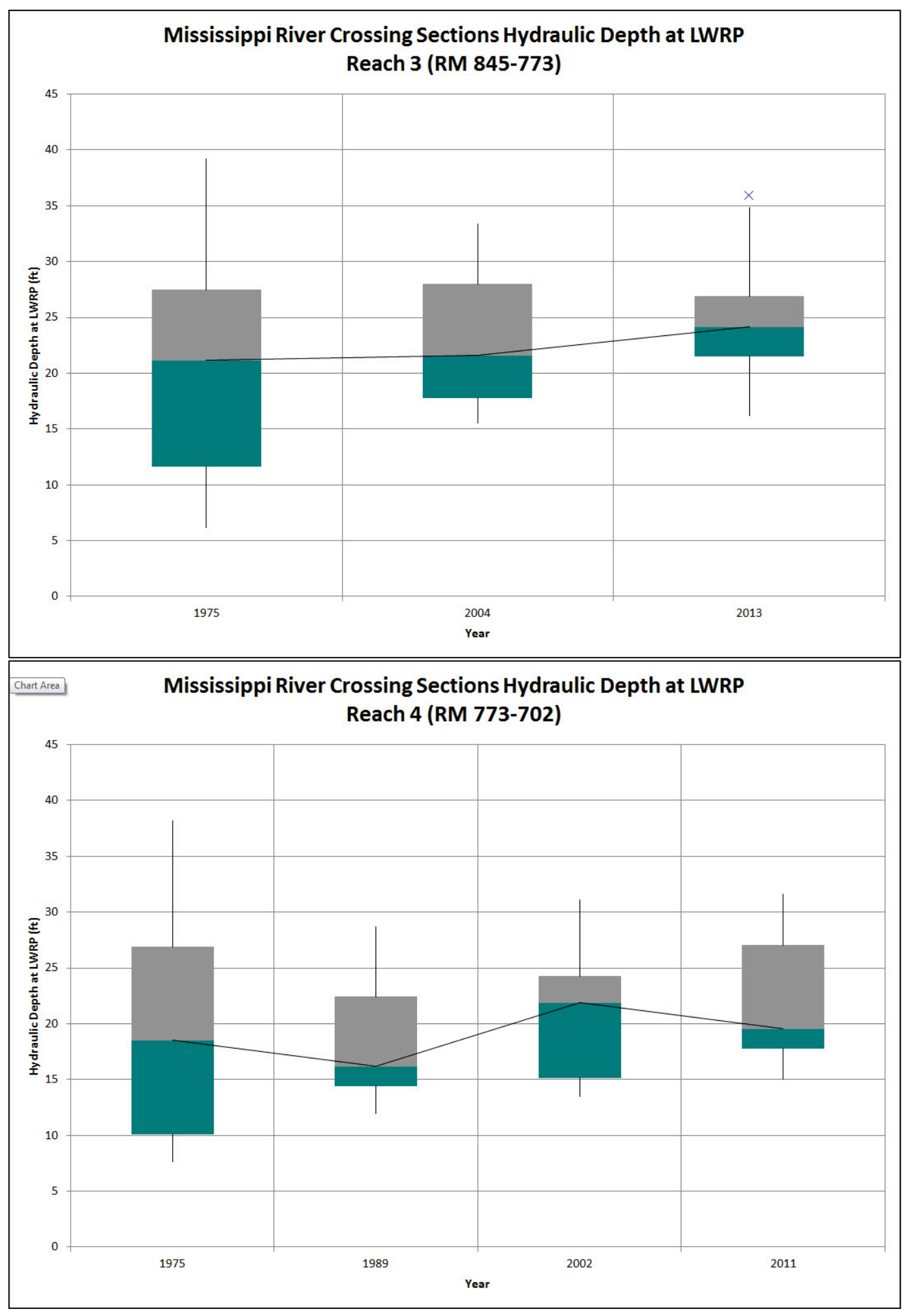




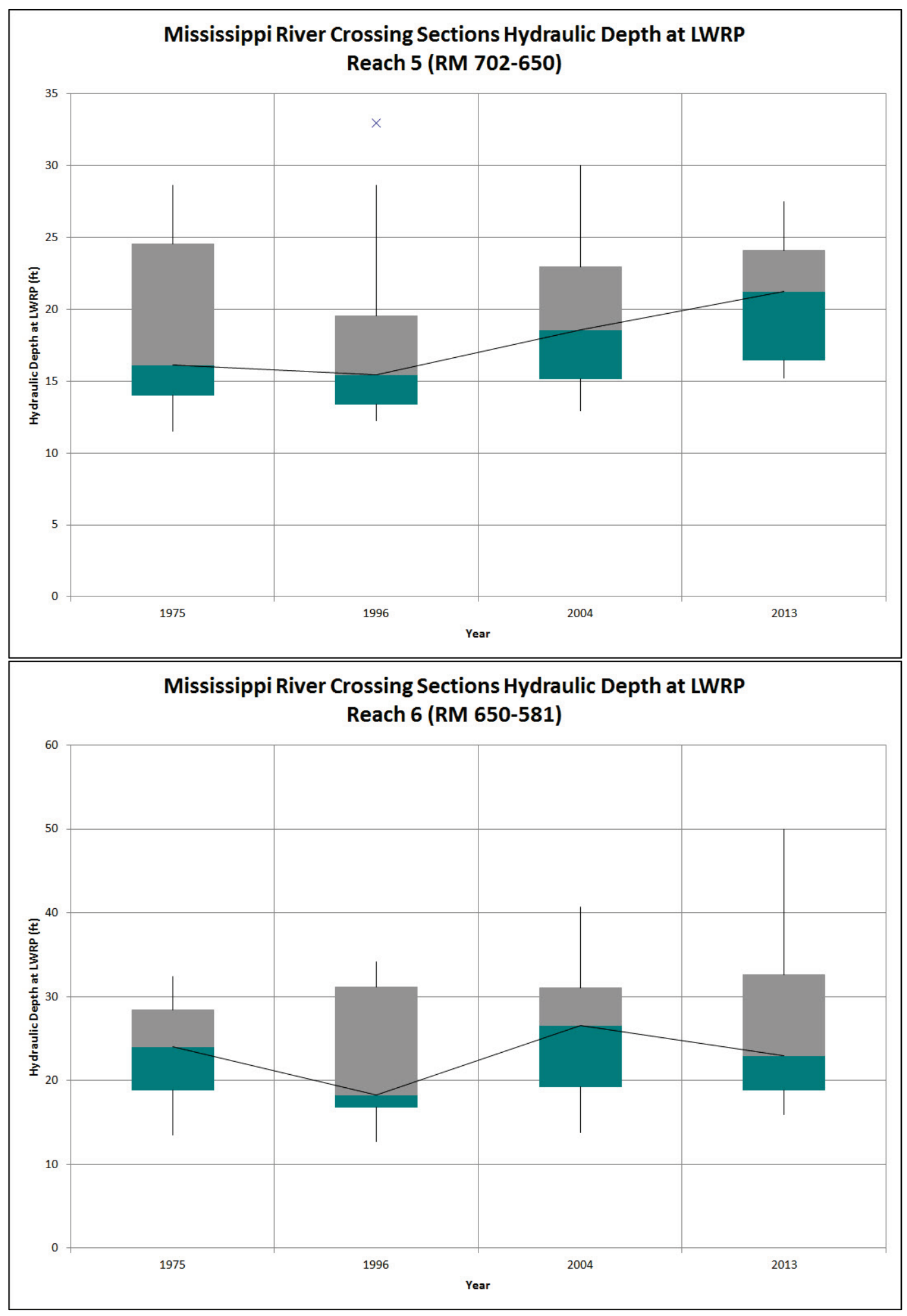




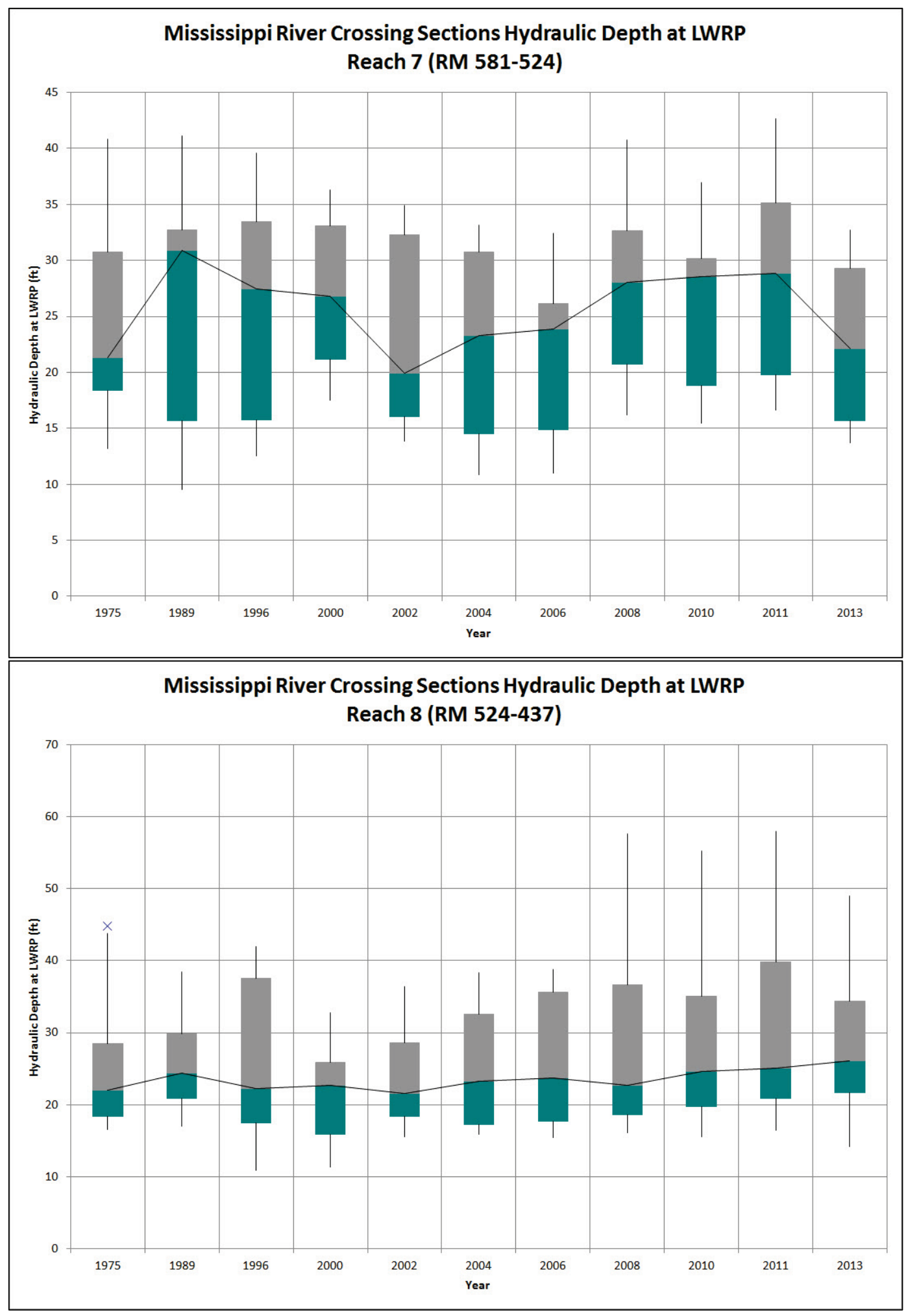




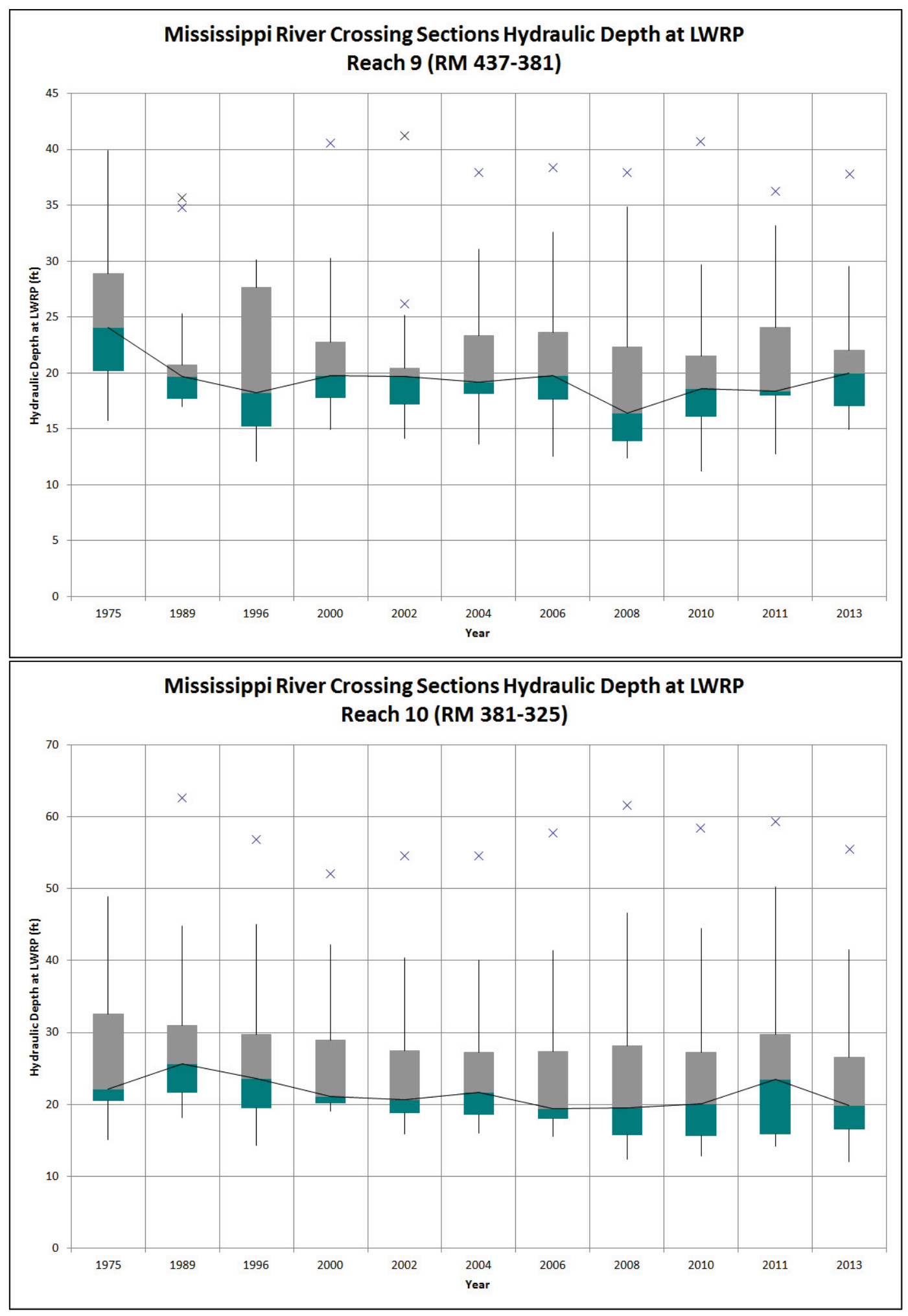




\section{Appendix D: Box Plots of Channel Conveyance for Crossing Sections, RM 325 to RM 954}




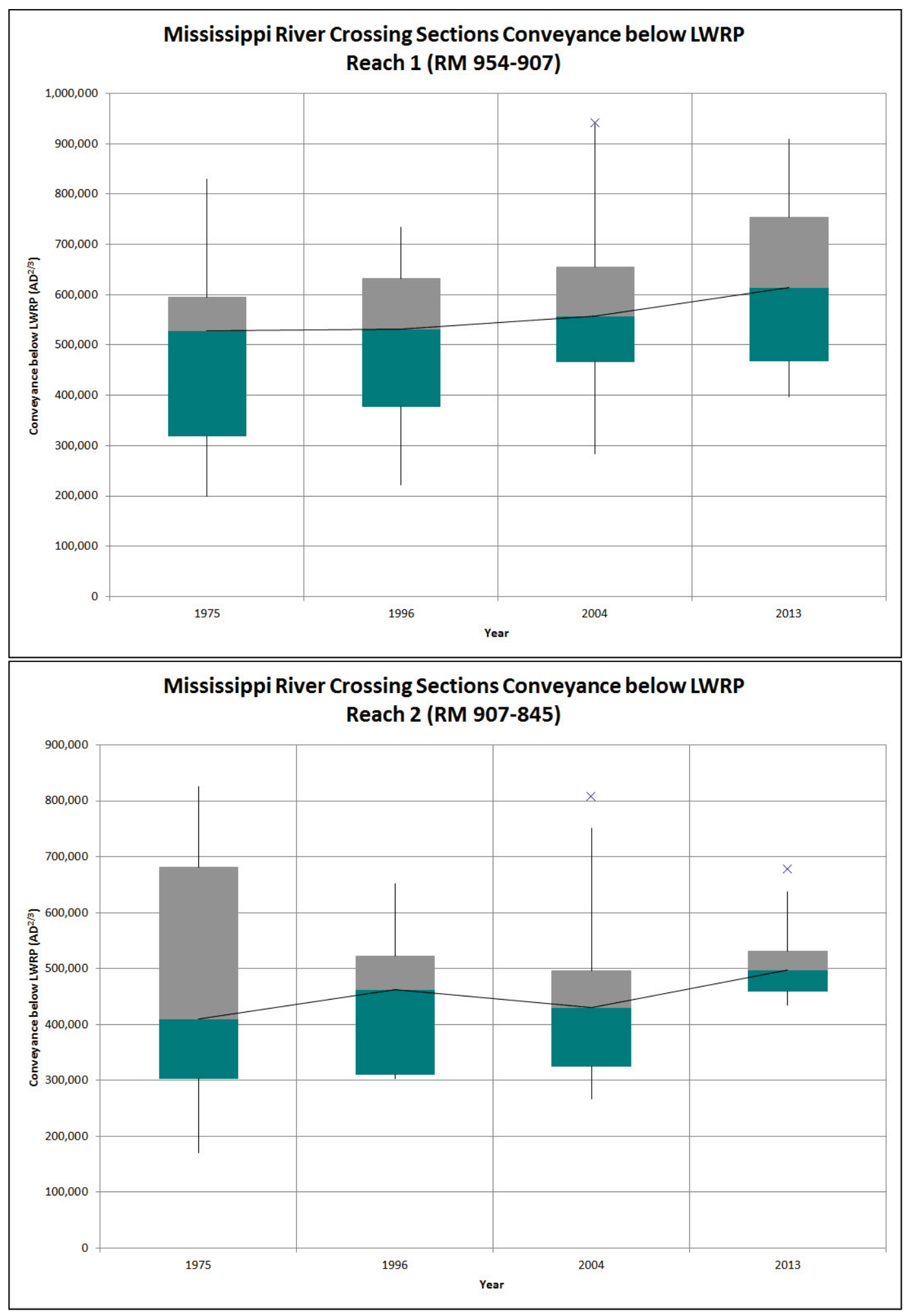




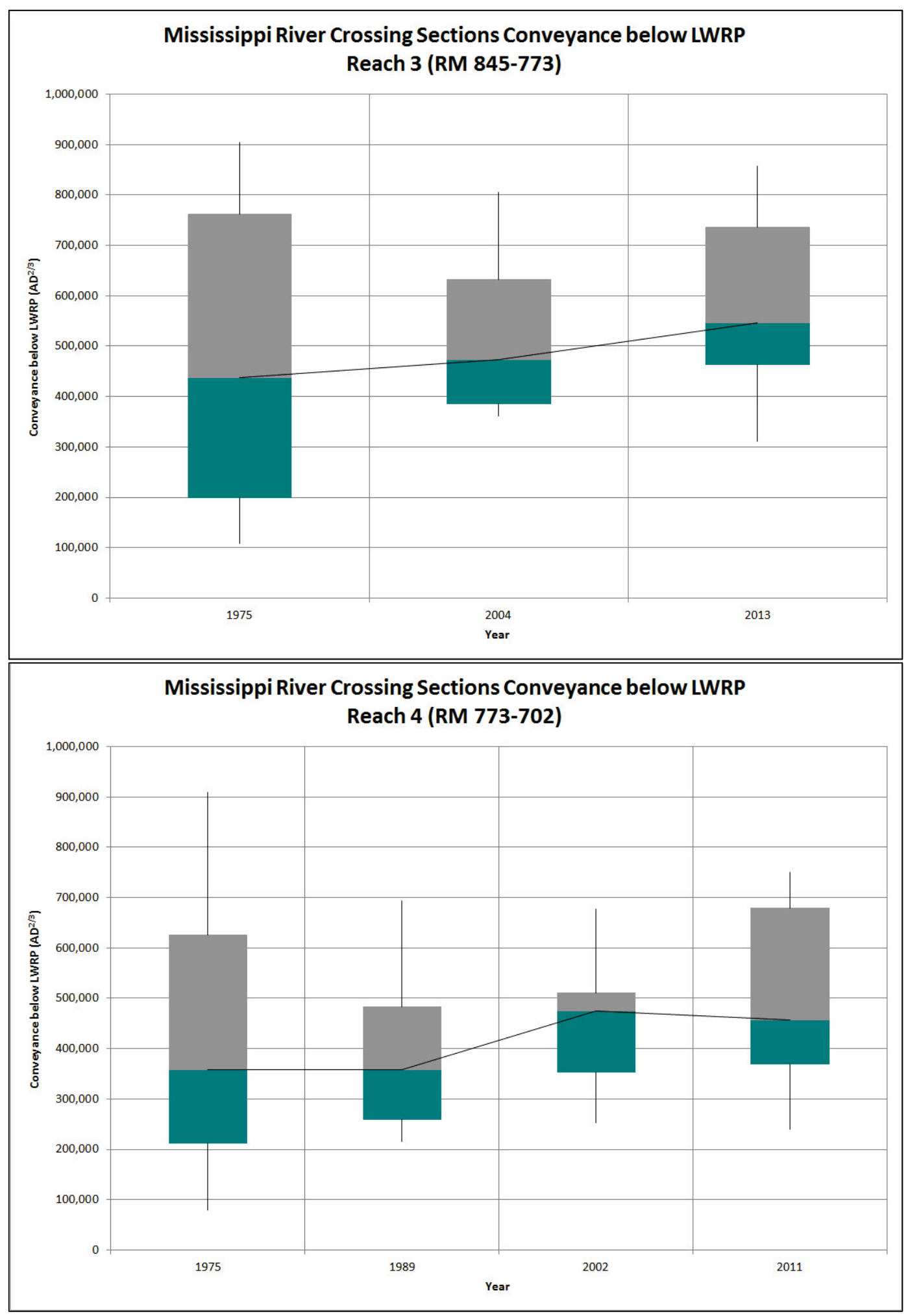




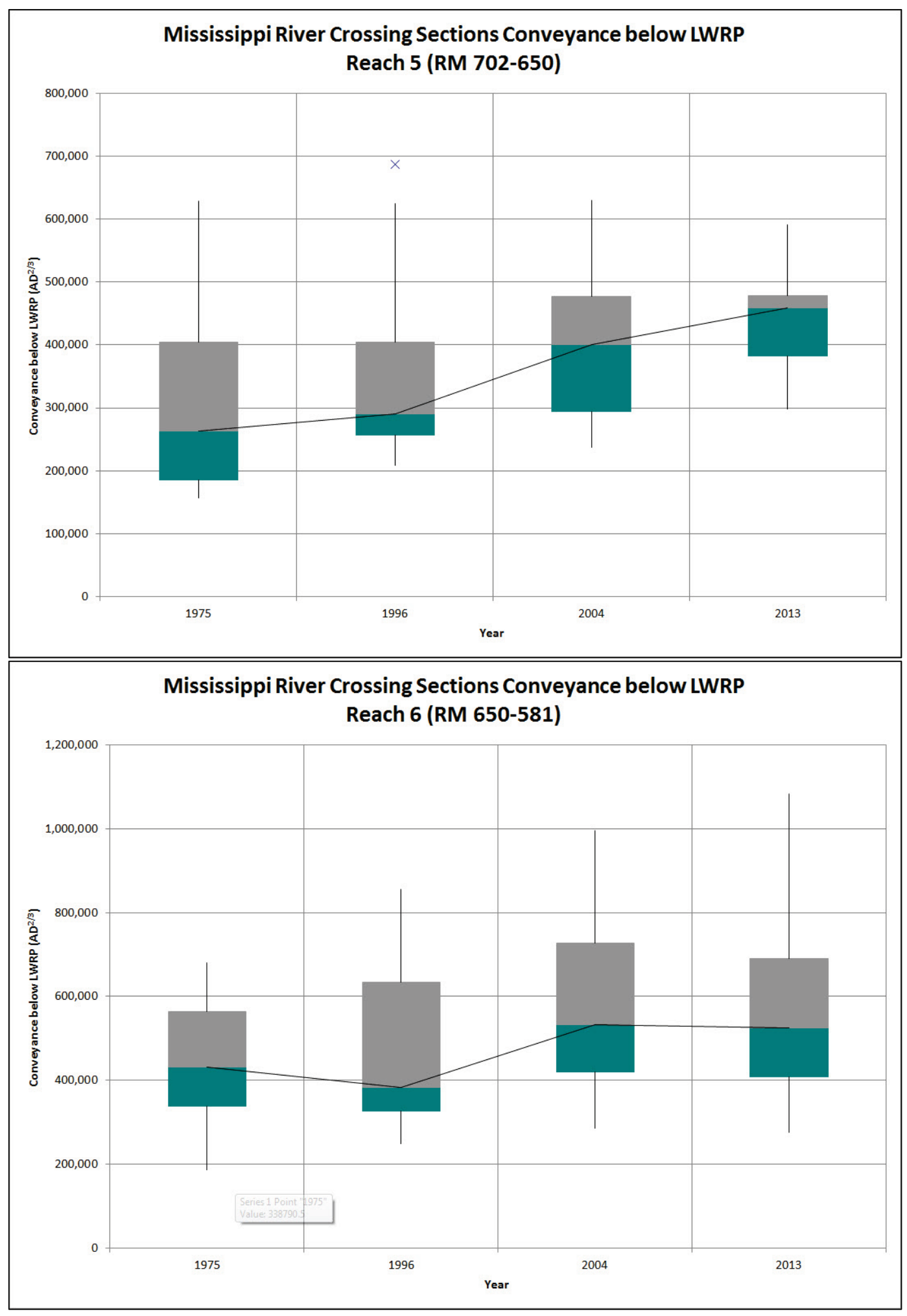




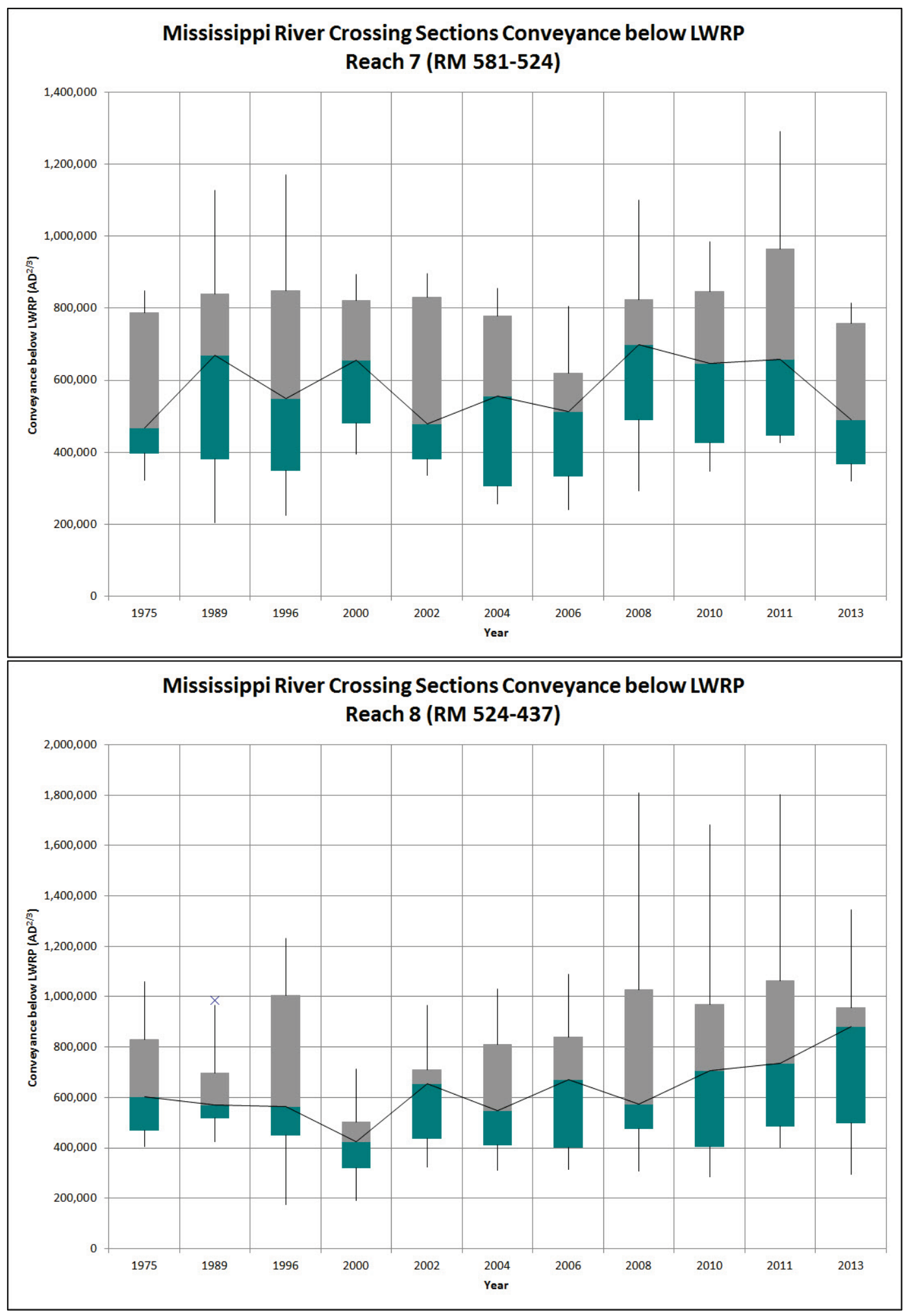




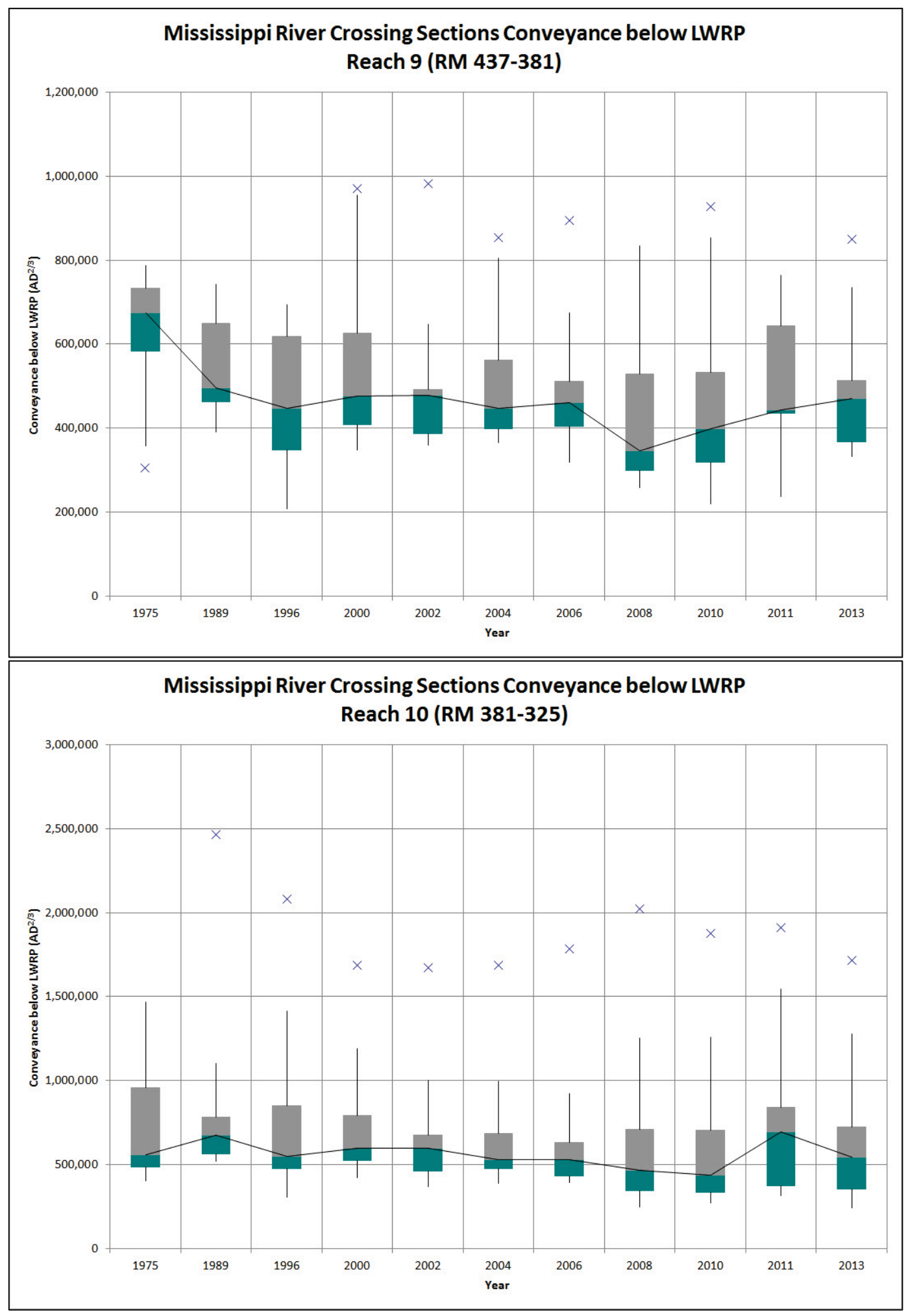




\section{Appendix E: Box Plots of Cross-sectional Area for Pool Sections, RM 325 to RM 954}



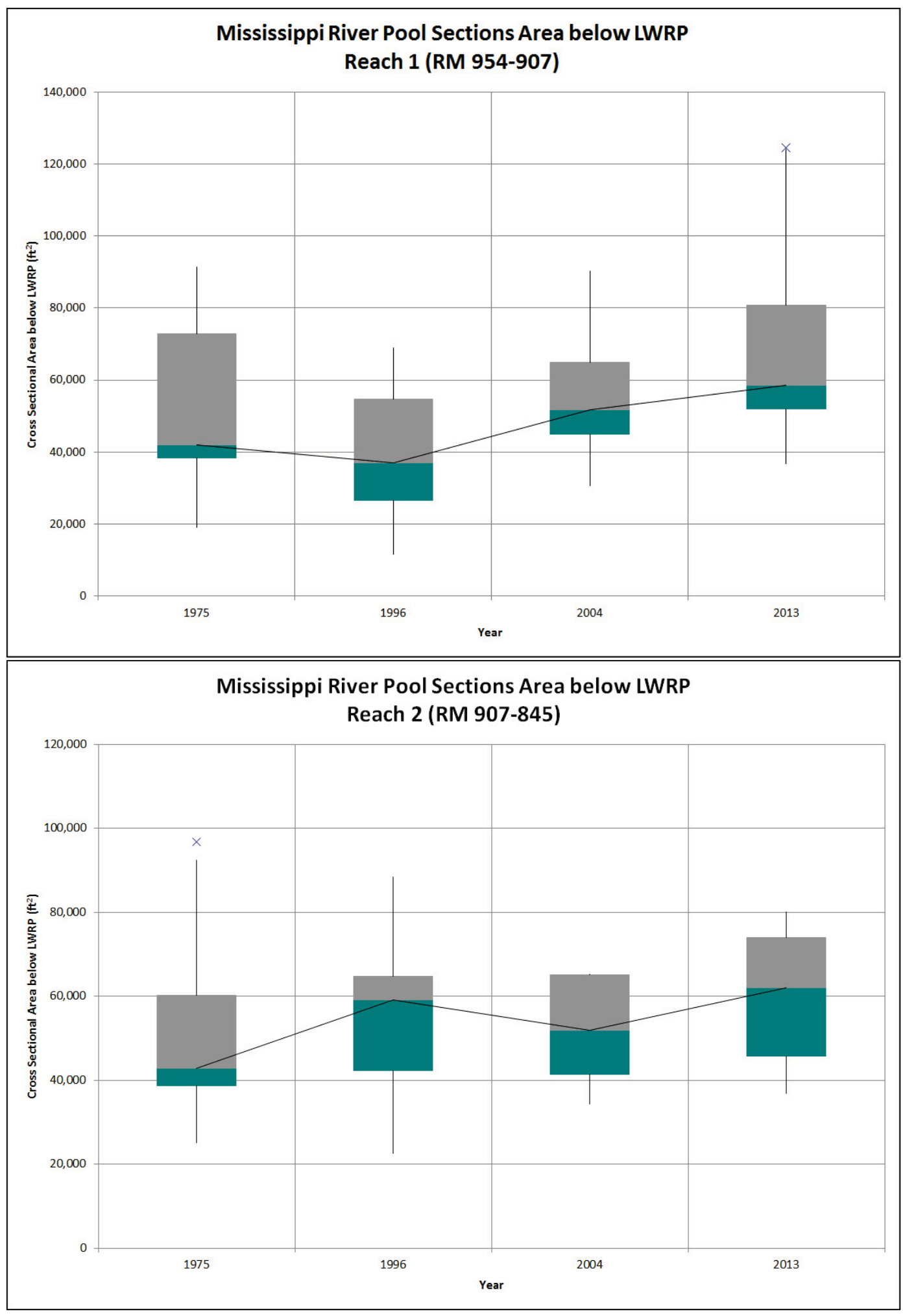


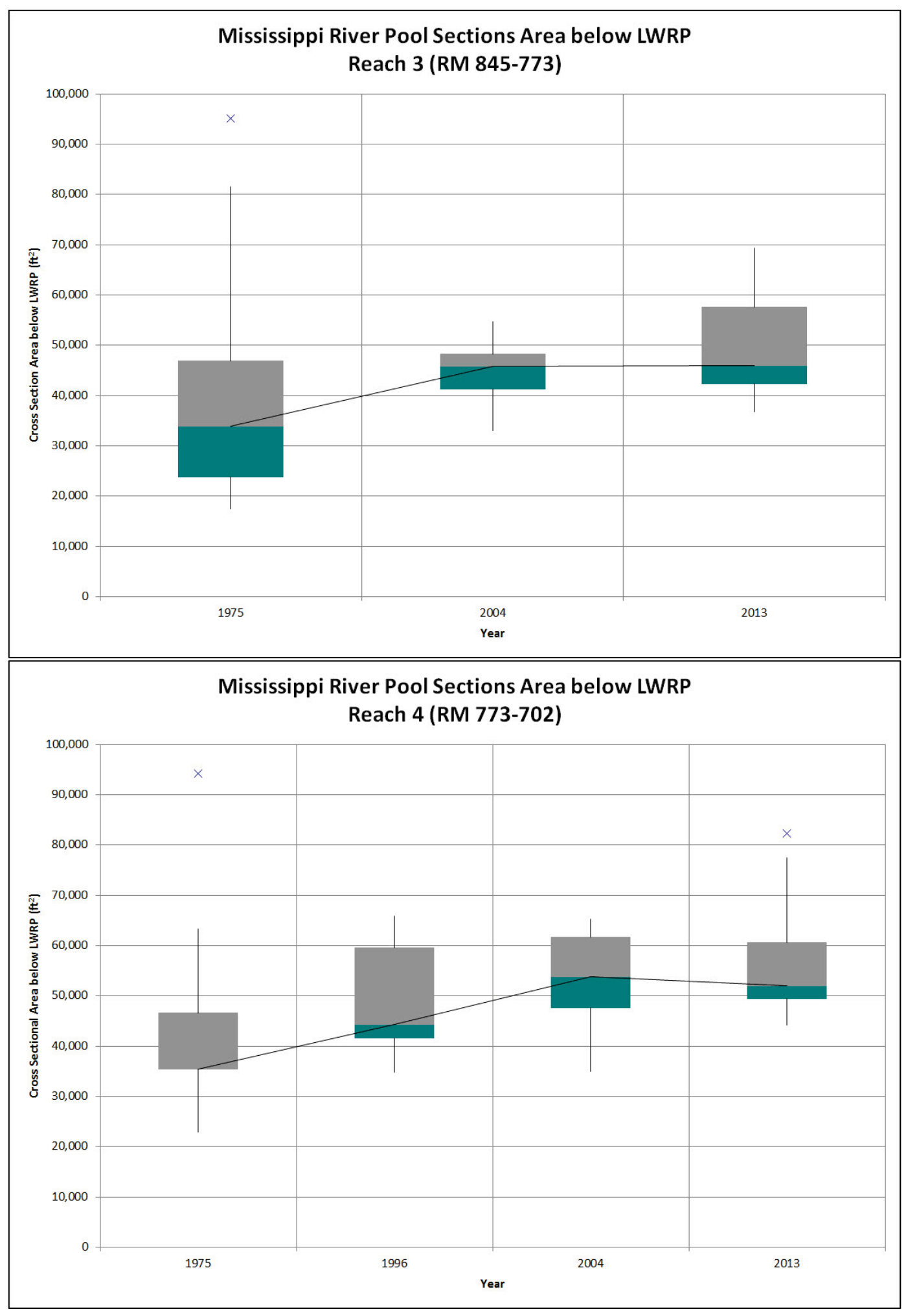




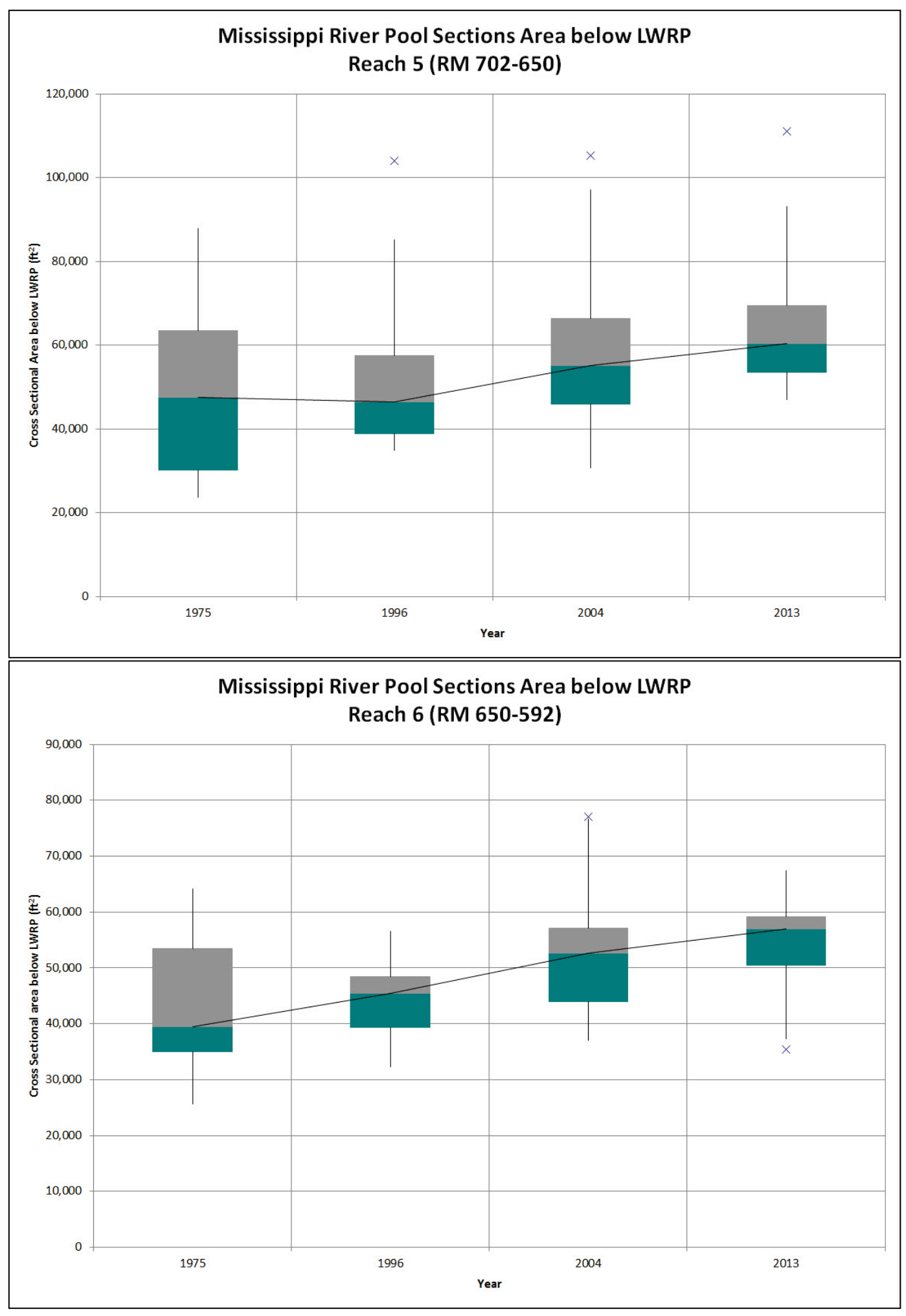




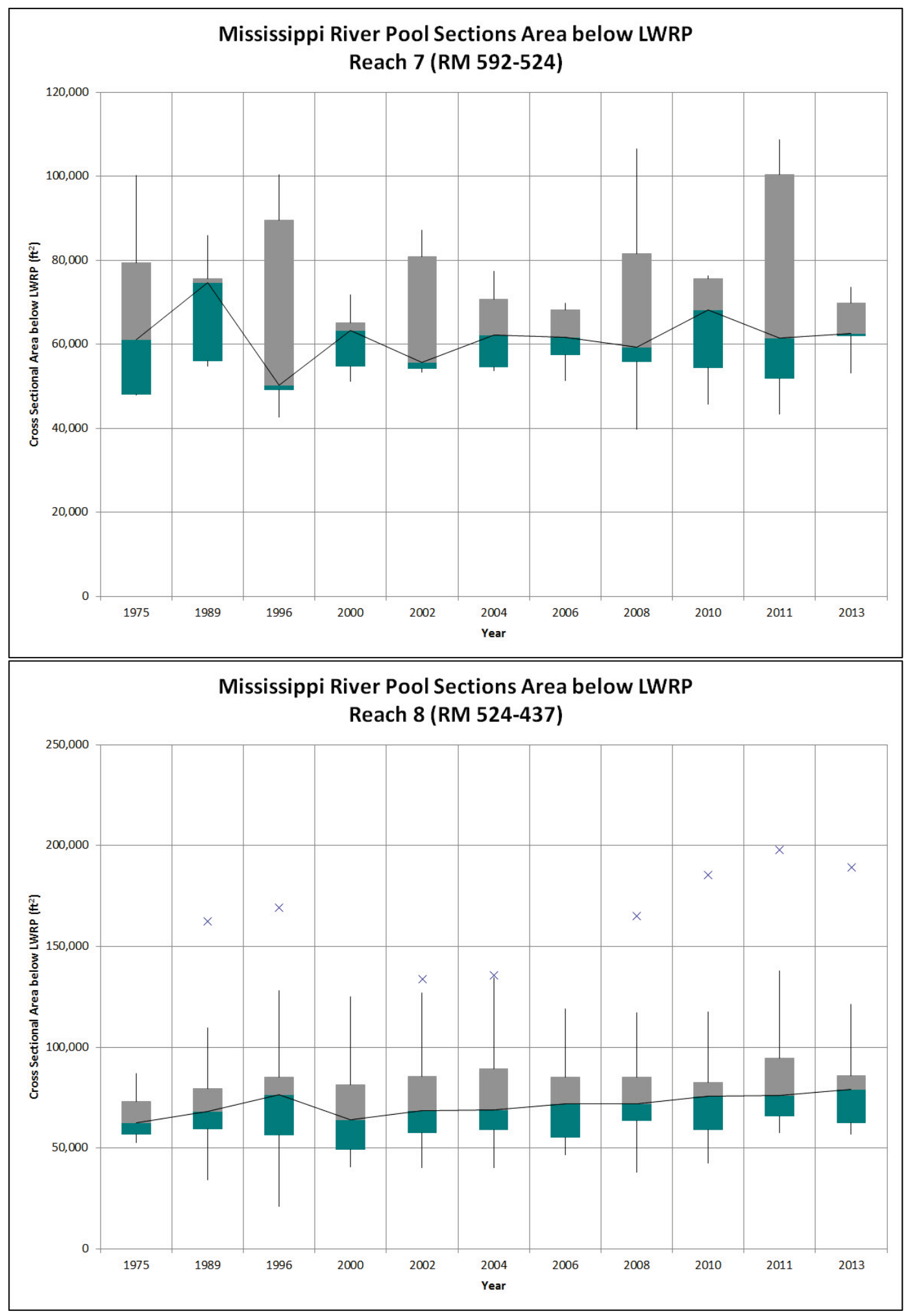




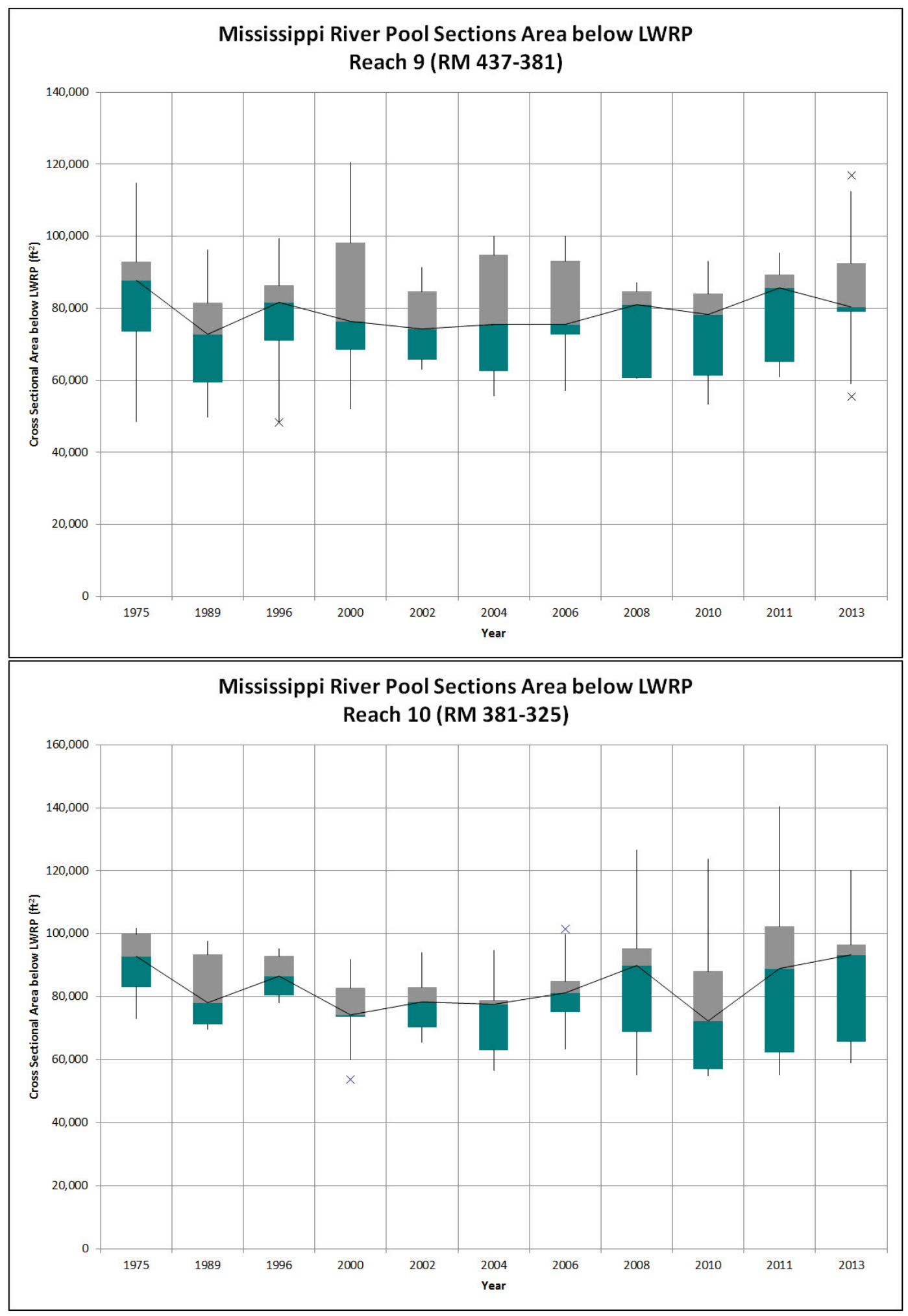




\section{Appendix F: Box Plots of Channel Width for Pool Sections, RM 325 to RM 954}




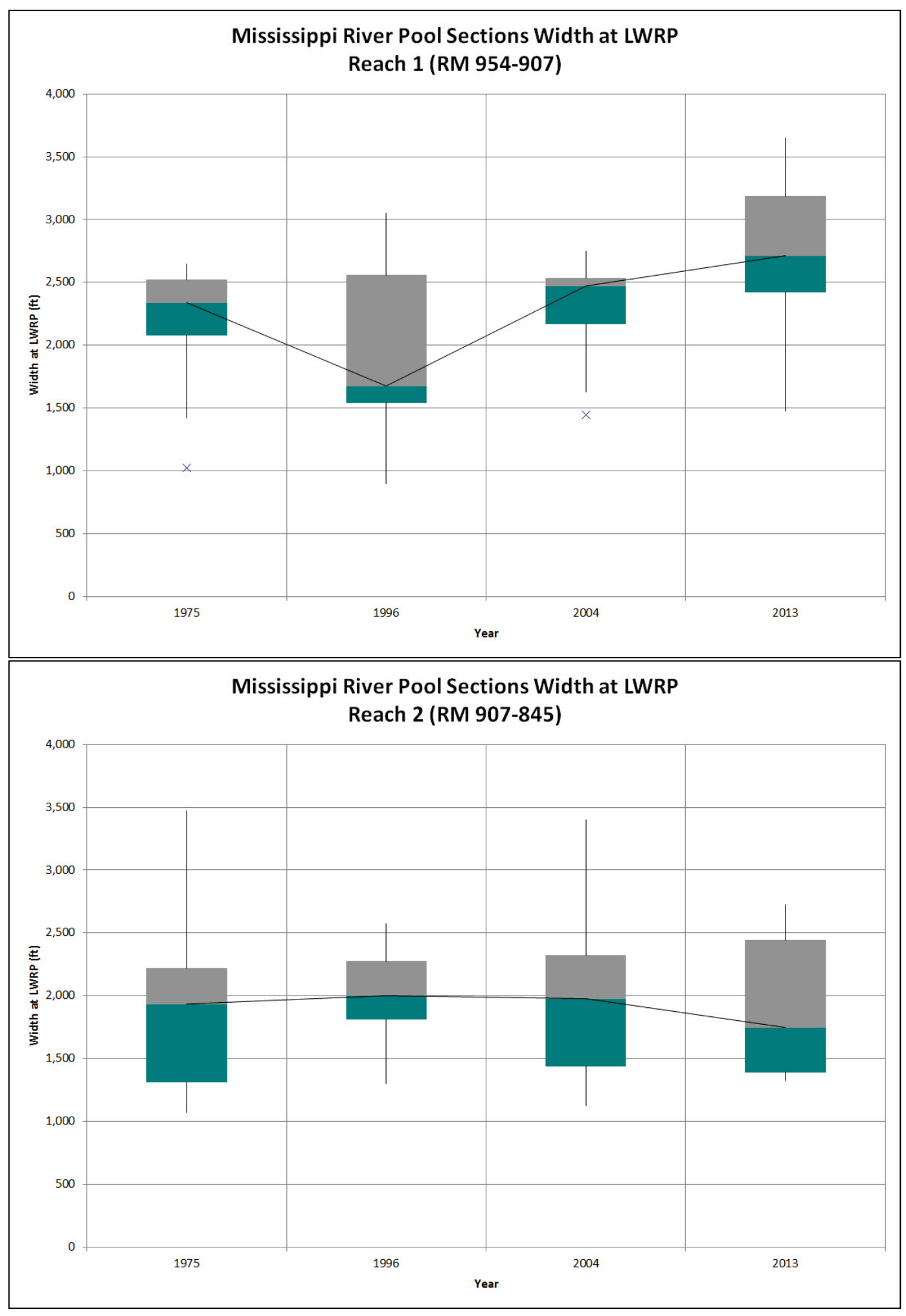




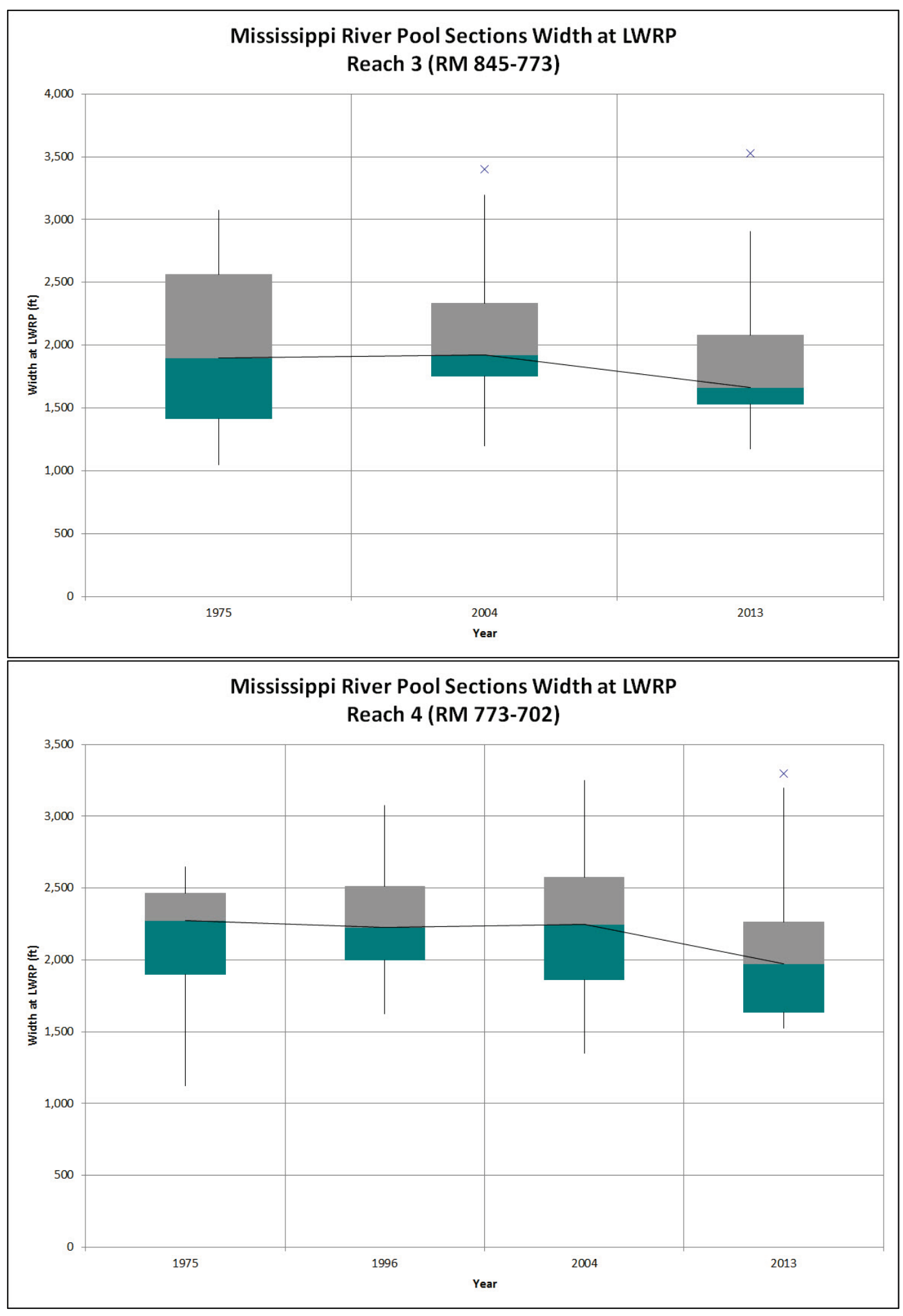




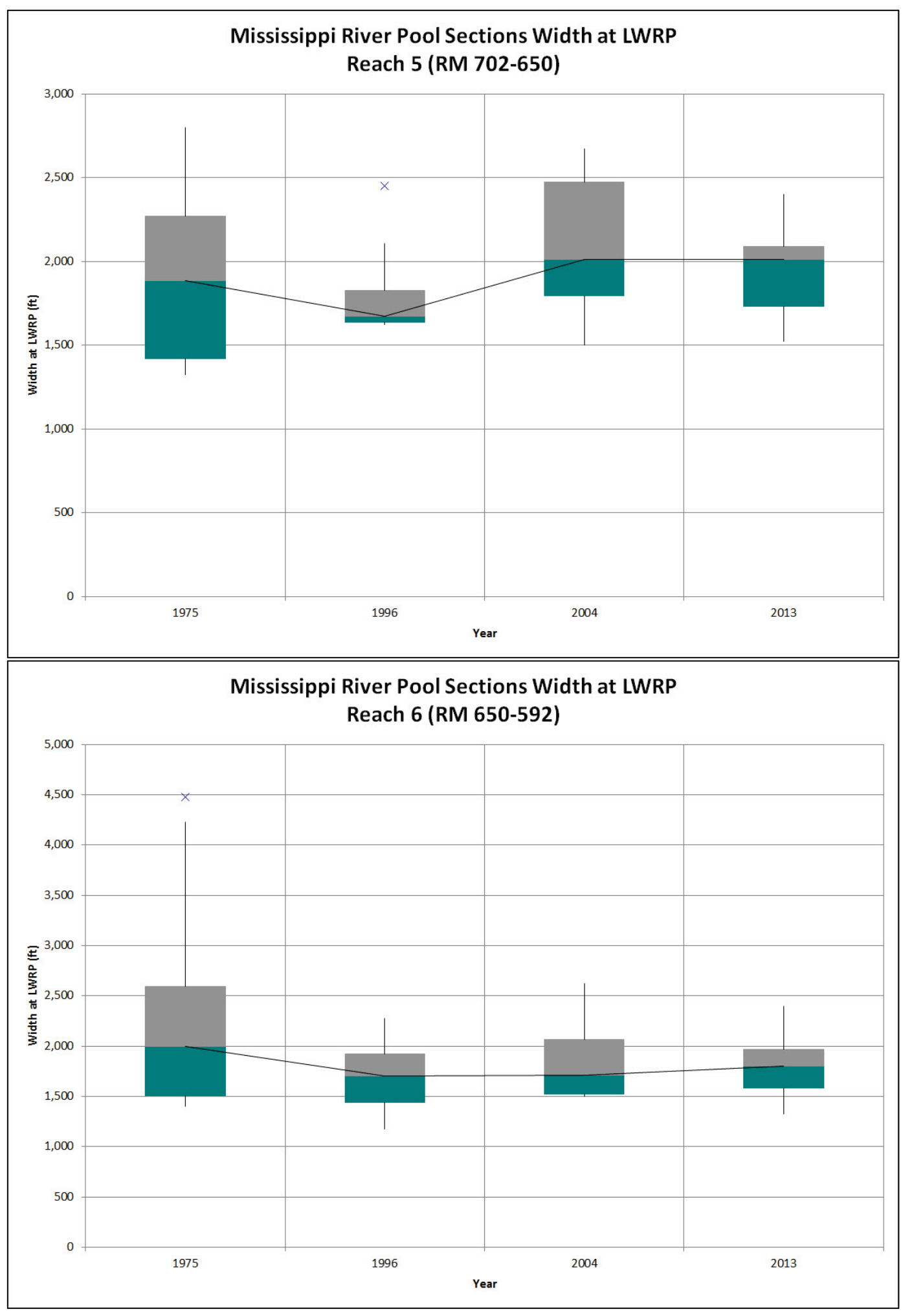




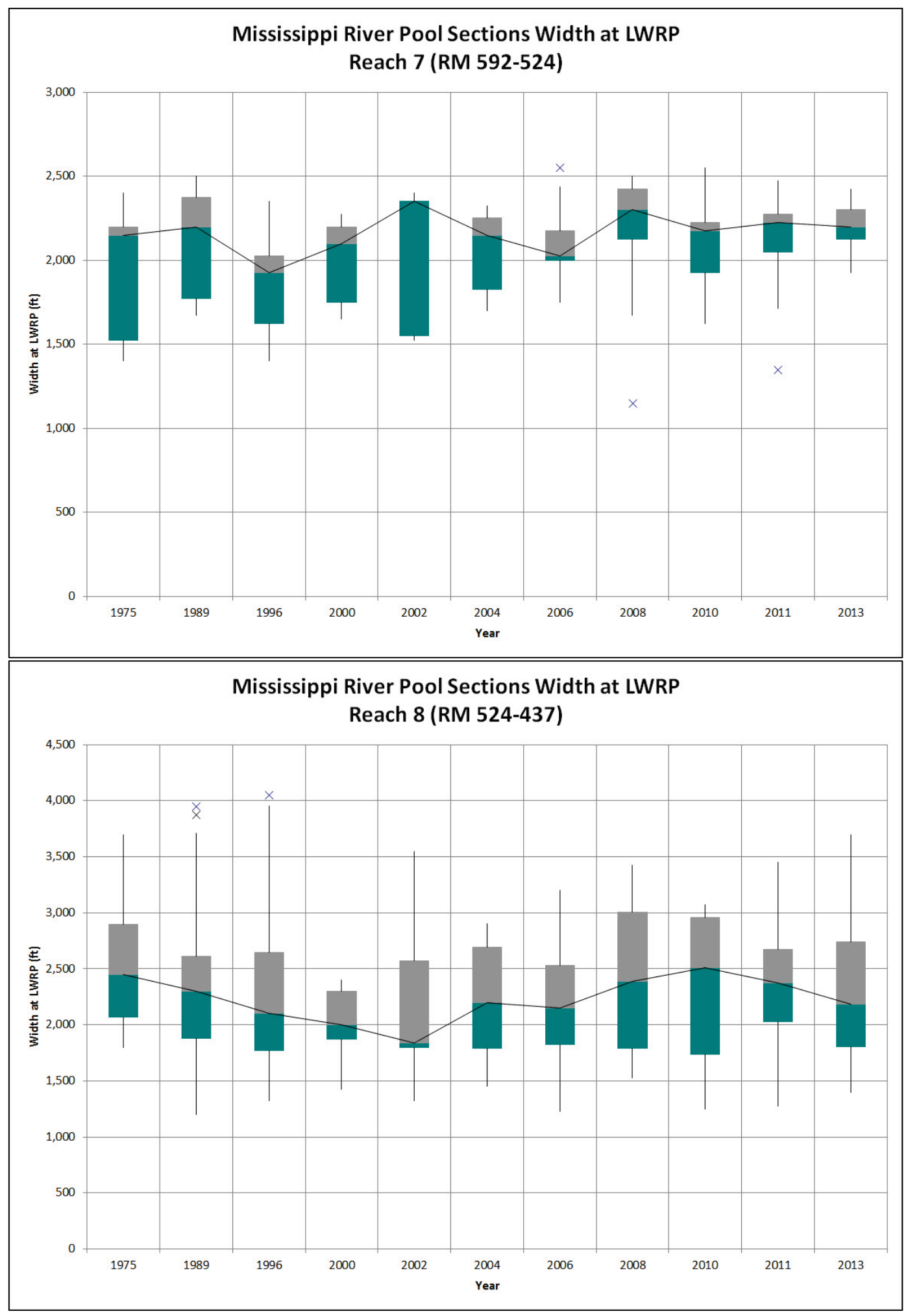




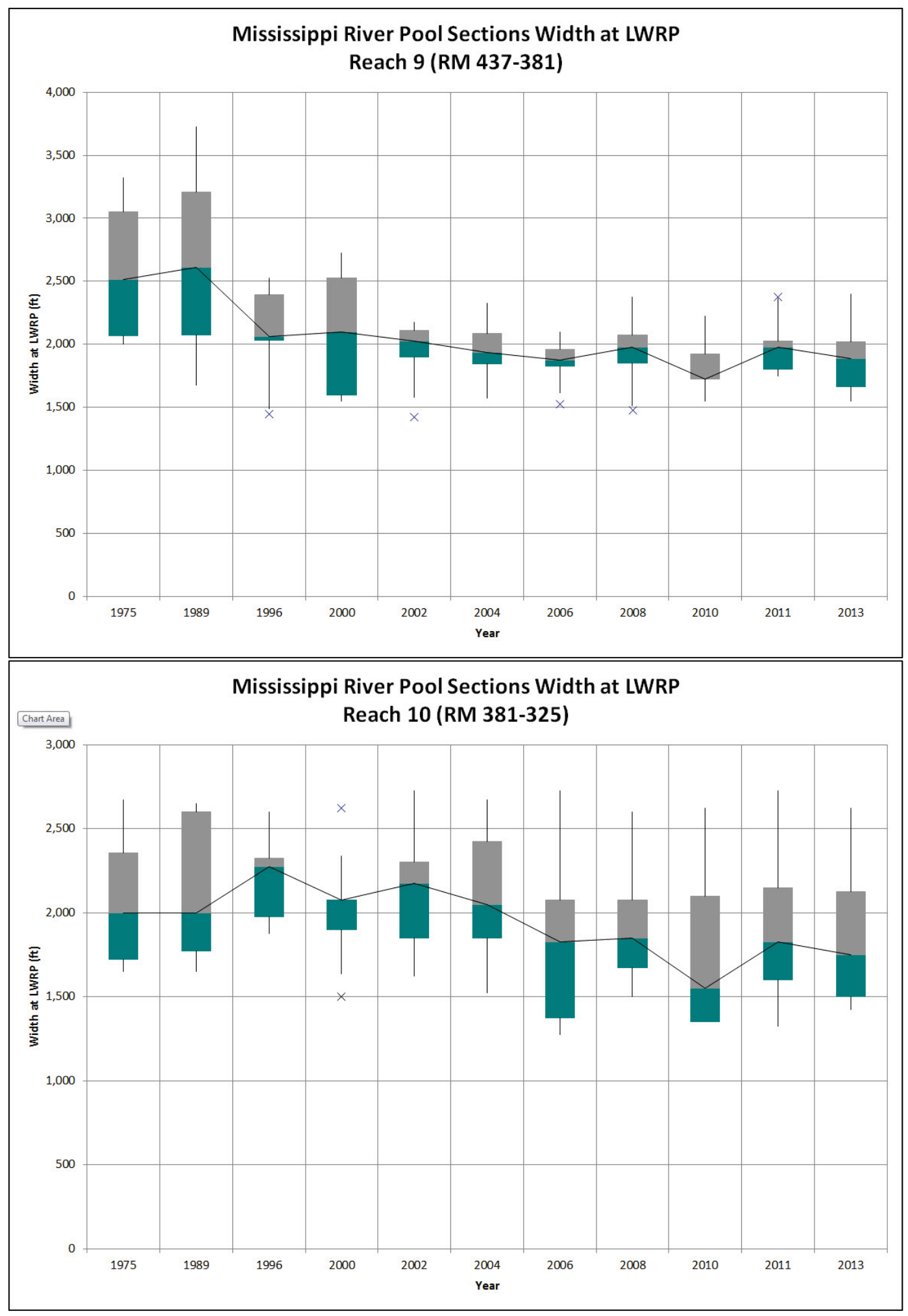




\section{Appendix G: Box Plots of Hydraulic Depth for Pool Sections, RM 325 to RM 954}




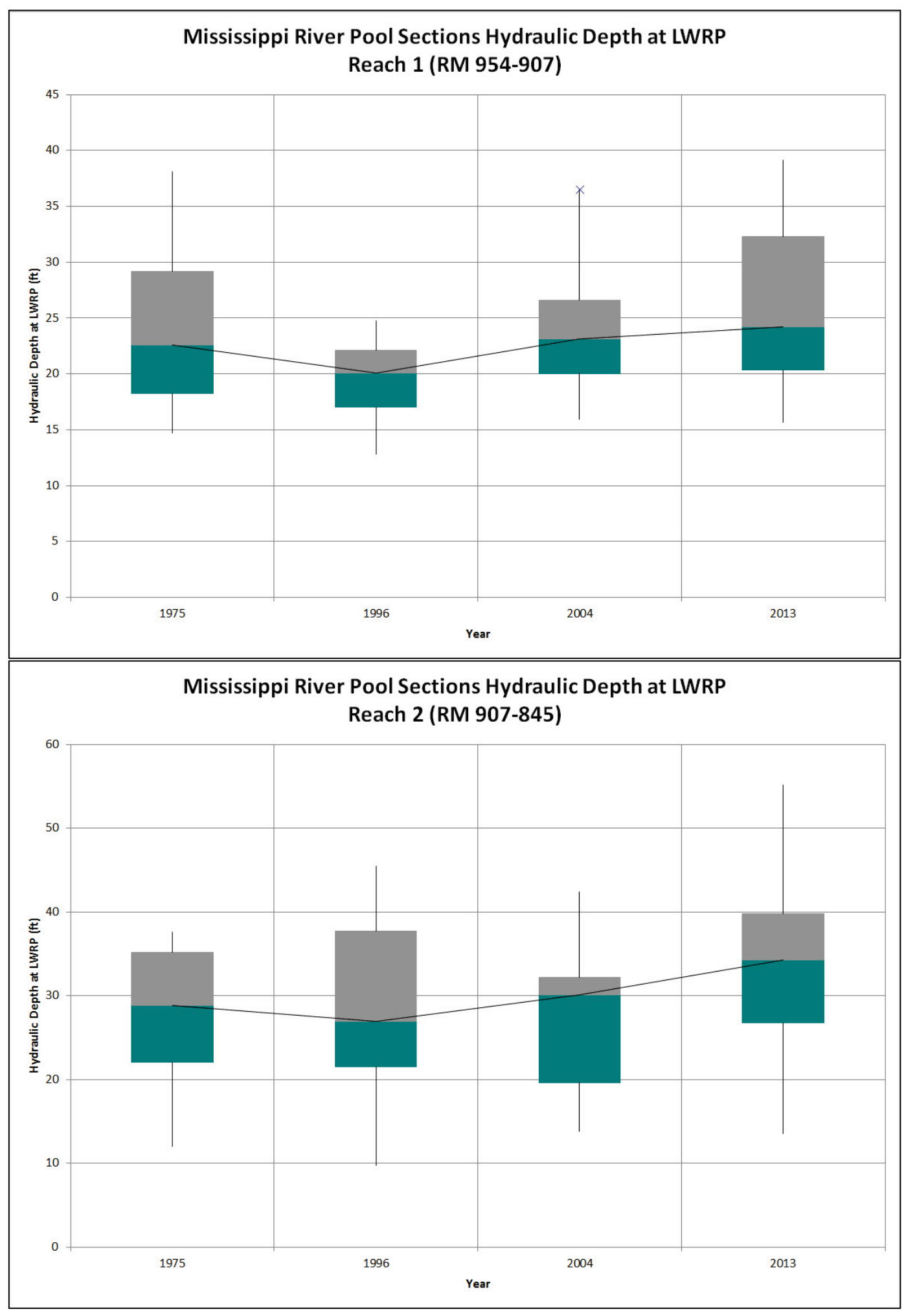




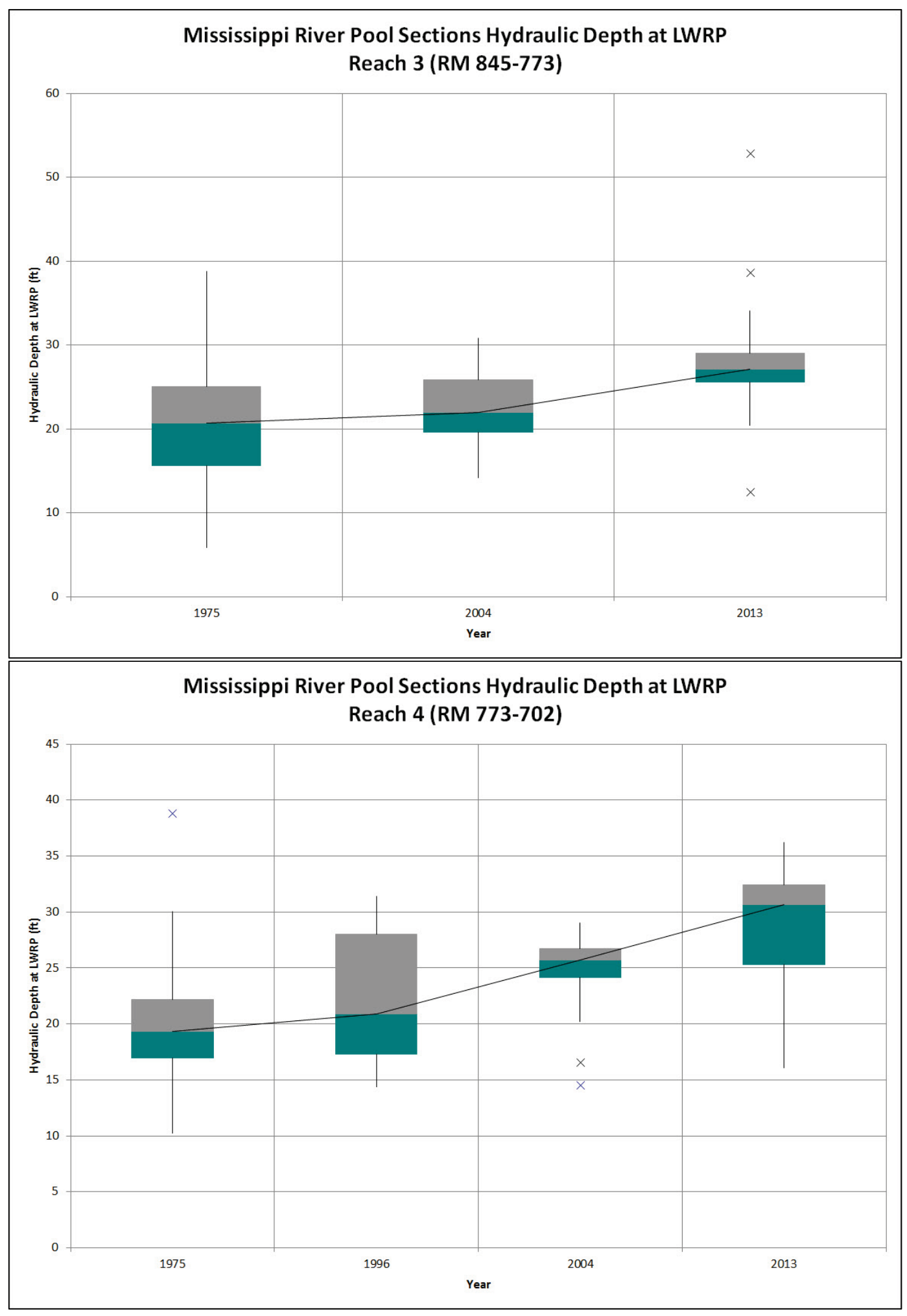




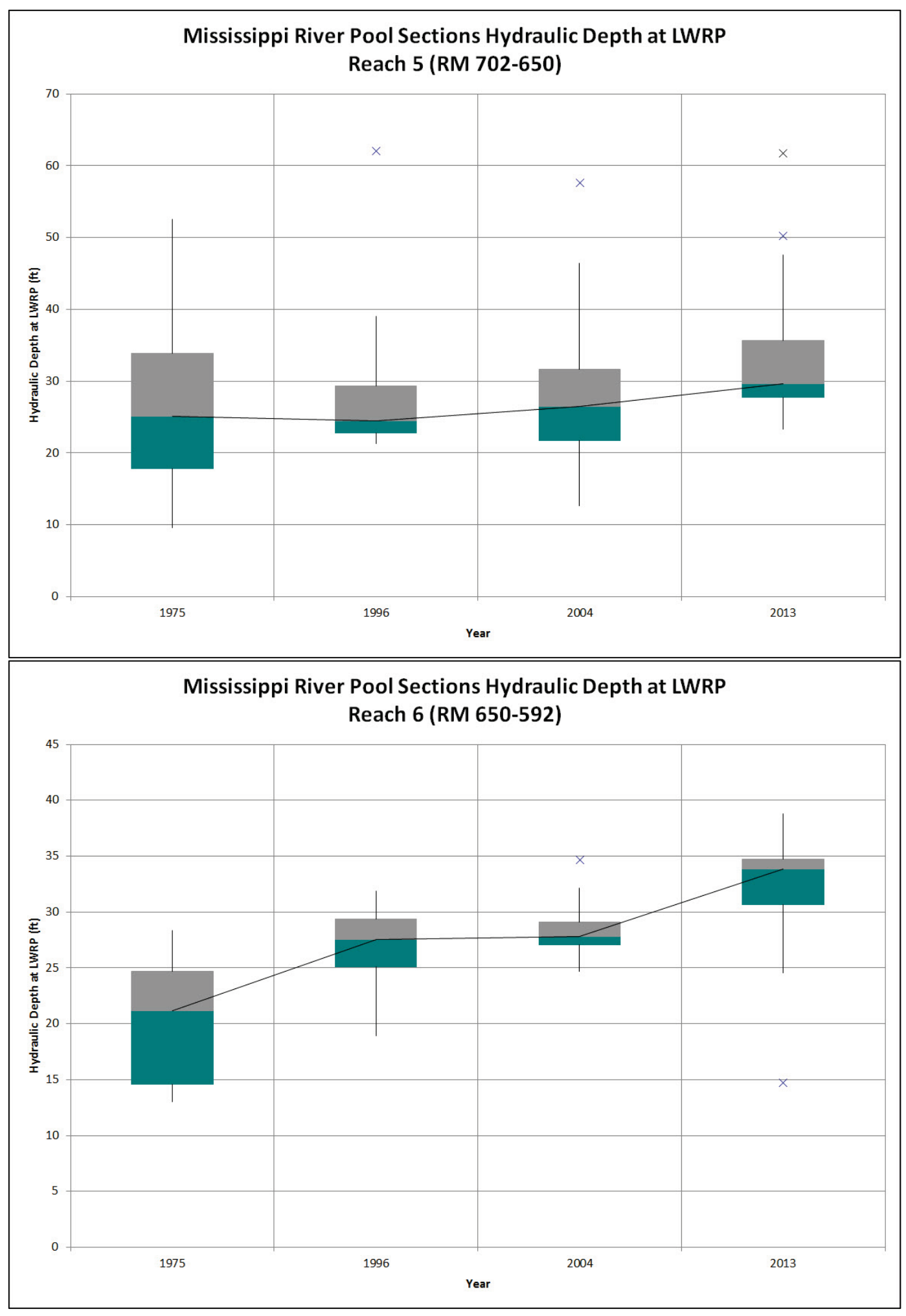




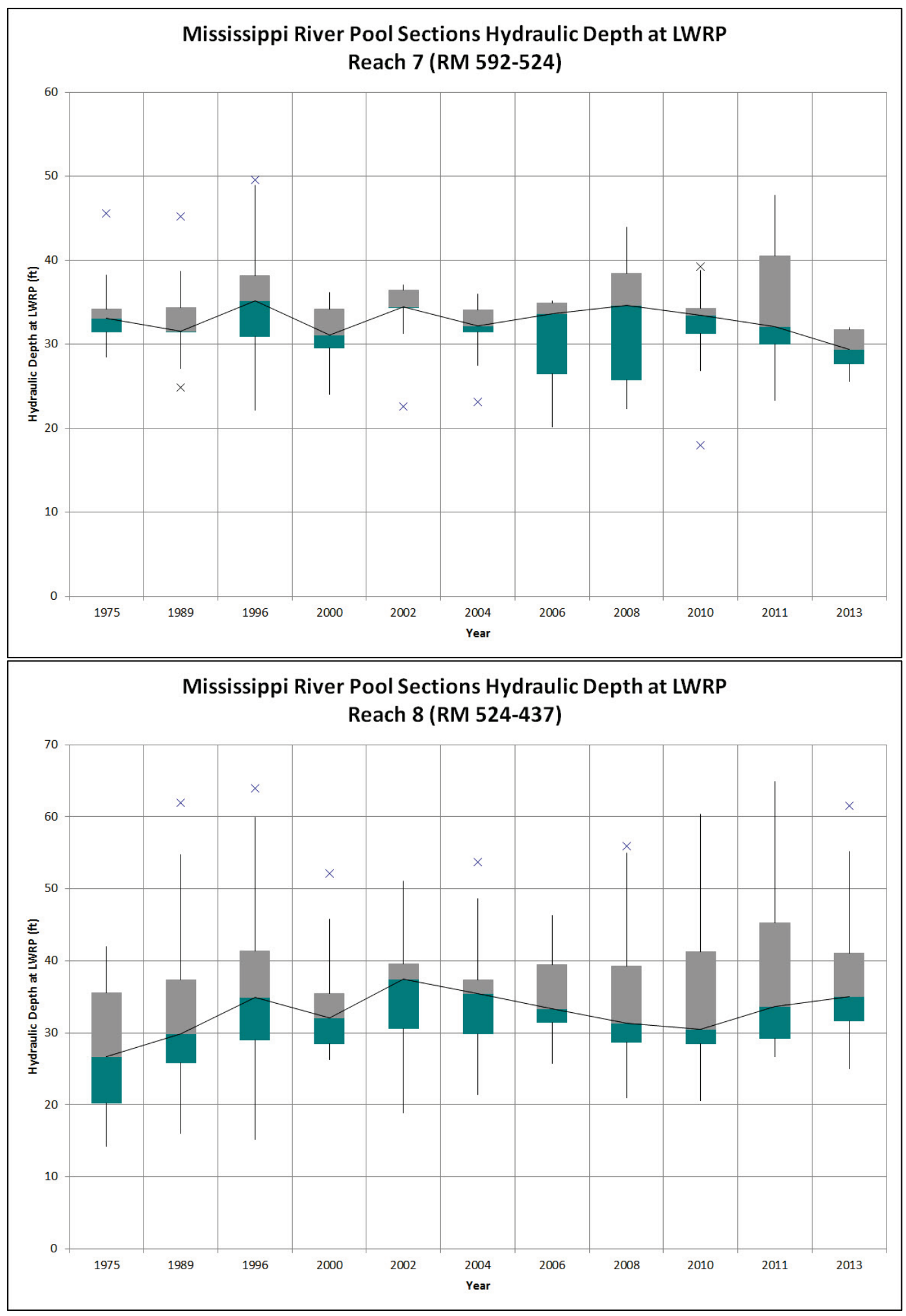




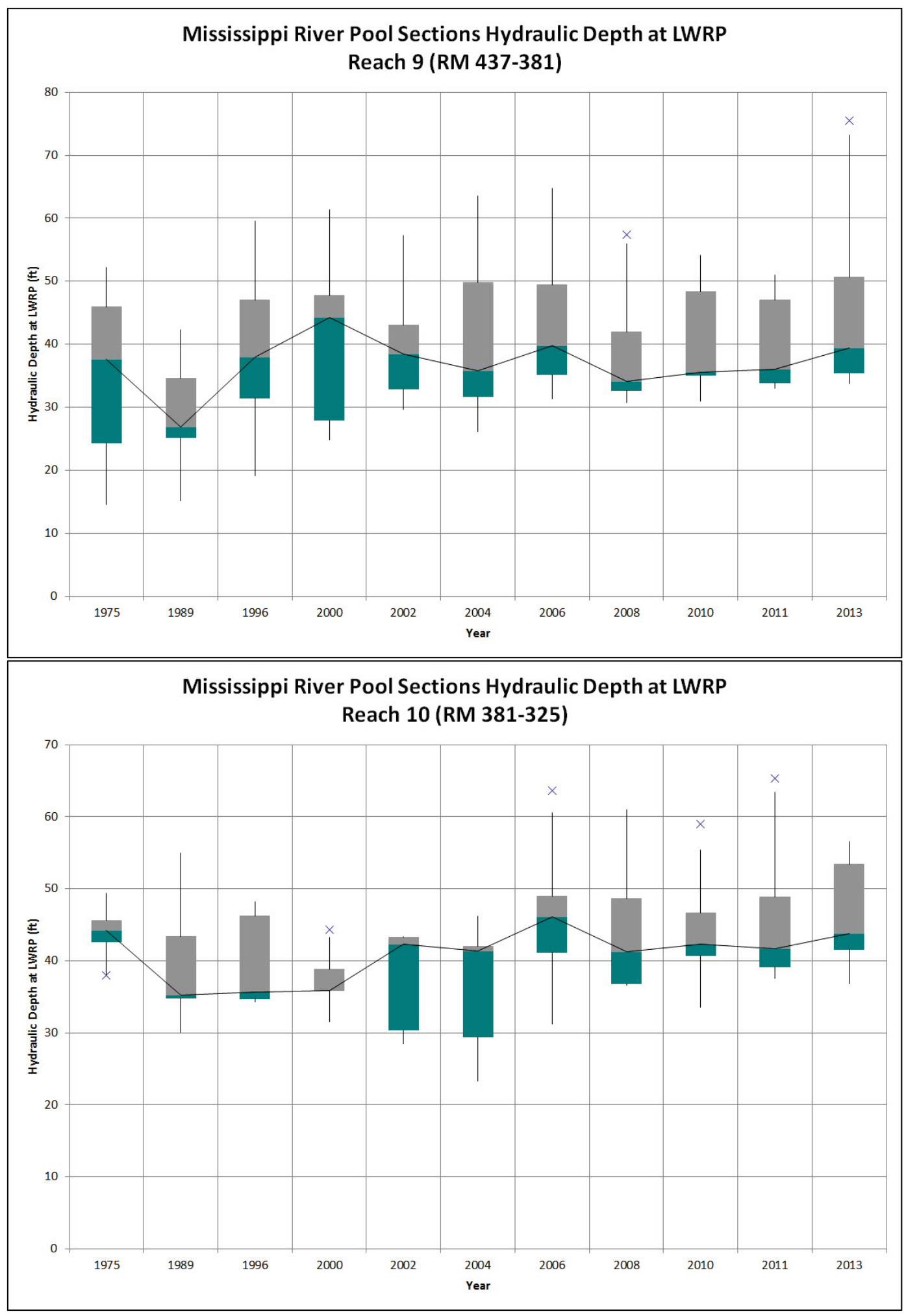




\section{Appendix H: Box Plots of Channel Conveyance for Pool Sections, RM 325 to RM 954}




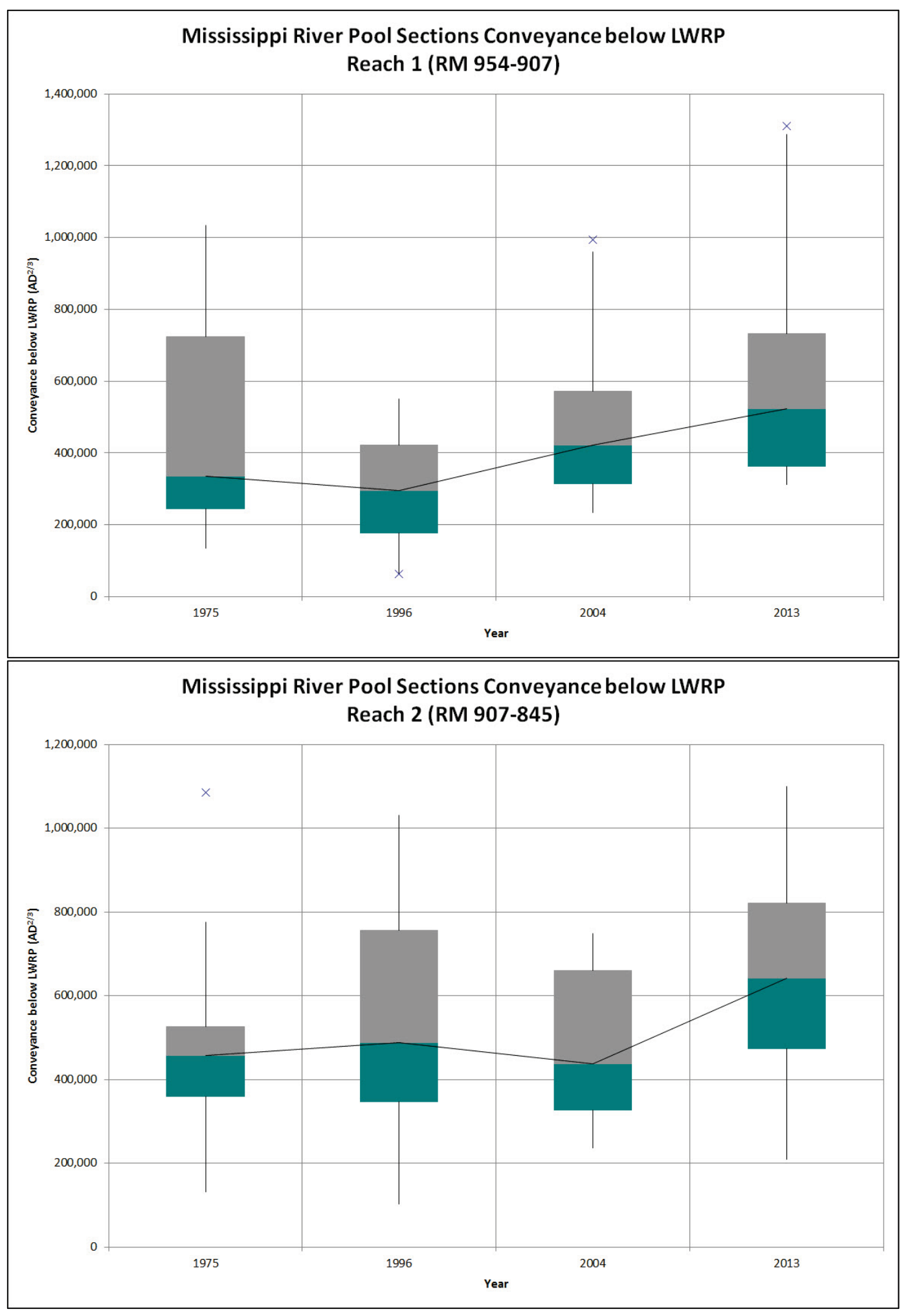




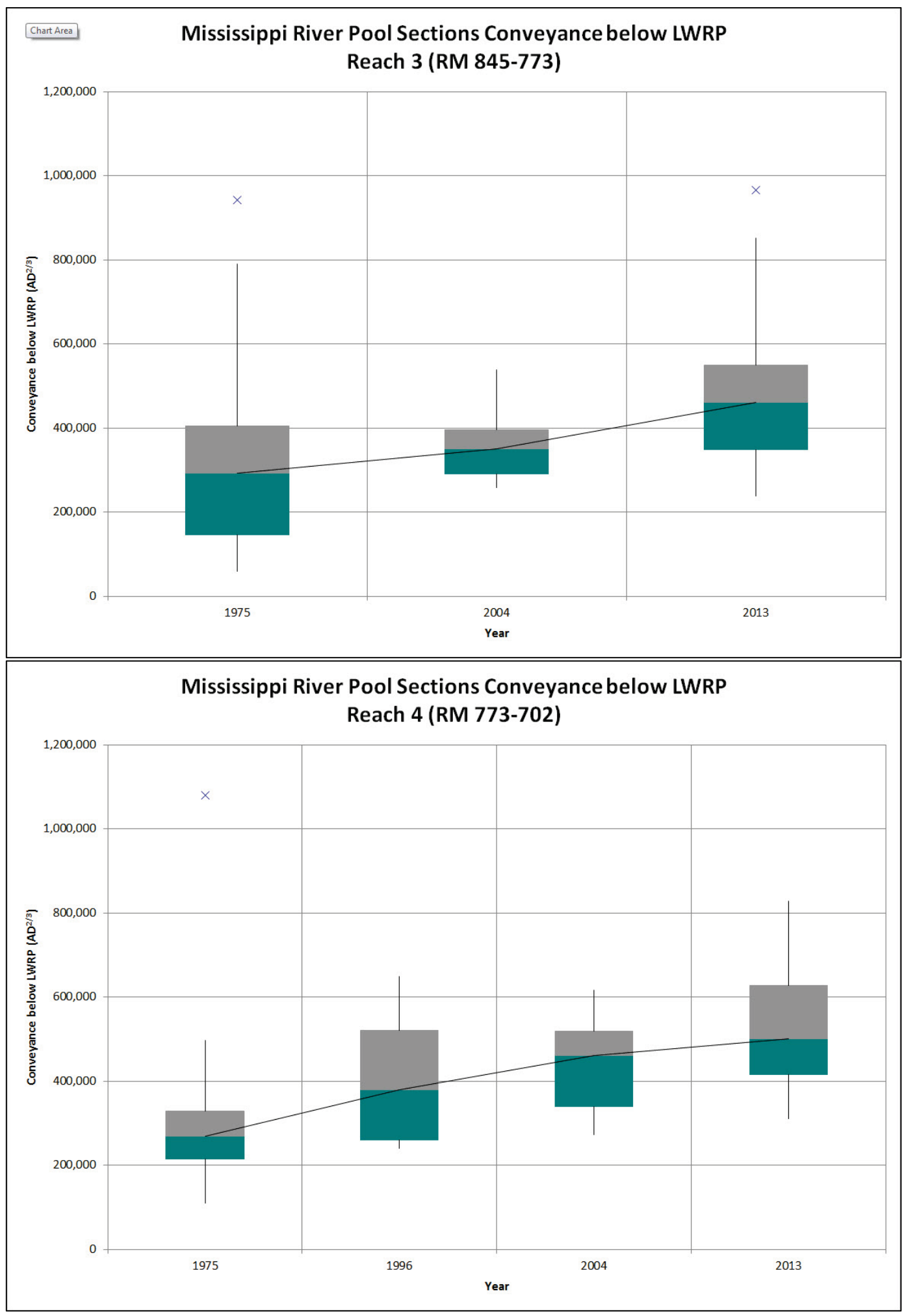




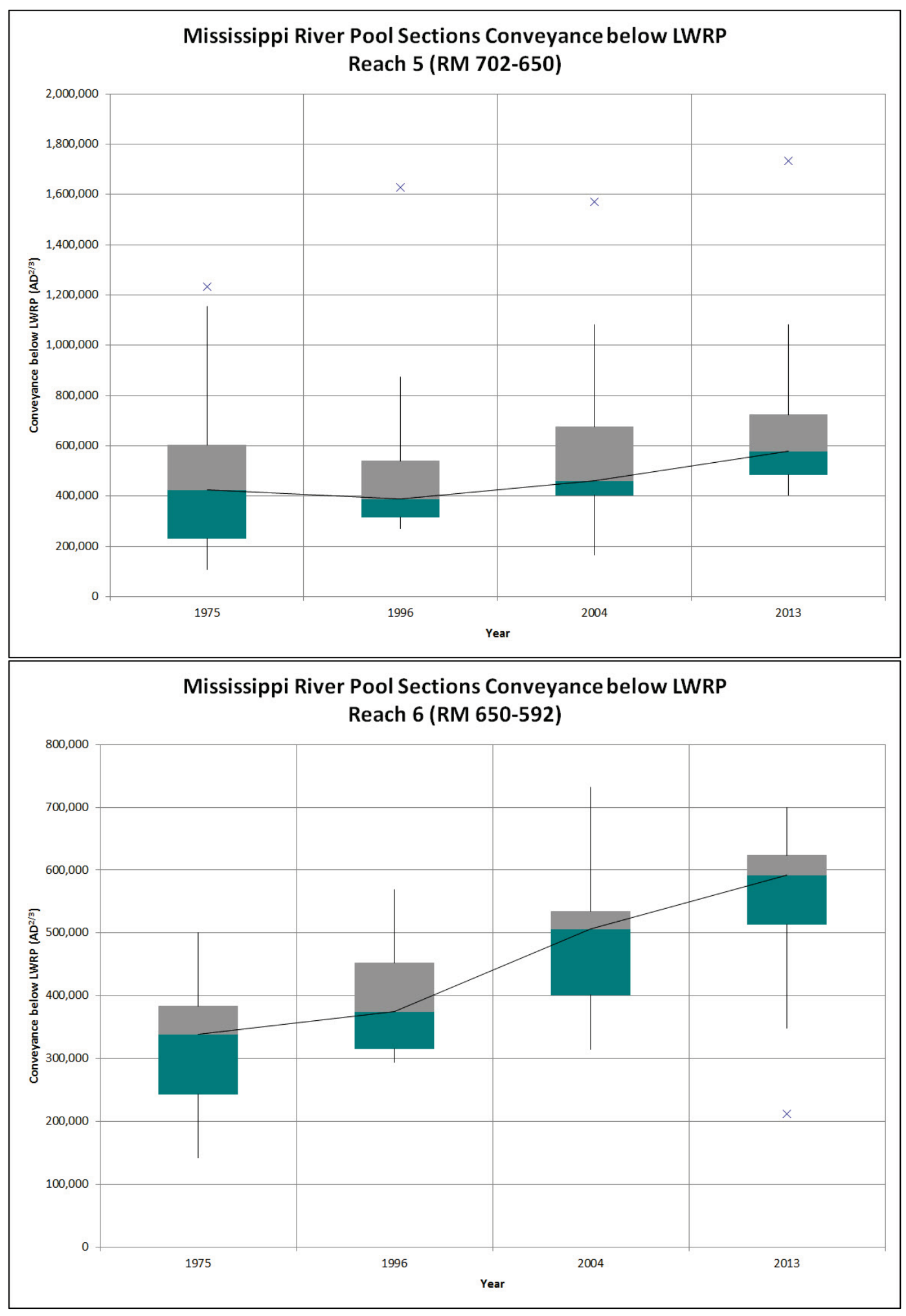




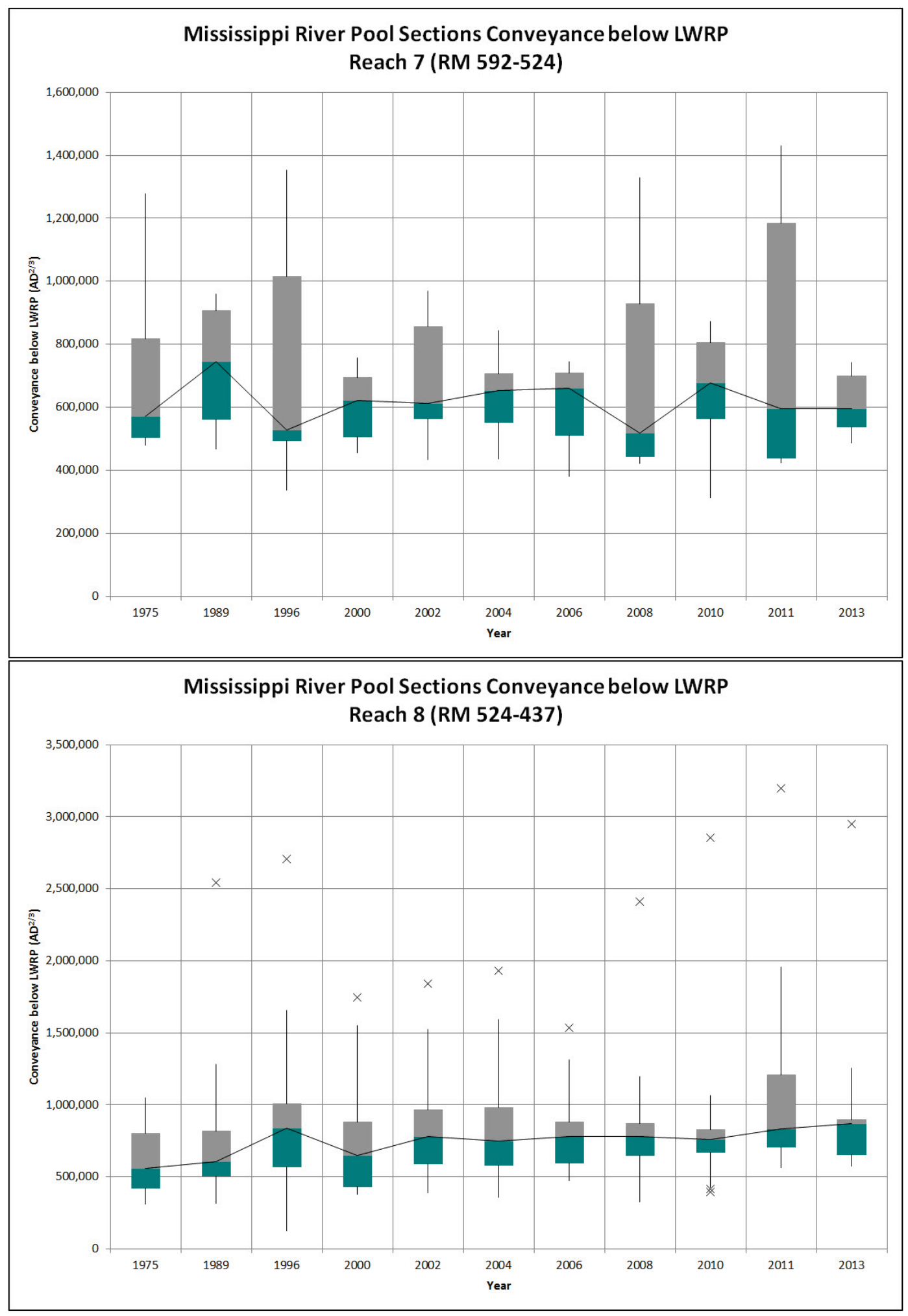




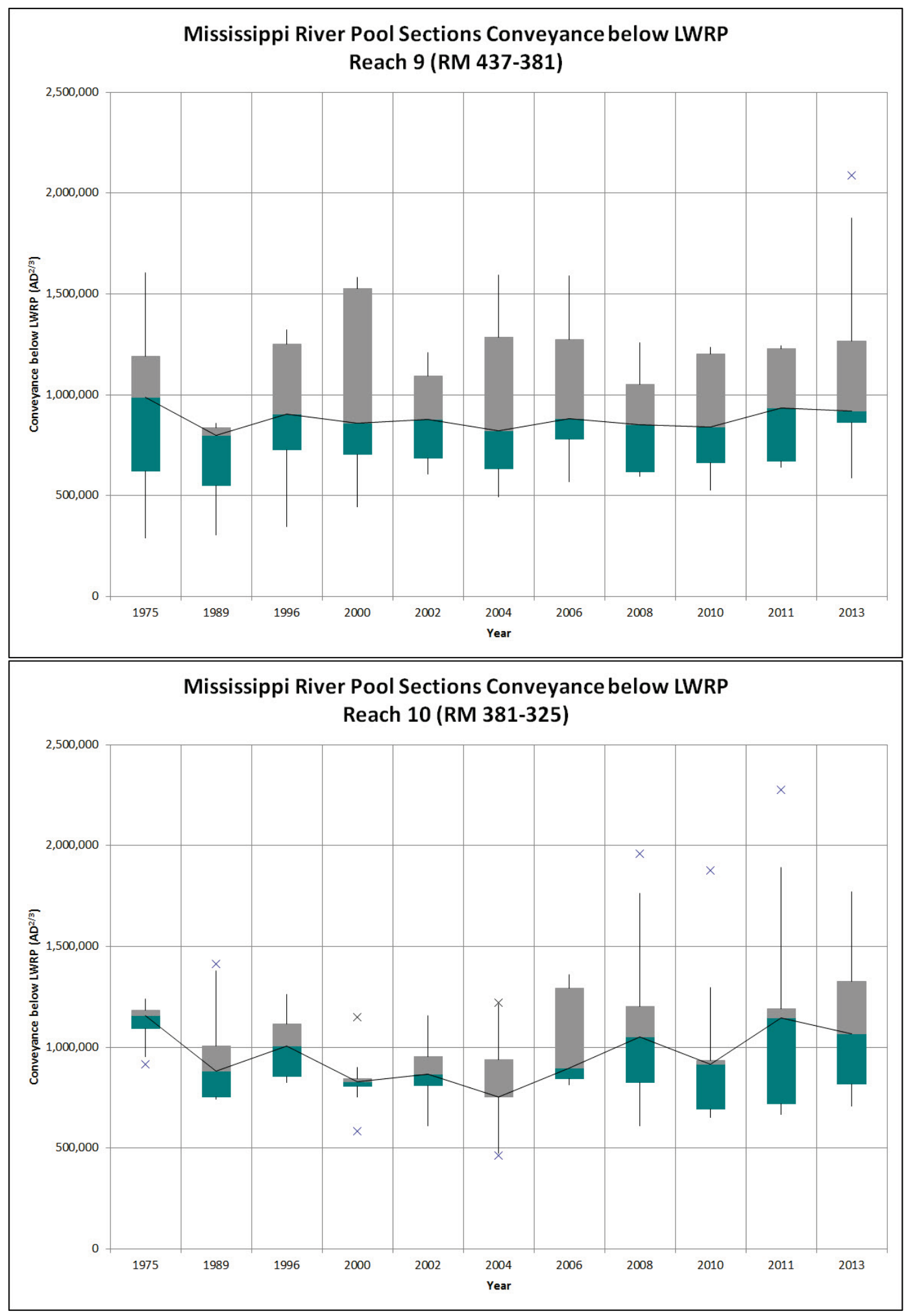


The public reporting burden for this collection of information is estimated to average 1 hour per response, including the time for reviewing instructions, searching existing data sources, gathering and maintaining the data needed, and completing and reviewing the collection of information. Send comments regarding this burden estimate or any other aspect of this collection of information, including suggestions for reducing the burden, to Department of Defense, Washington Headquarters Services, Directorate for Information Operations and Reports (0704-0188), 1215 Jefferson Davis Highway, Suite 1204, Arlington, VA 22202-4302. Respondents should be aware that notwithstanding any other provision of law, no person shall be subject to any penalty for failing to comply with a collection of information if it does not display a currently valid OMB control number. PLEASE DO NOT RETURN YOUR FORM TO THE ABOVE ADDRESS.

\begin{tabular}{l|l|l}
\hline $\begin{array}{l}\text { 1. REPORT DATE } \\
\text { July } 2017\end{array}$ & $\begin{array}{l}\text { 2. REPORT TYPE } \\
\text { Final Report }\end{array}$ & 3. DATES COVERED (From - To) \\
\hline 4. TITLEAND
\end{tabular}

\section{TITLE AND SUBTITLE}

5a. CONTRACT NUMBER

Channel Geometry Trends of Mississippi River, Old River Control Complex to St.

Louis, Missouri

\section{5b. GRANT NUMBER}

5c. PROGRAM ELEMENT NUMBER

\section{AUTHOR(S)}

Charles D. Little, Jr., David S. Biedenharn, Chester C. Watson, Mead A. Allison,

Troy McCullough, and Koby Wofford

5d. PROJECT NUMBER

127672

5e. TASK NUMBER

5f. WORK UNIT NUMBER

8. PERFORMING ORGANIZATION REPORT NUMBER

MRG\&P Report No. 11

U.S. Army Engineer Research Development Center

3909 Halls ferry Road

Vicksburg MS, 39180

9. SPONSORING/MONITORING AGENCY NAME(S) AND ADDRESS(ES)

U. S. Army Corps of Engineers, Mississippi Valley Division

Mississippi River Geomorphology and Potamology Program

1400 Walnut Street

Vicksburg, MS 39180

\section{DISTRIBUTION/AVAILABILITY STATEMENT}

Approved for public release; distribution is unlimited.

\section{SUPPLEMENTARY NOTES}

\section{ABSTRACT}

A geometric data analysis was conducted for the Mississippi River from the Old River Control Complex to St. Louis, MO, or approximately River Mile 325 Above Head of Passes to RM 180 Above Mouth of Ohio River. The purpose of the study was to document long-term trends in the dimension, pattern, and profile of the Mississippi River channel within the study reach. Hydrographic survey data from 1956 to 2013 were used to determine spatial and temporal variations in channel geometry and volume. Trends of geometric change in the channel were identified along defined geomorphic reaches of the river. Observed trends indicate the lower portion of the study reach from Old River to Vicksburg, MS, has experienced a general decrease in channel area and volume. Conversely, the reach from Helena, AR, to Hickman, KY, has undergone a general increase in area and volume. The reach of the middle Mississippi River above Cairo, IL, has seen a slight lowering of the channel.The results of this study will be part of a detailed geomorphic assessment of the Mississippi River to be conducted as part of the on-going Mississippi River Geomorphology and Potamology Program sponsored by the U.S. Army Corps of Engineers, Mississippi Valley Division Science and Technology Office.

\section{SUBJECT TERMS}

Geomorphology, Hydrographic surveying, Mississippi River, Potamology, River channels, Stream channelization

\begin{tabular}{|c|c|c|c|c|c|}
\hline \multicolumn{3}{|c|}{ 16. SECURITY CLASSIFICATION OF: } & \multirow{2}{*}{$\begin{array}{l}\text { 17. LIMITATION OF } \\
\text { ABSTRACT }\end{array}$} & \multirow{2}{*}{$\begin{array}{l}\text { 18. NUMBER OF } \\
\text { PAGES }\end{array}$} & \multirow{2}{*}{$\begin{array}{l}\text { 19a. NAME OF RESPONSIBLE PERSON } \\
\text { David Biedenharn }\end{array}$} \\
\hline a. REPORT & b. ABSTRACT & c. THIS PAGE & & & \\
\hline Unclassified & Unclassified & Unclassified & SAR & 118 & $\begin{array}{l}\text { 19b. TELEPHONE NUMBER (Include area code) } \\
601.634 .2923\end{array}$ \\
\hline
\end{tabular}

